\title{
CHEMICAL MODIFICATION OF MULTI-WALLED CARBON NANOTUBES AND THEIR POTENTIAL APPLICATIONS AS NEW ADSORBENTS FOR SOLID PHASE EXTRACTION FROM AQUEOUS SOLUTIONS
}

\author{
by \\ Mohamed Abdel Salam \\ Ph.D. (Ain Shams University, Cairo, Egypt) \\ M.Sc. (Carleton University, Ottawa, Canada)
}

A thesis submitted to the Faculty of Graduate Studies and Research in partial fulfillment of the requirements for the degree of Doctor of Philosophy

\author{
Department of Chemistry \\ Carleton University \\ Ottawa, Ontario \\ November 2006 \\ (C) copyright \\ 2006 Mohamed A. Salam
}




$\begin{array}{ll}\begin{array}{l}\text { Library and } \\ \text { Archives Canada }\end{array} & \begin{array}{l}\text { Bibliothèque et } \\ \text { Archives Canada }\end{array} \\ \begin{array}{l}\text { Published Heritage } \\ \text { Branch }\end{array} & \begin{array}{l}\text { Direction du } \\ \text { Patrimoine de l'édition }\end{array} \\ \begin{array}{l}\text { 395 Wellington Street } \\ \text { Ottawa ON K1A ON4 }\end{array} & \begin{array}{l}\text { 395, rue Wellington } \\ \text { Ottawa ON K1A ON4 } \\ \text { Canada }\end{array}\end{array}$

Your file Votre référence ISBN: 978-0-494-23284-2 Our file Notre référence ISBN: 978-0-494-23284-2

NOTICE:

The author has granted a nonexclusive license allowing Library and Archives Canada to reproduce, publish, archive, preserve, conserve, communicate to the public by telecommunication or on the Internet, loan, distribute and sell theses worldwide, for commercial or noncommercial purposes, in microform, paper, electronic and/or any other formats.

The author retains copyright ownership and moral rights in this thesis. Neither the thesis nor substantial extracts from it may be printed or otherwise reproduced without the author's permission.
AVIS:

L'auteur a accordé une licence non exclusive permettant à la Bibliothèque et Archives Canada de reproduire, publier, archiver, sauvegarder, conserver, transmettre au public par télécommunication ou par l'Internet, prêter, distribuer et vendre des thèses partout dans le monde, à des fins commerciales ou autres, sur support microforme, papier, électronique et/ou autres formats.

L'auteur conserve la propriété du droit d'auteur et des droits moraux qui protège cette thèse. $\mathrm{Ni}$ la thèse ni des extraits substantiels de celle-ci ne doivent être imprimés ou autrement reproduits sans son autorisation.
In compliance with the Canadian

Privacy Act some supporting forms may have been removed from this thesis.

While these forms may be included in the document page count, their removal does not represent any loss of content from the thesis.
Conformément à la loi canadienne sur la protection de la vie privée, quelques formulaires secondaires ont été enlevés de cette thèse.

Bien que ces formulaires aient inclus dans la pagination, il n'y aura aucun contenu manquant.

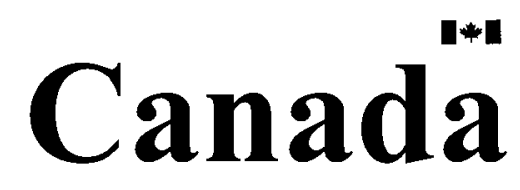




\section{Dedication}

To my family Samah, Omar and Sarah

Samah, you are great and without you I could not do this work.

Omar and Sarah are enlightening my dark nights with their smiles and joy. 


\begin{abstract}
The adsorptive potential of pristine and chemically modified multi-walled carbon nanotubes (MWCNTs) for solid phase extraction (SPE) of polar analytes; 2,4,5trichlorophenol (TCP) and pentachlorophenol (PCP), and non polar analytes; $3,3^{\prime}, 4,4^{\prime}-$ tetrachlorobiphenyl (PCB77) and 2,2',5,5'-tetrabromobiphenyl (PBB52), from aqueous solution was investigated.

Chemical modification of MWCNTs via oxidation followed by side wall functionalization using polyethylene glycol (PEG) or octadecylamine (ODA) was studied. Different characterization techniques were used to investigate the oxidized MWCNTs, MWCNTs-PEG and MWCNTs-ODA. The characterization techniques proved the presence of the functional groups on the MWCNTs surface.

Both pristine and chemically modified MWCNTs were good adsorbents for the elimination of organic pollutants from aqueous solution using SPE.

The kinetics of adsorption were investigated and showed that the process is diffusion controlled, but that this step is followed by intra-particle diffusion. Equilibrium adsorption on pristine and chemically modified MWCNTs at different temperatures was studied and the adsorption isotherms were well described using different adsorption models. The thermodynamic parameters of adsorption were measured; free energy, enthalpy and entropy. Small values for the enthalpy of adsorption indicated that adsorption is mainly physical. The trend for the thermodynamic parameters was mostly dependent on type of analyte and the type of adsorbent. Computer modeling was used to estimate the free energy of adsorption and the results showed a good correlation with the experimental free energy.
\end{abstract}


The SPE process was greatly affected by different factors such as the type of adsorbent, type of adsorbate, flow rate, mass of adsorbent, and $\mathrm{pH}$ of the aqueous solution.

Method development was performed to investigate the applicability of pristine and chemically modified MWCNTs as packing materials for SPE using model solution and freshwater samples. The method detection limits of SPE with different adsorbents were studied and were found to be $1.0 \mathrm{ng} / \mathrm{ml}$ for the chlorophenols, and $6.0 \mathrm{ng} / \mathrm{ml}$ for the PCB77 and PBB52, all with very good recoveries, especially when MWCNTs-ODA was used as the adsorbent. The regeneration and reusability of the different MWCNTs SPE cartridges were studied and the results showed that the SPE cartridge could be used for three cycles of adsorption/desorption with excellent efficiency.

Finally, it was found that MWCNTs-ODA was the best adsorbent and could be used successfully in SPE for the extraction of different organic pollutants; polar and non polar, with great efficiency, recovery, reproducibility, sensitivity and precision, and high dynamic range. 


\section{ACKNOWLEDGMENTS}

During my research I was like a traveler in the dark and wild desert and without light and guidance from the following people, or stars, I could not have crossed the desert and reached my goals.

The first star is my supervisor Dr. Robert C. Burk, or Bob as we are calling him. Bob was the closest person to my mind and my heart during my Ph.D. period. He was not just a supervisor; he was way more than that. Bob was (and still is) a close friend all the time, a flood of knowledge when you seek his help, a handyman when it comes to fixing instruments. Bob did not teach me only chemistry, he taught me how to think and survive. Thank you Bob so much for your consistent and continuous help and encouragement.

The second star is my comrade Barbara Gauthier. She was around me all the time, sharing the good and bad things together. Thank you so much Barb for listing to my gripes when I was feeling so overwhelmed.

The third and fourth stars are Rana Zoka and Helen Prochazka. Rana and Helen were shining lights all the time in the laboratory and both of them were of great help, especially for drinking Tim Horton's coffee.

I would like to thank David Blair for his continuous and effortless help, Alia Mahabir for organizing the lab and making my life easy, and Jenna, Kelly and Holly for adding more flavors to the lab.

I would like to thank Hooman Shadnia and Professor Jim Wright for the computer modeling, Yamile Wasslesn and Professor Sean Barry for the Thermal Gravimetric analysis, and Dr. Sundar Saimani and Professor P. Sundararajan for the X-Ray Diffraction measurements.

I would like to thank Jim Logan and Tony O'Neil for providing much technical support for all the instruments that I used; Fred Cassalman and Peter Mosher for their support through my teaching assistant times.

And Finally, but not lastly, to Ismail Al-Fasfous, Tahir Yapici, Joya Wang, Partha, Tayebeh, Getean and many others.

Many thanks to everyone at the chemistry department. 


\section{PUBLICATIONS AND PRESENTATIONS}

\section{CONFERENCE PRESENTATIONS}

1) Salam, M. S. A., Burk, R.C., (2006), Chemical functionalization and the production of stable suspension of multi-wall carbon nanotubes, $89^{\text {th }}$ Canadian Society for Chemistry Conference and Exhibition, May 28-31, 2006, Halifax, Nova Scotia, Canada. (Oral Presentation)

2) Salam, M. S. A., Burk, R.C., (2006), Adsorption of pentachlorophenol (PCP) from aqueous solution by multiwalls carbon nanotubes (MWCNTs), $89^{\text {th }}$ Canadian Society for Chemistry Conference and Exhibition, May 28-31, 2006, Halifax, Nova Scotia, Canada. (Oral Presentation).

3) Salam, M. S. A., Burk, R.C., (2006), The Application of Multi-Walled carbon Nanotubes as a new adsorbent for the solid Phase extraction of some persistent halogenated organic pollutants from aqueous solution" Ottawa-Carleton Chemistry Institute (OCCI) Symposium, May 19, 2006, Carleton University, Ottawa, Ontario, Canada. (Oral Presentation)

4) Salam, M. S. A., Burk, R.C., (2006), The Application of Multi-Walled carbon Nanotubes as a new adsorbent for the solid Phase extraction of some persistent halogenated organic pollutants from aqueous solution" EnviroAnalysis Conference, May 15-17, 2006, Toronto, Ontario, Canada. (Oral Presentation)

5) Abdel Salam, Mohamed S., Burk, R.C., (2004), Multiwalled Carbon Nanotubes as a Solid-Phase Extraction Adsorbent for PCB using GC-ECD, EnviroAnalysis Conference, May 16-21, 2004, Toronto, Ontario, Canada. (Oral Presentation) 


\section{TABLE OF CONTENTS}

$\begin{array}{ll}\text { Acceptance sheet } & \text { ii }\end{array}$

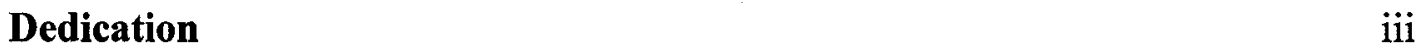

Abstract iv

Acknowledgements vi vi vis

Publications and Presentations vii

Table of Contents viii

List of Tables $\quad$ xiii

List of Figures $\quad$ xvi

CHAPTER 1

INTRODUCTION

1.1 Background 1

1.1.1 Carbon Nanotubes 1

$\begin{array}{ll}\text { 1.1.1.2 Properties } & 4\end{array}$

1.1.1.3 Applications $\quad 5$

1.1.1.4 Adsorption onto CNTs 5

1.1.2 Persistent Organic Pollutants (POPs) in the Environment 8

1.1.2.1 Physical and Chemical Properties of Chlorophenols $\quad 8$

1.1.2.2 Analysis of Chlorophenols $\quad 11$

1.1.2.3 Polychlorinated Biphenyls compounds (PCBs) 12

1.1.2.4 Polybrominated Biphenyls compounds (PBBs) 12

$\begin{array}{ll}\text { 1.2 Current State of Knowledge } & 13\end{array}$

1.3 Weaknesses of Current State of Knowledge 17

$\begin{array}{lr}1.4 \text { Objectives } & 18\end{array}$

viii 
CHAPTER 2

CHARACTERIZATION OF OXIDIZED MULTI-WALLED CARBON NANOTUBES

2.1. Introduction 28

$\begin{array}{lr}\text { 2.2. Experimental } & 29\end{array}$

2.2.1 Oxidation of MWCNTs 29

2.2.2 Characterization Techniques $\quad 30$

2.3. Results and Discussion 31

2.3.1 Suspension stability 31

2.3.2 Acidic functional group quantitation $\quad 36$

2.3.3 Total metals analysis $\quad 36$

2.3.4 Specific surface area measurements $\quad 38$

$\begin{array}{ll}\text { 2.3.5 Infrared spectroscopy } & 40\end{array}$

2.3.6 X-ray diffraction measurements $\quad 40$

2.3.7 Scanning Electron Microscopy $\quad 44$

$\begin{array}{ll}\text { 2.4. Conclusions } & 46\end{array}$

$\begin{array}{ll}\text { 2.5. References } & 47\end{array}$

CHAPTER 3

ADSORPTION OF PENTACHLOROPHENOL FROM AQUEOUS SOLUTION BY MULTI-WALLED CARBON NANOTUBES

3.1 Introduction $\quad 50$

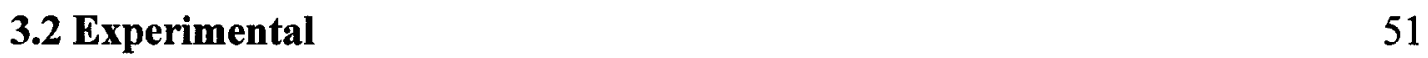

$\begin{array}{ll}\text { 3.2.1 Adsorbents } & 51\end{array}$

$\begin{array}{ll}\text { 3.2.2 Reagents } & 51\end{array}$ 
3.2.3 Solid Phase Extraction (SPE) of PCP 52

3.2.4 Kinetics study $\quad 52$

3.2.5 Adsorption equilibrium studies $\quad 52$

3.2.6 Analytical procedure $\quad 53$

3.2.7 Fitting the adsorption isotherms 53

3.2.8 Effect of temperature on the adsorption of PCP

$\begin{array}{ll}\text { 3.3 Results and discussion } & 55\end{array}$

3.3.1 Adsorption kinetic studies $\quad 55$

$\begin{array}{ll}\text { 3.3.2 Adsorption isotherms } & 63\end{array}$

$\begin{array}{ll}\text { 3.3.3 Temperature studies } & 65\end{array}$

$\begin{array}{ll}\text { 3.4 Conclusions } & 73\end{array}$

$\begin{array}{ll}\text { 3.5 References } & 75\end{array}$

CHAPTER 4

ADSORPTION OF PENTACHLOROPHENOL ON OXIDIZED MULTI-WALLED CARBON NANOTUBES

$\begin{array}{ll}4.1 \text { Introduction } & 80\end{array}$

$\begin{array}{ll}\text { 4.2 Experimental } & 80\end{array}$

$\begin{array}{ll}\text { 4.3 Results and Discussion } & 81\end{array}$

4.3.1 Adsorption of PCP on pristine and oxidized MWCNTs $\quad 81$

4.3.2 Adsorption isotherm of PCP on oxidized MWCNTs 83

4.3.3 Temperature studies and evaluation of the thermodynamic data $\quad 91$

4.3.4 Kinetics study of the adsorption of PCP on pristine $\begin{array}{ll}\text { and oxidized MWCNTs } & 94\end{array}$

$\begin{array}{ll}\text { 4.4. Conclusions } & 102\end{array}$

$\begin{array}{ll}\text { 4.5. References } & 103\end{array}$ 


\section{CHAPTER 5}

CHEMICAL MODIFICATION OF MULTI-WALLED CARBON NANOTUBES

$\begin{array}{ll}\text { 5.1 Introduction } & 106\end{array}$

$\begin{array}{ll}\text { 5.2 Experimental } & 106\end{array}$

$\begin{array}{ll}\text { 5.2.1 Reagents } & 106\end{array}$

$\begin{array}{ll}\text { 5.2.2 Procedures } & 107\end{array}$

5.2.2.1 Oxidation of MWCNTs 107

5.2.2.2 Formation of carbonyl chloride groups on MWCNTs $\quad 107$

5.2.2.3 Formation of MWCNTs-PEG 109

5.2.2.4 Formation of MWCNTs-ODA 109

5.2.3 Characterization of the chemically modified MWCNTs 109

$\begin{array}{ll}\text { 5.3 Results and Discussion } & 110\end{array}$

5.3.1 Thermal gravimetric analysis (TGA) $\quad 110$

$\begin{array}{ll}\text { 5.3.2 Infrared spectroscopy } & 114\end{array}$

$\begin{array}{ll}\text { 5.3.3 Modified MWCNTs solubility } & 116\end{array}$

$\begin{array}{ll}\text { 5.3.4 X-ray diffraction measurements } & 120\end{array}$

$\begin{array}{ll}\text { 5.3.5 Scanning electron microscopy (SEM) } & 122\end{array}$

$\begin{array}{ll}5.4 \text { Conclusions } & 122\end{array}$

$\begin{array}{ll}5.5 \text { References } & 125\end{array}$

CHAPTER 6

THERMODYNAMIC STUDY AND COMPUTER MODELING OF THE ADSORPTION OF ANALYTES ON CHEMICALLY MODIFIED MULTI-WALLED CARBON NANOTUBES

$\begin{array}{ll}\text { 6.1 Introduction } & 126\end{array}$

$\begin{array}{ll}\text { 6.2 Experimental } & 127\end{array}$

$\mathrm{xi}$ 
6.2.3 Thermodynamics studies

6.2.4 Adsorption computer modeling

\section{CHAPTER 7}

ADSORPTION STUDY AND METHOD DEVELOPMENT OF CHEMICALLY MODIFIED MULTI-WALLED CARBON NANOTUBES AS ADSORBENTS FOR SOLID PHASE EXTRACTION

7.2.2 Adsorbents

7.2.3 Chemicals 
7.2.6 Analytical procedure

7.2.7 Solid phase extraction (SPE) procedure

7.3. Results and Discussion

7.3.1 Adsorption study

7.3.1.1 Effect of flow rate

7.3.1.2 Effect of adsorbent mass

7.3.1.3 Effect of $\mathrm{pH}$

7.3.3 Desorption study

7.3.3.1 Effect of solvent type

7.3.3.2 Effect of solvent volume

7.3.4 Method development study

7.3.4.1 Limits of detection and Calibration curves

7.3.4.2 SPE method detection limits (MDL)

7.3.4.3 Analytical performance and real sample analysis 


\section{LIST OF TABLES}

Table 2.1

The concentrations of different acidic groups on the surface of MWCNTs after oxidation.

Table 2.2

The total metals concentration in MWCNTs before and after oxidation using ICP-MS.

Table 2.3

XRD pattern analysis for MWCNTs before and after oxidation.

Table 3.1

60

Kinetic parameters of the adsorption of PCP to

MWCNTs and AC using different kinetic models.

Table 3.2

Results of PCP adsorption isotherm analysis

using MWCNTs and $\mathrm{AC}$ at different temperatures.

Table 3.3

Values of thermodynamic parameters for the adsorption of PCP on MWCNTs and AC.

Table 4.1

Results of PCP adsorption isotherm analysis using pristine and oxidized MWCNTs at different temperatures.

Table 4.2

Values of thermodynamic parameters for the adsorption of PCP on pristine and oxidized MWCNTs.

Table 4.3

Kinetic parameters of the adsorption of PCP to pristine and oxidized MWCNTs using different kinetic models.

Table 4.4

Intra-particle diffusion parameters for the adsorption of PCP to pristine and oxidized MWCNTs.

Table 6.1

Different thermodynamic parameters for the adsorption of TCP, PCP, PCB77, and PBB52, onto pristine MWCNTs, oxidized MWCNTs, MWCNTs-PEG, MWCNTs-ODA, and C18. 
Table 6.2

Calculation of predicted $\Delta G_{\text {Adsorption }_{a q}}$ for the adsorption

of different analytes on pristine and modified MWCNTs.

Table 6.3

Relation between the \% adsorption and the predicted and experimental free energy of adsorption.

Table 7.1

Effect of mass on \% of analytes adsorbed by different adsorbent.

Table 7.2

Effect of elution solvent volume on the elution of TCP

PCP, PCB77, and PBB52, was previously adsorbed on

pristine MWCNTs, MWCNTs-ODA, MWCNTs-PEG, and C18.

Table 7.3

Figure of merits of TCP, PCP, PCB77, and PBB52

using gas chromatography-electron capture detector.

Table 7.4

$\%$ TCP, PCP, PCB77, and PBB52 adsorbed (average) on different SPE

Table 7.5

$\%$ Recovered (average) and method detection limits

of TCP, PCP, PCB77, and PBB52, adsorbed on different SPE adsorbent. 


\section{LIST OF FIGURES}

Figure 1.1

Single-walled (a) and multi-walled (b) carbon nanotubes.

Figure 1.2

Schematic representation of a $2 \mathrm{D}$ graphite layer.

Figure 1.3

Location of the possible adsorption sites on a bundle of SWCNTs (open end)

Figure 1.4

Chemical Structures of the target analytes.

Figure 2.1

Calibration curve of turbidity versus MWCNTs concentration in aqueous solution.

Figure 2.2

The stability of MWCNTs suspensions before and after oxidation in terms of MWCNTs concentration $(\mathrm{mg} / \mathrm{mL})$ versus time.

Figure 2.3

Vials containing aqueous suspensions of pristine and oxidized MWCNTs after standing for six months.

Figure 2.4

IR spectra of MWCNTs before and after oxidation.

Figure 2.5

XRD patterns of pristine and oxidized MWCNTs.

Figure 2.6

SEM images of pristine and oxidized MWCNTs.

Figure 3.1

The kinetic model for the adsorption of PCP to MWCNTs and AC and the comparison between the experimental data and the predicted values.

Figure 3.2

Weber-Morris intra-particle diffusion plots for the adsorption of PCP.

Figure 3.3

Adsorption isotherms for PCP on MWCNTs and AC at different temperatures. 
Comparison of different isotherm models for PCP adsorption on MWCNTs with experimental results.

Figure 3.5

Comparison of different isotherm models for PCP adsorption on

ACs with experimental results.

Figure 3.6

Temperature dependency plots for the adsorption of PCP on

MWCNTs and AC.

\section{Figure 4.1}

Adsorption of PCP by pristine MWCNTs and different oxidized MWCNTs.

Figure 4.2

Adsorption isotherms for PCP on MWCNTs oxidized with $\mathrm{H}_{2} \mathrm{O}_{2}$ at different temperatures.

\section{Figure 4.3}

Adsorption isotherms for PCP on MWCNTs oxidized with

$\mathrm{HNO}_{3}$ at different temperatures.

Figure 4.4

Comparison of different isotherm models for PCP adsorption on

MWCNTs oxidized by $\mathrm{H}_{2} \mathrm{O}_{2}$ with experimental results.

Figure 4.5

Comparison of different isotherm models for PCP adsorption on MWCNTs oxidized by $\mathrm{HNO}_{3}$ with experimental results.

\section{Figure 4.6}

Temperature dependency plots for the adsorption of PCP on pristine and oxidized MWCNTs.

Figure 4.7

The kinetic model for the adsorption of PCP to pristine and oxidized MWCNTs and the comparison between the experimental data and the predicted data.

Figure 4.8

Weber-Morris intra-particle diffusion plots for the adsorption of PCP to pristine and oxidized MWCNTs. 
Scheme 1

Surface functionalization of MWCNTs surface and the formation of MWCNTs-PEG and MWCNTs-ODA.

Figure 5.1

TGA plots of pristine MWCNTs, MWCNTs-PEG, and pure PEG.

Figure 5.2

TGA plots of pristine MWCNTs, MWCNTs-ODA, and pure ODA.

Figure 5.3

IR spectra of pristine MWCNTs, oxidized MWCNTs, MWCNTs-PEG and Pure PEG.

Figure 5.4

IR spectra of pristine MWCNTs, oxidized MWCNTs, MWCNTs-ODA and pure ODA.

Figure 5.5

Solubility's of the modified MWCNTs in different solvents.

Figure 5.6

XRD patterns of pristine MWCNTs, MWCNTs-PEG, MWCNTs-ODA, and pure ODA.

Figure 5.7

SEM images of pristine MWCNTs, MWCNTs-PEG, and MWCNTs-ODA.

Figure 6.1

Adsorption modeling of the four analytes on pristine MWCNTs.

Figure 6.2

Adsorption modeling of the four analytes on oxidized MWCNTs.

Figure 6.3

Adsorption modeling of the four analytes on MWCNTs-ODA.

Figure 6.4

Adsorption modeling of the four analytes on MWCNTs-PEG.

Figure 6.5

Comparison between the experimental and predicted free energies

of adsorption.

Figure 6.6

Schematic diagram of model vs. experiment for the adsorption on MWCNTs.

xviii 
Schematic diagram of the solid phase extraction system set up.

Figure 7.2

Effect of flow rate on the adsorption of TCP, PCP, PCB77, and PBB52 on pristine MWCNTs.

Figure 7.3

Effect of flow rate on the adsorption of TCP, PCP, PCB77, and PBB52 on MWCNTs-PEG.

Figure 7.4

Effect of flow rate on the adsorption of TCP, PCP, PCB77, and PBB52 on MWCNTs-ODA.

Figure 7.5

Effect of flow rate on the adsorption of TCP, PCP, PCB77, and PBB52 on C18.

Figure 7.6

Comparison between the adsorption of each analytes with different adsorbents.

Figure 7.7

Effect of pristine MWCNTs mass on the adsorption of TCP, PCP, PCB77, and PBB52.

Figure 7.8

Effect of MWCNTs-PEG mass on the adsorption of TCP, PCP, PCB77, and PBB52.

Figure 7.9

Effect of MWCNTs-ODA mass on the adsorption of TCP, PCP, PCB77, and PBB52.

Figure 7.10

Effect of $\mathrm{C} 18$ mass on the adsorption TCP, PCP, PCB77, and PBB52.

Figure 7.11

Effect of oxidized MWCNTs mass on the adsorption TCP, PCP, PCB77, and PBB52.

Figure 7.12

Effect of $\mathrm{pH}$ on the adsorption of PCP, TCP, PCB77, and PBB52 on pristine MWCNTs. 
Figure 7.13

Effect of $\mathrm{pH}$ on the adsorption of PCP, TCP, PCB77, and PBB52

on MWCNTs-PEG.

Figure 7.14

Effect of pH on the adsorption of PCP, TCP, PCB77, and PBB52

on MWCNTs-ODA.

Figure 7.15

Effect of $\mathrm{pH}$ on the adsorption of PCP, TCP, PCB77, and PBB52 on C18.

Figure 7.16

Effect of $\mathrm{pH}$ on the adsorption of PCP, TCP, PCB77, and PBB52 on the oxidized MWCNTs.

Figure 7.17

Effect of solvent on the elution of different analytes adsorbed on pristine MWCNTs.

Figure 7.18

Effect of solvent on the elution of different analytes adsorbed on

MWCNTs-ODA.

Figure 7.19

Effect of solvent on the elution of different analytes adsorbed on MWCNTs-PEG.

Figure 7.20

Effect of solvent on the elution of different analytes adsorbed on C18.

Figure 7.21

Full scan chromatogram of $50 \mathrm{ng} / \mathrm{ml}$ of TCP, PCP, PCB77 and

PBB52, by GC-ECD, in hexane.

Figure 7.22

Calibration curves of TCP, PCP, PCB77, and PBB52 using gas

chromatography-electron capture detector.

Figure 7.23

The dependence of the \% Recovery of four analytes, TCP, PCP, PCB52, and PBB77, on the concentrations, after solid phase extraction (SPE) using pristine MWCNTs, MWCNTs-ODA, MWCNTs-PEG, and C18.

Figure 7.24

The dependence of the \% Recovery of four analytes, TCP, PCP, PCB52, and PBB77, on the sample volume. 
Equilibration of the Rideau River Surface Water (RRSW) sample spiked with TCP, PCP, PCB77, and PBB52.

Figure 7.26

Regeneration/reusability of the SPE cartridge for the extraction of the four analytes, TCP, PCP, PCB52, and PBB77, using pristine MWCNTs, MWCNTs-ODA, MWCNTs-PEG, and C18.

Figure 7.27

The effect of decreasing the RRSW pH from 8.2 to 3.0 on

$\%$ adsorbed of the target analytes; on different SPE adsorbents; pristine MWCNTs, MWCNTs-PEG, MWCNTs-ODA, and C18. 


\section{CHAPTER 1}

\section{INTRODUCTION}




\subsection{Background}

\subsubsection{Carbon Nanotubes}

The discovery of carbon nanotubes can be traced back to the origin of fullerene chemistry (buckyball, $\mathrm{C}_{60}$ ) in 1985 [1]. $\mathrm{C}_{60}$ is a soccer ball-like molecule made of $\mathrm{sp}^{2}$ carbon atoms bonded in hexagon and pentagon configurations. In 1991, Iijima [2] reported the discovery of carbon nanotubes (CNTs), which are elongated fullerenes where walls of the tubes are hexagonal carbon and often capped at each end, in the soot produced by an arc-discharge of graphite. Since then, CNTs have captured the attention of researchers worldwide. A significant amount of work has been done to reveal the unique structural, electrical, mechanical, electromechanical and chemical properties of CNTs and to explore what might be the key applications of these novel materials. They exhibit exceptional electronic, mechanical, thermal, and transport properties. CNTs can be divided into single-walled carbon nanotubes (SWCNTs) [2] and multi-walled carbon nanotubes (MWCNTs) [3] according to the number of layers of carbon atoms making up the walls; as shown in Figure 1.1 [4].

A SWCNT is a graphene sheet rolled into a cylinder with a typical diameter of approximately $1.4 \mathrm{~nm}$, similar to that of a $\mathrm{C}_{60}$ buckyball. A MWCNT consists of concentric cylinders with mean value of interlayer spacing of about $3.4^{\circ} \mathrm{A}$ and a diameter which typically falls in the range of 10-20 nm. The length of the two types of tubes can be anywhere from one microns to even centimeters. As shown in Figure 1.2, the structure of a SWNT can be conceptualized by wrapping a one-atom-thick layer of graphite (called graphene) into a seamless cylinder [5]. The way the graphene sheet is wrapped is represented by a pair of indices $(n, m)$ called the chiral vector. The integers $n$ and $m$ 

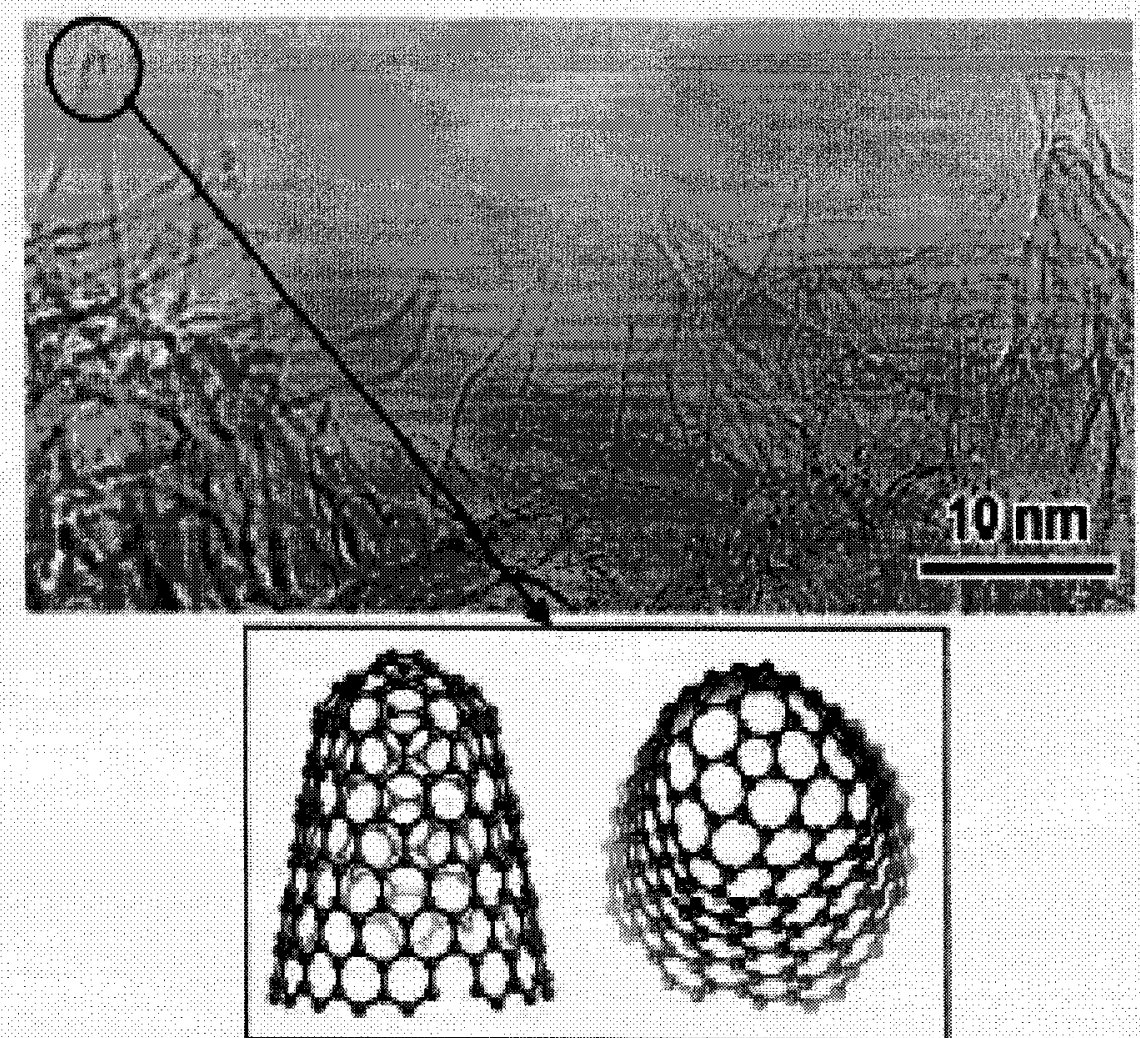

(a)
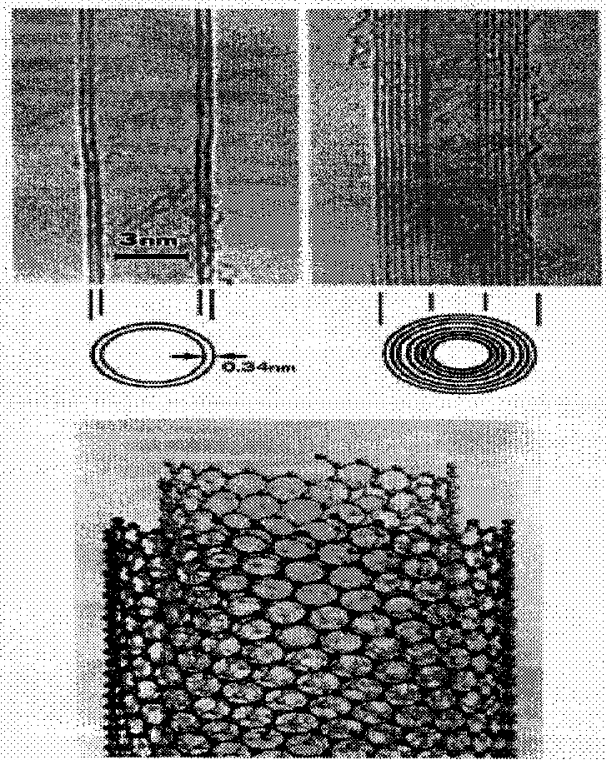

(b)

Figure 1.1. Single-walled (a) and multi-walled (b) carbon nanotubes [4]. 


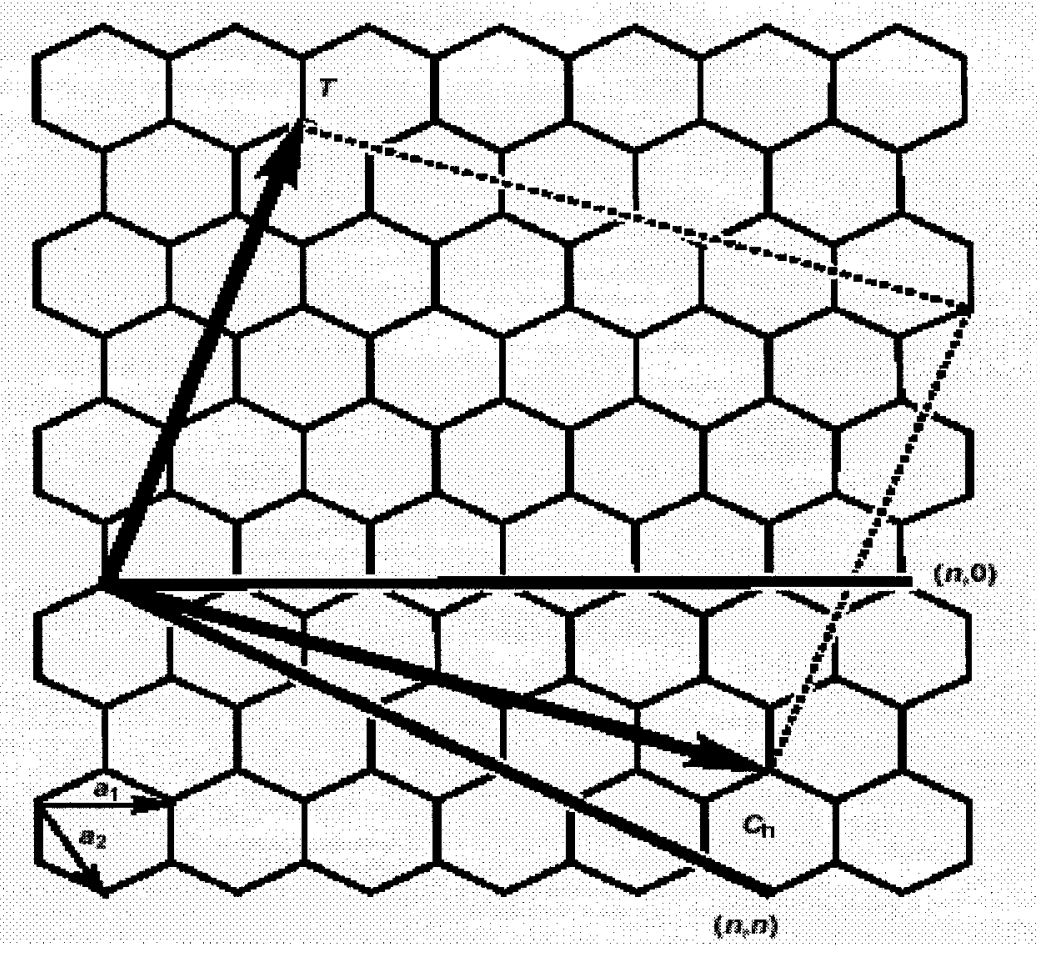

Figure 1.2. Schematic representation of a 2D graphite layer with lattice vectors $a_{1}$ and $a_{2}$ and the roll-up vector $C_{h}=n a_{1}+m a_{2}$. A chiral tubes exhibit roll-up vectrors derived from $(n, 0)$ (zigzag) or $(n, n)$ (armchair). The translation vector $T$ is parallel to the tube axis and defines the ID unit cell. The rectangle represents an unrolled unit cell, defined by $T$ and $C_{h}[5]$. 
denote the number of unit vectors along two directions in the honeycomb lattice of graphene. This is often thought of as representing the number of carbon atoms around the circumference of the tube, and the number of atoms down the tube axis. If $n=m$, the nanotubes are called "armchair". If $m=0$, the nanotubes are called "zigzag". Otherwise, they are called "chiral".

\subsubsection{Properties}

Carbon nanotubes are composed entirely of $\mathrm{sp}^{2}$ hybridized bonds, similar to graphite. This bonding structure, make the carbon nanotubes much stronger than diamond which have composed of $\mathrm{sp}^{3}$ bonds. This bonding structure of carbon nanotubes provides them with their unique strength. Nanotubes naturally align themselves into "ropes" held together by Van der Waals forces. During manufacturing, high pressure can merge nanotubes together and help trading some $\mathrm{sp}^{2}$ bonds for $\mathrm{sp}^{3}$ bonds. This effect give great possibility for the production of strong, unlimited-length wires through high-pressure nanotube linking. The covalent bonding that has occurred in CNTs means they have very high tensile strengths. The tensile strength of a SWNT was found to be 63GPa (in comparison, high-carbon steel has a tensile strength of approximately 1.2GPa). SWNTs also have very high elastic modulus, on the order of 1Tpa [4]. Under excessive tensile strain, the tubes will undergo plastic deformation, which means the deformation is permanent. This deformation begins at strains of approximately $5 \%$ and can increase the maximum strain the tube undergoes before fracture by releasing strain energy. CNTs are not nearly as strong under compression. Due to their hollow structure, they tend to undergo buckling when placed under compressive, torsional or bending stress. 


\subsubsection{Applications}

CNTs show the characteristics of unique size distributions, novel hollow-tube structures, high specific surface areas and electrical semi-conductivity and conductivity. These characteristics allow them to be used in a broad range of applications such as catalysts [5], different biological aspects [6-16], nanoscale electronics [17-19], mechanical systems [20], as scanning electron microscope probes and electron field emission tips [21,22], and adsorbents for a wide range of chemicals [23-58].

\subsubsection{Adsorption onto CNTs}

Adsorption is the process by which atoms or molecules of one material become attached to the surface of another. An interface is the contiguous area between two phases, such as solid and a gaseous phase and the material that is adsorbed becomes concentrated at the interface. Molecules and atoms can be attached to surfaces in two ways; physisorption and chemisorption. In physisorption (physical adsorption), there are Van der Waals interactions between the adsorbate (the adsorbed material) and the substrate. Van der Waals interactions are weak, and the energy released when a particle is physisorbed is of the same order of magnitude as the enthalpy of condensation. The enthalpy of physisorption values are thus in the region of $20 \mathrm{~kJ} \mathrm{~mol}^{-1}$. This small change is insufficient to lead to bond breaking, so a physisorbed molecule retains its identity, although it might be distorted by the presence of the surface. In chemisorption, the molecules stick to the surface by forming a strong chemical bond with greater enthalpy than that of the physisorption. The chemisorption enthalpy values are in the region of 200 $\mathrm{kJ} \mathrm{mol}^{-1}$. One of the most important differences between physisorption and chemisorption is the specificity. Physisorption is non-specific whereas chemisorption is specific. Calculating the enthalpy of adsorption is considered to be the principle test to distinguish 
between physisorption and chemisorption. Values more positive than $-25 \mathrm{~kJ} \mathrm{~mol}^{-1}$ may be taken to signify physisorption, and values more negative than about $-40 \mathrm{~kJ} \mathrm{~mol}^{-1}$ may be taken to signify chemisorption [59], but these are somewhat arbitrary values.

Physical adsorption on carbon nanotubes has been the focus of much recent attention [60-76]. The fundamental interest in this field of research is largely due to the one-dimensional environment provided by the nanotubes structure. Secondly, this structure provide a number of potential applications related to their high length to diameter ratio and their high specific surface area, for instance a gas storage device or for gas detection [77]. Indeed, a number of recent studies have revealed strong interactions between adsorbed gases and the electronic properties of nanotubes [78-80].

The bundle structure of CNTs produces at least four distinct sites, as shown in Figure 1.3. Gas molecules can adsorb onto: 1) the external bundle surface; 2) in a groove formed at the contact between adjacent tubes on the outside of the bundle; 3) within an interior pore of an individual tube; and 4) inside an interstitial channel formed at the contact of three or more tubes in the bundle interior. The access of molecules to the internal tube pores is either through open CNTs ends, or defects (holes) in the tube walls. For a particular gas molecule, some of these sites can be excluded on size considerations alone. Many mathematical models used to describe adsorption processes are accompanied by idealized assumptions. Currently used adsorption isotherms (e.g., Langmuir, Freundlich) have been adapted from early studies that analyzed the accumulation of gases at solid phases. In most isotherms, adsorbate-adsorbent interactions have been treated as rapid and reversible processes. The Langmuir model [81] assumes a finite number of adsorption sites, with each site having an equal affinity for the adsorbate, independent of the surface coverage. From aqueous solution, the adsorption is more complicated than from the gas 


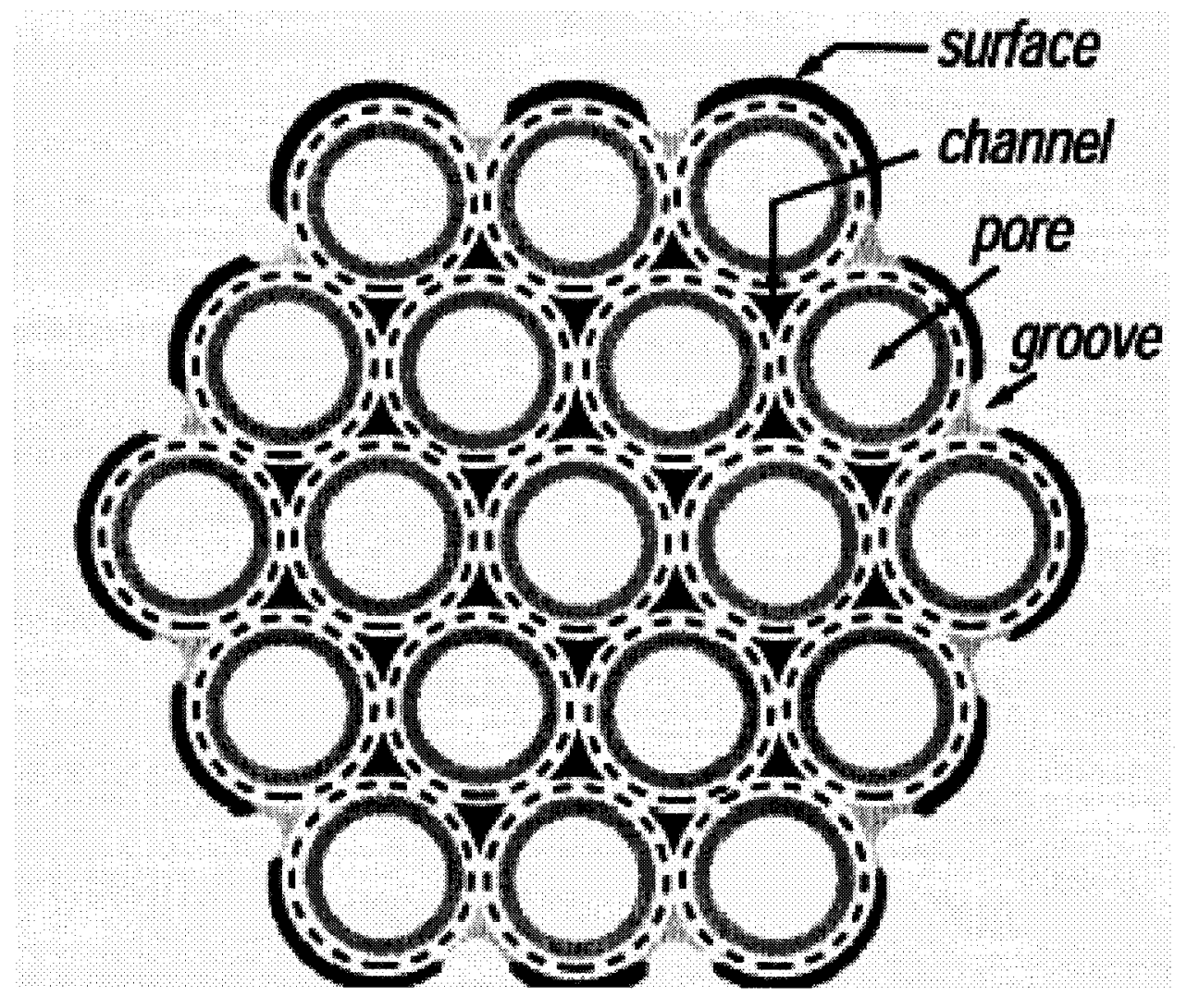

Figure 1.3 Location of the possible adsorption sites on a bundle of SWCNTs (open end) [80]. 
phase due to the interactions between the adsorbate molecules, as well as the interaction between the adsorbent material and the adsorbate molecules, and interactions of both (adsorbent and adsorbate) with the solvent molecules.

\subsubsection{Persistent Organic Pollutants (POPs) in the Environment}

Persistent organic pollutants (POPs) are a group of chemicals which have been introduced; intentionally or unintentionally, and widely distributed in the environment. Due to their stability and fat solubility, they have a capacity to accumulate in many fatcontaining foods, including human milk. The most commonly encountered POPs are organochlorine pesticides, such as DDT, industrial chemicals, most notably, chlorophenols (CPs), polychlorinated biphenyls (PCBs), polybrominated biphenyls (PBBs) and industrial by-products, especially, dioxins. These chemicals as a group have been of health concern, both for acute and chronic toxicity reasons.

\subsubsection{Physical and Chemical Properties of Chlorophenols}

Chlorophenols (CPs) are organic chemicals formed from phenol by substitution in the phenol ring with one or more atoms of chlorine. Nineteen congeners are possible, ranging from monochloro phenols to the fully chlorinated pentachlorophenol (PCP). Chlorophenols are solids at room temperature, except for 2-chlorophenol, which is a liquid. The aqueous solubility of chlorophenols is low, but the sodium or potassium salts of chlorophenols are up to four orders of magnitude more soluble in water than the parent compounds. The acidity of chlorophenols increases as the number of chlorine subsituations increases. The $n$-octanol/water partition coefficients of chlorophenols increase 
with chlorination, indicating a propensity for the higher chlorophenols to bioaccumulate. Taste and odour thresholds are quite low. The main advantages of PCP and its salts are that they are very effective biocides that have a broad application and are inexpensive. PCP and its derivatives have a variety of applications in agriculture, industry, and domestic fields. Their major application is wood preservation, particularly on a commercial scale. They protect construction lumber, and also poles and posts, from fungal rots and decay. They also prevent staining. PCP is also used as herbicide, defoliant, fungicide, pre-harvest desiccant, bactericide, insecticide, and molluscicide and to control termites. PCP has many registered industrial uses. It is used in construction of boats and buildings to control mould, in petroleum drilling and production, and in the treatment of cable coverings, canvas belting, nets, and construction lumber and poles. It is used in paints, pulp stock, pulp, and paper and as preservative for hard board and particle board. Because of increased concern about the potential health hazard from PCP and its impurities, the pattern of use has changed in the last few years. PCP is used in the home, both indoors and outdoors, mostly to treat wood. It is the main active ingredient in certain wood preservatives used in the home, and is added to products such as stains and paints. Cases of apparent PCP intoxications after indoor application in homes have been reported. (Its indoor use is forbidden in some countries, e.g., the Netherlands). Other applications of PCP include health-care products and disinfectants for the home, farms, and hospital. PCP may also be contained in dental- and skin-care products, bacterial soaps, and laundry products.

Pure pentachlorophenol (PCP) consists of light tan to white, needlelike crystals and is relatively volatile. It is soluble in most organic solvents, but practically insoluble in water at the slightly acidic $\mathrm{pH}$ generated by its dissociation (pKa 4.7). However, its salts such 
sodium pentachlorophenate (Na-PCP), are readily soluble in water. At the approximately neutral $\mathrm{pH}$ of most natural waters, PCP is more than $99 \%$ ionized. Apart from other chlorophenols, unpurified technical PCP contains several microcontaminants, particularly polychlorinated dibenzo- $p$-dioxins (PCDDs) and polychlorinated dibenzofurans (PCDFs), of which $\mathrm{H}_{6} \mathrm{CDD}$ is the most relevant congener toxicologically. 2,3,7,8-TCDD has only once been confirmed in commercial PCP samples $(0.25-1.1$ $\mu \mathrm{g} / \mathrm{kg}$ ). Depending on the thermolytic conditions, thermal decomposition of PCP or NaPCP may yield significant amounts of PCDDs and PCDFs. The use and the uncontrolled incineration of technical grade PCP is one of the most important sources of PCDDs and PCDFs in the environment. The relatively high volatility of PCP and the water solubility of its ionized form have led to widespread contamination of the environment with this compound. Depending on the solvent, temperature, $\mathrm{pH}$, and type of wood, up to $80 \%$ of PCP may evaporate from treated wood within 12 months. The ubiquitous occurrence of PCP is indicated by its detection, even in ambient air of mountain rural areas $(0.25-0.93$ $\mathrm{ng} / \mathrm{m}^{3}$ ). In urban areas, PCP levels of $5.7-7.8 \mathrm{ng} / \mathrm{m}^{3}$ have been detected. While elevated PCP concentrations can be found in groundwater (3 - $23 \mu \mathrm{g} /$ Litre) and surface water $(0.07-31.9 \mu \mathrm{g} /$ Litre) within wood-treatment areas, the PCP level of surface waters is usually in the range of $0.1-1.0 \mu \mathrm{g} / \mathrm{Litre}$, with maximum values of up to $11 \mu \mathrm{g} / \mathrm{Litre}$. PCP concentrations in the $\mathrm{mg} /$ Litre range can be encountered near industrial discharges.

2,4,5-Trichlorophenol (TCP) is found as colorless needles or gray flakes with a strong phenolic odor. It sublimes, is stable up to its melting point, and is a weak monobasic acid. It is soluble in acetone, benzene, carbon tetrachloride, ether, denatured alcohol, methanol, liquid petrolatum, soybean oil, and toluene. 2,4,5- Trichlorophenol is sparingly soluble in water $(0.12 \mathrm{~g} / 100 \mathrm{ml}$ at $25 \mathrm{C})$. It emits toxic fumes of chloride and explodes when heated 
to decomposition. It is widely used as a bactericide, fungicide, component in the synthesis of defoliants and herbicides. 2,4,5-trichlorophenol is grey in color, flaky in appearance and looks like small needles. This man-made substance is not found naturally in the environment. 2,4,5- Trichlorophenol has several uses. The paper and pulp mills use 2,4,5- trichlorophenol as a fungicide to destroy or prevent fungi from growing. It is also used as herbicide and to make other pesticides. There is no information on the effects of long term exposure to 2,4,5-trichlorophenol on human. However, animal studies show that long-term exposure in rats through diet caused some slight decline in the liver and kidneys. No information is available on whether 2,4,5-trichlorophenol can cause cancer in humans. The U.S. Environmental Protection Agency has determined that 2,4,5trichlorophenol is not classifiable regarding the likelihood of it causing cancer.

\subsubsection{Analysis of Chlorophenols}

Most of the analytical methods used today involve acidification of the aqueous sample to convert chlorophenols to their non-ionized form, extraction into an organic solvent, possible cleaning by back-extraction into a basic solution, and determination by gas chromatography with electron-capture detector (GC-ECD) or other chromatographic methods as ester or ether derivatives (e.g., acetyl-chlorophenol).

Generally, the occurrence of chlorophenols has been considered as a prerequisite for the formation of dioxins. Chlorophenols have thus been named as predioxins and can be contemplated as indicators of the formation of PCDDs [82]. 


\subsubsection{Polychlorinated Biphenyls compounds (PCBs)}

Polychlorinated biphenyls are mixtures of up to 209 individual chlorinated compounds (known as congeners) with no known natural sources. PCBs are either oily liquids or solids that are colorless to light yellow. Some PCBs can exist as a vapor in air. PCBs have no known smell or taste. Many commercial PCBs mixtures are known in the U.S. by the trade name Aroclor. PCBs have been used as coolants and lubricants in transformers, capacitors, and other electrical equipment because they don't burn easily and are good insulators. The manufacture of PCBs was stopped in the U.S. in 1977 because of evidence they build up in the environment and can cause harmful health effects. Products made before 1977 that may contain PCBs include old fluorescent lighting fixtures and electrical devices containing PCBs capacitors, and old microscope and hydraulic oils. Due to their relative insolubility in water and high solubility in fats, PCBs have become widespread environmental contaminants accumulating through food chains and causing permanent background contamination of food. They are known to cause effects on neurological development, immune function and thyroid function, reproductive disorders, dermatologic and hepatic abnormalities and increased cancer risk in humans have been attributed to more elevated PCBs contaminations [83]

\subsubsection{Polybrominated Biphenyls compounds (PBBs)}

Polybrominated biphenyls (PBBs) are manufactured chemicals which are usually colorless to off-white solids. They have been extensively applied as flame-retardants and added to the plastics used to make products like computer monitors, televisions, textiles, plastic foams. PBBs can leave these plastics and find their way into the environment. PBBs are still around in the environment because they do not degrade easily or quickly. 
Due to their structural similarity to PCBs, PBBs became the focus of many environmental studies as early as in the 1970s. The toxicological threat of PBBs was confirmed in 1973 when human food was accidentally contaminated with PBBs in Michigan due to accidentally mixing of animal feed with 500-1,000 pounds of PBBs. This contamination of the food chain affected millions of farm animals and humans living in Michigan at this time. Although, the production of PBBs was reduced world-wide, the presence of PBBs in the environment was confirmed in a wide range of samples [84]. In the United States, manufacturing of PBBs was stopped in 1976. Similar to PCBs, there are 209 different molecular combinations, or congeners, that are possible for PBBs. However, unlike PCBs, only a subset of these 209 congeners exists in commercial mixtures.

For this study, 2,4,5-trichlorophenol (TCP), pentachlorophenol (PCP), 3,3',4,4'tetrachlorobiphenyl (PCB77) and 2,2',5,5'-tetrabromobiphenyl (PBB52), where selected to study their interaction with different adsorbents, and their structure are presented in Figure 1.4.

\subsection{Current State of Knowledge}

Recently, the release of POPs into the environment had been the focus of scientists worldwide due to their toxicity, persistence, and bioaccumulation. Therefore, it is critical to develop simple, efficient, and rapid methods for environment monitoring. Chromatographic techniques such as gas chromatography (GC) and liquid chromatography (LC) are the most widely used methods for the analysis of POPs in different environmental samples. However, the sensitivity and selectively of the above mentioned methods are usually insufficient for direct determination of POPs at very low 


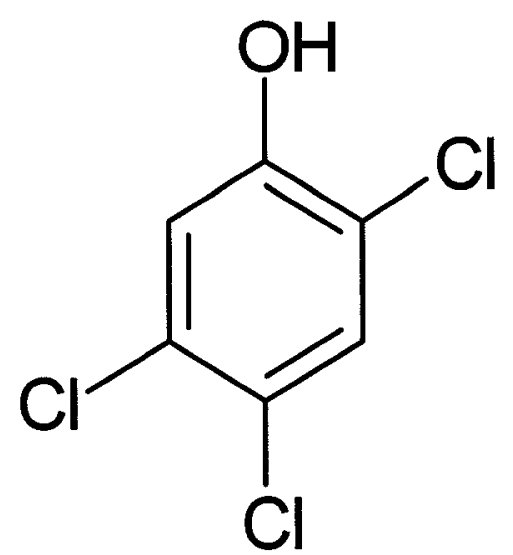

2,4,5-trichlorophenol (TCP)

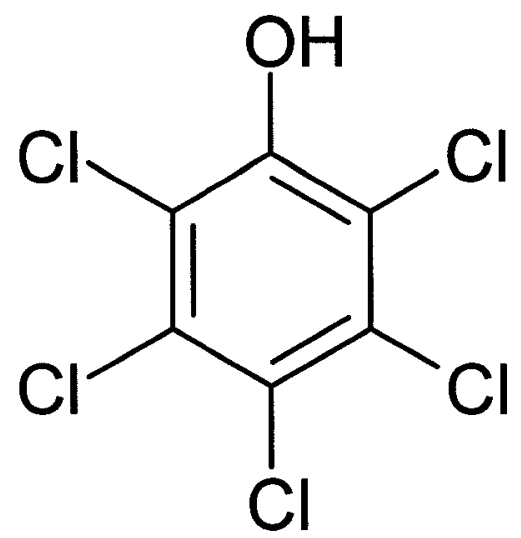

Pentachlorophenol (PCP)

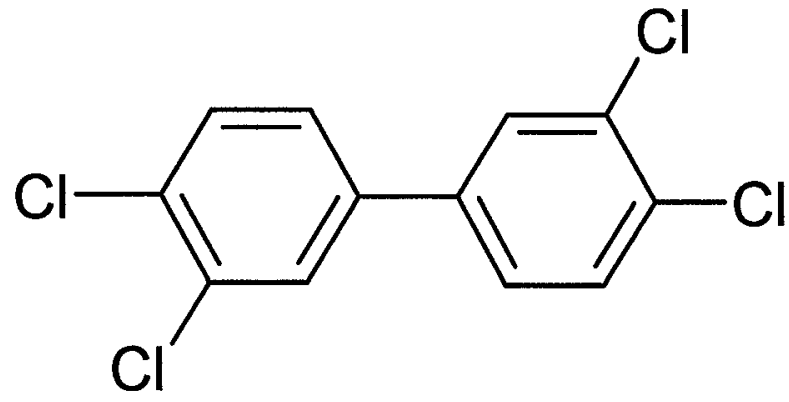

3,3',4,4'-tetrachlorobiphenyl (PCB77)

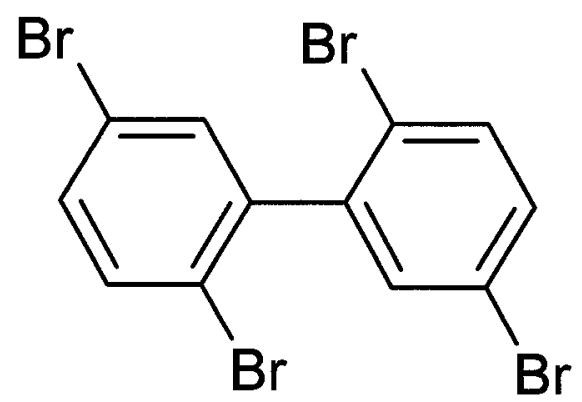

2,2',5,5'-tetrabromobiphenyl (PBB52)

Figure 1.4. Chemical Structures of the target analytes 
concentration levels; part per billion (ppb) or less, in complex matrix environmental samples. For that reason, sample pretreatment and preconcentration are very important steps prior to chromatographic analysis. Solid phase extraction (SPE) using a sorbent material; such as activated charcoal, and C18 and C8 silica, is the most commonly used technique for environmental water sample preconcentration with many advantages such as high recovery, short extraction time, high enrichment factor, low cost, and low consumption of organic solvents [85-89]. C18 silica is one of the most widely used adsorbents for SPE, but it shows relatively low recovery for some relatively polar analytes due to their low affinity for it and high affinity for water [90]. Carbon nanotubes were used as an analytical tool in different applications. It was reported that CNTs were used as filters and membranes for the elimination of heavy hydrocarbons from petroleum and the elimination of bacterial contaminants from water [91]. CNTs were used as well as chemical sensors and electrochemical detection. Recent studies have showed that CNTs can enhance the electrochemical reactivity of biomolecules and promote the electrontransfer reactions of proteins [92]. CNTs can be vertically aligned on the electrode surface, and act as molecular wires, allowing electrical communication between the underlying electrode and the redox enzyme or biomaterial, such as DNA [93] and dopamine [94]. MWCNTs was used in gas chromatography as column packing material for the separation of volatile compounds such as aromatic hydrocarbons and the results were satisfactory when it compared with graphitized carbon black [52]. It was concluded that MWCNTs are an interesting alternative stationary phase for volatile compounds with relative low boiling points. As was explained previously, the unique characteristic of CNTs allows them to interact strongly with organic molecules and hence be used as packing material for SPE. One of the most traditional adsorbent used for SPE is the 
activated charcoal (AC), which used for preconcentration and elimination of different pollutants in various mediums. Recent studies showed that carbon nanotubes have higher adsorption efficiency for the removal of different compounds compared with activated charcoal. Comparative study between CNTs and $\mathrm{AC}$ for the adsorption of trihalomethanes [25], dioxine [50], showed that CNTs have higher adsorption capacity than AC. A MWCNTs $\mu$-SPE device was developed to extract organophosporous pesticides from sewage sludge sample solution [55]. The $\pi-\pi$ electrostatic interaction with the analytes and the large surface area of MWCNTs facilitated the adsorption of the analytes of interest, with good reproducibility. Comparison was made with hollow fiber protected solid-phase micro extraction (SPME), and headspace SPME; $\mu$-SPE was demonstrated to be a fast, accurate, and cost-effective pretreatment method for sewage sludge samples. MWCNTs were used as SPE adsorbent for the extraction of many other materials such as atrazine and simazine [24, 27], isolation and quantification of amygdaline [29] in fruits, chlorophenol [30], drugs from urine [32], trace metals [36], bisphenol A, 4-n-nonylphenol, and 4-tert-octylphenol [45], copper [ 56], chlorobenzenes [58]. In general, MWCNTs showed good efficiency in the extraction of the above mentioned analytes and the determination of their concentrations in different complex matrices. One of the studies [27], made a comparison between different adsorbent materials (MWCNTs, $\mathrm{C}_{18}$ silica and activated carbon) for the extraction of atrazine and simazine. It was found that for the extraction of simazine, MWCNTs were much better than $\mathrm{C}_{18}$ silica, whereas for atrazine, $\mathrm{C} 18$ silica achieved greater extraction than MWCNTs. Activated carbon did not give the expected extraction efficiency because of its large size and less active sites for adsorption compared with MWCNTs and $\mathrm{C}_{18}$ silica. The study demonstrated that MWCNTs could be used as a valuable alternative adsorbent 
for SPE of atrazine and simazine in many real water samples.

\subsection{Weaknesses of Current State of Knowledge}

Although there are many studies concerning the applicability of using MWCNTs as a potential SPE adsorbent, there are not enough studies about the extraction of different types of analytes, polar and non-polar. Most of the studies were more focused on the extraction of certain types of analytes, such as chlorophenols [30], or trace metals $[36,56]$, or pesticides (organophosphorus pesticides or atrazine and simazine) [24,27]. In nature, all pollutants are present simultaneously and the adsorption is mostly, controlled by different factors such as the type of the adsorbent, and adsorbate as well as the environmental conditions such as $\mathrm{pH}$, temperature and concentrations. Kinetics and equilibrium studies of the adsorption on MWCNTs by different analytes are scarce in the literature. There were few studies about the adsorption behavior of different analytes, polar and non polar, on carbon nanotubes at different environmental conditions, and the application of different adsorption models using different adsorption isotherms. Moreover, investigations of the adsorption kinetics and the uptake of different analytes by CNTs are very limited. More work is needed to understand the adsorption behavior (kinetics and thermodynamics) of various analytes on MWCNTs. Kinetic studies are very important factor for understanding the mass transfer of different analytes for the bulk phase to the adsorbent and to determine the different conditions affecting this transfer. Thermodynamics calculation of the adsorption process at equilibrium is required as well to understand the mechanism of adsorption and to understand the spontaneity, and heat of adsorption by calculating different thermodynamic parameters of the adsorption.

Moreover, to our knowledge, none of the research studies investigated the modification effect; via chemical functionalization of carbon nanotubes with different functional 
groups, on the adsorption behavior of different analytes. Most of the adsorption studies mentioned previously used either pristine or purified carbon nanotubes. Chemical modifications of carbon nanotubes and their potential application as solid phase packing material for SPE could be a promising field. These chemical modifications could extend the applications of carbon nanotubes in environmental and analytical chemistry as selective binding agents for various analytes in various matrices. It is crucial to study the affinities of various analytes towards different chemically modified carbon nanotubes.

In this research work, the adsorption of PCP, TCP, PCB77, and PBB52 was studied on different MWCNTs; namely, pristine MWCNTs, oxidized MWCNTs, MWCNTs functionalized with octadecyl amine (MWCNTs-ODA) and polyethylene glycol (MWCNTs-PEG).

\subsection{Objectives}

The objectives of this work were the following:

1) oxidation of MWCNTs using various oxidizing agents.

2) characterizations of the oxidized MWCNTs using a variety of techniques, such as infrared spectroscopy, x-ray diffraction, scanning electron microscopy, surface area analysis, surface oxygen containing acidic functional group measurements and the formation of stable aqueous dispersion of MWCNTs.

3) investigation of the adsorption of PCP from aqueous solution by the pristine and oxidized MWCNTs and evaluation of the kinetic and thermodynamic parameters of adsorption, i.e.: the free energy, enthalpy and entropy of adsorption in order to achieve a better understanding of the adsorption process. 
4) further modification and characterization of MWCNTs using different functional groups; MWCNTs-ODA and MWCNTs-PEG.

5) study the thermodynamics of the adsorption of PCP, TCP, PCB77, and PBB52 on the pristine and chemically modified MWCNTs and different type of solvents can be used for efficient elution of the previously mentioned analytes.

6) computer modeling for the adsorption of different analytes on pristine and modified MWCNTs.

7) application of different MWCNTs-based materials as packing materials for solid phase extraction of different POPs; PCP, TCP, PCB77, and PBB52.

8) method development and evaluation of pristine and modified MWCNTs as solid phase extraction adsorbents for the preconcentration and analysis of natural water sample (Rideau River) spiked with the four target analytes.

9) study the regeneration/reusability of carbon nanotubes SPE cartridge packing materials for the adsorption/desorption of the four different analytes from real sample.

\subsection{Organization of the Thesis}

Chapter 1 provides a brief introduction about the structure, properties and applications of carbon nanotubes as well as the target analytes and current states of knowledge. Chapter 2 presents the oxidation and characterization of multi-walled carbon nanotubes. Chapter 3 discusses the adsorption of pentachlorophenol on pristine multi-walled carbon nanotubes and the evaluation of various thermodynamic parameters. Chapter 4 presents the the adsorption of pentachlorophenol on oxidized multi-walled carbon nanotubes and the evaluation of different thermodynamic parameters. Chapter 5 discusses the modification 
and characterization of MWCNTs using octadecyl amine and polyethylene glycol. Chapter 6 presents the effect of temperature and thermodynamic calculation of the adsorption at equilibrium and further comparison with computer models, and Chapter 7 discuss the adsorption of different analytes on the modified MWCNTs in an SPE cartridge and the effect of different factors on the adsorption and the application of different solvents for the elution of the different analytes. Details the optimized analytical method that can be used for the determination of PCP, TCP, PCB77, and PBB52, using SPE packed with different adsorbents. Chapter 8 will presents the conclusions and the findings of this research study. 


\subsection{References}

[1] Kroto H W, Heath J R, O.'Brien S C, Curl R F, Smalley R E, Nature 1985, 318, 162.

[2] Iijima S, Nature 1991,354, 56.

[3] Iijima S, Ichihashi T, Nature 1993, 363, 603.

[4] Xie X L, Mai Y W, Zhou X P, Materials Science and Engineering, $R$ 2005, 49, 89.

[5] Dillon A C, Jones K M, Bekkedahl T A, Kiang C H, Bethune D S, Heben M J, Nature 1997, 386, 377.

[6] Bianco A, Prato M, Advanced materials 2003, 15, 1765.

[7] Zhang M G, Smith A, Gorski W, Analytical Chemistry 2004, 76, 5045.

[8] Gooding J J, Electroanalysis 2002, 14, 1149.

[9] He P, Dai L, Chemical Communications 2004, 3, 348.

[10] Heller I, Kong J, Heering H A, Williams K A, Lemay S G, Dekker C, Nano Letters 2005, 5, 137.

[11] Azamian B R, Coleman K S., Davis J J, Hanson N, Green M L H, Chemical Communications. 2002, 4, 366.

[12] Snowden T S, Ansyln E V, Current Opinion in Chemical Biology 1999, 3, 740.

[13] Cloninger M J, Current Opinion in Chemical Biology 2002, 6, 742.

[14] Azamian B R, Davis J J, Coleman K S, Bagshaw C, Green M L H, Journal of the American Chemical Society 2002, 124, 12664.

[15] Hill H A O, Coordination Chemistry Reviews 1996, 151,115.

[16] Yu X, Mu T, Huang H, Liu Z, Wu N, Surface Science 2000, 461, 199. 
[17] Collins P G, Zettl A, Bando H, Thess A, Smalley R E, Science 1997, 278, 100.

[18] Kong J, Franklin N R, Zhou C, Chapline M G, Michael G, Peng S, Science 2000, 287, 622 .

[19] Collins P G, Bradley K, Ishigami M, Zettl A, Science 2000, 287, 1801.

[20] Iijima S, in, Proceedings of the IEEE 11th Annual International Workshop on MicroElectro Mechanical Systems, Heidelberg, 1998, p. 520.

[21] Dai H, Hafner J H, Rinzler A G, Colbert D T, Smalley R E. Nature 1996,384, 147.

[22] Rinzler A G, Hafner J H, Nikolaev P, Lou L, Kim S G, Tomanek D, Nordlander P, Colbert D T, Smalley R E, Science 1995, 269, 1550.

[23] Di Z C, Ding J, Peng X J, Li Y H, Luan Z Kun, Liang J, Chemosphere 2006, 62, 861.

[24] Zhou Q, Xiao J, Wang W, Liu G, Shi Q, Wang J, Talanta 2006, 68, 1309.

[25] Lu C, Chiu H, Chemical Engineering Science 2006, 61, 1138.

[26] Li Y H, Zhu Y, Zhao Y, Wu D, Luan Z, Diamond and Related Materials 2006, 15, 90.

[27] Zhou Q, Wang W, Xiao J, Wang J, Liu G, Shi Q, Guo G, Microchimica Acta 2006, 152, 215-224.

[28] Yan H, Gong A, He H, Zhou J, Wei Y, Lv L, Chemosphere 2006, 62, 142.

[29] Lu W F, Ding M Y, Zheng R, Journal of Chromatographic Science 2005, 43, 383.

[30] Cai Y, Cai Y, Mou S, Lu Y, Journal of Chromatographia A 2005, 1081, 245.

[31] Lu C, Chung Y L, Chang K F, Water Research 2005, 39, 1183.

[32] Pan C, Xu S, Zou H, Guo Z, Zhang Y, Guo B, Journal of the American Society for Mass Spectrometry 2005, 16, 263. 
[33] Peng X, Luan Z, Di Z, Zhang Z, Zhu C, Carbon 2005, 43, 880.

[34] Di Z C, Li Y H, Luan Z K, Liang J, Adsorption Science \& Technology 2004, 22, 467.

[35] Peng X, Luan Z, Ding J, Di Z, Li Y, Tian B, Materials Letters 2005, 59, 399.

[36] Liang P, Liu Y, Guo L, Zeng J, Lu H, Journal of Analytical Atomic Spectrometry 2004, 19, 1489.

[37] Fugetsu B, Satoh S, Shiba T, Mizutani T, Lin Y Bo, Terui N, Nodasaka Y, Sasa K, Shimizu K, Akasaka T, Shindoh M, Shibata K, Yokoyama A, Mori M, Tanaka K, Sato Y, Tohji K, Tanaka S, Nishi N, Watari F, Environmental Science \& Technology 2004, 38, 6890 .

[38] Yan H, Pan G, Zou H, Li X, Chen H, Chinese Science Bulletin 2004, 49, 1694.

[39] Fugetsu B, Satoh S, Iles A, Tanaka K, Nishi N, Watari F, Analyst 2004, 129, 565.

[40] Li Q L, Yuan D X, Lin Q M, Journal of Chromatographia A 2004, 1026, 283.

[41] Li Y H, Luan Z, Xu X, Zhou X, Xu C, Wu D, Wei B, Adsorption Science \& Technology 2003, 21, 475.

[42] Peng X, Li Y, Luan Z, Di Z, Wang H, Tian B, Jia Z, Chemical Physics Letters 2003, 376, 154.

[43] Wang S, Li Y, Gong X, Zhao H, Luan Z, Xu C, Wu D, Chinese Science Bulletin $2003,48,441$.

[44] Li Y. H, Wang, S., Zhang, X., Wei, J., Xu, C., Luan, Z., Wu, D., Wei, B. Environmental Technology 2003, 24, 391.

[45] Cai Y, Jiang G, Liu J, Zhou Q, Analytical Chemistry 2003, 75, 2517.

[46] Cai Y, Jiang G, Liu J, Zhou Q, Analytica Chimica Acta 2003, 494,149. 
[47] Power T D, Skoulidas A I, Sholl D S, Journal of the American Chemical Society 2002, 124, 1858.

[48] Li Y H, Wang S C, Anyuan Z D, Zhang X, Xu C, Luan Z, Ruan D, Liang J, Wu D, Wei B, Chemical Physics Letters 2001, 350, 412.

[49] Long R Q, Yang R T, Journal of the American Chemical Society 2001, 123, 2058.

[50] Yang R T, Long R Q, Padin J, Takahashi A, Industrial \& Engineering Chemistry Research 1999, 38, 2726.

[51] Li Y, Wang S, Luan Z, Ding J, Xu C, Wu D, Carbon 2003, 41, 1057.

[52] Li Q, Yuan D, Journal of Chromatographia A 2003, 1003, 203.

[53] Li Y, Wang S, Zhang X, Wei J, Xu C, Luan Z, Wu D, Materials research Bulletin 2003, 38, 469 .

[54] Li Y, Ding J, Luan Z, Di Z, Zhu Y, Xu C, Wu D, Wei B, Carbon 2003, 41, 2787.

[55] Basheer C, Alnedhary A A, Rao B S M, Valliyaveettil S, Lee H K, Analytical Chemistry 2006, 78, 2853.

[56] Liang P, Ding Q, Song F, Journal of Separation Science 2005, 28, 2339.

[57] Kerman K, Morita Y, Takamura Y, Tamiya E, Analytical and Bioanalytical Chemistry 2005, 381, 1114.

[58] Liu G, Wang J, Zhu Y, Zhang X, Analytical Letters 2004, 37, 3085.

[59] Atkins P, Physical Chemistry, Sixth edition, W.H. Freeman and Company, New York, 1998, page 857

[60] Kuznetsova A, Mawhinney D B, Naumenko V, Yates Jr J T, Smalley R E, Chemical Physics Letters 2000, 32, 292. 
[61] Kuznetsova A, Yates Jr J T, Liu J, Smalley R E, Journal of Chemical Physics 2000, $112,9590$.

[62] Talapatra S, Krungleviciute V, Migone A D, Physical Review Letters 2002, 89, 246106.

[63] Fujiwara A, Ishii K, Sue Matsu H, Kataura H, Maniwa Y, Suzuky S, Chemical Physics Letters 2001, 336, 205.

[64] Byl O, Kondratyuk P, Forth S T, FitzGerald S A, Chen L, Johnson J K, Journal of the American Chemical Society 2003, 125, 5889.

[65] Ulbricht H, Moos G, Hertel T, Surface Science 2003, 532, 852.

[66] Muris M, Dufau N, Bienfait M, Dupont-Pavlovsky N, Grillet Y, Palmari JP, Langmuir 2000, 16, 7019.

[67] Muris M, Dupont-Pavlovsky N, Bienfait M, Zeppenfeld P, Surface Science 2001, $492,67$.

[68] Babaa M R, Stepanek I, Masenelli V K, Dupont P N, McRae E, Bernier P, Surface Science 2003, 531, 86.

[69] Masenelli V K, McRae E, Dupont P N, Applied Surface Science 2002, 196, 209.

[70] Talapatra S, Migone A D, Physical Review Letters 2001, 87, 206106.

[71] Wilson T, Vilches O E, Physica B 2003, 278, 329.

[72] Muris M, Bienfait M, Zeppenfeld P, Dupont P N, Johnson M, Vilches O E, Applied Physics A 2002, 74, S1293.

[73] Zhao J, Buldum A, Han J, Lu J P, Nanotechnology 2002, 13, 195. 
[74] Calbi M M, Cole M W, Gatica S M, Bojan M J, Stan G, Reviews of Modern Physics 2001, 73, 857.

[75] Calbi M M, Toigo F, Cole M W, Physical Review Letters 2001, 86, 5062.

[76] Bienfait M, Zeppenfeld P, Dupont P N, Palmari J P, Johnson M R, Wilson T, Physical Review Letters 2003, 91, 035503.

[77] Dresselhaus M S, Williams K A, Eklund P C, MRS Bulletin 1999, 24, 45.

[78] Kong J, Franklin N R, Zhou C, Chapline M G, Michael G, Peng S, Science $2000,287,622$.

[79] Collins P G, Bradley K, Ishigami M, Zettl A, Science 2000, 287, 1801.

[80] Clement K W A, Sumanasekera U, Pradhan B K, Romeo H E, Eklund P C, Chemical Physics Letters 2001, 337, 31.

[81] Langmuir J, Journal of the American Chemical Society 1918, 40, 1361.

[82] Galve R, Camps F, Baeza F S, Marco M P, Analytical Chemistry 2000, 72, 2237.

[83] De Vos S, Verschueren D, De Schrijver R, Chemosphere 2005, 58, 1553.

[84] Götsch A, Mariussen E, Recke R, Herzke D, Berger U, Vetter W, Journal of Chromatographia A 2005, 1063, 193.

[85] Lin C K, Trends Analytical Chemistry 1988, 7, 340.

[86] Moors M, Massart D L, McDowall R. D, Pure and Applied Chemistry 1994, 66, 27.

[87] Thurmn E M, Mills M S, Solid-Phase extraction, Principles and Practice. Wiley, New York, 1988.

[88] Terada K, Analytical Sciences 1991, 7, 187

[89] Barceló D, Hennion M C, Analytica Chimica Acta 1995, 318, 1. 
[90] Pichon V, Journal of Chromatography A. 2000, 885, 195.

[91] Srivastava A, Srivastava O N, Talapatra S, Vajtai R, Ajayan P M, Nature Materials 2004, 3, 610 .

[92] Wang J, Electroanalysis 2005, 17, 7.

[93] Cai H, Jiang X N, He P A, Fang Y Z, Analytical and Bioanalytical Chemistry 2003, 375, 287 .

[94] Lin L, Qiu P, Yang L, Cao X, Jin L, Analytical and Bioanalytical Chemistry 2006, 384, 1308 . 


\title{
CHAPTER 2
}

\author{
CHARACTERIZATION OF OXIDIZED
}

MULTI-WALLED CARBON NANOTUBES 


\subsection{Introduction}

Carbon nanotubes (CNTs) have become the focus of wide applications since their discovery by Iijima in 1991 [1]. Many applications of carbon nanotubes require modification to make them more amenable to rational and predictable manipulation, especially their potential application as components of nanoscale electronics and sensors [2]. These promising applications have led to successful modifications of different carbon nanotubes [3-11]. The modification procedures may be divided into two categories: noncovalent and covalent functionalizations. As examples of non-covalent functionalization, CNTs can be solubilized in water by "wrapping" them with polymers [3] such as poly (vinyl pyrrolidone) and poly (styrene sulfonate). Using this method, the polymers rigidly and uniformly associate with the sides of nanotubes, disrupting the hydrophobic interface with water and the inter-tubes interactions within the tubular aggregates. Wrapping of CNTs with DNA oligonuceotide sequences has been applied for the separation of metallic and semi-conducting nanotubes [4]. On the other hand, covalent functionalization has been studied using different functional groups, such as fluorination [5-6], glucosamine attachment [9], bioactive molecules [12] and side walled carboxylic acid functionalization [10]. The latter can be used to enhance the solubility of CNTs as well as providing a high binding affinity and selectivity with other species through the formation of different types of chemical bonds, from weak van der Waals bonds to hydrogen or even covalent bonds. For biological and medical applications, or any application where the CNTs must be suspended in aqueous solutions, they must be chemically derivatized with hydrophilic substituents, such as hydroxyl or carboxylic acid groups. 
Different oxidants have been used for the introduction of oxidized functional groups onto the surface of CNTs, including $\mathrm{H}_{2} \mathrm{O}_{2}[13], \mathrm{KMnO}_{4}[13,14]$ and various acids [14-18]. The solubility of CNTs is determined to a large extent by the number and nature of surface acidic functional groups. The number of these groups can vary over a wide range, as can their reactivity, and both depend on the type of oxidizing agent used and the conditions during the oxidation process. Oxidation with nitric acid produces a greater amount of the more acidic carboxylic groups, whereas oxidation with hot air produces a greater amount of relatively weak acidic surface functional groups (e.g. phenolic) [19].

In this chapter, oxidation of MWCNTs with different oxidizing agents, namely nitric acid, hydrogen peroxide, and potassium permanganate, were studied. Different techniques were used for the characterization of the oxidized CNTs produced. The surface characterization of the oxidized MWCNTs is expected to play a crucial role in determining their potential applications. Characterization of the oxidized MWCNTs was performed in terms of elucidation of the new acidic groups using infrared spectroscopy analyses, surface area using BET $\mathrm{N}_{2}$ adsorption, stability of their dispersions in water using turbidity measurements, concentration of the surface acidic groups using Boehm's titration, crystallinity using X-ray diffraction, as well as imaging using Scanning Electron Microscopy (SEM).

\subsection{Experimental}

\subsubsection{Oxidation of MWCNTs}

MWCNTs were purchased from Sun Nanotech (China) and were used as received. The MWCNTs $(2.0 \mathrm{~g})$ were added to $200 \mathrm{~mL}$ solutions of $8 \mathrm{MHNO}_{3}, 18 \% \mathrm{H}_{2} \mathrm{O}_{2}$ and $1 \mathrm{M}$ 
$\mathrm{KMnO}_{4}$ (acidified), separately. The $\mathrm{HNO}_{3}$ suspension was refluxed at $140^{\circ} \mathrm{C}$ for 4 hours. The $\mathrm{H}_{2} \mathrm{O}_{2}$ and $\mathrm{KMnO}_{4}$ suspensions were heated at $80^{\circ} \mathrm{C}$ for 4 hours. MWCNTs oxidized with $\mathrm{KMnO}_{4}$ were further treated with $\mathrm{H}_{2} \mathrm{SO}_{4}$ in order to remove $\mathrm{MnO}_{2}$ from the product. The three suspensions were then washed with distilled water until the wash water was $\mathrm{pH}$ neutral and a centrifuge (3500 rpm for 30 minutes) was used for solid liquid separation. The solid products were dried in air at $50^{\circ} \mathrm{C}$.

\subsubsection{Characterization Techniques}

Suspension stability was measured by dispersing $0.2 \mathrm{~g}$ of MWCNTs (pristine or oxidized) in $40 \mathrm{~mL}$ of distilled water followed by shaking for 10 minutes and sonication for 45 minutes. $0.5 \mathrm{~mL}$ of the supernatant was then diluted to $10 \mathrm{~mL}$ with distilled water and the turbidity was measured with a turbidity meter (LaMotte 2020).

Turbidity refers to the cloudiness or absence of clarity in water. The principle of operation involves the passage of light through the sample and the turbidity meter measures the amount of light scattered due to the presence of suspended particles in the water. Turbidity is measured in Normal Turbidity Units, commonly referred as NTU. A calibration curve for the turbidity versus the amount of CNTs suspended was constructed. Different amount of pristine MWCNTs were dispersed in deionized water and their turbidity was measured.

The acidic functional groups on the oxidized MWCNTs were qualitatively and quantitatively determined by titration with base [20]. The acid-base neutralization method involved the dispersing of $6.0 \mathrm{mg}$ of the oxidized MWCNTs in $15.0 \mathrm{~mL}$ of $1.0 \mu \mathrm{M}$ aqueous solutions of $\mathrm{NaOH}, \mathrm{NaHCO}_{3}$ or $\mathrm{Na}_{2} \mathrm{CO}_{3}$. The mixtures were shaken, sonicated 
for 4 hours, and then centrifuged for 30 minutes at $3500 \mathrm{rpm} .4 .0 \mathrm{~mL}$ of the supernatant of each solution was added to $10.0 \mathrm{~mL}$ of $1.0 \mu \mathrm{M} \mathrm{HCl}$ to neutralize the unreacted base, and the solutions were back-titrated with $1.0 \mu \mathrm{M} \mathrm{NaOH}$ using a potentiometer to determine the endpoint. The titration of pristine MWCNTs was used as a blank.

The total metals analysis was performed using ICP-MS after digestion of the sample in $50 \% \mathrm{HNO}_{3}$ for 6 hours. A reagent blank was analyzed and used to correct metal concentrations in the sample.

The specific surface area of the pristine and oxidized MWCNTs were measured by nitrogen adsorption at $77 \mathrm{~K}$ using the single point BET method with a Micromeretics model 2200 surface area analyzer.

Infrared spectra measurements of the oxidized MWCNTs were performed on an $\mathrm{ABB}$ Bomem MB Series FTIR spectrometer using $\mathrm{KBr}$ pellets.

The XRD profile was acquired using a Philips $1710 \mathrm{X}$-ray diffraction system ( $35 \mathrm{kV}$ and $50 \mathrm{~mA}$ ) with a $\mathrm{Cu} \mathrm{K} \alpha$ target. A scanning speed of $0.02^{\circ} /$ second was employed. SEM was done using a JEOL JSM-6400 Digital Scanning Electron Microscope.

\subsection{Results and Discussion}

\subsubsection{Suspension stability}

A calibration curve was constructed of turbidity versus the pristine MWCNT's concentration (mg MWCNTs $/ \mathrm{mL}$ ) and the results are presented in Figure 2.1. It is clear from the Figure that the relationship between the concentration of MWCNTs and the turbidity is linear $\left(\mathrm{R}^{2}=0.988\right)$. This calibration curve was used to quantitatively determine the concentration of MWCNTs suspended in water. 


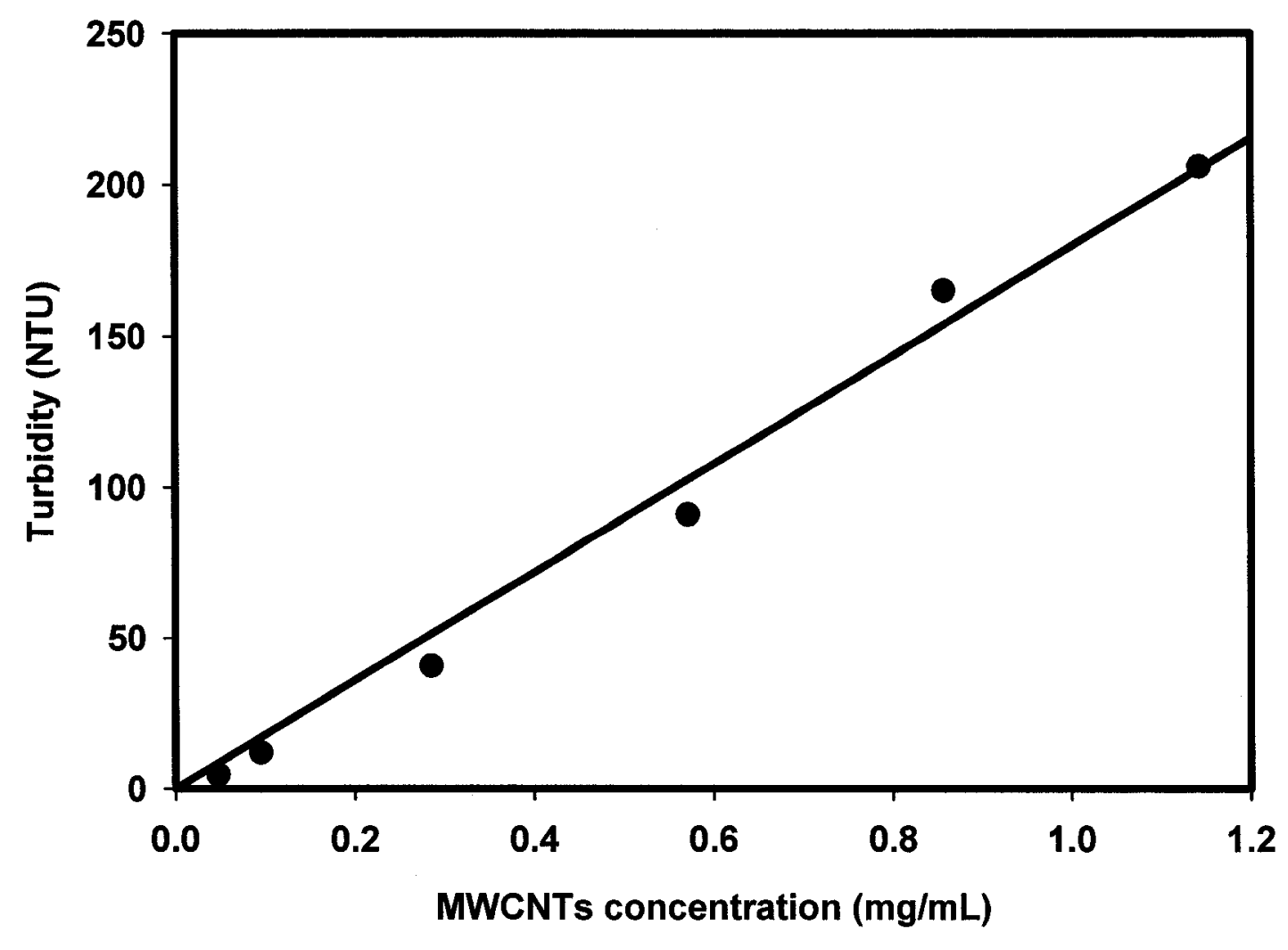

Figure 2.1. Calibration curve of turbidity versus MWCNTs concentration in aqueous solution. 
Figure 2.2 shows a quantitative comparison of the dispersion of the pristine MWCNTs and the oxidized MWCNTs in water assessed by turbidity measurements over a period of 30 days. It is clear that the oxidation of the MWCNTs improves the dispersion of the tubes in water. At the beginning of the experiment, the MWCNTs oxidized with either $\mathrm{H}_{2} \mathrm{O}_{2}$ or $\mathrm{HNO}_{3}$ have the higher suspension concentrations, 2.93 and $1.61 \mathrm{mg}$ MWCNTs/mL respectively, whereas the pristine MWCNTs and the sample oxidized with $\mathrm{KMnO}_{4}$ have lower suspended concentrations, 0.11 and $0.20 \mathrm{mg} \mathrm{MWCNTs} / \mathrm{mL}$, respectively. The suspension concentration of the latter samples decreased dramatically almost to zero after 3 days. The concentration of the suspensions of MWCNTs oxidized with $\mathrm{H}_{2} \mathrm{O}_{2}$ or $\mathrm{HNO}_{3}$ decreased with time and after 8 days reached steady state values of 0.51 and $0.49 \mathrm{mg} \mathrm{MWCNTs} / \mathrm{mL}$, respectively. The concentrations of the suspension were measured after 6 months and surprisingly, the concentration of the suspended MWCNTs was the same as after 31 days. This study was the first to measure the concentration of the MWCNTs suspended in aqueous solution quantitatively especially after a long period of time.

Figure 2.3 is a photograph of the aqueous suspensions of the four MWCNTs (pristine and oxidized) after 6 months. It is obvious that the CNTs oxidized with $\mathrm{H}_{2} \mathrm{O}_{2}$ or $\mathrm{HNO}_{3}$ are well suspended in comparison with the pristine MWCNTs and those treated with $\mathrm{KMnO}_{4}$. These results can be explained by the introduction of polar, hydrophilic groups such as hydroxylic and carboxylic, which interact favorably with water. Suspensions in isopropyl alcohol [10], aqueous, unsaturated $\mathrm{CS}_{2}$ [21], and aqueous solutions of different surfactants [22] have been demonstrated. But few publications have presented the suspension of CNTs in water $[23,24]$. The present results demonstrate that oxidized 


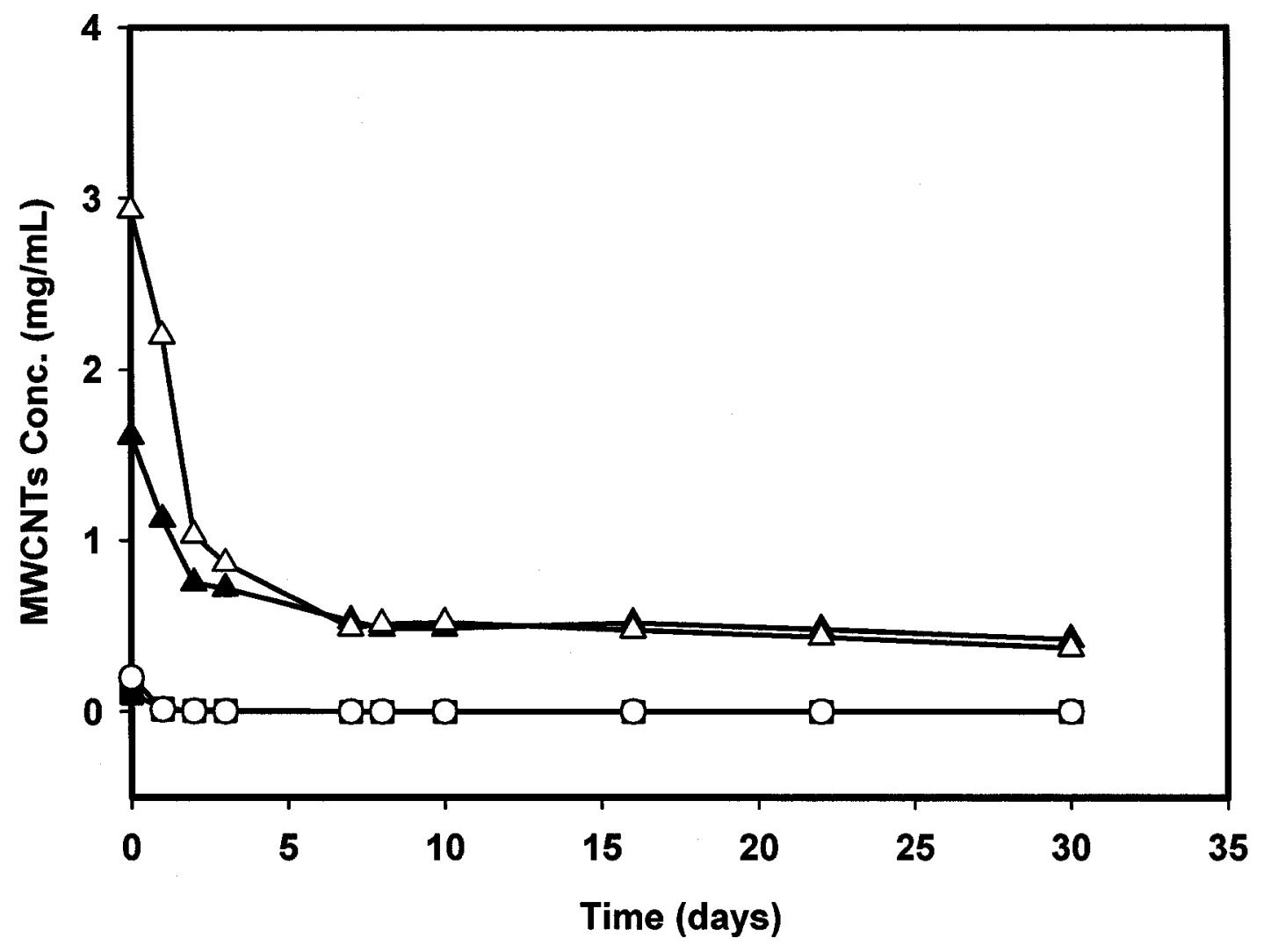

Figure 2.2. The stability of MWCNTs suspensions before and after oxidation in terms of MWCNTs concentration $(\mathrm{mg} / \mathrm{mL})$ versus time. - Pristine MWCNTs, O MWCNTs oxidized with $\mathrm{KMnO}_{4}, \Delta$ MWCNTs oxidized with $\mathrm{HNO}_{3}$, and $\Delta$ MWCNTs oxidized with $\mathrm{H}_{2} \mathrm{O}_{2}$. 


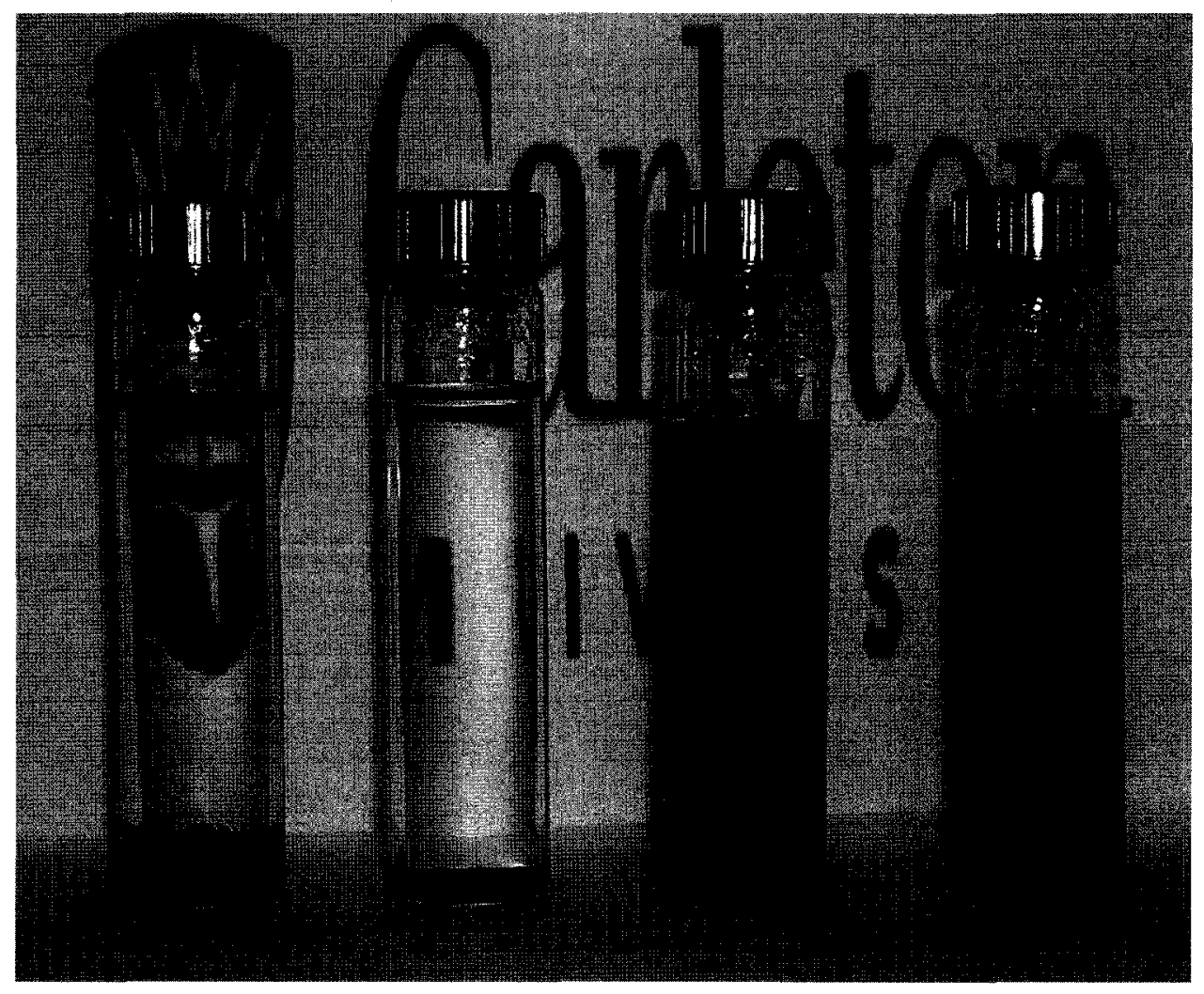

Figure 2.3. Vials containing aqueous suspensions of (left to right) pristine MWCNTs, MWCNTs oxidized with $\mathrm{KMnO}_{4}, \mathrm{HNO}_{3}$, and $\mathrm{H}_{2} \mathrm{O}_{2}$, after standing for six months $(0.2 \mathrm{~g}$ MWCNTs in $40 \mathrm{~mL}$ ). 
MWCNTs can be suspended in water with great stability and for prolonged time.

\subsubsection{Acidic functional group quantitation}

The concentrations of the different acidic functional groups on the surface of the oxidized MWCNTs were determined qualitatively and quantitatively using an acid-base neutralization method. According to this method, $\mathrm{NaOH}$ can neutralize all the acidic functional groups (carboxylic groups, lactones and phenols), $\mathrm{Na}_{2} \mathrm{CO}_{3}$ can neutralize some of the acidic function groups (carboxylic groups and lactones), whereas, $\mathrm{NaHCO}_{3}$ can neutralize only strong acidic function groups (carboxylic groups). The results of the titrations are shown in Table 2.1. Each titration was performed three times and the pristine MWCNTs were used as a blank. The concentrations of acidic functional groups were considerable, and were in agreement with other values reported in the literatures $[13,14]$. The total concentration of the acidic functional groups are higher for the MWCNTs oxidized with $\mathrm{HNO}_{3}$ and $\mathrm{H}_{2} \mathrm{O}_{2}, 1.27 \mathrm{mmol} \mathrm{g}^{-1}$ and $1.04 \mathrm{mmol} \mathrm{g}$, respectively, whereas the MWCNTs oxidized with $\mathrm{KMnO}_{4}$ have the lowest concentration, $0.56 \mathrm{mmol}$ $\mathrm{g}^{-1}$. This is likely the reason that the MWCNTs oxidized with $\mathrm{HNO}_{3}$ and $\mathrm{H}_{2} \mathrm{O}_{2}$ are well suspended in water whereas those oxidized by $\mathrm{KMnO}_{4}$ were poorly suspended in water.

\subsubsection{Total metals analysis}

It is well known that the preparation of CNTs requires the use of metallic catalysts. The concentrations of some of the metals; aluminum, iron and nickel in the MWCNTs (pristine and oxidized samples) were measured using ICP-MS and the results are shown in Table 2.2. It is obvious from the table that the pristine MWCNTs have high 
Table 2.1 The concentrations of different acidic groups on the surface of MWCNTs after oxidation. The total acidic surface group concentration (neutralized carboxylic groups, lactones and phenols) was determined by titration with $\mathrm{NaOH}$, carboxylic groups by titration with $\mathrm{NaHCO}_{3}$, whereas lactones concentration was determined by the difference between $\mathrm{Na}_{2} \mathrm{CO}_{3}$ titration (carboxylic groups and lactones) and $\mathrm{NaHCO}_{3}$ titration.

\begin{tabular}{ccccc}
\hline & $\begin{array}{c}\text { Carboxylic } \\
\text { Oroups }\end{array}$ & $\begin{array}{c}\text { Lactone } \\
\text { Groups }\end{array}$ & $\begin{array}{c}\text { Phenolic } \\
\text { Groups }\end{array}$ & Total \\
& $\left(\mathrm{mmol} \mathrm{g}^{-1}\right)$ & $\left(\mathrm{mmol} \mathrm{g}^{-1}\right)$ & $\left(\mathrm{mmol} \mathrm{g}^{-1}\right)$ & \\
\hline $\mathrm{KMnO}_{4}$ & $0.13 \pm 0.00$ & $0.23 \pm 0.08$ & $0.21 \pm 012$ & $0.56 \pm 0.04$ \\
$\mathrm{HNO}_{3}$ & $0.47 \pm 0.03$ & $0.52 \pm 0.07$ & $0.27 \pm 0.24$ & $1.27 \pm 0.20$ \\
$\mathrm{H}_{2} \mathrm{O}_{2}$ & $0.35 \pm \mathbf{0 . 1 4}$ & $\mathbf{0 . 4 4} \pm \mathbf{0 . 3 1}$ & $0.24 \pm 0.33$ & $1.04 \pm 0.16$ \\
\hline
\end{tabular}


Table 2.2. The total metals concentration in MWCNTs before and after oxidation using ICP-MS.

BDL: below detection limit.

\begin{tabular}{cccc}
\hline Sample & $\% \mathrm{Al}$ & $\% \mathrm{Fe}$ & $\% \mathrm{Ni}$ \\
\hline Pristine MWCNTs & $0.34 \pm 0.00$ & $1.2 \pm 0.08$ & $0.44 \pm 012$ \\
$\mathrm{KMnO}_{\mathbf{4}}$ treated MWCNTs & $0.46 \pm 0.00$ & $0.40 \pm 0.08$ & $0.14 \pm 012$ \\
$\mathrm{HNO}_{\mathbf{3}}$ treated MWCNTs & $0.10 \pm 0.03$ & $\mathrm{BDL}$ & $0.11 \pm 0.24$ \\
$\mathrm{H}_{\mathbf{2}} \mathbf{O}_{\mathbf{2}}$ treated MWCNTs & $0.42 \pm 0.14$ & $1.2 \pm 0.31$ & $0.46 \pm 0.33$ \\
\hline
\end{tabular}


concentrations of those three metals, but generally, oxidation of the MWCNTs reduced these concentrations. Treating the MWCNTs with $\mathrm{HNO}_{3}$ decreased the metal concentrations substantially compared with the other two oxidizing agents. This is clear evidence that the acidity of the oxidized MWCNTs, measured by the acid-base titration, is mainly due to the introduction of the acidic functional groups on the MWCNTs surface and not due to the reaction of the metals present in the samples with acid/base used for titration. Although treating the MWCNTs with $\mathrm{KMnO}_{4}$ decreased the metal concentrations, the total metal analysis showed that the sample treated with $\mathrm{KMnO}_{4}$ had the highest concentration of manganese $(11 \%)$ with respect to all the washing procedures used after the oxidation. This manganese may react with the base/acid used for the titration and give false measurements. This may explain why the MWCNTs oxidized with $\mathrm{KMnO}_{4}$ were non-suspendable in aqueous solution although it contains considerable concentration of the acidic functional groups.

\subsubsection{Specific surface area measurements}

The specific surface areas of the pristine and oxidized MWCNTs were measured using the $\mathrm{BET}$ method by nitrogen adsorption at $77 \mathrm{~K}$. The specific surface area for the pristine MWCNTs was found to be $148 \pm 5 \mathrm{~m}^{2} / \mathrm{g}$, which was in good agreement with the other reported values $[13,25-27]$. The specific surface area of the oxidized MWCNTs was slightly lower; $144 \pm 6 \mathrm{~m}^{2} / \mathrm{g}$ and $140 \pm 3 \mathrm{~m}^{2} / \mathrm{g}$ for the MWCNTs oxidized with $\mathrm{H}_{2} \mathrm{O}_{2}$ and $\mathrm{HNO}_{3}$, respectively. For the MWCNTs oxidized with $\mathrm{KMnO}_{4}$ the specific surface area of the oxidized tube was smaller; $106 \pm 3 \mathrm{~m}^{2} / \mathrm{g}$. This may suggest that $\mathrm{KMnO}_{4}$ as an oxidizing agent was very strong and effective enough to remove most of the amorphous 
carbon as well as damaging some of the MWCNTs. This may explain why the aqueous suspension of the MWCNTs oxidized with $\mathrm{KMnO}_{4}$ was not stable enough in comparison with the other MWCNTs oxidized with $\mathrm{H}_{2} \mathrm{O}_{2}$ and $\mathrm{HNO}_{3}$.

\subsubsection{Infrared spectroscopy}

The IR measurements were performed in order to confirm the formation of acidic functional groups upon oxidation. Figure 2.4 shows the IR spectra of pristine and oxidized MWCNTs. It is clear from Figure 2.4 that the oxidized MWCNTs spectra show absorption peaks at $1730 \mathrm{~cm}^{-1}$ corresponding to the stretching vibration of $\mathrm{C}=\mathrm{O}$ from the carboxylic acid groups (-COOH) $[15,21,28-31]$. This absorption peak was very clear and strong for the MWCNTs oxidized with $\mathrm{HNO}_{3}$, whereas it was much weaker with the MWCNTs oxidized with $\mathrm{H}_{2} \mathrm{O}_{2}$ and $\mathrm{KMnO}_{4}$. A broad peak at approximately $3500 \mathrm{~cm}^{-1}$ was much stronger in the $\mathrm{H}_{2} \mathrm{O}_{2}$ and $\mathrm{HNO}_{3}$ treated MWCNTs. This peak is characteristic of an $\mathrm{O}-\mathrm{H}$ stretch. It is either due to moisture, alcohol or phenol, $\mathrm{OH}^{-}$or carboxylic groups in these samples. The aromatic $C=C$ stretch is observed at $1645 \mathrm{~cm}^{-1}$ and at 1450 $\mathrm{cm}^{-1}$ for all of the spectra with comparable intensities. The peak at $1450 \mathrm{~cm}^{-1}$ is more intense for the MWCNTs oxidized with $\mathrm{HNO}_{3}$ and $\mathrm{H}_{2} \mathrm{O}_{2}$ than in the pristine and MWCNTs oxidized with KMnO4. The weak, broad peaks at $1130 \mathrm{~cm}^{-1}$ are found in all the oxidized MWCNTs it could be due to a C-O stretch from either a phenol or lactone. These results and the titration data show clearly that the MWCNTs can be oxidized and that carboxylic, phenolic and lactone groups are likely obtained.

\subsubsection{X-ray diffraction measurements}

X-ray diffraction was applied in order to follow the effects of the different oxidants on the crystallinity of the MWCNTs. Figure 2.5 compares the XRD patterns for the pristine 


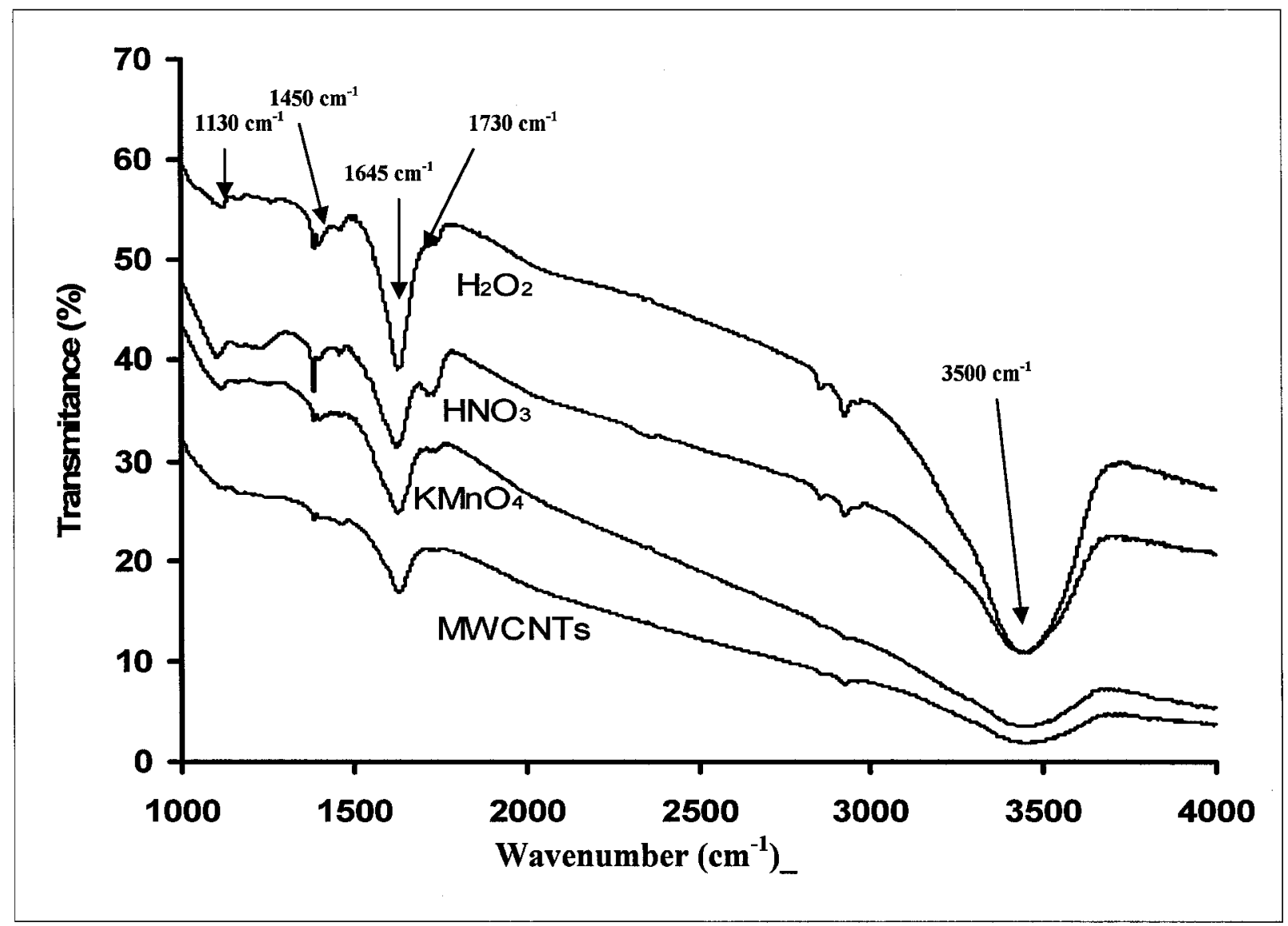

Figure 2.4. IR spectra of MWCNTs before and after oxidation. 


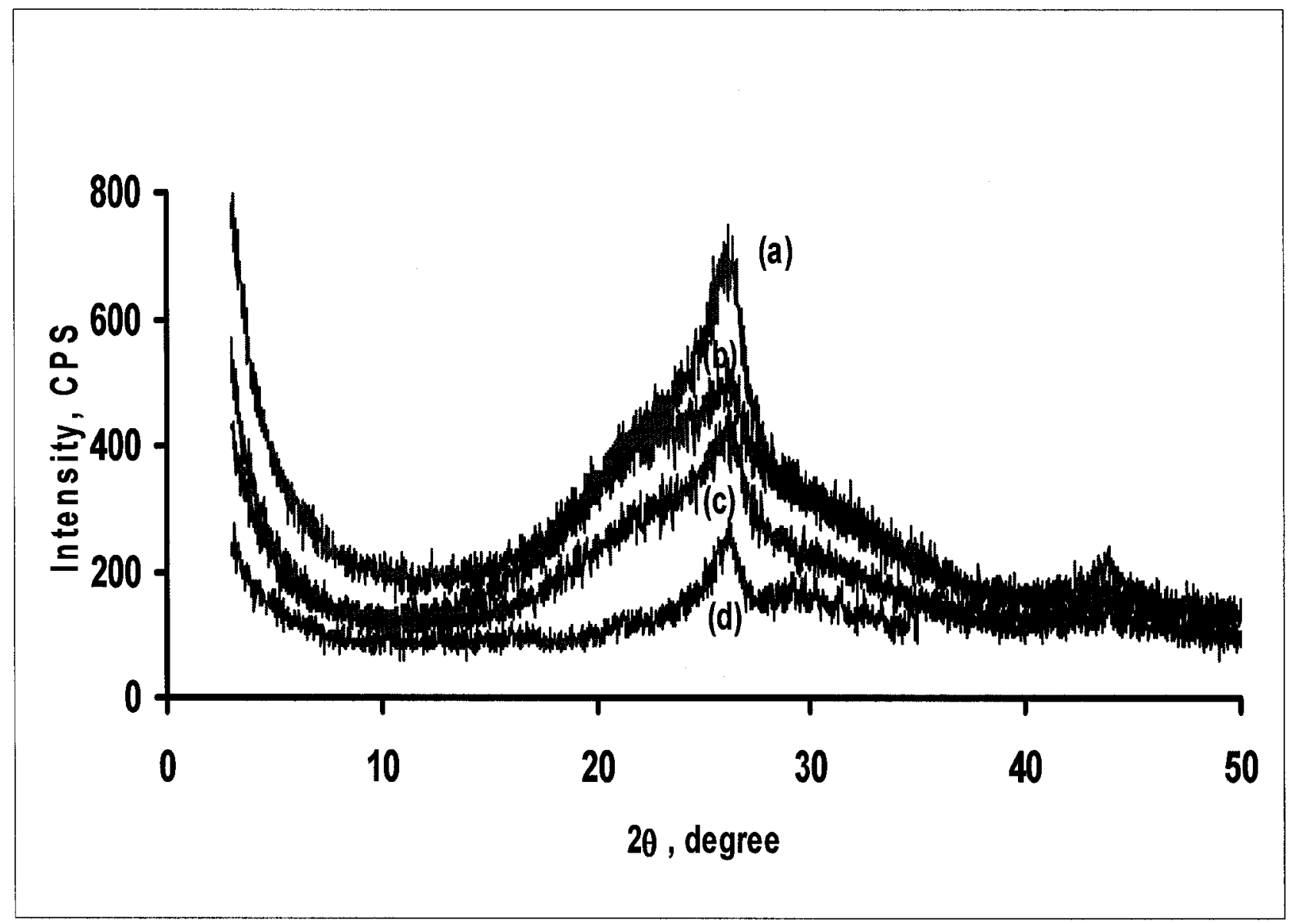

Figure 2.5. XRD patterns of (a) pristine MWCNTs, (b) MWCNTs after oxidation with $\mathrm{HNO}_{3}$, (c) MWCNTs oxidized with $\mathrm{H}_{2} \mathrm{O}_{2}$, and (d) MWCNTs oxidized with $\mathrm{KMnO}_{4}$. 
Table 2.3. XRD pattern analysis for MWCNTs before and after oxidation.

\begin{tabular}{|c|c|c|c|c|}
\hline & \multicolumn{2}{|c|}{ (002 plane) } & \multicolumn{2}{|c|}{ (100 plane) } \\
\hline Sample & $2 \Theta^{\circ}$ & d-spacing $\left(A^{o}\right)$ & $2 \Theta^{\circ}$ & d-spacing $\left(A^{0}\right)$ \\
\hline Pristine MWCNTs & 26.14 & 3.406 & 44.22 & 2.046 \\
\hline MWCNTs oxidized by $\mathrm{HNO}_{3}$ & 26.12 & 3.408 & 44.22 & 2.046 \\
\hline MWCNTs oxidized by $\mathrm{H}_{2} \mathrm{O}_{2}$ & 26.14 & 3.406 & 43.84 & 2.063 \\
\hline MWCNTs oxidized by $\mathrm{KMnO}_{4}$ & 26.2 & 3.398 & 43.82 & 2.064 \\
\hline
\end{tabular}


and oxidized MWCNTs. From the XRD patterns the interlayer spacing was calculated and the results are presented in Table 2.3. It is clear that the pristine MWCNTs exhibit two peaks; one at $26.14^{\circ}$ (002 plane) and the other $44.22^{\circ}$ (100 plane), corresponding to an interplanar space of $3.41 \mathrm{~A}^{\circ}$ and $2.05 \mathrm{~A}^{\circ}$, respectively. This was in a good agreement with the literature values for CNTs [27, 32-35]. It was found that all the MWCNTs (pristine and oxidized) have nearly the same d-spacing values for both planes; (002) and (100), but with different intensities. The intensity of the (002) peak decreased gradually for the MWCNTs oxidized with $\mathrm{HNO}_{3}, \mathrm{H}_{2} \mathrm{O}_{2}$, and $\mathrm{KMnO}_{4}$, respectively. This is may be due to either damage of the MWCNTs or changing of the degree of the CNTs alignment. It has been found that the intensity of the (002) peak decreases if the CNTs are better aligned [32]. Thus, propose that the degree of MWCNTs alignment was increased by oxidation. On the other hand, the much wider (002) peak of the MWCNTs oxidized with $\mathrm{HNO}_{3}$ and $\mathrm{H}_{2} \mathrm{O}_{2}$ suggests that a much smaller number of layers are involved in the coherently scattering structural units in these samples [35], or it may be indicating that the degree of long-range order of these nanostructures is relatively low in comparison with that of the pristine MWCNTs [27].

\subsubsection{Scanning Electron Microscopy}

SEM imaging was used to study the surface of the MWCNTs before and after oxidation. Representative images are presented in Figure 2.6. It is clear from the Figure 2.6 (a) that the pristine MWCNTs are highly tangled tubes with diameters of 100-200 nm. The MWCNTs oxidized with $\mathrm{HNO}_{3}$ (Figure 2.6 (b)) are uniform in size, but have smaller diameters than the untreated CNTs. Those oxidized with $\mathrm{H}_{2} \mathrm{O}_{2}$ (Figure 2.6(c)) appear to 
(a)

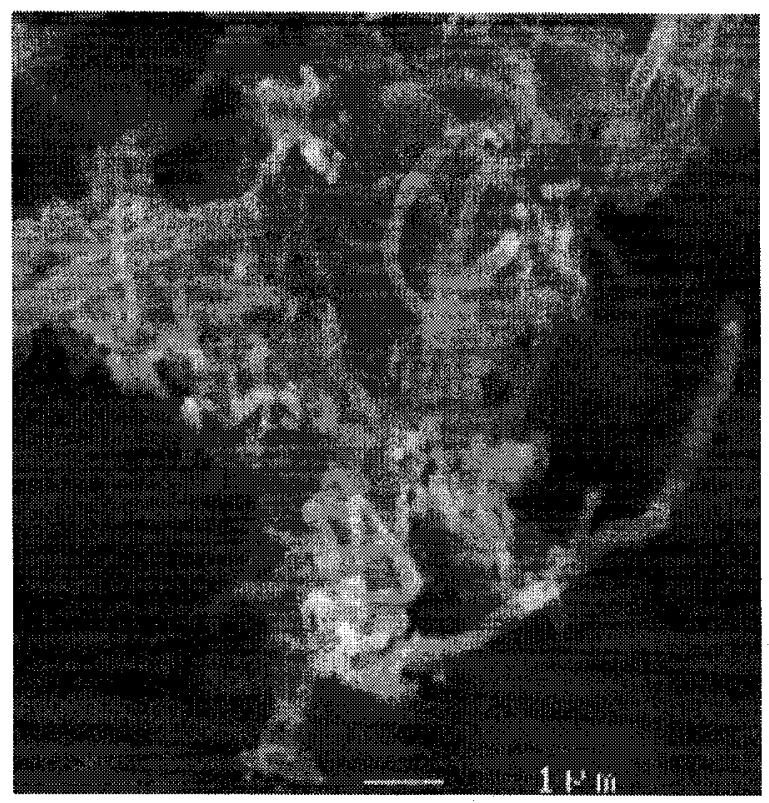

(c)

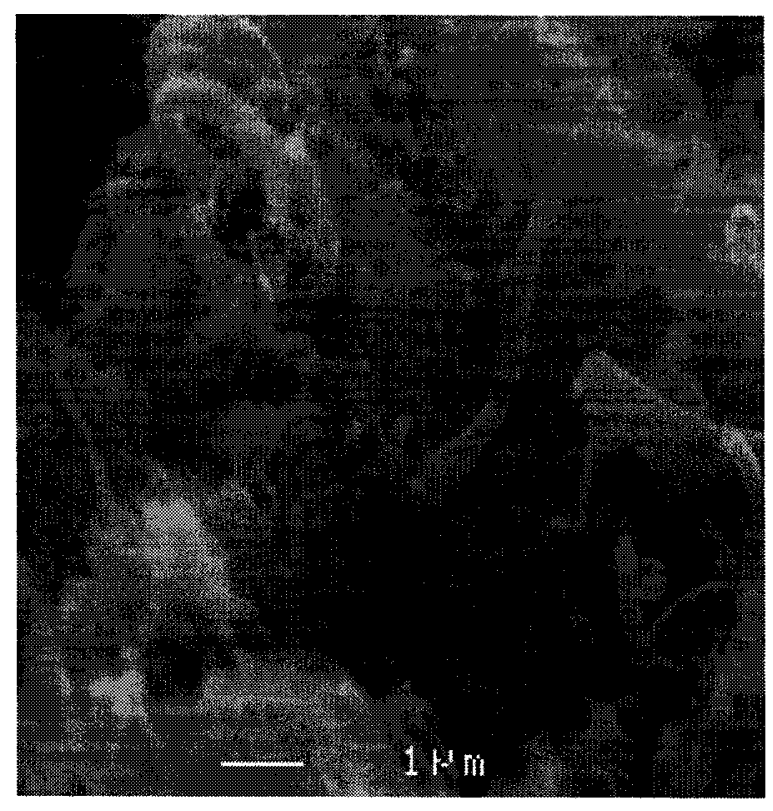

(b)

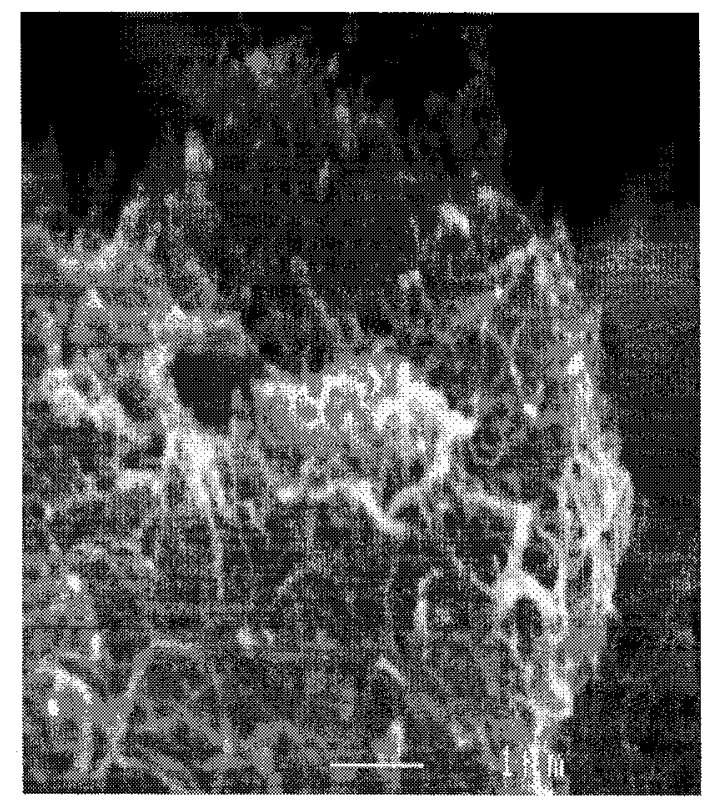

(d)

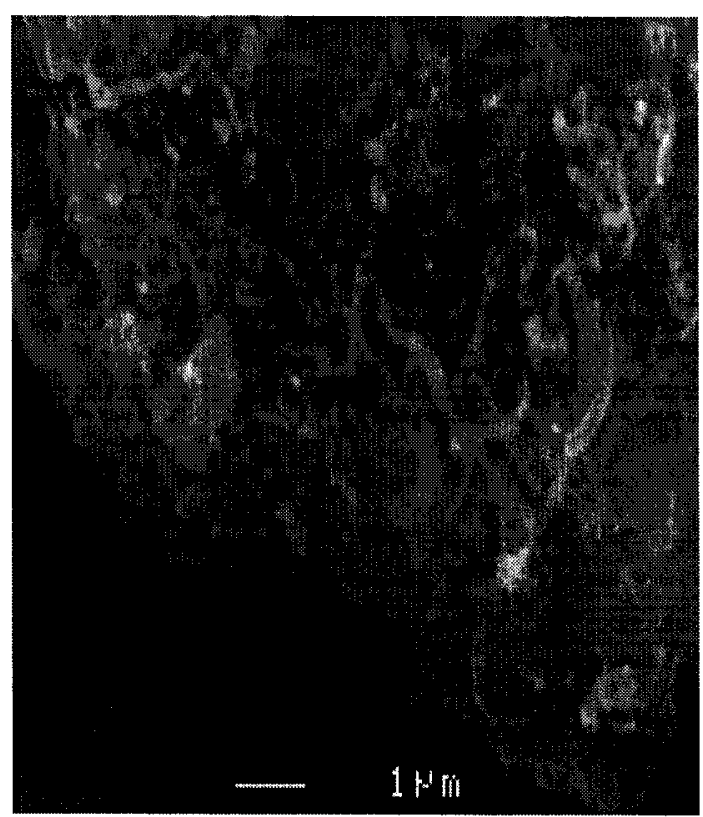

Figure 2.6. SEM images of (a) pristine MWCNTs, (b) MWCNTs after oxidation with $\mathrm{HNO}_{3}$, (c) MWCNTs oxidized with $\mathrm{H}_{2} \mathrm{O}_{2}$, and (d) MWCNTs oxidized with $\mathrm{KMnO}_{4}$. 
have similar diameters to the untreated CNTs. However, MWCNTs oxidized with $\mathrm{KMnO}_{4}$ (Figure 2.6 (d)), were mostly destroyed and SEM showed the appearance of large pieces of carbon. This may explain the fact that suspension of $\mathrm{KMnO}_{4}$ treated CNTs are not stable, and that the concentration of acidic groups in these samples is lower than the others.

\subsection{Conclusions}

Chemical modification of MWCNTs via oxidation proved to be a useful tool to improve the suspension stability and solubility of MWCNTs in aqueous solution. The oxidized MWCNTs can be suspended in water; with high stability, for a long time. Titration of the oxidized MWCNTs revealed the presence of considerable amounts of the acidic functional groups that likely enhance the suspension of the MWCNTs. IR measurements showed the presence of carboxylic acid function groups especially for the MWCNTs oxidized with nitric acid and hydrogen peroxide. XRD showed that the oxidation did not change the crystallographic structure of the MWCNTs significantly. Microscopy and other data suggested that oxidation by $\mathrm{KMnO}_{4}$ destroys the MWCNTs. 


\subsection{References}

[1] Iijima S, Nature 1991,354, 56.

[2] Gruner G, Analytical and Bioanalytical Chemistry 2006, 384, 322.

[3] O'Connell M J, Tour P, Ausman K D, Smalley R E, Chemical Physics Letters $2001,342,265$.

[4] Zheng M, Jagota A, Semke E D, Diner B A, Mclean R S, Lusting S R, Richardson R E, Tassi N G, Nature Materials.2003, 2, 338.

[5] Michelson E T, Chiang I W, Zimmerman J L, Boul P J, Lozano J, Liu J,Smalley R E, Hauge R H, Margrave J L, Journal of Physical Chemistry, B 1999, 103, 4318.

[6] Chen J, Rao A M, Lyuksyutov S, Itkis M E, Hamon M A, Hu H, Cohn R W, Eklund P C, Colbert D T, Smalley R E, Haddon R C, Journal of Physical Chemistry, B 2001, 105, 2525.

[7] Georgakilas N, Kordatos K, Prato M, Guldi D M, Holzinger M, Hirsch A, Journal of the American Chemical Society 2002, 124, 760.

[8] Bahr J L, Yang J, Kosynkin D V, Bronikowski M J, Smalley R E, Tour J M, Journal of the American Chemical Society 2001, 123, 6536.

[9] Pompeo F, Resasco D E, Nano Letters 2002, 2, 369.

[10] Peng H, Alemany L B, Margrave J L, Khabashesku V N, Journal of the American Chemical Society 2003, 125, 15174.

[11] Williams K A, Veenhuizen P T M, de la Torre B G, Eritja R, Dekker C, Nature 2002, 420,761 .

[12] Bianco A, Prato M, Advanced Materials 2003, 15, 1765.

[13] Li Y, Wang S, Luan Z, Ding J, Xu C, Wu D, Carbon 2003, 41, 1057. 
[14] Satishkumar B C, Govindaraj A, Mofokeng J, Subbanna G N, Rao C N R, Journal of Physics B, Atomic, Molecular and Optical Physics 1996, 29, 4925.

[15] Sun W, Huang Z, Zhang L, Zhu J, Carbon 2003, 41, 1685.

[16] Zhang W, Xie Y, Ai S, Wan F, Wang J, Jin L, Jin J, Journal of Chromatographia $B$ 2003, 791,217.

[17] Strong K L, Anderson D C, Lafdi K, Kuhn J N, Carbon 2003, 41, 1477.

[18] An K H, Jeon K K, Moon J, Eum S J, Yang C W, Park G, Park C Y, Lee Y H, Synthetic Metals 2004, 140, 1.

[19] Strelko Jr V, Malik D J, Streat M, Carbon 2002, 40, 95-104.

[20] Toles C A, Marshall W E, Johns M M, Carbon 1999, 37, 1207.

[21] Chen J, Hamon M A, H. Hu, Y. Chen, Rao A M, Eklund P C, Haddon R C, Science 1998, 282, 95.

[22] Islam M F, Rojas E, Bergey D M, Johnson A T, Yodh A G, Nano Letters 2003, 3, 269.

[23] Jiang L, Gao L, Sun J, Journal of Colloid and Interface Science 2003, 260, 89.

[24] Zhao W, Song C, Pehrsson P E, Journal of the American Chemical Society 2002, $124,12418$.

[25] Cai Y, Jiang G, Liu J, Zhou Q, Analytica Chimica Acta 2003, 494,149.

[26] Cai Y, Jiang G, Liu J, Zhou Q, Analytical Chemistry 2003, 75, 2517.

[27] Li Q, Yuan D, J. Chromatographia A 2003, 1003, 203.

[28] Shaffer M S P, Fan X, Windle A H, Carbon 1998, 36, 1603.

[29] M.A. Hamon, H. Hu, R.C. Haddon, Chemical Physics Letters 2001, 347, 8. 
[30] Chen J, Smalley R E, Haddon R C, Journal of Physical Chemistry, B 2001, 105, 2525 .

[31] Koshio A, Yudasaka M, Zhang M, Iijima S, Nano Letters 2001, 1, 361.

[32] Cao A, Xu C, Liang J, Wu D, Wei B, Chemical Physics Letters 2001, 344, 13.

[33] Weglikowska U D, Benoit J M, Chiu P W, Graupner R, Lebedkin S, Roth S, Current Applied Physics.2002, 2, 497.

[34] Zhu W Z, Miser D E, Chan W G, Hajaligol M R, Materials Chemistry and Physics 2003, 82, 638.

[35] Onyestyák G, Valyon J, Hernádi K, Kiricsi I, Rees L VC, Carbon 2003, 41, 1241. 


\section{CHAPTER 3}

\section{ADSORPTION OF PENTACHLOROPHENOL FROM AQUEOUS SOLUTION BY MULTI-WALLED}

CARBON NANOTUBES 


\subsection{Introduction}

Pentachlorophenol (PCP) is widely used as a textile and wood preservative [1], as well as a microbiocide, fungicide, insecticide and herbicide [2]. It is well known to be toxic to living organisms and its bioaccumulation, persistence and toxicity pose environmental problems [3-7]. Knowledge of PCP adsorption characteristics is necessary for predicting its mobility and fate in aquatic ecosystems. PCP is sparingly soluble in water but the removal of this toxic compound from aqueous systems represents a problem, especially when it is at very low concentrations. The conventional treatment methods for wastewater include biological treatment [8], adsorption by porous solids such as granulated activated carbon [9], photocatalytic degradation [10], and solvent extraction [11]. Among these methods, adsorption is regarded as a promising method for the removal of PCP. By adsorption-desorption processes, the water and adsorbent could be recycled. For an analytical process, efficient adsorption and desorption are needed. Hence, it is important to look for new types of adsorbents and to develop new efficient analytical methods.

Multi-walled carbon nanotubes (MWCNTs) have become the focus of wide ranging of research for their intrinsic properties and their possible applications. It has been reported that MWCNTs have very strong adsorption capability for many different compounds [1247]. This may be due to their unique size distributions, novel hollow-tube structures, and high specific surface areas. However, the studies on the adsorption of trace pollutants by MWCNTs are still scarce in literature. There have been many studies devoted to the adsorption of PCP using different adsorbents [9, 48-61], but there are none which study the adsorption behavior of PCP using MWCNTs. 
The objectives of this work were to investigate the adsorption of PCP from aqueous solution by MWCNTs at different temperatures and hence to evaluate the thermodynamic parameters of adsorption, i.e.: the free energy, enthalpy and entropy of adsorption in order to achieve a better understanding of the adsorption process. To evaluate the adsorption behaviour of MWCNTs, a comparative study between MWCNTs and powdered activated carbon was also conducted.

\subsection{Experimental}

\subsubsection{Adsorbents}

MWCNTs ( $>80 \%$ purity, 10-30 nm diameter) were purchased from Sun Nanotech (China) and were used as received. Activated charcoal (AC) was purchased from Aldrich-sigma $(16,155-1)$ and was used as received. The specific surface areas of the MWCNTs and AC were measured by nitrogen adsorption at $77 \mathrm{~K}$ using the single point BET method with a Micromeretics model 2200 surface area analyzer.

\subsubsection{Reagents}

Stock solutions were prepared by dissolving pentachlorophenol (Aldrich $99.0+\%$ ) in deionized water followed by serial dilutions. Acetylation of PCP was done using acetic anhydride (Aldrich) and a $5 \%$ solution (w/v) of $\mathrm{K}_{2} \mathrm{CO}_{3}$ prepared from anhydrous potassium carbonate (Aldrich). n-hexane (Optima, Fisher) was used for all liquid-liquid extractions. 


\subsubsection{Solid Phase Extraction (SPE) of PCP}

$3 \mathrm{~mL}$ inert glass tubes (Supelco) were used as the packing cartridges for SPE and $5.0 \mathrm{mg}$ of the MWCNTs were packed into the cartridge. Teflon upper and lower frits $(20 \mu \mathrm{m}$ pore size) at each end of the cartridge were used to hold the MWCNTs packing in place. The PCP solution $(1.0 \mathrm{mg} / \mathrm{L})$ was passed through the cartridge at a flow rate of $2 \mathrm{~mL} / \mathrm{min}$ using suction. The aqueous solution was then analyzed for the remaining PCP.

\subsubsection{Kinetics study}

The kinetics study was done using $14 \mathrm{~mL}$ glass vials with Teflon lined caps. In each vial, $10 \mathrm{~mL}$ of the $1.0 \mathrm{mg} / \mathrm{L}$ PCP solution was added to $5.0 \mathrm{mg}$ of MWCNTs. The vials were mounted on a shaker and shaken at $23 \pm 2{ }^{\circ} \mathrm{C}$ for different intervals of time. Each suspension was centrifuged at $3000 \mathrm{rpm}$ and the supernatant solution was analyzed for PCP.

\subsubsection{Adsorption equilibrium studies}

$2.0 \mathrm{mg}$ of MWCNTs were introduced into $14 \mathrm{~mL}$ glass vials. $10 \mathrm{~mL}$ aqueous PCP solution with different concentration ranging from 0.030 to $1.2 \mathrm{mg} / \mathrm{L}$ was added to the MWCNTs. The vials were then shaken for 24 hours at different temperatures. Each suspension was then centrifuged at $3000 \mathrm{rpm}$ and the supernatant solution was analyzed for PCP after derivatization using GC-ECD. PCP adsorbed by MWCNTs at equilibrium was calculated as follows:

$$
\mathrm{q}=\frac{\left(\mathrm{C}_{0}-\mathrm{C}_{\mathrm{t}}\right) \mathrm{V}}{\mathrm{m}}
$$


Where $\mathrm{q}$ is the amount of $\mathrm{PCP}$ adsorbed $(\mathrm{mg} / \mathrm{g}), \mathrm{C}_{0}$ is the initial aqueous concentration of PCP $(\mathrm{mg} / \mathrm{L}), \mathrm{C}_{\mathrm{t}}$ is the concentration of PCP after shaking for a certain period of time $(\mathrm{mg} / \mathrm{L}), \mathrm{V}$ is the solution volume $(\mathrm{L})$ and $\mathrm{m}$ is the mass of MWCNTs $(\mathrm{g})$.

\subsubsection{Analytical procedure}

For acetylation of $\mathrm{PCP}, 3.0 \mathrm{~mL}$ of $5 \% \mathrm{~K}_{2} \mathrm{CO}_{3}$ solution was added to the aqueous solution of PCP and stirred for 1 minute, followed by the addition of $2.0 \mathrm{~mL}$ of acetic anhydride and stirred vigorously for 2 minutes to ensure complete acetylation of the PCP. The acetylated PCP was extracted into $4.0 \mathrm{ml} \mathrm{n}$-hexane with 2 minutes of shaking. The acetylated PCP was analyzed using a Varian 3600 gas chromatograph with an electron capture detector (GC-ECD) and a $30 \mathrm{~m} \times 0.25 \mu \mathrm{m}$ id $\times 0.25 \mu \mathrm{m}$ film thickness DB-5 silica capillary column (Varian). The GC conditions were as follows: helium as the carrier gas at a flow rate of $1 \mathrm{~mL} / \mathrm{min}$; nitrogen as the make-up gas at a flow rate of 27 $\mathrm{mL} / \mathrm{min}$; injector temperature, $300^{\circ} \mathrm{C}$; column initial temperature, $70^{\circ} \mathrm{C}$; and final temperature, $280^{\circ} \mathrm{C}$; with heating rate, $15^{\circ} \mathrm{C} / \mathrm{min}$; detector temperature, $300^{\circ} \mathrm{C}$. The sample size injected was $1 \mu \mathrm{L}$.

\subsubsection{Fitting the adsorption isotherms}

An adsorption isotherm is important in order to be able to predict the equilibrium loading, or to determine the external adsorbent surface loading of PCP during the mass transfer rate experiments of PCP adsorption. The adsorption equilibrium data were fitted with various adsorption isotherm models, usually used for adsorption from aqueous solutions. The two-parameter Langmuir [62] and Freundlich [63] models are two of the most 
commonly used isotherms. The three-parameter Radke and Prausnitz model [64], and the four-parameter Fritz-Schlünder model [65], were also fitted to the data. The Langmuir isotherm can be derived by assuming that only monolayer coverage of the adsorbent surface is possible.

$\mathrm{q}_{\mathrm{e}}=\frac{\mathrm{q}_{\mathrm{m}} \mathrm{K}_{\mathrm{L}} \mathrm{C}_{\mathrm{e}}}{\left(1+\mathrm{K}_{\mathrm{L}} \mathrm{C}_{\mathrm{e}}\right)}$

where $\mathrm{C}_{\mathrm{e}}$ is the equilibrium PCP concentration $(\mathrm{mg} / \mathrm{L}), \mathrm{q}_{\mathrm{e}}$ is the amount adsorbed $(\mathrm{mg} / \mathrm{g})$, $\mathrm{K}_{\mathrm{L}}$ is a Langmuir constant related to the adsorption energy, and $\mathrm{q}_{\mathrm{m}}$ is a Langmuir constant related to the adsorption capacity, which is related to the amount of adsorbate adsorbed at monolayer coverage.

The Freundlich isotherm provides an empirical description of a single-solute adsorption equilibrium:

$\mathrm{q}_{\mathrm{e}}=\mathrm{K}_{\mathrm{F}} \mathrm{C}_{\mathrm{e}}^{1 / \mathrm{n}}$

where $\mathrm{K}_{\mathrm{F}}$ and $1 / \mathrm{n}$ are Freundlich constants related to adsorption capacity and energy distribution of the adsorption sites, respectively.

Radke and Prausnitz suggested an empirical correlation to describe equilibrium for the adsorption of organic solutes from dilute aqueous solutions and their equation is:

$\frac{1}{q_{e}}=\frac{1}{K_{e}}+\frac{1}{{k C_{e}}^{1 / p}}$

where $\mathrm{K}, \mathrm{k}$ and $\mathrm{p}$ are Radke and Prausnitz isotherm constants.

Finally, for a single solute the Fritz-Schlünder equation may be expressed as:

$q_{e}=\frac{\alpha_{1} C_{e}^{\beta 1}}{\left(1+\alpha_{2} C_{e}^{\beta 2}\right)}$

where $\alpha_{1}, \alpha_{2}, \beta 1$, and $\beta 2$ are Fritz-Schlünder isotherms constants. 
Statistical software (Polymath version 5.1) was used to fit the data to these four adsorption isotherm models.

\subsubsection{Effect of temperature on the adsorption of PCP}

The effect of temperature on the equilibrium adsorption of PCP on the MWCNTs and AC was studied at different temperatures; $5^{\circ} \mathrm{C}, 15^{\circ} \mathrm{C}, 25^{\circ} \mathrm{C}$, and $35^{\circ} \mathrm{C}$ using a temperature controlled water bath. All samples were equilibrated for 24 hours.

\subsection{Results and discussion}

\subsubsection{Adsorption kinetic studies}

The kinetics of PCP adsorption in aqueous solution on MWCNTs and AC were measured and the results are shown in Figure 3.1. Surprisingly, $88 \%$ of the PCP was adsorbed by the MWCNTs and $76 \%$ by the AC within the first 5 minutes of the experiments. The adsorption capacity reached $1.76 \mathrm{mg} / \mathrm{g}$ and $1.52 \mathrm{mg} / \mathrm{g}$ for the MWCNTs and the AC respectively. The adsorption of PCP by MWCNTs achieved equilibrium gradually at about 60 minutes and the final adsorption capacity reached $1.92 \mathrm{mg} / \mathrm{g}$, whereas it took 120 minutes for the PCP in the presence of $\mathrm{AC}$ to reach the equilibrium concentration of $1.78 \mathrm{mg} / \mathrm{g}$. The kinetic adsorption curves of PCP may suggest that adsorption onto the surface occurs quickly, followed by a slower diffusion of PCP into the pores of the AC, and possibly into the interior of the MWCNTs [42]. Another explanation for that is the fact that during the initial stage a large number of active vacant sites are available for adsorption, and after a period of time, the remaining vacant surface sites are difficult to 


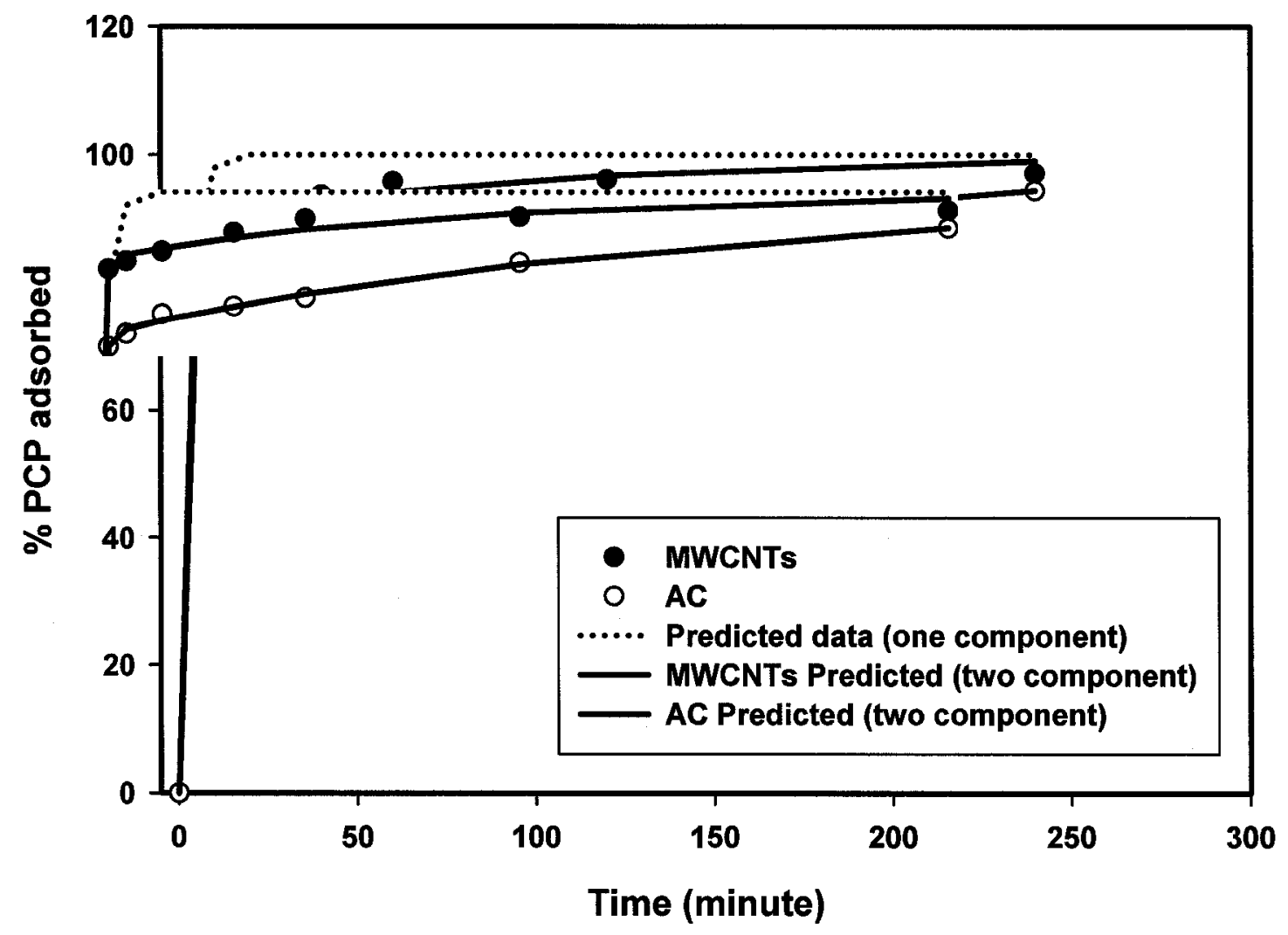

Figure 3.1. The kinetic model for the adsorption of PCP to MWCNTs and AC and the comparison between the experimental data and the predicted values. 
be occupied due to the repulsive forces as well as the competition, between the PCP molecules on the adsorbent surface [66].

The short time needed to reach equilibrium also suggests that MWCNTs are efficient adsorbent and have high capacity to remove PCP from aqueous solution. Most studies report that for the adsorption of PCP it took one day or more to reach equilibrium; on carbonized bark [51], chitosan [56], and soil [57], whereas in this study it took only a few hours to reach equilibrium. This may be due to the fact that in this study very low concentrations of $\mathrm{PCP}$ in aqueous solutions were used $1.0 \mathrm{mg} / \mathrm{L}$, whereas the other studies used very concentrated solutions. Accordingly, the adsorption equilibrium studies were performed after 18 hours (over night) to be sure that equilibrium was attained.

The transport of the PCP from the aqueous solution to the surface of the adsorbent may occurs in several steps [66]. The overall adsorption process may be controlled by one or more steps, e.g. film or external diffusion, pores diffusion, surface diffusion and adsorption on the pore surface, or a combination of more than one step.

In order to distinguish between the different adsorption steps, the following kinetic model was adopted.

The adsorption of PCP molecules from aqueous solution to an active site $\mathrm{S}$, on the adsorbent (MWCNTs or AC) can be represented as:

$$
\text { Analyte }_{(\text {aq.) }}+\text { Adsorbent }_{(\text {(aq). }} \underset{\text { desorption }}{\stackrel{\text { adsortion }}{\longrightarrow} \text { Analyte-adsorbent complex }} \text { (aq.) }
$$

or

$$
P C P+S \underset{k_{-1}}{\stackrel{k_{1}}{\rightleftarrows}} P C P-S
$$


where PCP-S is the PCP adsorbed and $k_{1}$ and $k_{-1}$ are the adsorption and desorption rate constants.

The rate of formation of the PCP-S is determined by the following equation:

$\frac{d[P C P-S]}{d t}=-\frac{d[P C P]}{d t}=k_{1}[P C P][S]$

In the case where $[\mathrm{S}] \gg \gg[\mathrm{PCP}]$ and before significant adsorption has occurred, the adsorption is considered a pseudo-first-order, and the rate of adsorption can be simplified as:

$\frac{d[P C P-S]}{d t}=-\frac{d[P C P]}{d t}=k_{1}[P C P]$

By assuming that the adsorption of PCP from the aqueous phase to the solid phase occurs in different steps; film or external diffusion, pores diffusion, surface diffusion and adsorption on the pore surface, and if PCP molecules undergo a first-order or pseudofirst-order adsorption to the solid adsorbent, the sum of the concentrations of all PCP adsorbed at the solid adsorbent at time $t, C_{P C P-S}(t)$ increases exponentially as:

$C_{P C P-S}(t)=\sum_{i=1}^{n} C_{i}^{0}\left[1-\exp \left(-k_{i} t\right)\right]$

where $C_{i}^{0}$ is the initial concentration of $\mathrm{PCP}_{\mathrm{i}}$, the ith component. The concentration of PCP-S adsorbed to the adsorbent, $C_{P C P-S}(t)$, is determined as a function of time by measuring the concentration of PCP remaining in solution. The percentage of PCP remaining in the aqueous solution and the percentage adsorbed to the solid adsorbent can be calculated using the following equation: 
$\%$ removed $=\frac{100\left(C_{0}-C_{e}\right)}{C_{0}}$

and

$\%$ remaining $=100-\%$ removed

where $C_{0}$ is the initial solution phase PCP concentration $(\mathrm{mg} / \mathrm{L})$ and $C_{e}$ the equilibrium solution phase PCP concentration $(\mathrm{mg} / \mathrm{L})$.

The experimental data were analyzed for discrete values of the adsorption rate constants by non-linear regression. One of the important conditions for the application of the kinetic model is the speed convergence of the regressions, and there should be a reasonable fit (as measured by correlation coefficient, $\mathrm{R}^{2}$ ) with the kinetic data.

Figure 3.1 shows the relation between the \% of PCP adsorbed from the aqueous solution to the adsorbent versus time, $\mathrm{t}$ (minutes), for MWCNTs and AC. The experimental data presented in Figure 3.1 were fitted to the kinetic model (equation 3.9) and analyzed using a non-linear regression method to obtain the numerical values of the kinetically distinguishable components and the associated adsorption rate constants. The values for kinetic parameters of the PCP adsorption are presented in Table 3.1. From the table, it is clear that applying the one component kinetic model for the adsorption of PCP on pristine MWCNTs and AC was not good, as the predicted data did not fit the experimental data. This may indicate that the adsorption was mainly in more than one step for both pristine MWCNTs and AC.

A two component kinetic model was used to fit the experimental data and their values are presented in Table 3.1. It is clear that the two component kinetic model fits much better than the one component kinetic model, especially in the case of AC. 
Table 3.1. Kinetic parameters of the adsorption of PCP to MWCNTs and AC using different kinetic models (*one component, ${ }^{* *}$ two components).

\begin{tabular}{|c|c|c|c|c|c|}
\hline \multicolumn{6}{|c|}{ Kinetic Parameters } \\
\hline & $\% \mathrm{C}_{1}$ & $k_{1} \times 10^{-1}\left(\min ^{-1}\right)$ & $\% \mathrm{C}_{2}$ & $k_{2} \times 10^{-3}\left(\mathrm{~min}^{-1}\right)$ & $\mathbf{R}^{2}$ \\
\hline MWCNTs* & $100.0 \pm 2.7$ & $3.8 \pm 0.9$ & & & 0.967 \\
\hline$A C^{*}$ & $100.0 \pm 6.6$ & $2.2 \pm 0.8$ & & & 0.801 \\
\hline MWCNTs** & $89.2 \pm 1.7$ & $7.9 \pm 2.4$ & $10.8 \pm 2.6$ & $9.9 \pm 7.5$ & 0.998 \\
\hline $\mathbf{A C} * *$ & $77.5 \pm 0.7$ & $7.1 \pm 0.8$ & $22.2 \pm 2.9$ & $5.9 \pm 1.8$ & 0.999 \\
\hline
\end{tabular}


It is clear that \% of PCP adsorbed during the first step was significantly higher in the case of MWCNTs; $89.2 \%$, compared with the AC, $77.5 \%$, although both of the steps have almost the same rate constants, almost $7.0 \times 10^{-1}\left(\mathrm{~min}^{-1}\right)$. This step may be attributed to the adsorption of the PCP to the surface of the adsorbent. The more uniform structure of the MWCNTs could be the reason for the higher adsorption value in the first step. For the second component, $10.8 \%$ and $22.2 \%$ of the PCP were adsorbed on the MWCNTs and the AC, respectively. This step may be attributed to intra-particle diffusion in aggregates of MWCNTs, or in the porous structure of AC.

The probability of intra-particle diffusion was explored by using the intra-particle diffusion model [67].

$q_{t}=k_{i d} t^{1 / 2}+C$

where, $q_{t}$ is adsorption capacity at any time $(t), k_{i d}$ is the intra-particle diffusion rate constant $\left(\mathrm{mg} / \mathrm{g} \mathrm{min}{ }^{1 / 2}\right)$ and $C(\mathrm{mg} / \mathrm{g})$ is a constant proportional to the thickness of the boundary layer. Plotting $q_{t}$ versus $t^{1 / 2}$ a "Weber-Morris plot" [67] can give an indication of the dependency of adsorption on the intra-particle diffusion. If the plot gives a straight line, then the adsorption (or sorption) process is controlled by intra-particle diffusion only, and if it exhibits multi-linear plots, then there are two or more steps affecting the adsorption process.

Figure 3.2. shows the Weber-Morris plot of the PCP adsorption to MWCNTs and AC. It is clear from the graph that the adsorption of PCP to the AC gives a straight line with good $\mathrm{R}^{2}(0.989)$ plot which indicates, according to Weber-Morris plot, that the adsorption 


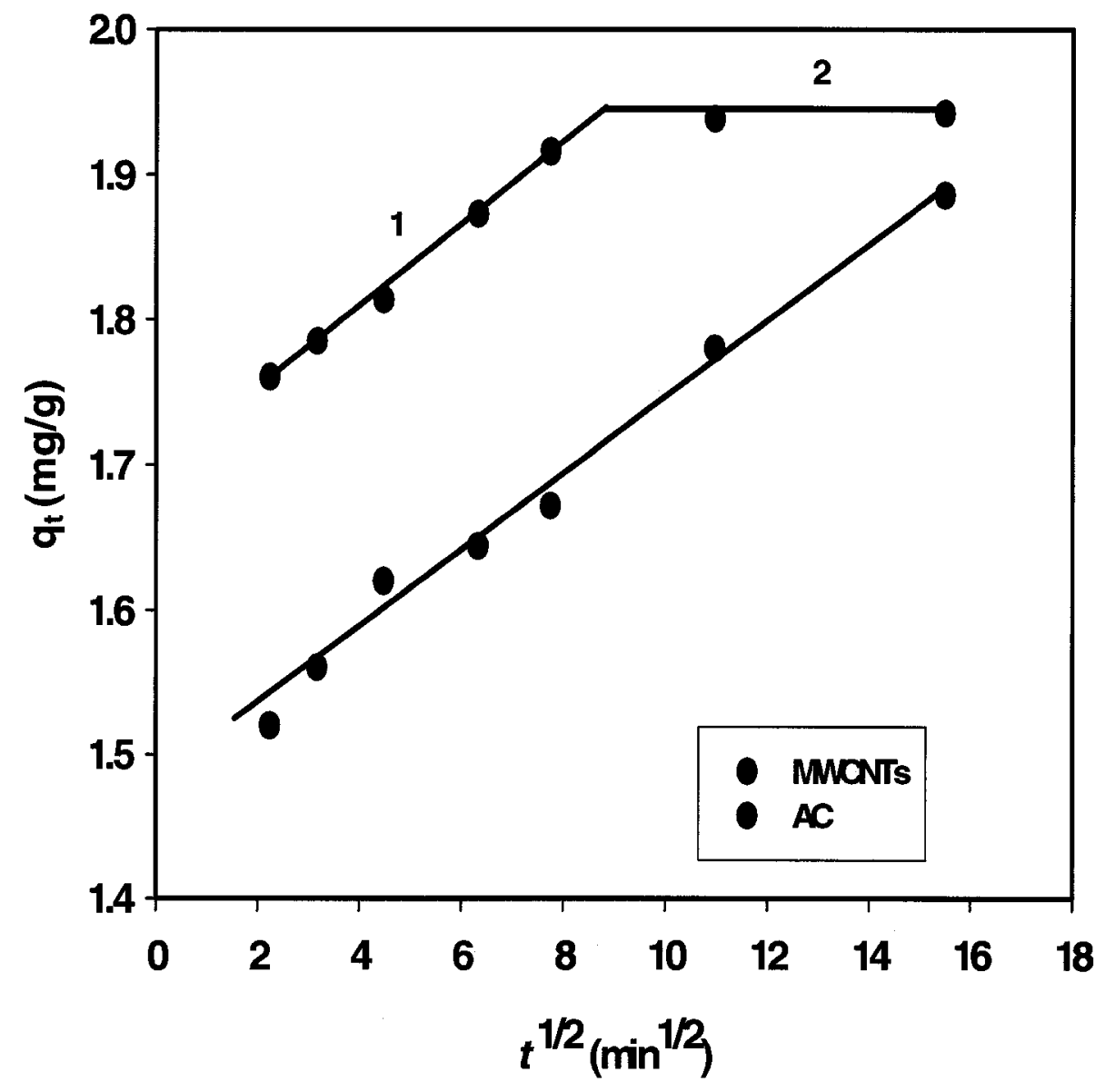

Figure 3.2. Weber-Morris intra-particle diffusion plots for the adsorption of PCP. 
process is governed mainly by intra-particle diffusion, whereas in the case of MWCNTs, it gives two different straight lines. This may indicate that the adsorption of PCP to the MWCNTs is controlled by two steps. The first part of the straight line is may be due to the adsorption to the surface of the MWCNTs, whereas the second part could be due to the intra-particle diffusion. The slope of the $q_{t}$ versus $t^{1 / 2}$ in the region where the intraparticle diffusion control the adsorption, are defined as the $k_{i d}$ is the intra-particle diffusion rate constant $\left(\mathrm{mg} / \mathrm{g} \min ^{1 / 2}\right) . k_{i d}$ values were $(2.7 \pm 0.1) \times 10^{-2}\left(\mathrm{mg} / \mathrm{g} \mathrm{min}^{1 / 2}\right)$ and $(8.4 \pm 0.0) \times 10^{-4}\left(\mathrm{mg} / \mathrm{g} \mathrm{min}^{1 / 2}\right)$ for the AC and MWCNTs, respectively. This may explain the dependency of $\mathrm{AC}$ on the intra-particle diffusion for the adsorption of PCP from aqueous solution than MWCNTs and explain the mismatching between the predicted and experimental data for the MWCNTs for the one component kinetic model.

\subsubsection{Adsorption isotherms}

One of the most important studies to understand and optimize the adsorption process of certain adsorbate to a specific adsorbent is to establish the adsorption isotherm. The equilibrium adsorption of PCP on MWCNTs and $\mathrm{AC}$ at different temperatures; $5^{\circ} \mathrm{C}, 15^{\circ} \mathrm{C}$, $25^{\circ} \mathrm{C}$, and $35^{\circ} \mathrm{C}$, was studied and the adsorption curves are presented in Figures 3.3. (a) and (b). The Figures show that PCP adsorbs strongly onto the MWCNTs and the AC at all temperatures. It is clear from the Figures that the adsorption of PCP on MWCNTs was slightly higher than on the AC. Using MWCNTs, the equilibrium concentrations were in the range of $3 \mathrm{mg} \mathrm{PCP} / \mathrm{g}$ at $35^{\circ} \mathrm{C}$ and $6 \mathrm{mg} \mathrm{PCP} / \mathrm{g}$ at $5^{\circ} \mathrm{C}$. The equilibrium adsorption data of the PCP on MWCNTs and AC at different temperatures were fitted to the different isotherm models; Langmuir, and Freundlich models (two parameters), Radke-Prausnitz 

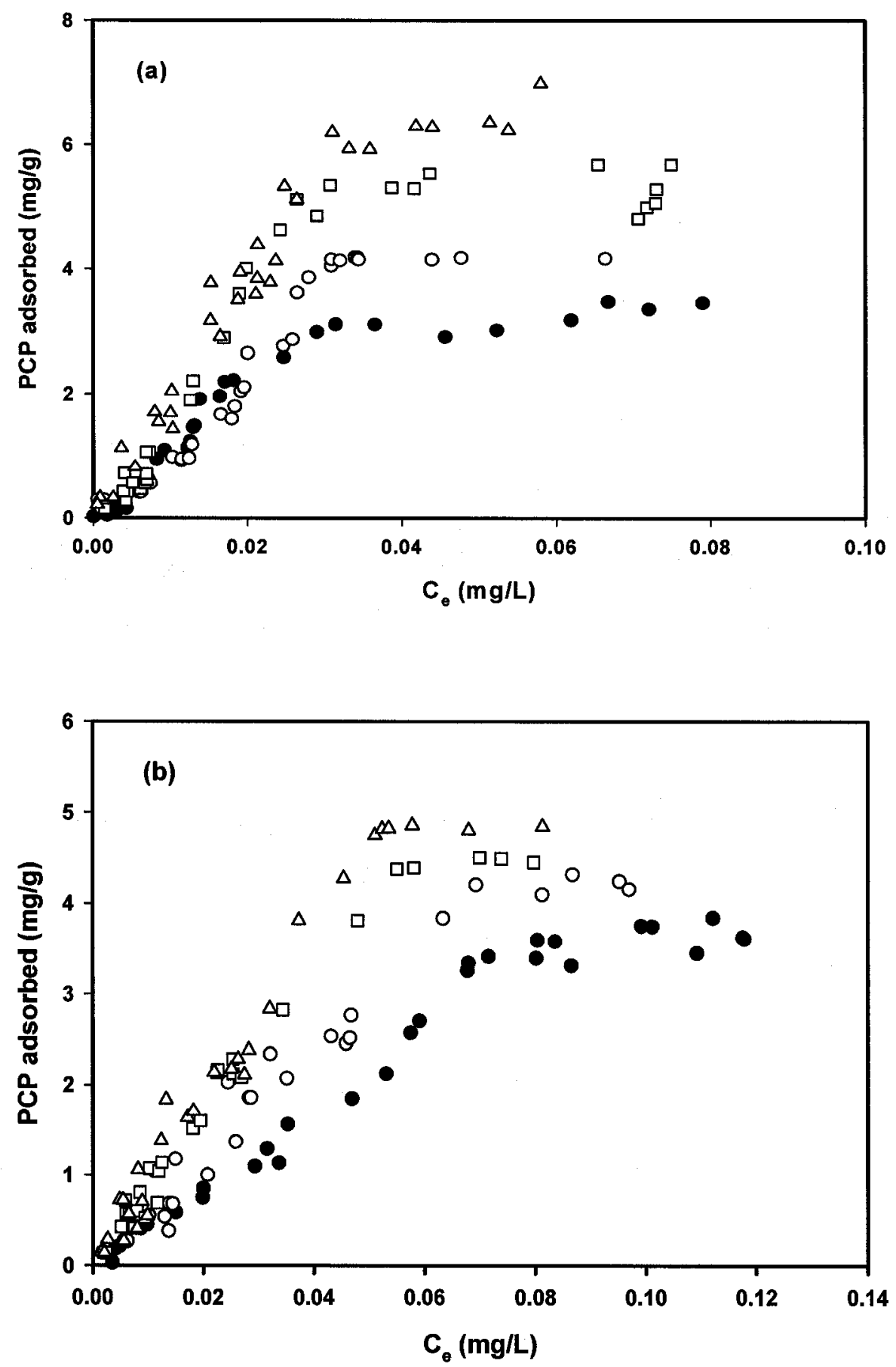

Figure 3.3. Adsorption isotherms for PCP on MWCNTs (a) and AC (b) at different temperatures; $\Delta, 5^{\circ} \mathrm{C} ; \square, 15^{\circ} \mathrm{C} ; \circ, 25^{\circ} \mathrm{C} ; \bullet, 35^{\circ} \mathrm{C}$. 
model (three parameters) and Fritz-Schlünder model (four parameters) and the results are presented in Figure 3.4. and Figure 3.5. Table 3.2 presents the values of the isotherm parameters for the different models. In general, it can be seen from Table 3.2 that the adsorption models fit the data well, as evidenced by the good regression coefficients $\left(\mathrm{R}^{2}\right)$. The PCP adsorption efficiency, $\mathrm{K}_{\mathrm{f}}$ for Freundlich model and $\mathrm{q}_{\mathrm{m}}$ for Langmuir model, increased markedly from $35^{\circ} \mathrm{C}$ to $5^{\circ} \mathrm{C}$. Comparing the adsorption of PCP on MWCNTs and AC shows that MWCNTs have slightly higher adsorbability than AC despite the fact that $\mathrm{AC}$ has a higher specific surface area $\left(311 \pm 1 \mathrm{~m}^{2} / \mathrm{g}\right)$ than the MWCNTs $(148 \pm 5$ $\mathrm{m}^{2} / \mathrm{g}$ ). However, the low values of $\mathrm{R}^{2}$ may be due to limitations of Freundlich and Langmuir models, as both models are valid for adsorption over a restricted range of concentrations as well as the homogeneity of the adsorbent surface. For a heterogeneous surface such as MWCNTs and AC and at low concentrations of PCP, neither of the models are suitable [66].

Both Radke-Prausnitz and Fritz-Schlünder models were in good agreement with the experimental data as evidenced by good $\mathrm{R}^{2}$ values. These are both empirical models and the fitting parameters have no physical significance.

\subsubsection{Temperature studies}

The effect of temperature on the adsorption equilibrium was studied in order to help understand the adsorption mechanism. The adsorption equilibrium depends on the temperature in two different ways. High temperature, generally, increases the rate of 

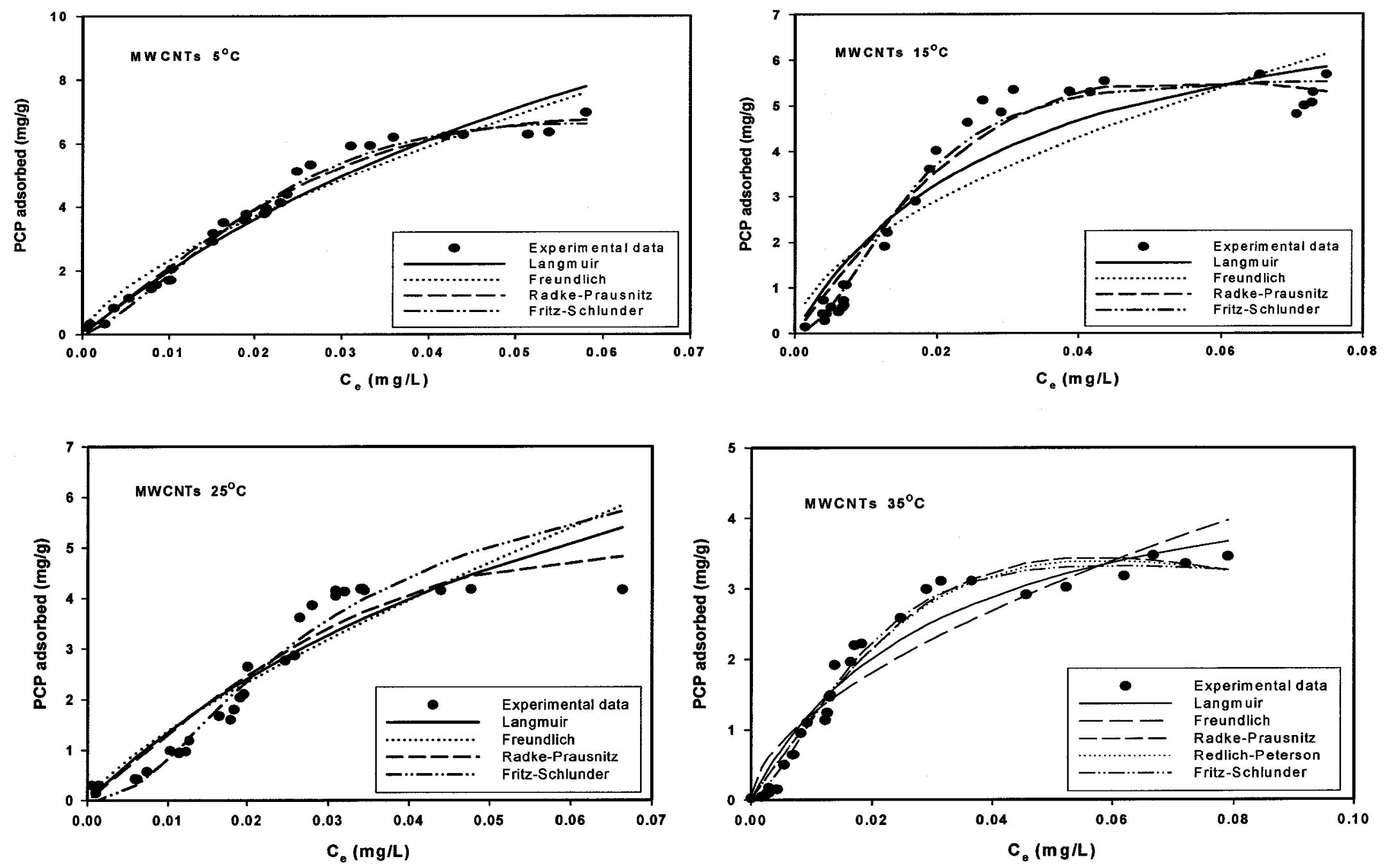

Figure 3.4. Comparison of different isotherm models for PCP adsorption on MWCNTs with experimental results. 

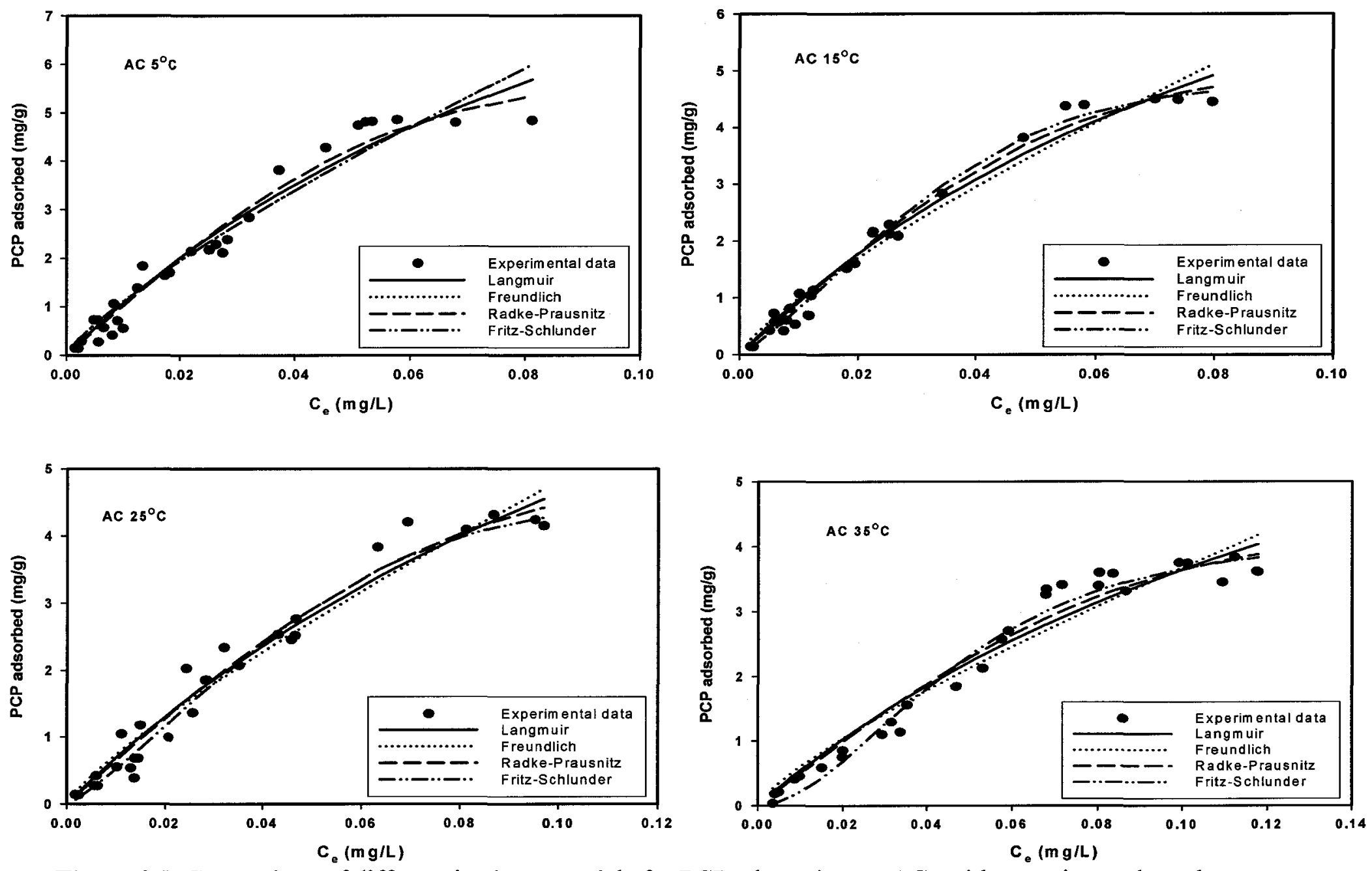

Figure 3.5. Comparison of different isotherm models for PCP adsorption on ACs with experimental results. 
Table 3.2. Results of PCP adsorption isotherm analysis using MWCNTs and AC at different temperatures.

\begin{tabular}{|c|c|c|c|c|c|c|c|c|c|c|c|c|c|c|c|c|}
\hline \multirow{2}{*}{\multicolumn{2}{|c|}{ Temperature adsorbent }} & \multicolumn{3}{|c|}{$\begin{array}{l}\text { Freundlich } \\
\mathrm{qe}_{\mathrm{e}}=\mathrm{K}_{\mathrm{f}} \mathrm{C}_{\mathrm{e}}^{1 / \mathrm{n}}\end{array}$} & \multicolumn{3}{|c|}{$\begin{array}{l}\text { Langmuir } \\
q_{e}=q_{m} K_{L} C_{e} /\left(1+K_{L} C_{e}\right)\end{array}$} & \multicolumn{4}{|c|}{$\begin{array}{l}\text { Radke and Prausnitz } \\
1 / q_{\mathrm{e}}=1 / \mathrm{KC}_{\mathrm{e}}+1 / \mathrm{kC}_{\mathrm{e}}^{1 / \mathrm{b}}\end{array}$} & \multicolumn{5}{|c|}{$\begin{array}{l}\text { Fritz-Schlunder } \\
\mathrm{qe}=\alpha_{1} \mathrm{C}_{\mathrm{e}}{ }^{\beta 1} /\left(1+\alpha_{2} \mathrm{C}_{\mathrm{e}}{ }^{\beta 2}\right)\end{array}$} \\
\hline & & $\mathbf{K}_{\mathbf{f}}$ & $1 / \mathbf{n}$ & $\mathbf{R}^{2}$ & $\mathbf{q}_{\mathbf{m}}$ & $\mathbf{K}_{\mathbf{I}}$ & $\mathbf{R}^{2}$ & $\mathbf{K}$ & $\mathbf{k}$ & $1 / b$ & $\mathbf{R}^{2}$ & $\alpha_{1}$ & $\alpha_{2}$ & $\beta 1$ & $\beta 2$ & $\mathbf{R}^{2}$ \\
\hline \multirow[t]{2}{*}{$35^{\circ} \mathrm{C}$} & $\mathbf{A C}$ & 22.5 & 0.79 & 0.943 & 10.1 & 5.64 & 0.957 & 0.75 & 85.9 & 0.580 & 0.969 & 3.19 & 9.004 & -0.197 & -1.99 & 0.979 \\
\hline & MWCNTs & 16.9 & 0.57 & 0.885 & 5.07 & 32.9 & 0.943 & 2.56 & 93.5 & 1.29 & 0.968 & 1007 & 631 & 1.44 & 1.77 & 0.983 \\
\hline \multirow[t]{2}{*}{$25^{\circ} \mathrm{C}$} & $\mathbf{A C}$ & 31.7 & 0.82 & 0.953 & 12.9 & 5.62 & 0.962 & 0.699 & 83.8 & 0.775 & 0.969 & 1.45 & 0.011 & -0.79 & -1.99 & 0.971 \\
\hline & MWCNTs & 26.2 & 0.56 & 0.814 & 8.18 & 33.4 & 0.893 & 1.641 & 105.3 & 1.92 & 0.956 & 5.36 & 0.003 & -0.033 & -1.99 & 0.973 \\
\hline \multirow[t]{2}{*}{$15^{\circ} \mathrm{C}$} & $\mathbf{A C}$ & 38.1 & 0.79 & 0.965 & 12.1 & 8.56 & 0.977 & 0.955 & 87.8 & 1.05 & 0.986 & 1.17 & 0.006 & -0.79 & -1.99 & 0.988 \\
\hline & MWCNTs & 46.3 & 0.77 & 0.844 & 11.6 & 13.1 & 0.879 & 1.42 & 64.3 & 2.06 & 0.914 & 12.3 & 0.004 & 0.25 & -1.99 & 0.957 \\
\hline \multirow[t]{2}{*}{$5^{\circ} \mathrm{C}$} & AC & 44.8 & 0.81 & 0.943 & 14.2 & 8.26 & 0.956 & 0.839 & 93.5 & 1.11 & 0.968 & 28.7 & -0.359 & 0.801 & 0.00 & 0.943 \\
\hline & MWCNTs & 52.0 & 0.68 & 0.943 & 19.9 & 11.1 & 0.952 & 1.171 & 138.5 & 1.56 & 0.967 & 1.38 & 0.002 & -0.71 & -1.98 & 0.987 \\
\hline
\end{tabular}


diffusion of the adsorbate molecules through the solution to the external and internal surface of the adsorbent, and may change the equilibrium adsorption capacity of the adsorbent for the particular adsorbate. To determine the effect of temperature on the adsorption of PCP on MWCNTs and AC, four different temperatures were selected to represent a wide range of natural water temperatures; from $5^{\circ} \mathrm{C}$ to $35^{\circ} \mathrm{C}$. It is clear from Figures 3.3 and Table 3.2, that the adsorption onto MWCNTs was increased markedly by decreasing the temperature from $35^{\circ} \mathrm{C}$ to $5^{\circ} \mathrm{C}$, indicating that adsorption of PCP on MWCNTs is an exothermic process. Thermodynamic parameters were calculated from the variation of the thermodynamic equilibrium constant $\mathrm{K}_{0}$ with a change in temperature $[31,68] . \mathrm{K}_{0}$ for the adsorption reaction can be defined as follows:

$\mathrm{K}_{0}=\frac{\mathrm{a}_{\mathrm{s}}}{\mathrm{a}_{\mathrm{e}}}=\frac{\gamma_{\mathrm{s}}\left(\mathrm{C}_{\mathrm{s}} / \mathrm{C}_{\mathrm{s}}^{0}\right)}{\gamma_{\mathrm{e}}\left(\mathrm{C}_{\mathrm{e}} / \mathrm{C}_{\mathrm{e}}^{0}\right)}$

whereas and $a_{e}$ are the activities of adsorbed solute and the solute in solution at equilibrium, respectively. $\mathrm{C}_{\mathrm{s}}$ is the surface concentration of PCP in $\mathrm{mg}$ per gram of MWCNTs, $\mathrm{C}_{\mathrm{e}}$, is the aqueous concentration of $\mathrm{PCP}$ at equilibrium $(\mathrm{mg} / \mathrm{L}), \mathrm{C}_{\mathrm{s}}^{0}$ is the surface concentration of PCP at monolayer coverage of the adsorbent, $\mathrm{C}_{\mathrm{e}}^{0}$ is molar concentration of PCP at standard conditions; equal $1 \mathrm{M}, \gamma_{\mathrm{s}}$ is the activity coefficient of the adsorbed solute and $\gamma_{\mathrm{e}}$ is the activity coefficient of the solute in solution. In dilute solution and at low surface coverage, the activity coefficients approach unity, reducing equation (3.14) to the form:

$$
\mathrm{K}_{0}=\frac{\mathrm{C}_{\mathrm{s}} / \mathrm{C}_{\mathrm{s}}^{0}}{\mathrm{C}_{\mathrm{e}} / \mathrm{C}_{\mathrm{e}}^{0}}
$$


The standard free energy change $\left(\Delta G^{\circ}\right)$ for adsorption was calculated from the relationship:

$\Delta \mathrm{G}^{\circ}=-\mathrm{RT} \ln \left(\mathrm{K}_{0}\right)$

where $\mathrm{R}$ is the universal gas constant and $\mathrm{T}$ is the temperature in Kelvin. Using the Van't Hoff equation, the average standard enthalpy change $\left(\Delta \mathrm{H}^{\circ}\right)$ can be calculated from the relation between $\mathrm{K}_{0}$ and $\mathrm{T}$ :

$\ln \left(\mathrm{K}_{0}\right)=\frac{-\Delta \mathrm{H}^{0}}{\mathrm{RT}}+\mathrm{const}$

and standard entropy changes $\left(\Delta S^{\circ}\right)$ can be calculated from:

$\Delta G^{\circ}=\Delta H^{\circ}-T \Delta S^{\circ}$

Using the above relations, the thermodynamic parameters for the adsorption of PCP on MWCNTs and AC where obtained and their values are presented in Table 3.3. In general, the data show that the adsorption equilibrium constant, $\mathrm{K}_{\mathrm{o}}$ increases as the temperature decreases. Figure 3.6 shows the Van't Hoff plot for the adsorption equilibrium constant, $\ln \mathrm{K}_{\mathrm{o}}$ versus (1/temperature) according to equation (3.17) for both MWCNTs and activated charcoal. There were good correlation between $\ln \mathrm{K}_{0}$.and $1 /$ temperature with regression coefficients $\left(R^{2}\right)$ values greater than 0.96 . The values of $\Delta H^{\circ}$ were estimated from the slope as in equation (3.17), and were found to be $-23.7 \pm 6 \mathrm{~kJ} / \mathrm{mole}$ and $-19.2 \pm$ $3 \mathrm{~kJ} / \mathrm{mole}$, for the adsorption of PCP on MWCNTs and AC, respectively. There were no significance difference between $\Delta \mathrm{H}^{\circ}$ for both MWCNTs and AC and this may be due to the fact that both adsorbents made up of carbon. The negative value of $\Delta \mathrm{H}^{\circ}$ suggests that 
Table 3.3. Values of thermodynamic parameters for the adsorption of PCP on MWCNTs and AC.

\begin{tabular}{|c|c|c|c|c|c|c|c|c|}
\hline & \multicolumn{2}{|c|}{$35^{\circ} \mathrm{C}$} & \multicolumn{2}{|c|}{$25^{\circ} \mathrm{C}$} & \multicolumn{2}{|c|}{$15^{\circ} \mathrm{C}$} & \multicolumn{2}{|c|}{$5^{\circ} \mathrm{C}$} \\
\hline & MWCNTs & AC & MWCNTs & $\mathbf{A C}$ & MWCNTs & $\mathbf{A C}$ & MWCNTs & $\mathbf{A C}$ \\
\hline $\operatorname{Ln} K_{0}$ & $13.2 \pm 1$ & $12.7 \pm 1$ & $13.6 \pm 2$ & $13.1 \pm 1$ & $13.8 \pm 1$ & $13.4 \pm 1$ & $14.3 \pm 1$ & $13.5 \pm 1$ \\
\hline$\Delta G^{0}(\mathrm{~kJ} / \mathrm{mol})$ & $-33.9 \pm 0.4$ & $-32.6 \pm 0.2$ & $-33.7 \pm 2$ & $-32.3 \pm 0.2$ & $-33.1 \pm 0.3$ & $-32.1 \pm 0.2$ & $-32.9 \pm 0.2$ & $-31.2 \pm 0.2$ \\
\hline$\Delta \mathbf{H}^{\mathbf{0}}(\mathrm{kJ} / \mathrm{mol})$ & $-23.7 \pm 6$ & $-19.2 \pm 3$ & $-23.7 \pm 6$ & $-19.2 \pm 3$ & $-23.7 \pm 6$ & $-19.2 \pm 3$ & $-23.7 \pm 6$ & $-19.2 \pm 3$ \\
\hline$\Delta S^{0}(\mathrm{~J} / \mathrm{K} \mathrm{mol})$ & $33.1 \pm 17$ & $41.6 \pm 9$ & $33.5 \pm 2$ & $42.2 \pm 10$ & $32.6 \pm 18$ & $42.6 \pm 10$ & $33.4 \pm 19$ & $41.3 \pm 10$ \\
\hline
\end{tabular}




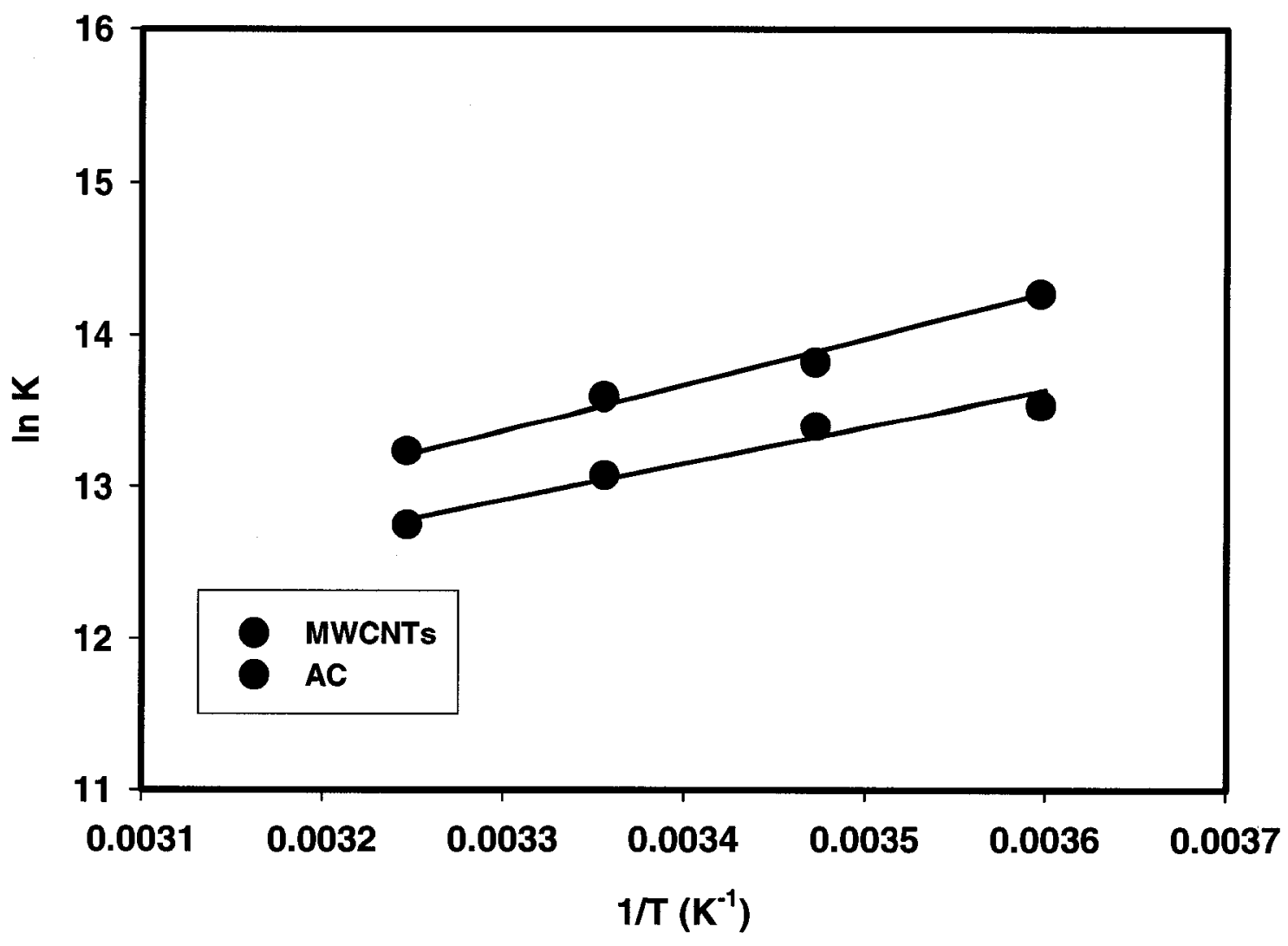

Figure 3.6. Temperature dependency plots for the adsorption of PCP on MWCNTs and AC. 
the PCP-MWCNTs interaction is exothermic, which was the reason for the increase in adsorption at lower temperature. The negative values of $\Delta \mathrm{H}^{\circ}$ suggested that the rise in the solution temperature did not favour PCP adsorption on either MWCNTs or AC. The same effect was reported for p-chlorophenol and phenol on AC [69] and chitosan [56].The magnitude of $\Delta \mathrm{H}^{\circ}(\approx-20 \mathrm{~kJ} / \mathrm{mol})$ suggests a weak type of bonding between the PCP and the MWCNTs such as physical adsorption. The values obtained in this study agreed with the other values found in the literature for adsorption of chlorophenols, in general, on different adsorbents $[56,70,71]$. The decrease in the standard free energy change, $\Delta \mathrm{G}^{\circ}$, with increasing temperature is consistent with the exothermic adsorption process. $\Delta \mathrm{G}^{\circ}$ values were found to be negative for both MWCNTs and AC, as would be expected for a product favored reaction. As a results, the entropy values for both adsorbents; MWCNTs and $\mathrm{AC}$, were positive implying that the $\mathrm{PCP}$ is more ordered on the aqueous phase than at the MWCNTs or AC surface and from the loss of structured water surrounding the PCP molecules.

\subsection{Conclusions}

MWCNTs are good adsorbents for the elimination of PCP from aqueous solutions in a very short time. The kinetics of the adsorption showed that the adsorption is mainly due to the diffusion of PCP from the aqueous phase to the solid phase. There was a part of the diffusion controlled by intra-particle diffusion. This contribution was more significant for activated charcoal compared with MWCNTs. The equilibrium adsorption of PCP on MWCNTs and AC at different temperatures was studied and the adsorption equilibrium is well described using different adsorption models. The thermodynamic 
parameters showed that the adsorption process is product favored, and becomes more so at lower temperature, since the adsorption is exothermic. The magnitude of the enthalpy suggests a weak type of bonding between the PCP and the MWCNTs. The entropy values were positive, indicating that PCP is more ordered on the aqueous phase than at the MWCNTs or AC surface and from the loss of structured water surrounding the PCP molecules and or the adsorbent surface. 


\subsection{References}

[1] Cooper P A, Ung T, Assessment of Preserved Wood Disposal Practices, Report of Environment Canada, Ottawa, Ontario, Canada, 1989.

[2] Tomlin C, The Pesticide Manual incorporating the Agrochemical Handbook, $10^{\text {th }}$ ed., British Crop Protection Council, The Royal Society of Chemistry, Bath Press, UK 1994, pp. 780.

[3] Ruiter D C, Brinkman J W, Frei R W, Lingeman H, Brinkman U A, van Zoonen P, Analyst 1990, 115, 1033.

[4] Lee M R, Yeh Y C, Hsiang W S, Hwang B H, Journal of Chromatographia A $1998,806, \quad 317$.

[5] Veningerová M, Prachar V, Uhnák J, Lukácsová M, Trnovec T, Journal of Chromatographia B. 1994, 657, 103.

[6] US EPA, Integrated Risk Information System (IRIS) http.//epa.gov/iriswebp/iris/subst/0086.htm.

[7] Jensen J, Reviews of Environmental Contamination \& Toxicology 1996, 146, 25.

[8] Jianlong W, Yi Q, Horan N, Stentiford E, Bioresource Technology 2000, 75, 157.

[9] Liu X, Quan X, Bo L, Chen S, Zhao Y, Carbon 2004, 42, 415.

[10] Hanna K, de Brauer C, Chovelon J M, Ferronato C, Science of the Total Environment 2004, 332, 51.

[11] Khodadoust A P, Suidan M T, Aheson C M, Brenner R C, Chemosphere 1999, 38, 2681. 
[12] Di Z C, Ding J P, Xian J, Li Y H, Luan Z K, Liang J, Chemosphere 2006, 62, 861.

[13] Zhou Q, Xiao J, Wang W, Liu G, Shi Q, Wang J, Talanta 2006, 68, 1309.

[14] Lu C, Chiu H, Chemical Engineering Science 2006, 61, 1138.

[15] Li Y H, Zhu Y, Zhao Y, Wu D, Luan Z, Diamond and Related Materials 2006, 15, 90.

[16] Zhou Q, Wang W, Xiao J, Wang J, Liu G, Shi Q, Guo G, Microchimica Acta 2006, $152,215-224$.

[17] Yan H, Gong A, He H, Zhou J, Wei Y, Lv L, Chemosphere 2006, 62, 142.

[18] Lu W F, Ding M Y, Zheng R, Journal of Chromatographic Science 2005, 43, 383.

[19] Cai Y, Cai Y, Mou S, Lu Y, Journal of Chromatographia A 2005, 1081, 245.

[20] Lu C, Chung Y L, Chang K F, Water Research 2005, 39, 1183.

[21] Pan C, Xu S, Zou H, Guo Z, Zhang Y, Guo B, Journal of the American Society for Mass Spectrometry 2005, 16, 263.

[22] Peng X, Luan Z, Di Z, Zhang Z, Zhu C, Carbon 2005, 43, 880.

[23] Di Z C, Li Y H, Luan Z K, Liang J, Adsorption Science \& Technology 2004, 22, 467.

[24] Peng X, Luan Z, Ding J, Di Z, Li Y, Tian B, Materials Letters 2005, 59, 399.

[25] Liang P, Liu Y, Guo L, Zeng J, Lu H, Journal of Analytical Atomic Spectrometry 2004, 19, 1489.

[26] Fugetsu B, Satoh S, Shiba T, Mizutani T, Lin Y Bo, Terui N, Nodasaka Y, Sasa K, Shimizu K, Akasaka T, Shindoh M, Shibata K, Yokoyama A, Mori M, Tanaka K, Sato Y, Tohji K, Tanaka S, Nishi N, Watari F, Environmental Science \& Technology 2004, 38, 6890 . 
[27] Yan H, Pan G, Zou H, Li X, Chen H, Chinese Science Bulletin 2004, 49, 1694.

[28] Fugetsu B, Satoh S, Iles A, Tanaka K, Nishi N, Watari F, Analyst 2004, 129, 565.

[29] Li Q L, Yuan D X, Lin Q M, Journal of Chromatographia A 2004, 1026, 283.

[30] Li Y H, Luan Z, Xu X, Zhou X, Xu C, Wu D, Wei B, Adsorption Science \& Technology 2003, 21, 475.

[31] Peng X, Li Y, Luan Z, Di Z, Wang H, Tian B, Jia Z, Chemical Physics Letters $2003,376,154$.

[32] Wang S, Li Y, Gong X, Zhao H, Luan Z, Xu C, Wu D, Chinese Science Bulletin $2003,48,441$.

[33] Li Y. H, Wang, S., Zhang, X., Wei, J., Xu, C., Luan, Z., Wu, D., Wei, B. Environmental Technology 2003, 24, 391.

[34] Cai Y, Jiang G, Liu J, Zhou Q, Analytical Chemistry 2003, 75, 2517.

[35] Cai Y, Jiang G, Liu J, Zhou Q, Analytica Chimica Acta 2003, 494,149.

[36] Power T D, Skoulidas A I, Sholl D S, Journal of the American Chemical Society $2002,124,1858$.

[37] Li Y H, Wang S C, Anyuan Z D, Zhang X, Xu C, Luan Z, Ruan D, Liang J, Wu D, Wei B, Chemical Physics Letters 2001, 350, 412.

[38] Long R Q, Yang R T, Journal of the American Chemical Society 2001, 123, 2058.

[39] Yang R T, Long R Q, Padin J, Takahashi A, Industrial \& Engineering Chemistry Research 1999, 38, 2726.

[40] Li Y, Wang S, Luan Z, Ding J, Xu C, Wu D, Carbon 2003, 41, 1057.

[41] Li Q, Yuan D, Journal of Chromatographia A 2003, 1003, 203. 
[42] Li Y, Wang S, Zhang X, Wei J, Xu C, Luan Z, Wu D, Materials research Bulletin 2003, 38, 469 .

[43] Li Y, Ding J, Luan Z, Di Z, Zhu Y, Xu C, Wu D, Wei B, Carbon 2003, 41, 2787.

[44] Basheer C, Alnedhary A A, Rao B S M, Valliyaveettil S, Lee H K, Analytical Chemistry 2006, 78, 2853.

[45] Liang P,Ding Q, Song F, Journal of Separation Science 2005, 28, 2339.

[46] Kerman K, Morita Y, Takamura Y, Tamiya E, Analytical and Bioanalytical Chemistry 2005, 381, 1114.

[47] Liu G, Wang J, Zhu Y, Zhang X, Analytical Letters 2004, 37, 3085.

[48] Tam S C, Johnson S A, Graham A, Water, Air, and Soil Pollution 1999, 115, 337.

[49] Viraraghavan T, Slough K, Chemosphere 1999, 39, 1487.

[50] Slaney A J, Bhamidimarri R, Water Science and Technology 1998, 38, 227.

[51] Edgehill R U, Lu G. O. (Max), Journal of Chemical Technology \& Biotechnology 1998, 71, 27.

[52] Mollah A H, Robinson C W, Water Research 1996, 30, 2901.

[53] Mollah A H, Robinson C W, Water Research 1996, 30, 2907.

[54] Jianlong W, Yi Q, Horan N, Stentiford E, Bioresource Technology 2000, 75, 157.

[55] Tanjore S, Viraraghavan T, Water, Air, and Soil Pollution 1997, 100, 151.

[56] Zheng S, Yang Z, Jo D H, Park Y H, Water Research 2004, 38, 2315.

[57] DiVincenzo J P, Sparks D L, Archives of Environmental Contamination \& Toxicology 2001, 40, 445 . 
[58] Liu X, Quan X, Bo L, Chen S, Zhao Y, Carbon, 2004, 42, 415.

[59] Shen D S, Liu X W, He Y H, Journal of Hazard Materials 2005, 125, 231.

[60] Brás I, Lemos L T, Alves A, Pereira M F R, Management of Environmental Quality 2004, 15, 491.

[61] Han D M, Fang G Z, Yan Z P, Journal of Chromatographia A, 2005, 1100, 131.

[62] Langmuir J, Journal of the American Chemical Society 1918, 40, 1361.

[63] Freundlich H Z, Journal of Physical Chemistry 1907, 57, 385.

[64] Radke C J, Prausnitz J M, Industrial \& Engineering Chemistry Fundamentals $1972,11,445$.

[65] Fritz W, Schlünder E U, Chemical Engineering Science 1974, 29, 1279.

[66] Srivastava V C, Swamy M M, Mall I D, Prasad B, Mishra I M, Colloids and Surfaces A, Physicochemical and Engineering Aspects 2006, 272, 89.

[67] Weber W J Jr, Morris J C, J Sanitary Eng. Div. ASCE 89 (SA2), 1963, 31.

[68] Niwas R, Gupta U, Khan A A, Colloids and Surfaces A, Physicochemical and Engineering Aspects 2000, 164, 115.

[69] Varghese S, Vinod V P, Anirudhan T S, Indian Journal of Chemical Technology 2004, 116,825 .

[70] Severtson S J, Banerjee S, Environmental Science \& Technology 1996, 30, 1961.

[71] Ehrlich R S, Huang C P, Journal of the Chinese Institute of Environmental Engineering 1993, 3, 143. 


\section{CHAPTER 4}

\section{ADSORPTION OF PENTACHLOROPHENOL ON \\ OXIDIZED MULTI-WALLED CARBON}

NANOTUBES 


\subsection{Introduction}

Chlorophenolic compounds, such as pentachlorophenol (PCP) are generally generated from a number of industrial manufacturing processes. Those compounds comprise the bulk of the environmental pollutants. The adsorption over solid adsorbent is well established technique used for the removal of different pollutants, especially chlorophenols, from domestic and industrial effluents. Many studies were devoted to the adsorption of chlorophenols on different adsorbents [1-18]. Although, there is only one study exploring the potentiality of using pristine MWCNTs [19], but there is no study on the adsorption behavior of PCP, as an example of the chlorophenols, on oxidized MWCNTs. Oxidized MWCNTs were used previously for the adsorption of lead, copper and cadmium ions [20,21] and trihalomethanes [22] from aqueous solutions. These research studies concluded that oxidized CNTs show higher adsorption capacities for the target pollutants compared with other adsorbents such as activated carbon.

More research studies are required in order to understand the adsorption behavior of PCP to pristine and oxidized MWCNTs.

In this chapter, the adsorption of PCP to different oxidized form of multi-walled carbon nanotubes (MWCNTs) will be studied in order to determine the effect of introducing oxygen containing functional group on the adsorption of PCP on the MWCNTs. The study focus on the kinetics and equilibrium of the adsorption.

\subsection{Experimental}

Oxidation of MCNTs are the same as mentioned in Chapter 2. Adsorption studies are the same as mentioned in Chapter 3. 


\subsection{Results and Discussion}

\subsubsection{Adsorption of PCP on pristine and oxidized MWCNTs}

The adsorption of PCP to pristine and oxidized MWCNTs were studied after packing the CNTs in an solid phase extraction (SPE) cartridge and the results are shown in Figure 4.1. It is clear from the Figure that oxidation of the MWCNTs decreased the adsorption of PCP in general. The amount of PCP adsorbed was found to be $91.9 \%$ for the pristine MWCNTs, and $76.4 \%, 77.8 \%$, and $43.4 \%$ for the MWCNTs oxidized with $\mathrm{HNO}_{3}, \mathrm{H}_{2} \mathrm{O}_{2}$, and $\mathrm{KMnO}_{4}$, respectively. It was expected that PCP, with its phenolic group would strongly interact with the oxygen containing acidic functional groups; carboxylic, phenolic and lactonic, that were created upon oxidation of the MWCNTs, and consequently the adsorption of PCP would be increased. However, the adsorption of PCP on the oxidized MWCNTs actually decreased compared with the pristine MWCNTs. This may be explained as follows.

Generally, in the case of adsorption from the liquid-phase to solid phase, the adsorption capacity of any carbonueous adsorbent for aromatic compounds, such as PCP, depends on the following factors [23]:

- the physical nature of the adsorbent, such as pore structure, and the presence of surface functional groups.

- the nature of the adsorbate, such as its $\mathrm{p} K \mathrm{a}$, functional groups present, polarity, molecular weight and size.

- the conditions of the solution, such as $\mathrm{pH}$, ionic strength as well as the adsorbate concentration 


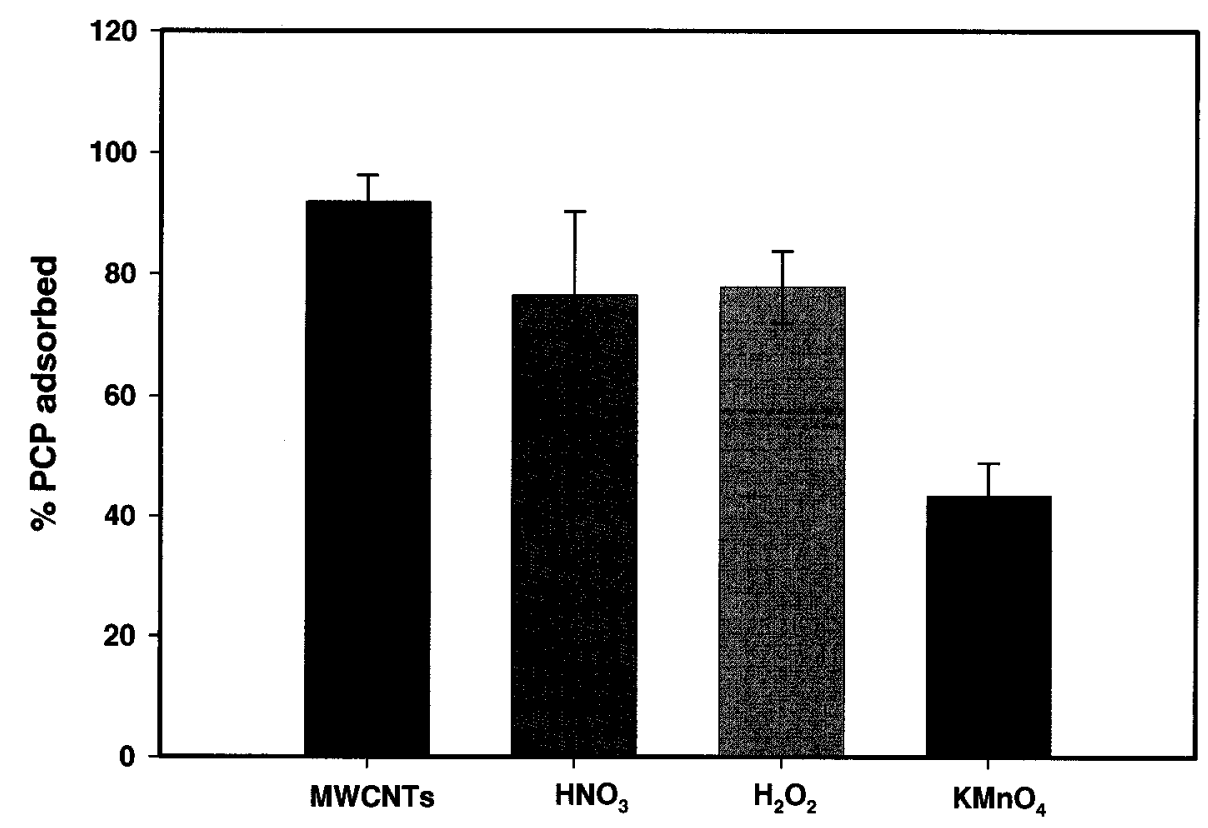

Figure 4.1. Adsorption of PCP by pristine MWCNTs and different oxidized MWCNTs. The error bars represents 3 standard deviations, $5 \mathrm{mg}$ of the adsorbent, $2 \mathrm{ml} / \mathrm{min}$ flow rate, PCP concentration is $20 \mathrm{ng} / \mathrm{ml}$. 
From the physical nature of the adsorbent point of view, one of the important features for most of carbon adsorbent is their aromaticity, due to the presence of the delocalized $\pi$ electrons. Pristine MWCNTs, mostly, have a uniform surface with many delocalized $\pi$ electrons which increases their adsorption capability in comparison with other carbonueous materials. It was found that the adsorptive properties of carbonueous material are determined mostly by its surface chemical composition. The presence of oxygen and hydrogen within the surface groups crucially affected the adsorptive properties of the adsorbent. Functional groups and delocalized electrons of the MWCNTs structure determine the chemical character of the MWCNTs surface [24]. It was reported that the presence of the carboxyl and hydroxyl groups inhibited the adsorption of phenolic compounds. This effect can be explained by PCP adsorption that is governed by " $\pi-\pi$ dispersion interaction" between the MWCNTs and the aromatic ring of the PCP. Oxygen containing functional groups can localize the $\pi$ electrons, and consequently, remove them from the $\pi$-electron system of the MWCNTs $[25,26]$, lowering the dispersive forces with PCP $\pi$-electron. Another explanation is the adsorption of water molecules to the oxygen containing function groups on the surface of the oxidized MWCNTs by the means of hydrogen bonding [27] which is the "solvent effect".

It can be concluded here that the oxidation of MWCNTs and the introduction of oxygen containing functional groups inhibit the adsorption of PCP due to the localization of the $\pi$-electron of the MWCNTs as well as the solvent effect.

\subsubsection{Adsorption isotherm of PCP on oxidized MWCNTs}

The adsorption of PCP to the oxidized MWCNTs at different temperatures; $5^{\circ} \mathrm{C}, 15^{\circ} \mathrm{C}$, $25^{\circ} \mathrm{C}$, and $35^{\circ} \mathrm{C}$, was studied and the adsorption curves are presented in Figures 4.2 for 
the MWCNTs oxidized with $\mathrm{H}_{2} \mathrm{O}_{2}$ and Figure 4.3 for the MWCNTs oxidized with $\mathrm{HNO}_{3}$. In general, the Figures show that PCP adsorbs strongly onto the oxidized MWCNTs at all temperatures. The adsorption of both the oxidized MWCNTs was less than the pristine MWCNTs, as it was explained previously. The adsorption of PCP is slightly lower for the MWCNTs oxidized with $\mathrm{HNO}_{3}$ compared with the MWCNTs oxidized with $\mathrm{H}_{2} \mathrm{O}_{2}$. The reason for that is, as was presented in Chapter 2, the oxidation with $\mathrm{HNO}_{3}$ introduced more oxygen containing function groups; carboxylic, phenolic and lactonic, which decreased the adsorption of PCP to their surfaces. The equilibrium concentrations were in the range of $3.19 \mathrm{mg} \mathrm{PCP} / \mathrm{g}$ at $35^{\circ} \mathrm{C}$ and $1.6 \mathrm{mg} \mathrm{PCP} / \mathrm{g}$ at $5^{\circ} \mathrm{C}$ for the $\mathrm{MWCNTs}$ oxidized with $\mathrm{HNO}_{3}$ and of $3.49 \mathrm{mg} \mathrm{PCP} / \mathrm{g}$ at $35^{\circ} \mathrm{C}$ and $2.06 \mathrm{mg} \mathrm{PCP} / \mathrm{g}$ at $5^{\circ} \mathrm{C}$ for the $\mathrm{MWCNTs}$ oxidized with $\mathrm{H}_{2} \mathrm{O}_{2}$, whereas it was of $3.80 \mathrm{mg} \mathrm{PCP} / \mathrm{g}$ at $35^{\circ} \mathrm{C}$ and $6.28 \mathrm{mg} \mathrm{PCP} / \mathrm{g}$ at $5^{\circ} \mathrm{C}$ for the pristine MWCNTs. The equilibrium adsorption data of the PCP on oxidized MWCNTs at different temperatures were fitted to the different isotherms models; Langmuir, and Freundlich models, Radke-Prausnitz model and Fritz-Schlünder model and the results are presented in Figure 4.4 and Figure 4.5. Table 4.1 shows the values of the isotherm parameters for the different models. In general, it can be seen from Table 4.1 that the adsorption models fit the data well, as evidenced by the good regression coefficients $\left(\mathrm{R}^{2}\right)$. At $25{ }^{\circ} \mathrm{C}$ and using Freundlich model fitting data, the adsorption efficiency, $\mathrm{K}_{\mathrm{f}}$, decreased sharply from 46.3 , to 4.58 and 4.13 , for the pristine and MWCNTs oxidized $\mathrm{H}_{2} \mathrm{O}_{2}$, and $\mathrm{HNO}_{3}$, respectively. At the same temperature; $25^{\circ} \mathrm{C}$, and using Langmuir model fitting data, the same effect was found. The adsorption capacity, $\mathrm{q}_{\mathrm{m}}$, decreased markedly from 11.6 , to 4.35 and 3.86 , for the pristine and MWCNTs oxidized $\mathrm{H}_{2} \mathrm{O}_{2}$, and $\mathrm{HNO}_{3}$, respectively. 


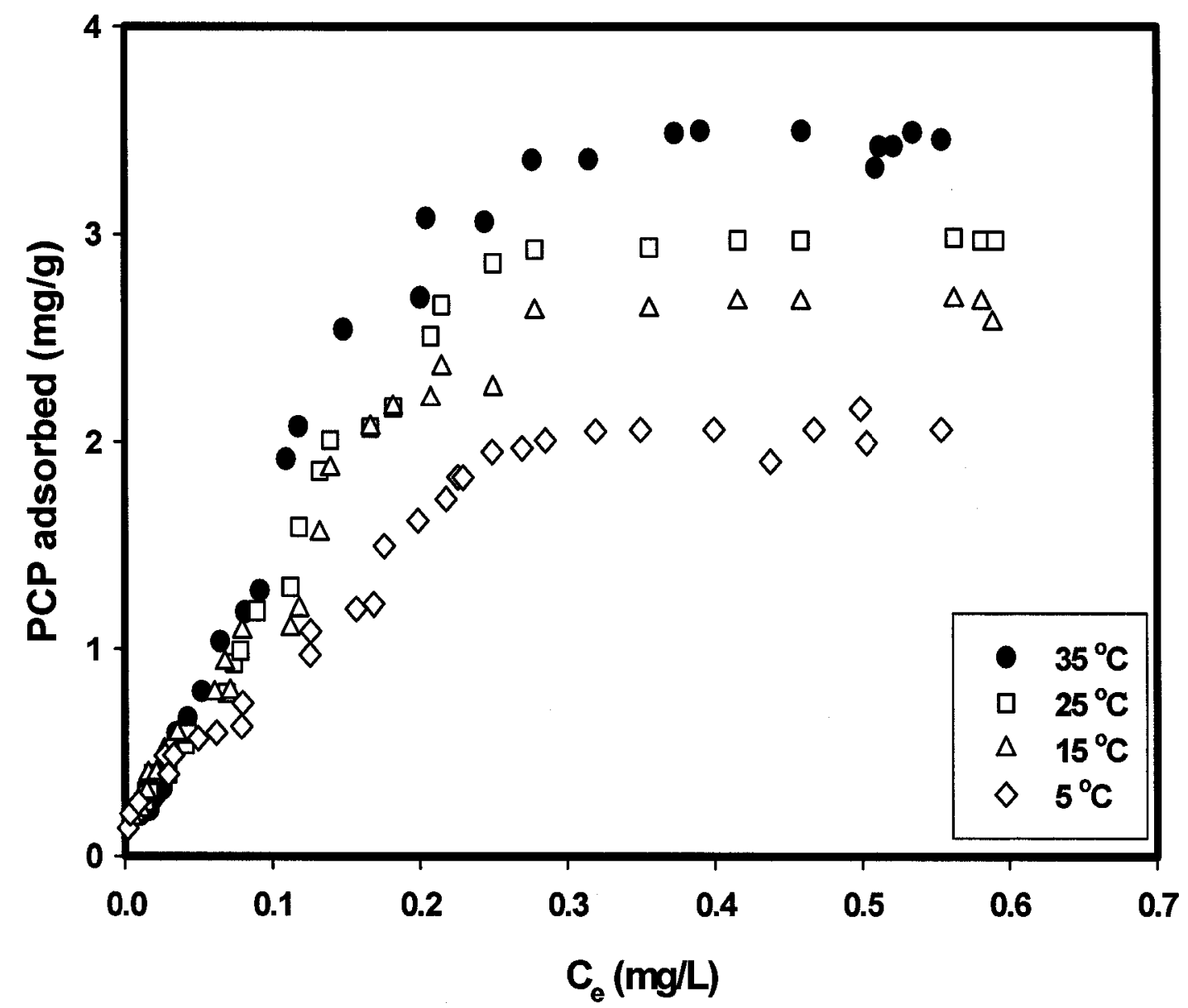

Figure 4.2. Adsorption isotherms for $\mathrm{PCP}$ on MWCNTs oxidized with $\mathrm{H}_{2} \mathrm{O}_{2}$ at different temperatures. 


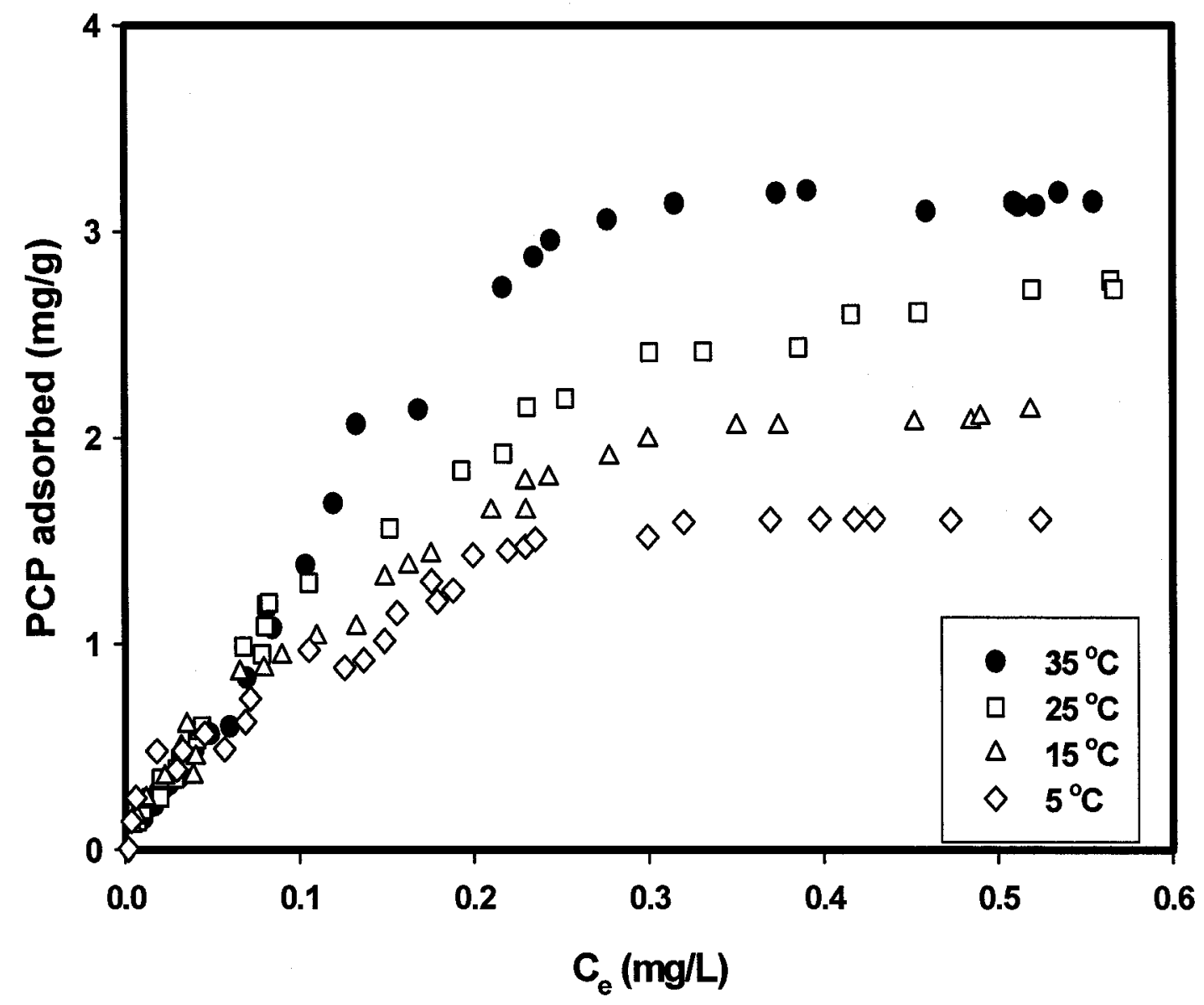

Figure 4.3. Adsorption isotherms for $\mathrm{PCP}$ on MWCNTs oxidized with $\mathrm{HNO}_{3}$ at different temperatures. 

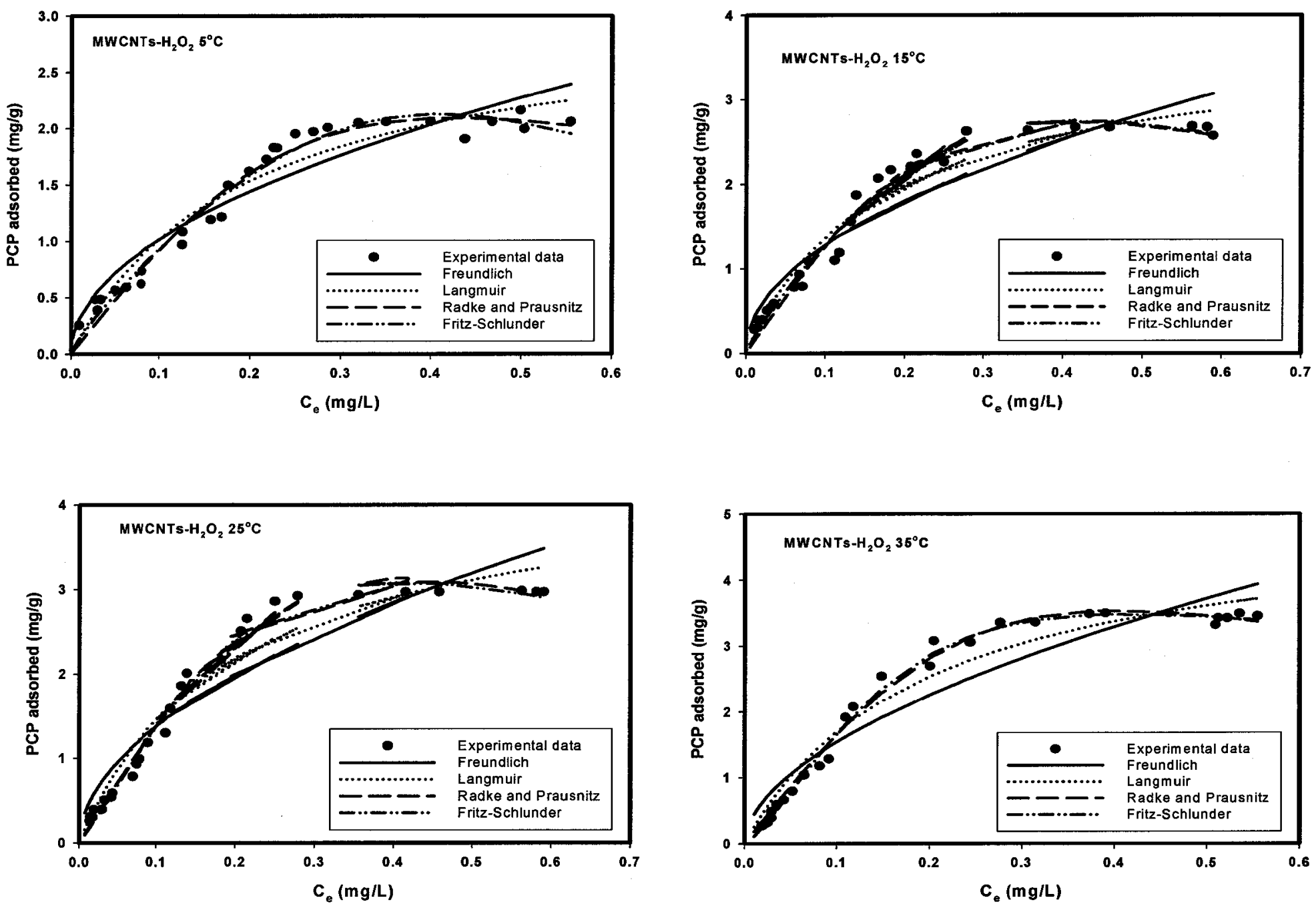

Figure 4.4. Comparison of different isotherm models for $\mathrm{PCP}$ adsorption on MWCNTs oxidized by $\mathrm{H}_{2} \mathrm{O}_{2}$ with experimental results. 

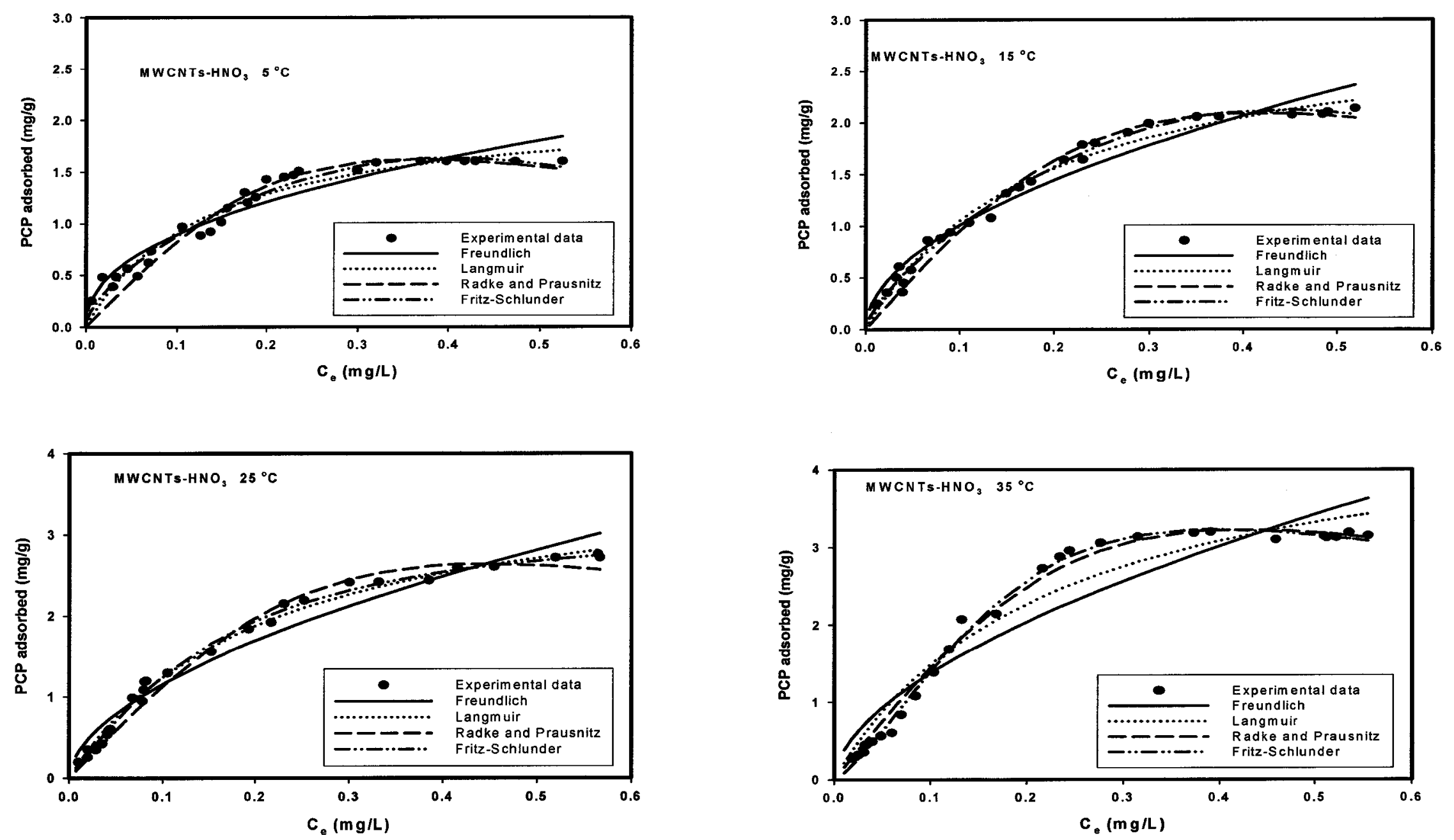

Figure 4.5. Comparison of different isotherm models for PCP adsorption on MWCNTs oxidized by $\mathrm{HNO}_{3}$ with experimental results. 
Table 4.1. Results of PCP adsorption isotherm analysis using pristine and oxidized MWCNTs at different temperatures.

\begin{tabular}{|c|c|c|c|c|c|c|c|c|c|c|c|c|c|c|c|c|}
\hline \multirow{2}{*}{\multicolumn{2}{|c|}{ Temperature adsorbent }} & \multicolumn{3}{|c|}{$\begin{array}{l}\text { Freundlich } \\
\mathbf{q e}=K_{\mathrm{f}} \mathrm{C}_{\mathrm{e}}{ }^{1 / \mathrm{n}}\end{array}$} & \multicolumn{3}{|c|}{$\begin{array}{l}\text { Langmuir } \\
q_{e}=q_{m} K_{L} C_{e} /\left(1+K_{L} C_{e}\right)\end{array}$} & \multicolumn{4}{|c|}{$\begin{array}{l}\text { Radke and Prausnitz } \\
1 / \mathbf{q}_{\mathrm{e}}=1 / \mathrm{KC}_{\mathrm{e}}+1 / \mathrm{kC}_{\mathrm{e}}{ }^{1 / \mathrm{b}}\end{array}$} & \multicolumn{5}{|c|}{$\begin{array}{r}\text { Fritz-Schlunder } \\
q_{e}=\alpha_{1} C_{e}^{\beta 1} /\left(1+\alpha_{2} C_{e}^{\beta 2}\right)\end{array}$} \\
\hline & & $\mathbf{K}_{\mathbf{f}}$ & $1 / n$ & $\mathbf{R}^{2}$ & $\mathbf{q}_{\mathbf{m}}$ & $\mathbf{K}_{\mathbf{L}}$ & $\mathbf{R}^{2}$ & $\mathbf{K}$ & $\mathbf{k}$ & $1 / b$ & $\mathbf{R}^{2}$ & $\alpha_{1}$ & $\boldsymbol{\alpha}_{2}$ & $\beta 1$ & $\beta 2$ & $\mathbf{R}^{2}$ \\
\hline \multirow[t]{3}{*}{$35^{\circ} \mathrm{C}$} & MWCNTs & 16.9 & 0.57 & 0.885 & 5.07 & 32.9 & 0.943 & 2.56 & 93.5 & 1.29 & 0.968 & 1007 & 631 & 1.44 & 1.77 & 0.983 \\
\hline & $\mathbf{H}_{2} \mathbf{O}_{2}$ & 5.44 & 0.55 & 0.912 & 5.04 & 5.06 & 0.966 & 0.35 & 3.08 & 0.18 & 0.992 & 36.8 & 1.27 & $7 \quad 11.9$ & 1.79 & 0.990 \\
\hline & $\mathrm{HNO}_{3}$ & 5.07 & 0.57 & 0.908 & 4.81 & 4.46 & 0.960 & 0.36 & 10.3 & 0.67 & 0.991 & 28.0 & 1.26 & $\begin{array}{ll}5 & 10.8\end{array}$ & 2.00 & 0.995 \\
\hline \multirow[t]{3}{*}{$25^{\circ} \mathrm{C}$} & MWCNTs & 26.2 & 0.56 & 0.814 & 8.18 & 33.4 & 0.893 & 1.64 & 105.3 & 1.92 & 0.956 & 5.36 & 0.01 & -0.03 & -1.99 & 0.973 \\
\hline & $\mathbf{H}_{2} \mathbf{O}_{2}$ & 4.58 & 0.52 & 0.902 & 4.35 & 5.06 & 0.961 & 0.38 & 10.4 & 0.72 & 0.990 & 16.8 & 1.06 & 6.60 & 2.00 & 0.991 \\
\hline & $\mathrm{HNO}_{3}$ & 4.13 & 0.55 & 0.964 & 3.86 & 4.75 & 0.993 & 0.42 & 4.0 & 0.33 & 0.983 & 21.4 & $4 \quad 1.09$ & 6.31 & 1.20 & 0.995 \\
\hline \multirow[t]{3}{*}{$15^{\circ} \mathrm{C}$} & MWCNTs & 46.3 & 0.77 & 0.844 & 11.6 & 13.1 & 0.879 & 1.42 & 64.3 & 2.06 & 0.914 & 12.3 & 0.01 & 0.25 & -1.99 & 0.957 \\
\hline & $\mathbf{H}_{2} \mathbf{O}_{2}$ & 3.98 & 0.49 & 0.912 & 3.69 & 5.89 & 0.963 & 0.44 & 9.59 & 0.72 & 0.980 & 9.36 & 0.85 & 4.14 & 2.18 & 0.983 \\
\hline & $\mathrm{HNO}_{3}$ & 3.32 & 0.52 & 0.961 & 3.00 & 5.41 & 0.985 & 0.575 & 3.96 & 0.39 & 0.980 & 5.01 & 0.70 & 3.47 & 2.87 & 0.993 \\
\hline \multirow[t]{3}{*}{$5^{\circ} \mathrm{C}$} & MWCNTs & 52.0 & 0.68 & 0.943 & 19.9 & 11.1 & 0.952 & 1.17 & 138.5 & 1.56 & 0.967 & 1.38 & 0.002 & -0.71 & -1.98 & 0.987 \\
\hline & $\mathbf{H}_{2} \mathbf{O}_{2}$ & 3.21 & 0.50 & 0.918 & 3.05 & 5.07 & 0.952 & 0.56 & 7.90 & 0.81 & 0.970 & 6.31 & 0.83 & 5.21 & 2.82 & 0.978 \\
\hline & $\mathrm{HNO}_{3}$ & 2.45 & 0.44 & 0.941 & 2.15 & 7.47 & 0.961 & 0.84 & 3.53 & 0.40 & 0.953 & 3.62 & 0.61 & 3.80 & 2.92 & 0.978 \\
\hline
\end{tabular}


This was expected due to the introduction of the oxygen containing functional groups on the surface of the MWCNTs upon oxidation using either $\mathrm{H}_{2} \mathrm{O}_{2}$ or $\mathrm{HNO}_{3}$ as the oxidizing agent. Comparing the adsorption capacity at different temperatures using the same isotherm model reveals the following:

- For the MWCNTs oxidized with $\mathrm{H}_{2} \mathrm{O}_{2}$ and using Freundlich model fitting data, the adsorption capacity, $\mathrm{K}_{\mathrm{f}}$, decreased gradually from 5.44 , to $4.58,3.98,3.21$ by decreasing the temperature from $35^{\circ} \mathrm{C}$, to $25^{\circ} \mathrm{C}, 15^{\circ} \mathrm{C}$, and $5^{\circ} \mathrm{C}$, respectively. The same effect was found when the Langmuir model was adopted, the adsorption capacity, $\mathrm{K}_{\mathrm{f}}$, decreased gradually from 5.04 , to $4.35,3.69,3.05$ by decreasing the temperature from $35^{\circ} \mathrm{C}$, to 25 ${ }^{\circ} \mathrm{C}, 15^{\circ} \mathrm{C}$, and $5{ }^{\circ} \mathrm{C}$, respectively.

- For the MWCNTs oxidized with $\mathrm{HNO}_{3}$ and using Freundlich model fitting data, the adsorption capacity, $\mathrm{K}_{\mathrm{f}}$, decreased gradually from 5.07 , to $4.13,3.32,2.45$ by decreasing the temperature from $35^{\circ} \mathrm{C}$, to $25^{\circ} \mathrm{C}, 15^{\circ} \mathrm{C}$, and $5^{\circ} \mathrm{C}$, respectively. The same effect was found when the Langmuir model was adopted, the adsorption capacity, $\mathrm{K}_{\mathrm{f}}$, decreased gradually from 4.81 , to $3.86,3.00,2.15$ by decreasing the temperature from $35^{\circ} \mathrm{C}$, to 25 ${ }^{\circ} \mathrm{C}, 15^{\circ} \mathrm{C}$, and $5^{\circ} \mathrm{C}$, respectively.

The reasons for inhibition of the PCP adsorption on the oxidized MWCNTs with decreasing the temperatures will be discussed in the following section.

However, the low values of $\mathrm{R}^{2}$, compared with the other two isotherm models, may be due to limitations of Freundlich and Langmuir models, as was explained in the previous chapter, Chapter 3. 
Both Radke-Prausnitz and Fritz-Schlünder models were in a good agreement with the experimental data; good $\mathrm{R}^{2}$ values, as they often used to represent solute adsorption data on heterogeneous surfaces such as MWCNTs and AC. However, the change in the values of their fitting parameters was not significant and it was not clear to withdraw any conclusions.

\subsubsection{Temperature studies and evaluation of the thermodynamic data}

The effect of temperature on the adsorption of PCP on the oxidized MWCNTs, was studied at four different temperatures; $5^{\circ} \mathrm{C}, 15^{\circ} \mathrm{C}, 25^{\circ} \mathrm{C}$ and $35^{\circ} \mathrm{C}$ and the data are shown in Figure 4.2 and Figure 4.3. It is clear from both Figures that the adsorption onto the oxidized MWCNTs was decreased markedly by decreasing the temperature from $35^{\circ} \mathrm{C}$ to $5^{\circ} \mathrm{C}$, indicating that adsorption of PCP on MWCNTs is an endothermic process. This observation was different from the pristine MWCNTs, which was exothermic. In order to verify this finding, the thermodynamic parameters were calculated. The thermodynamic parameters; the standard free energy change, $\Delta \mathrm{G}^{\circ}$, the standard enthalpy change, $\Delta \mathrm{H}^{\circ}$, and the change in the entropy, $\Delta \mathrm{S}^{\circ}$, were calculated from the variation of the thermodynamic equilibrium constant $\mathrm{K}_{0}$ with a change in temperature using the equations presented in Chapter 3. Table 4.2 summarizes the variation of the thermodynamic parameters for the adsorption of PCP on the pristine and oxidized MWCNTs. In general, for the oxidized MWCNTs the adsorption equilibrium constant, $\mathrm{K}_{0}$, decreases as the temperature decreases. The standard free energy change, $\Delta \mathrm{G}^{\circ}$, is negative for both oxidized MWCNTs, as would be expected for a product favored reaction, and become more negative as the temperature was increased. Figure 4.6 shows 
Table 4.2. Values of thermodynamic parameters for the adsorption of PCP on pristine and oxidized MWCNTs.

\begin{tabular}{|c|c|c|c|c|c|}
\hline & & $\operatorname{Ln} K_{\mathbf{0}}$ & $\Delta G^{0}(\mathbf{k J} / \mathbf{m o l})$ & $\Delta \mathbf{H}^{0}(\mathbf{k J} / \mathbf{m o l})$ & $\Delta \mathbf{S}^{\mathbf{0}}$ (J/K.mol) \\
\hline \multirow[t]{3}{*}{$35^{\circ} \mathrm{C}$} & Pristine MWCNTs & $13.2 \pm 1$ & $-33.9 \pm 0.4$ & $-23.7 \pm 6$ & $33.1 \pm 2$ \\
\hline & MWCNTs- $\mathrm{H}_{2} \mathrm{O}_{2}$ & $12.2 \pm 0.3$ & $-31.2 \pm 0.1$ & $+10.8 \pm 1$ & $136 \pm 2$ \\
\hline & MWCNTs- $\mathrm{HNO}_{3}$ & $12.5 \pm 0.6$ & $-32.0 \pm 0.2$ & $+16.4 \pm 0.9$ & $157 \pm 3$ \\
\hline \multirow[t]{3}{*}{$25^{\circ} \mathrm{C}$} & Pristine MWCNTs & $13.6 \pm 2$ & $-33.7 \pm 2$ & $-23.7 \pm 6$ & $33.5 \pm 2$ \\
\hline & MWCNTs- $\mathrm{H}_{2} \mathrm{O}_{2}$ & $12.0 \pm 0.5$ & $-29.8 \pm 0.1$ & $+10.8 \pm 1$ & $137 \pm 1$ \\
\hline & MWCNTs- $\mathrm{HNO}_{3}$ & $12.2 \pm 0.1$ & $-30.3 \pm 0.1$ & $+16.4 \pm 0.9$ & $157 \pm 1$ \\
\hline \multirow[t]{3}{*}{$15^{\circ} \mathrm{C}$} & Pristine MWCNTs & $13.8 \pm 1$ & $-33.1 \pm 0.3$ & $-23.7 \pm 6$ & $32.6 \pm 2$ \\
\hline & MWCNTs- $\mathrm{H}_{2} \mathrm{O}_{2}$ & $11.9 \pm 0.1$ & $-28.5 \pm 0.1$ & $+10.8 \pm 1$ & $137 \pm 3$ \\
\hline & MWCNTs- $\mathrm{HNO}_{3}$ & $12.0 \pm 0.2$ & $-28.8 \pm 0.2$ & $+16.4 \pm 0.9$ & $156 \pm 0.2$ \\
\hline \multirow[t]{3}{*}{$5^{\circ} \mathrm{C}$} & Pristine MWCNTs & $14.3 \pm 1$ & $-32.9 \pm 0.2$ & $-23.7 \pm 6$ & $33.4 \pm 10$ \\
\hline & MWCNTs- $\mathrm{H}_{2} \mathrm{O}_{2}$ & $11.7 \pm 0.2$ & $-27.1 \pm 0.1$ & $+10.8 \pm 1$ & $136 \pm 6$ \\
\hline & MWCNTs- $\mathrm{HNO}_{3}$ & $11.8 \pm 0.1$ & $-27.3 \pm 0.3$ & $+16.4 \pm 0.9$ & $157 \pm 2$ \\
\hline
\end{tabular}




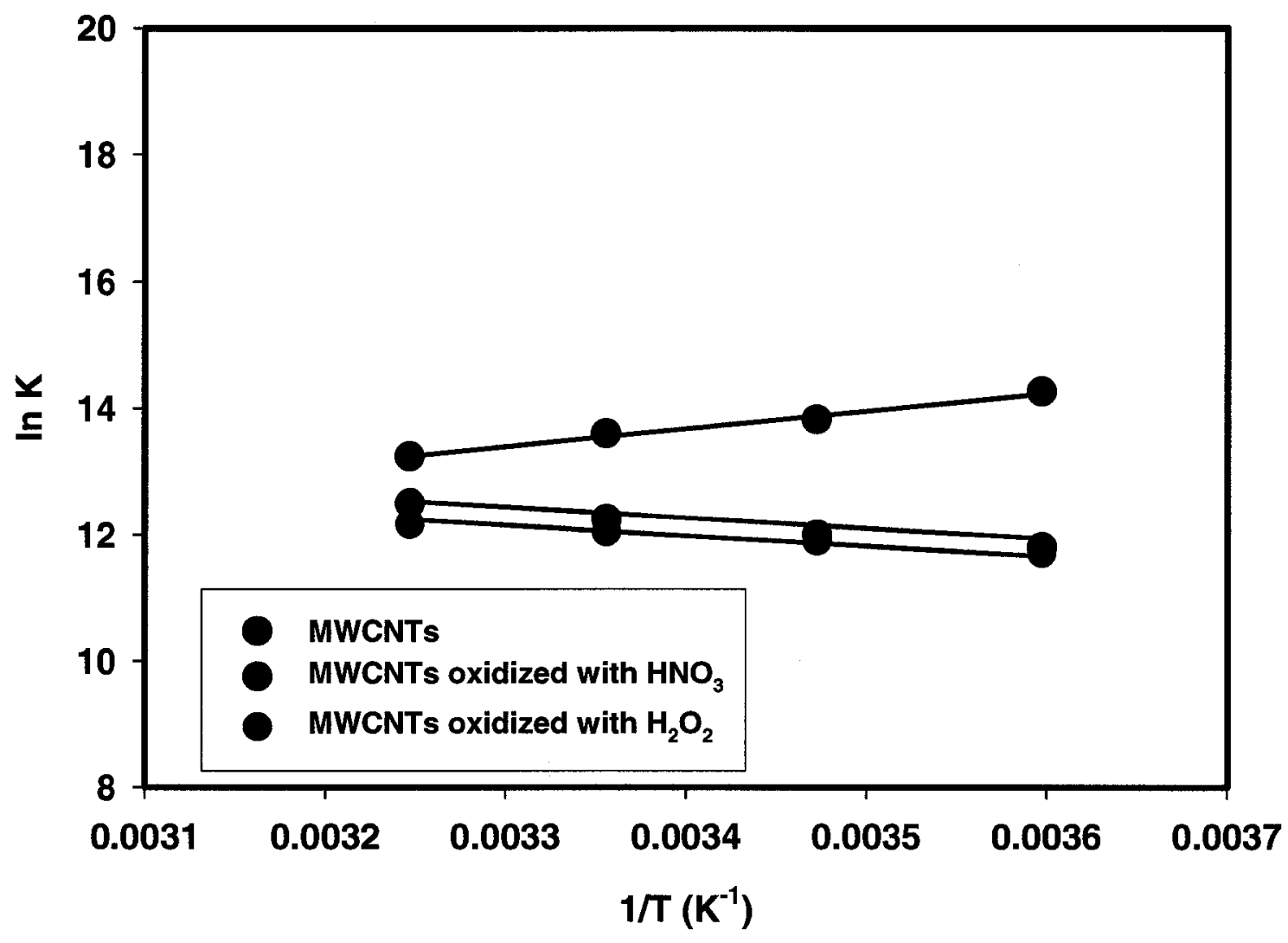

Figure 4.6. Temperature dependency plots for the adsorption of PCP on pristine and oxidized MWCNTs. 
the Van't Hoff plot for the adsorption of PCP onto the pristine and the oxidized MWCNTs. It is clear from Figure 4.6 and Table 4.2 that the positive value of $\Delta \mathrm{H}^{\circ}$ suggests that the PCP-MWCNTs interaction is endothermic, which was the reason for the decrease in adsorption at lower temperature. The magnitude of $\Delta \mathrm{H}^{\circ}$ suggests a weak type of bonding between the PCP and the MWCNTs. The decrease in $\Delta \mathrm{G}^{\circ}$ (become less negative) with decreasing the temperature is consistent with the endothermic process. In the case of the adsorption of PCP on the oxidized MWCNTs, the change in entropy was found to be positive. The positive entropy value may suggest an-entropy driven process, especially with the endothermic reaction (+ve $\Delta \mathrm{H}^{\circ}$ ) and spontaneous adsorption (-ve $\Delta \mathrm{G}^{\circ}$ ) due to the hydrophobic bonding between PCP and the oxidized MWCNTs surface [28]. The positive entropy, generally, comes from the loss of structured water surrounding the PCP molecules.

\subsubsection{Kinetics study of the adsorption of PCP on pristine and oxidized MWCNTs}

The kinetics of PCP adsorption in aqueous solution on pristine or oxidized MWCNTs were studied and the results are presented in Figure 4.7. Within the first 5 minutes $88 \%$ of the PCP was adsorbed by the pristine MWCNTs whereas $88.9 \%, 87.1 \%$ and $75.0 \%$ by the oxidized MWCNTs; $\mathrm{H}_{2} \mathrm{O}_{2}, \mathrm{HNO}_{3}$, and $\mathrm{KMnO}_{4}$, respectively. The adsorption capacity reached $1.76 \mathrm{mg} / \mathrm{g}$ for the pristine MWCNTs and $1.78,1.74$, and $1.50 \mathrm{mg} / \mathrm{g}$ for the MWCNTs oxidized with $\mathrm{H}_{2} \mathrm{O}_{2}, \mathrm{HNO}_{3}$ and $\mathrm{KMnO}_{4}$, respectively. The adsorption of PCP by pristine MWCNTs and the oxidized MWCNTs $\left(\mathrm{HNO}_{3}, \mathrm{H}_{2} \mathrm{O}_{2}\right)$ achieved equilibrium gradually at about 60 minutes and the final adsorption capacity reached $1.92 \mathrm{mg} / \mathrm{g}, 1.88$ $\mathrm{mg} / \mathrm{g}$ and $1.89 \mathrm{mg} / \mathrm{g}$, respectively. For the other oxidized MWCNTs it took 120 minutes 
to reach the equilibrium concentration of $1.69 \mathrm{mg} / \mathrm{g}$ and for oxidized $\mathrm{MWCNTs}^{\mathrm{KMnO}} \mathrm{H}_{4}$. Comparing the kinetics results of the \% PCP adsorbed by the oxidized MWCNTs with the SPE application (Figure 4.1) showed that the oxidized MWCNTs adsorbed less if they are packed inside the SPE cartridge. The explanation for that may be attributed to the fact that the diffusion of the PCP molecules during the kinetics experiment was fast due to the shaking of the solution during the experiment. This shaking enhanced the transfer of the PCP from the liquid phase to the solid phase as well as exposed most of the MWCNTs to the PCP molecules.

Analysis of the kinetics of PCP adsorption to the pristine and the oxidized MWCNTs was performed using the proposed kinetic model discussed in Chapter 3.

The kinetic adsorption curves of PCP may suggest that adsorption onto the surface occurs quickly, followed by a slower diffusion step. The short time needed to reach equilibrium also suggests that both the pristine and oxidized MWCNTs, excluding the tubes oxidized with $\mathrm{KMnO}_{4}$, are superior adsorbents to remove PCP from aqueous solution. The experimental data were analyzed for discrete values of the adsorption rate constants by a non-linear regression. Figure 4.7 shows the relation between the $\%$ of PCP adsorbed from the aqueous solution to the adsorbent and time for pristine and oxidized MWCNTs. The data were fitted using the one component model and the values for kinetic parameters of the PCP adsorption are presented in Table 4.3. From this table, it is clear that applying the one component kinetic model for the adsorption of PCP to MWCNTs, were converges well and the value of the $\mathrm{R}^{2}$ was acceptable (more than 0.95 ), whereas in the case of the CNTs oxidized with $\mathrm{KMnO}_{4}$, the $\mathrm{R}^{2}$ was not acceptable with a value of 0.75 . 


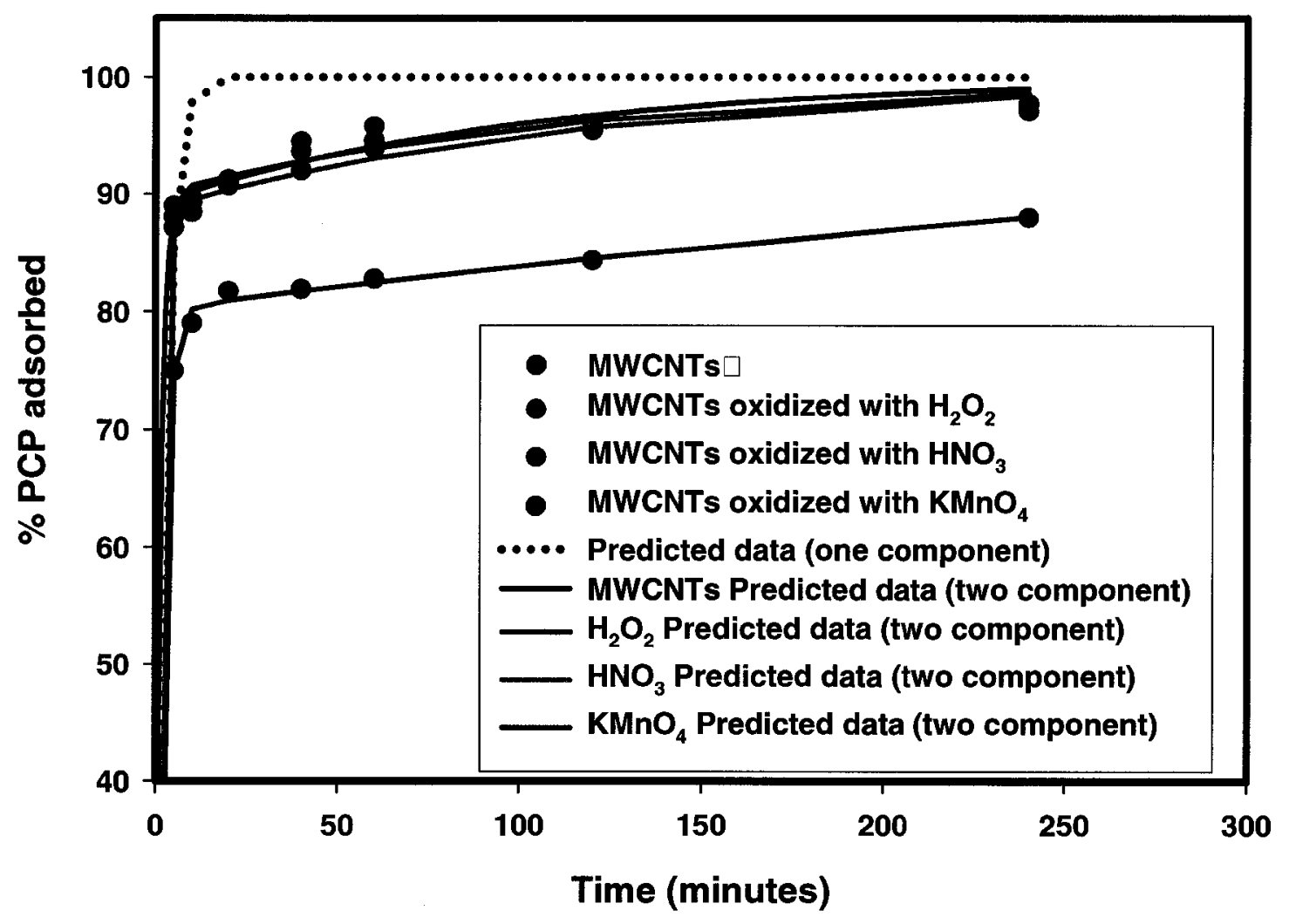

Figure 4.7. The kinetic model for the adsorption of PCP to pristine and oxidized MWCNTs and the comparison between the experimental data and the predicted data (one component, two component). 
This may be due to the fact that $\mathrm{KMnO}_{4}$ was a harsh oxidizing agent which destroyed the crystalline structure of the MWCNTs and led to the formation of amorphous carbon. This was discussed in Chapter 2. So, from now on, the discussion will exclude the MWCNTs oxidized with $\mathrm{KMnO}_{4}$. Comparing the one component predicted data (dotted line) with the experimental data of the PCP adsorption to the pristine and the oxidized tubes shows significant differences. Again, the fitted data did not match the experimental data at all.This may imply that the adsorption of PCP mainly in more than one step. The two component kinetic model was used to fit the experimental data and the results are presented in Table 4.3 and Figure 4.7. It was obvious from the graph and the table that the two component kinetic model fits much better than the one component kinetic model as the predicted data fitted well with the experimental data with very good correlation coefficients $\left(\mathrm{R}^{2}=0.998\right.$ and 0.999$)$. In general, the \% PCP adsorbed during the first step $\left(\% \mathrm{C}_{1}\right)$ was significantly higher than the second step $\left(\left(\% \mathrm{C}_{2}\right)\right.$ in the case of pristine MWCNTs; $89.2 \%$, and the oxidized MWCNTs; $90.0 \%$ and $88.7 \%$, for the MWCNTs oxidized with $\mathrm{H}_{2} \mathrm{O}_{2}$ and $\mathrm{HNO}_{3}$, respectively. The differences between the first rate constant for the pristine and the oxidized MWCNTs was not significant. The first component may be attributed to the fast diffusion of the PCP from the aqueous phase to the surface of the MWCNTs.

The fact that the difference between the pristine and the oxidized MWCNTs for the first component was not significant may indicate that the oxidation of the MWCNTs with $\mathrm{H}_{2} \mathrm{O}_{2}$ and $\mathrm{HNO}_{3}$ was successful. This oxidation increases the hydrophilic character of the 
Table 4.3. Kinetic parameters of the adsorption of PCP to pristine and oxidized MWCNTs using different kinetic models (one component, two component).

\section{Kinetic Parameters}

$$
\% \mathrm{C}_{1} \quad \mathrm{k}_{1} \times 10^{-1}\left(\mathrm{~min}^{-1}\right) \quad \% \mathrm{C}_{2} \quad \mathrm{k}_{2} \times 10^{-3}\left(\mathrm{~min}^{-1}\right) \quad \mathrm{R}^{2}
$$

\section{One component model}

\begin{tabular}{cccccc} 
MWCNTs & $100.0 \pm 2.7$ & $3.84 \pm 0.9$ & 0.967 \\
$\mathbf{H}_{2} \mathbf{O}_{2}$ & $100.0 \pm 2.7$ & $4.02 \pm 1.0$ & 0.969 \\
$\mathbf{H N O}_{3}$ & $100.0 \pm 3.0$ & $3.67 \pm 1.0$ & 0.960 \\
$\mathbf{K M n O}_{4}$ & $100.0 \pm 7.1$ & $2.15 \pm 0.8$ & 0.753 \\
\hline \multicolumn{5}{c}{ Two component model } \\
MWCNTs & $89.2 \pm 1.7$ & $7.85 \pm 2.4$ & $10.8 \pm 2.6$ & $9.9 \pm 7.5$ & 0.998 \\
$\mathbf{H}_{\mathbf{2}} \mathbf{O}_{2}$ & $90.0 \pm 1.3$ & $8.30 \pm 2.4$ & $10.0 \pm 2.8$ & $8.4 \pm 6.4$ & 0.999 \\
$\mathbf{H N O}_{3}$ & $88.7 \pm 0.9$ & $7.53 \pm 1.2$ & $11.4 \pm 1.9$ & $8.2 \pm 4.0$ & 0.999 \\
$\mathbf{K M n O}_{4}$ & $80.1 \pm 0.7$ & $5.34 \pm 0.4$ & $19.9 \pm 2.8$ & $2.1 \pm 3.9$ & 0.999 \\
\hline
\end{tabular}


MWCNTs through the introduction of carboxylic and phenolic groups on the surface of the tubes without destroying the tube like what happened in the case of $\mathrm{KMnO}_{4}$. Analysis of the second component shows that nearly $10 \%$ of the PCP was adsorbed on the pristine and the oxidized MWCNTs. This step may be attributed to another diffusion step such as intra-particle diffusion.

The intra-particle diffusion model that was proposed by Weber-Morris (equation 3.12 Chapter 3) was performed to explore the applicability of the model to the oxidized MWCNTs and the results were plotted in Figure 4.8. It is clear from the graph that the adsorption of PCP to the pristine and the oxidized MWCNTs two different straight lines. This may indicate that the adsorption of PCP to MWCNTs, both pristine and oxidized MWCNTs, is controlled by two steps. The first part of the straight line may be due to the adsorption to the surface of the MWCNTs due to the fast diffusion from the aqueous phase to the solid phase of the MWCNTs, whereas the second part could be due to the intra-particle diffusion. The slope of the $q_{t}$ versus $t^{1 / 2}$ in the region where the intraparticle diffusion control the adsorption are defined as the $k_{i d}$ is the intra-particle diffusion rate constant $\left(\mathrm{mg} / \mathrm{g} \min ^{1 / 2}\right)$. The values for $k_{i d}$ and $C(\mathrm{mg} / \mathrm{g}$ ) (a constant proportional to the thickness of the boundary layer) are tabulated in Table 4.4. It is clear from this table that diffusion constant value for the pristine MWCNTs is the lowest compared with the oxidized tubes, which may indicates the less dependcy of the pristine MWCNTs on the intra-particle diffusion. For the oxidized MWCNTs the difference between the $k_{i d}$ values was not significant between the MWCNTs oxidized with $\mathrm{HNO}_{3}$ 


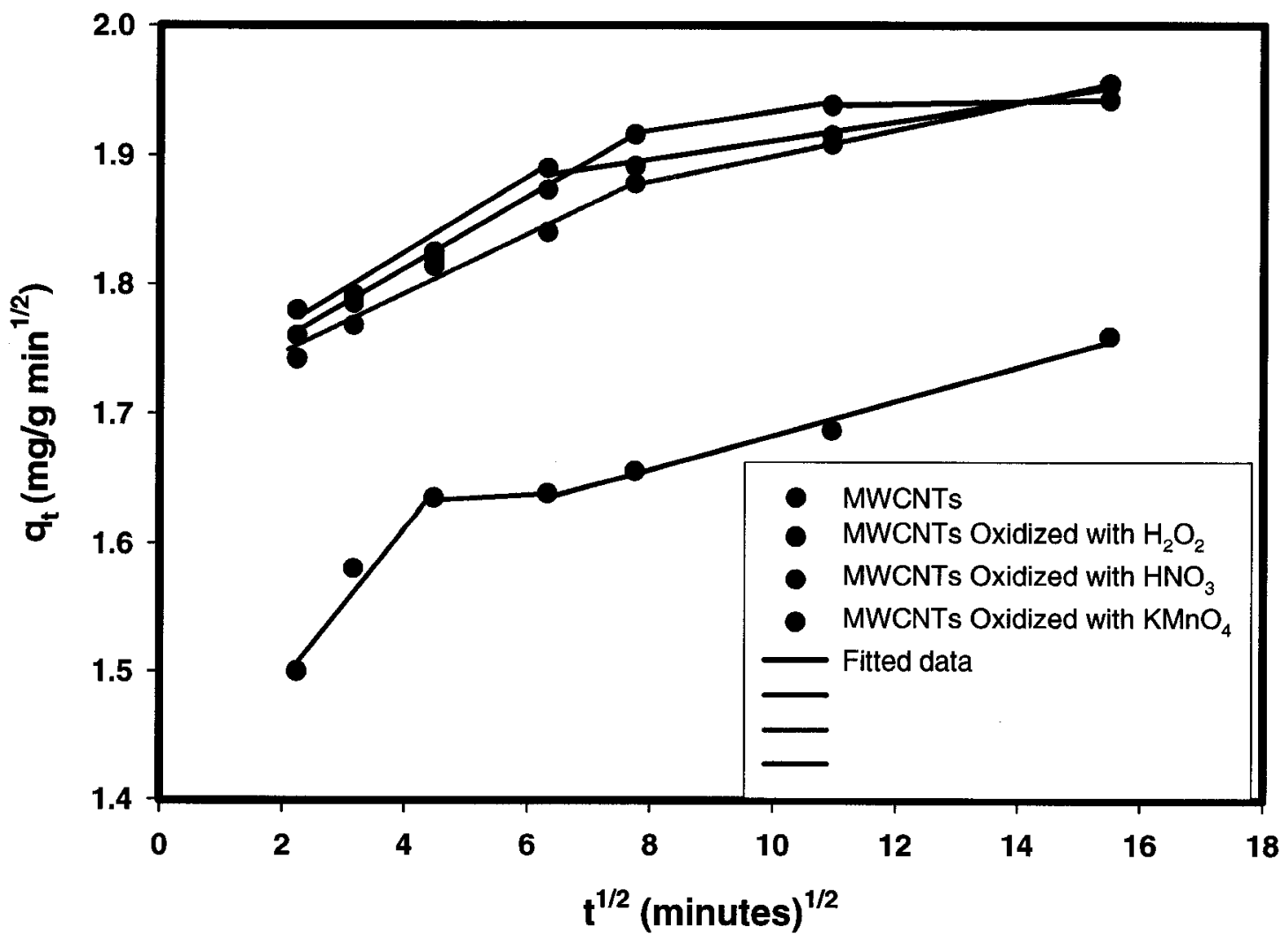

Figure 4.8. Weber-Morris intra-particle diffusion plots for the adsorption of PCP to pristine and oxidized MWCNTs. 
Table 4.4. Intra-particle diffusion parameters for the adsorption of PCP to pristine and oxidized MWCNTs.

\begin{tabular}{|c|c|c|c|}
\hline \multicolumn{4}{|c|}{ Intra-particle diffusion parameters } \\
\hline & $k_{i d}\left(\mathrm{mg} / \mathrm{g} \mathbf{m i n}^{1 / 2}\right)$ & $C(\mathrm{mg} / \mathrm{g})$ & $\mathbf{R}^{2}$ \\
\hline MWCNTs & $(8.38 \pm 0.0) \times 10^{-4}$ & $1.93 \pm 0.00$ & 1.000 \\
\hline $\mathbf{H}_{2} \mathbf{O}_{2}$ & $(7.21 \pm 0.8) \times 10^{-3}$ & $1.84 \pm 0.01$ & 0.979 \\
\hline $\mathrm{HNO}_{3}$ & $(9.90 \pm 0.1) \times 10^{-3}$ & $1.80 \pm 0.00$ & 0.999 \\
\hline $\mathrm{KMnO}_{4}$ & $(1.31 \pm 0.1) \times 10^{-2}$ & $1.55 \pm 0.00$ & 0.987 \\
\hline
\end{tabular}


and $\mathrm{H}_{2} \mathrm{O}_{2}$, whereas this value was the highest in the case of the tubes oxidized with $\mathrm{KMnO}_{4}$. There was not a clear explanation for this criterion.

\subsection{Conclusions}

Although the adsorption of PCP onto the oxidized MWCNTs was less than the pristine MWCNTs, but they can considered to be a good adsorbents for the removal of PCP from aqueous solutions. The kinetics study showed that the transfer of PCP to the surface of the oxidized MWCNTs is very fast due to the diffusion of PCP from the liquid phase to the solid phase, which followed by a second slower step of adsorption due to intraparticle diffusion. The equilibrium adsorption of PCP on the oxidized MWCNTs at various temperatures was studied and the adsorption equilibrium is well described using different adsorption models. The thermodynamic parameters showed that the adsorption process is product favored, and becomes more so at higher temperature, since the adsorption is endothermic. The magnitude of the enthalpy suggests a weak type of bonding between the PCP and the MWCNTs. The entropy values were positive, implying that the PCP is more ordered on the aqueous phase than at the oxidized MWCNTs surface mainly due to loss of structured water surrounding the PCP molecules. 


\subsection{References}

[1] Jianlong W, Yi Q, Horan N, Stentiford E, Bioresources Technology. 2000, 75, 157.

[2] Yamada K, Akiba Y, Shibuya T, Kashiwada A, Matsuda K, Hirata M, Biotechnology Progress 2005, 21, 823.

[3] Zheng S, Yang Z, Jo D H, Park Y H, Water Research 2004, 38, 2315.

[4] Denizli A, Cihangir N, Tüzmen N, Alsancak G, Bioresource Technology 2005, 96, 59.

[5] Lee J W, Shim W G, Ko J Y, Moon H, Separation Science and Technology 2004, 39, 2041.

[6] Gupta V K, Ali I, Saini V K, Environmental Science and Technology 2004, 38,4012 .

[7] Denizli, A, Ozkan G, Ucar M, Separation and Purification Technology 2001, 24, 255.

[8] Kao P C, Tzeng J H, Huang T L, Journal of Hazardous Materials 2000, 6, 237.

[9] Tutem E, Apak R, Unal C F, Water Research 1998, 32, 2315.

[10] Danis T G, Albanis T A, Petrakis D E, Pomonis P J, Water Research 1998, 32, 295.

[11] Danis T G, Albanis T A, Toxicological and Environmental Chemistry 1997, 62,65 . 
[12] Torres L G, Albiter V, Jimenez B, In Situ and On-Site Bioremediation, Papers from the International In Situ and On-Site Bioremediation Symposium, 4th, New Orleans, Apr. 28-May 1, 1997, 2, 447.

[13] Lee K C, Ku Y, Separation Science and Technology 1996, 31, 2557.

[14] Gryglewicz G, Grabas K, Grabowska E L, Carbon 2002, 40, 2403.

[15] Slaney A J, Bhamidimarri R, Water Science and Technology 1998, 38, 227.

[16] Wilson G J, Khodadoust A P, Suidan M T, Brenner R C, Water Science and Technology 1997, 36, 107.

[17] Koran K M, Suidan M T, Khodadoust A P, Sorial G A, Brenner R C, Water Research 2001, 35, 2363.

[18] Edgehill R U, Lu G Q (Max), Journal of Chemical Technology and Biotechnology. 1998, 71, 27.

[19] Cai Y, Mou S, Lu Y, Journal of Chromatographia A. 2005, 1081, 245.

[20] Li Y, Ding J, Luan Z, Di Z, Zhu Y, Xu C, Wu D, Wei B. Carbon 2003, 41,2787.

[21] Li Y, Wang S, Luan Z, Ding J, Xu C, Wu D, Carbon 2003, 41,1057.

[22] Lu C, Chung, Y L, Chang K F, Water Research 2005, 39, 1183.

[23] Haghseresh F, Nouri S, Finnert J J, Lu G Q, Journal of Physical Chemistry, B 2002, 106, 10935.

[24] León C A, Radovic L R, In, P.A. Thrower (Ed.), Chemistry and Physics of Carbon 1994, vol. 24, Marcel Dekker, New York, p. 214.

[25] Couglin R W, Ezra F S, Environmental Science \& Technology.1968, 2, 291.

[27] Dąbrowski A, Podkościenly P, Hubicki Z, Barczak M, Chemosphere 2005, 58, 1049. 
[28] Peng X, Li Y, Luan Z, Di Z, Wang H, Tian B, Jia Z, Chemical Physics Letters $2003,376,154$.

[29] DiVincenzo J P, Sparks D L, Archives of Environmental Contamination \& Toxicology 2001, 40, 445. 


\title{
CHAPTER 5
}

\section{CHEMICAL MODIFICATION OF MULTI-WALLED}

\author{
CARBON NANOTUBES
}




\subsection{Introduction}

The unusual interest in carbon nanotubes (CNTs) resides in their possible technological applications in various fields of science. Recent reports on the chemical compatibility and dissolution properties of CNTs show a great deal of interest in developing modification or functionalization of their surfaces [1]. The modification procedure may be divided into two categories: non-covalent and covalent functionalizations. As examples of non-covalent functionalization, CNTs can be solubilized in water by "wrapping" them with polymers [2] such as poly (vinyl pyrrolidone) and poly (styrene sulfonate). Covalent functionalization has been studied using different functional groups [3-10]. Most modification are, generally, for the sake of tailoring the physical properties of the CNTs and the fabrication of nanotubes devices such as sensors and gas storage devices [8].

This chapter presents the chemical modification of MWCNTs via side wall carboxylic acid functionalization and further modification using ODA (octadecyl amine, $\mathrm{CH}_{3}$ $\left.\left(\mathrm{CH}_{2}\right)_{17}-\mathrm{NH}_{2}\right)$ and PEG (polyethylene glycol, $\left.\mathrm{HO}-\left(\mathrm{CH}_{2}-\mathrm{CH}_{2}-\mathrm{O}\right)_{n}-\mathrm{OH}\right)$, in order to produce novel absorbents to be used in solid phase extraction (SPE).

\subsection{Experimental}

\subsubsection{Reagents}

Thionyl chloride ( $\mathrm{SOCl}_{2}$ ), dimethylformamide (DMF), anhydrous tetrahydrofuran (THF), polyethyleneglycol (PEG, weight average molecular weight $M_{n} \sim 10,000 \mathrm{~g} / \mathrm{mol}, M_{n} / M_{w} \sim$ 1.1), octadecylamine (ODA, melting point, $55^{\circ} \mathrm{C}$ to $57{ }^{\circ} \mathrm{C}$ ), benzene, methanol, dichloromethane, and hexane were purchased from Sigma-Aldrich. 


\subsubsection{Procedures}

MWCNTs surface were chemically functionalized in different steps. The functionalization scheme of the MWCNTs and formation of MWCNTs-PEG (multiwalled carbon nanotubes with side wall functionalization with polyethylene glycol groups) and MWCNTs-ODA (multi-walled carbon nanotubes with side wall functionalization with octadecyl amine groups) are shown in scheme 1.

\subsubsection{Oxidation of MWCNTs}

MWCNTs with were purchased from Sun Nanotech (China) and were used as received. The MWCNTs $(10.0 \mathrm{~g})$ were added to $400 \mathrm{~mL}$ solutions of $8 \mathrm{M} \mathrm{HNO}_{3}$. The suspension was refluxed at $140^{\circ} \mathrm{C}$ for 4 hours, then washed with distilled water until the wash water was $\mathrm{pH}$ neutral and centrifugation $(3000 \mathrm{rpm})$ was used for solid liquid separation. The solid products were dried in air at $50^{\circ} \mathrm{C}$.

\subsubsection{Formation of carbonyl chloride groups on MWCNTs}

After oxidation of the MWCNTs with the nitric acid and the introduction of carboxylic groups (MWCNTs-COOH), the MWCNTs with carbonyl chloride groups (MWCNTs$\mathrm{COCl}$ ) were prepared as follows:

Oxidized MWCNTs (MWCNTs-COOH), $10 \mathrm{~g}$, were stirred in $200 \mathrm{ml}$ of $\mathrm{SOCl}_{2}$ (thionyl chloride) in the presence of $5 \mathrm{~mL}$ of dimethylformamide (DMF) at $70^{\circ} \mathrm{C}$ for 24 hours. After centrifugation of the reaction solution, the brown-black supernatant was decanted and the remaining solid was washed with anhydrous tetrahydrofuran (THF). After centrifugation, the pale yellow-colored solution was decanted and discarded. 


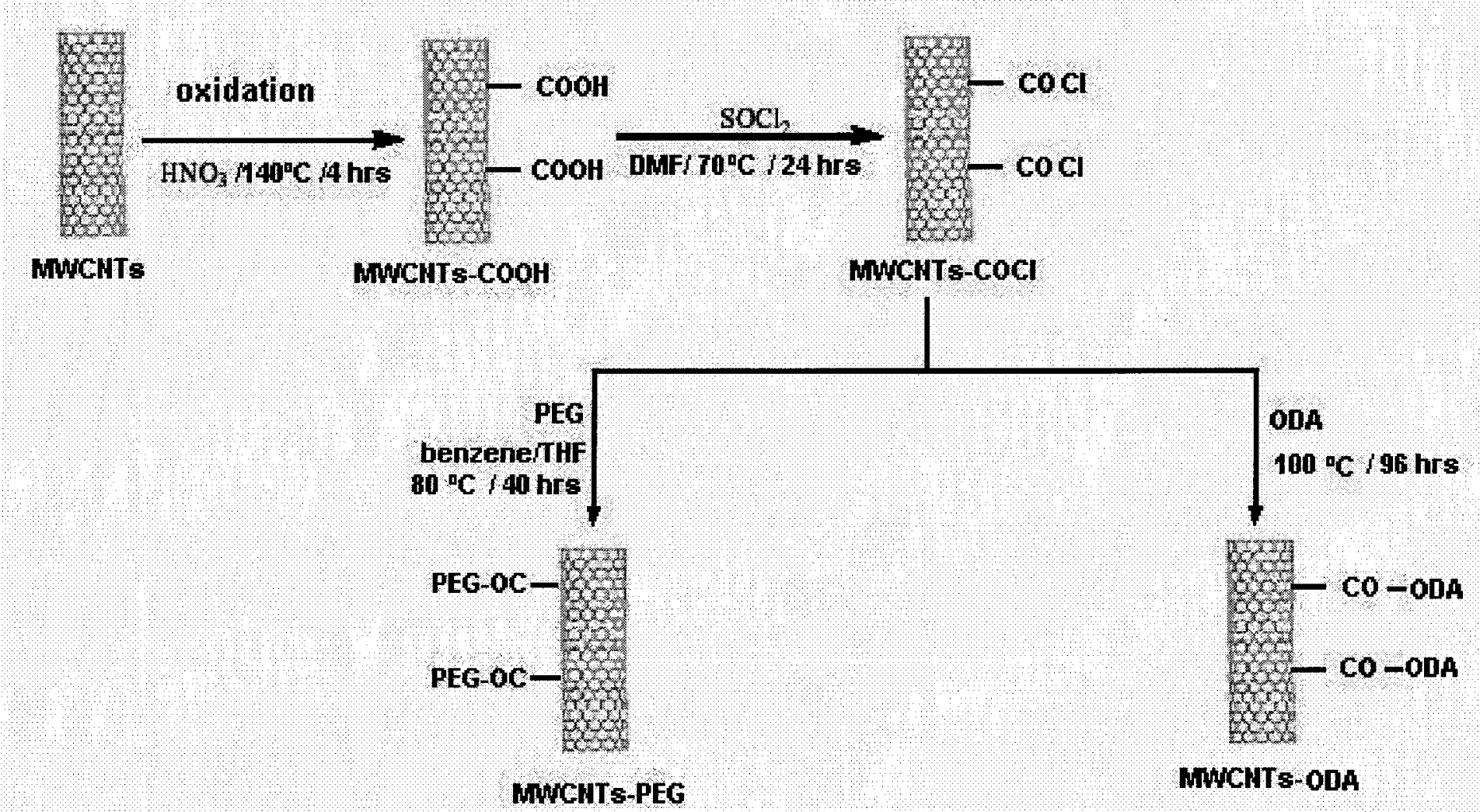

Scheme 1. Surface functionalization of MWCNTs surface and the formation of MWCNTs-PEG and MWCNTs-ODA. 
The remaining solid was dried at room temperature under vacuum.

\subsubsection{Formation of MWCNTs-PEG}

After MWCNTs-COCl had been prepared, the dried solid was reacted with polyethylene glycol (PEG) as follows:

MWCNTs-COCl, $5 \mathrm{~g}$, was mixed with $10 \mathrm{~g}$ of polyethylene glycol (PEG) in $100 \mathrm{ml}$ benzene/THF solvent mixture $(\mathrm{v} / \mathrm{v}=3 / 1)$ and stirred for 40 hours at $80^{\circ} \mathrm{C}$. After centrifugation, the black solid was washed with deionized water until the wash-water was clear. The remaining black solid was retained after drying at vacuum.

\subsubsection{Formation of MWCNTs-ODA}

MWCNTs-COCl, $5 \mathrm{~g}$, was mixed with $20 \mathrm{~g}$ of octadecylamine (ODA) at $100^{\circ} \mathrm{C}$ for 96 hours. After cooling to room temperature, the excess ODA was removed by washing with ethanol with sonication for 10 minutes. This washing process was repeated 8 times, until the ethanol was clear. The remaining black solid was dissolved in dichloromethane, and after centrifugation, the remaining black-colored solid was taken to dryness under vacuum.

\subsubsection{Characterization of the chemically modified MWCNTs}

Infrared spectral measurements of the functionalized MWCNTs were performed on an ABB Bomem MB Series FTIR spectrometer using KBr pellets. The thermogravimetric analysis (TGA) experiment was performed with a model 2200 thermal analyzer system (TA Instrument) under $\mathrm{N}_{2}$ flow at a heating rate of $10^{\circ} \mathrm{C} /$ minute. The functionalized 
MWCNTs were also suspended in various solvents including, water and methanol as examples of polar solvents, and dichloromethane and hexane as examples of non-polar solvent.

\subsection{Results and Discussion}

There are different methods to confirm the chemical functionalization the MWCNTs. In this chapter, thermal gravimetric analysis (TGA), IR measurements, solubility in various organic solvents, XRD (X-ray diffraction) and SEM (Scanning electron microscopy), were used for the characterization of the modified MWCNTs.

\subsubsection{Thermal gravimetric analysis (TGA)}

TGA was used to explore the degree of functionalization of the MWCNTs with PEG and ODA. TGA experiment was performed on MWCNTs-PEG and MWCNTs-ODA and the results were compared with those of both the pristine MWCNTs and PEG and ODA pure materials, as a function of temperature at a heating rate of $10{ }^{\circ} \mathrm{C} / \mathrm{min}$. As presented in Figure 5.1, the pristine MWCNTs weight decreased with increasing temperature, but this weight loss was insignificant (less than $2 \%$ ), compared with pure PEG and MWCNTsPEG. Pure PEG weight decreased sharply with increasing temperature and reached $98 \%$ weight loss near $400{ }^{\circ} \mathrm{C}$. On the other hand, MWCNTs-PEG was more stable within the temperature range and its weight loss reached $16 \%$ at $800^{\circ} \mathrm{C}$. This weight loss may be due to mostly the decomposition of the PEG chains.

Figure 5.2 shows the TGA plots of pristine MWCNTs, MWCNTs-ODA and pure ODA. 


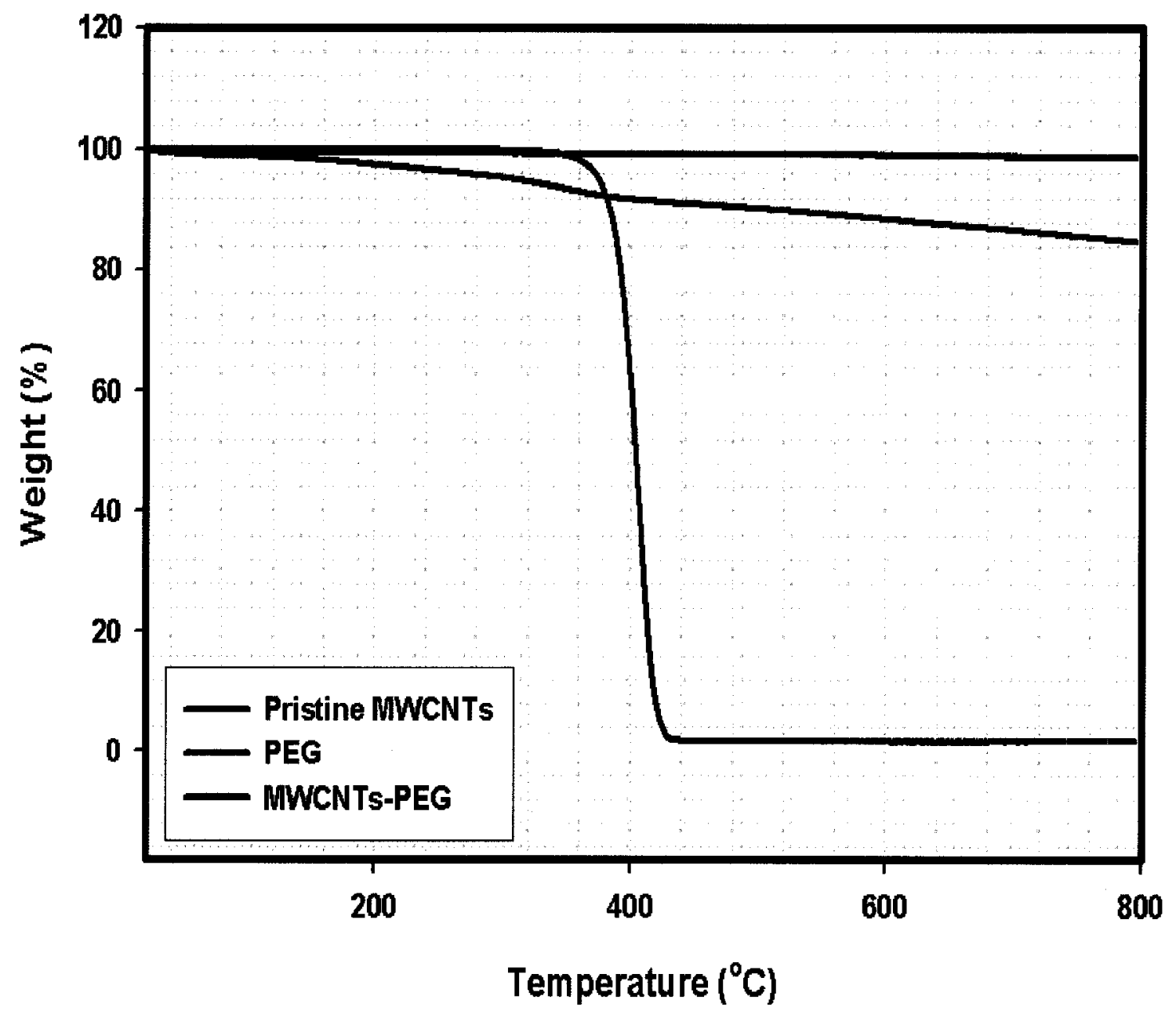

Figure 5.1. TGA plots of pristine MWCNTs, MWCNTs-PEG, and pure PEG. 


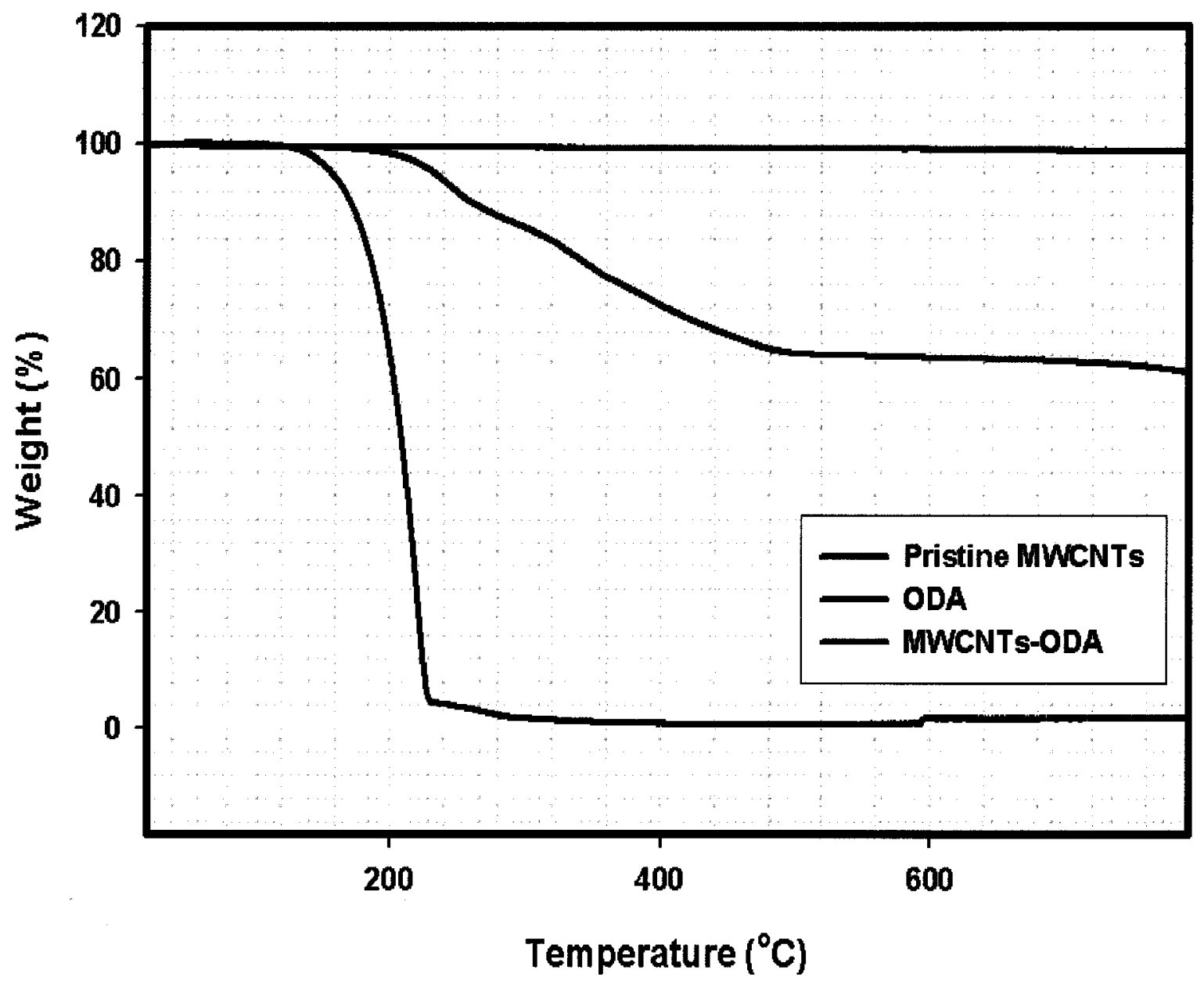

Figure 5.2. TGA plots of pristine MWCNTs, MWCNTs-ODA, and pure ODA. 
It is clear from the graph that pure ODA weight decreased sharply with rising the temperature, above its boiling point $\left(55^{\circ} \mathrm{C}\right.$ to $\left.57^{\circ} \mathrm{C}\right)$ and reached $98 \%$ weight loss near $300^{\circ} \mathrm{C}$, whereas MWCNTs-ODA weight decreased steadily with increasing temperature and its weight loss reached $39 \%$ at $800{ }^{\circ} \mathrm{C}$. This weight loss may be due to the decomposition of the ODA chains.

The surface area of MWCNTs covered with PEG or ODA can be estimated from the \% MWCNTs functionalized according to the TGA analysis. Mainly, both compounds, ODA and PEG, when they attached on the MWCNTs, form a long chain out of the MWCNTs surfaces. By imagining that this chain consists mainly of $\mathrm{H}-\mathrm{C}-\mathrm{H}$ groups which connected together from the carbon atom the length and the width of these can be calculated from the $\mathrm{C}-\mathrm{H}$ bond length $(109 \mathrm{pm})$. So, the surface area occupied by each molecule would equal to $4.75 \times 10^{-20} \mathrm{~m}^{2} /$ molecule. TGA analysis shows MWCNTs-ODA contain $39 \%$ by weight ODA. Calculating the total surface area covered by ODA chains indicated that almost $46.3 \%$ of the MWCNTs surface is covered by ODA chains. Taking into considerations that the ODA chains are not attached to each other may lead to the approximation that more than $46.3 \%$ of the MWCNTs surface is covered with ODA chains. The same calculation was done for PEG chains, and the result showed that $0.38 \%$ of the MWCNTs surface was covered with the PEG chains. Taking into consideration the fact that PEG chains are long polymeric chains with an average molecular weight 10,000 $\mathrm{g} /$ mole, may covered much more surface of the MWCNTs, as these long chains can be tangled, folded and unfolded, which increase the surface of the MWCNTs covered.

The total concentration of the oxygen containing active sites (carboxylic, phenolic, lactonic groups) on the surface of the oxidized MWCNTs was determined using acid- 
base titration (Chapter 2), and it was found to be $1.27 \mathrm{mmole} / \mathrm{g}$ of MWCNTs. This concentration is almost close to the number of moles of ODA that had been attached to the MWCNTs; 1.46 mmole ODA/g of MWCNTs. This approximation could indicate that most of the acidic functional groups that was created on the surface of the MWCNTs via oxidation had been attached to ODA groups. Meanwhile, the number of PEG moles was estimated to be 0.016 mmole PEG/g MWCNTs. This number was much lower than the number of acidic functional groups on the MWCNTs surface available for biding.

\subsubsection{Infrared spectroscopy}

IR measurements were performed to provide more evidence of attachments of PEG and ODA to the MWCNTs. Figure 5.3 shows the IR spectra of the pristine and oxidized MWCNTs, and MWCNTs-PEG and pure PEG. It is clear from the Figure that introducing PEG groups on the surface of the oxidized MWCNTs changed its IR spectral slightly. The peak at approximately $3500 \mathrm{~cm}^{-1}$, characteristic of an $\mathrm{H}$ bonded $\mathrm{O}-\mathrm{H}$ stretch, became more pronounced in MWCNTs-PEG than the oxidized MWCNTs. This is may be due to the introduction of more OH groups with the PEG on the surface of MWCNTs. A sharp peak at $1730 \mathrm{~cm}^{-1}$ corresponding to $\mathrm{C}=\mathrm{O}$ stretching vibration of the carboxylic acid became less intense with the MWCNTs-PEG. The MWCNTS-PEG spectrum shows a peak at $1100 \mathrm{~cm}^{-1}$ corresponding to the $\mathrm{C}-\mathrm{O}$ stretch vibration of the ether group of PEG (same peak appears in pure PEG). Two more strong peaks appear more between 2850

and3000 $\mathrm{cm}^{-1}$ due to the $\mathrm{C}-\mathrm{H}$ stretching in the PEG chain. The same peaks were more strongly on the pure PEG spectrum. The intensities of the above mentioned peaks were 


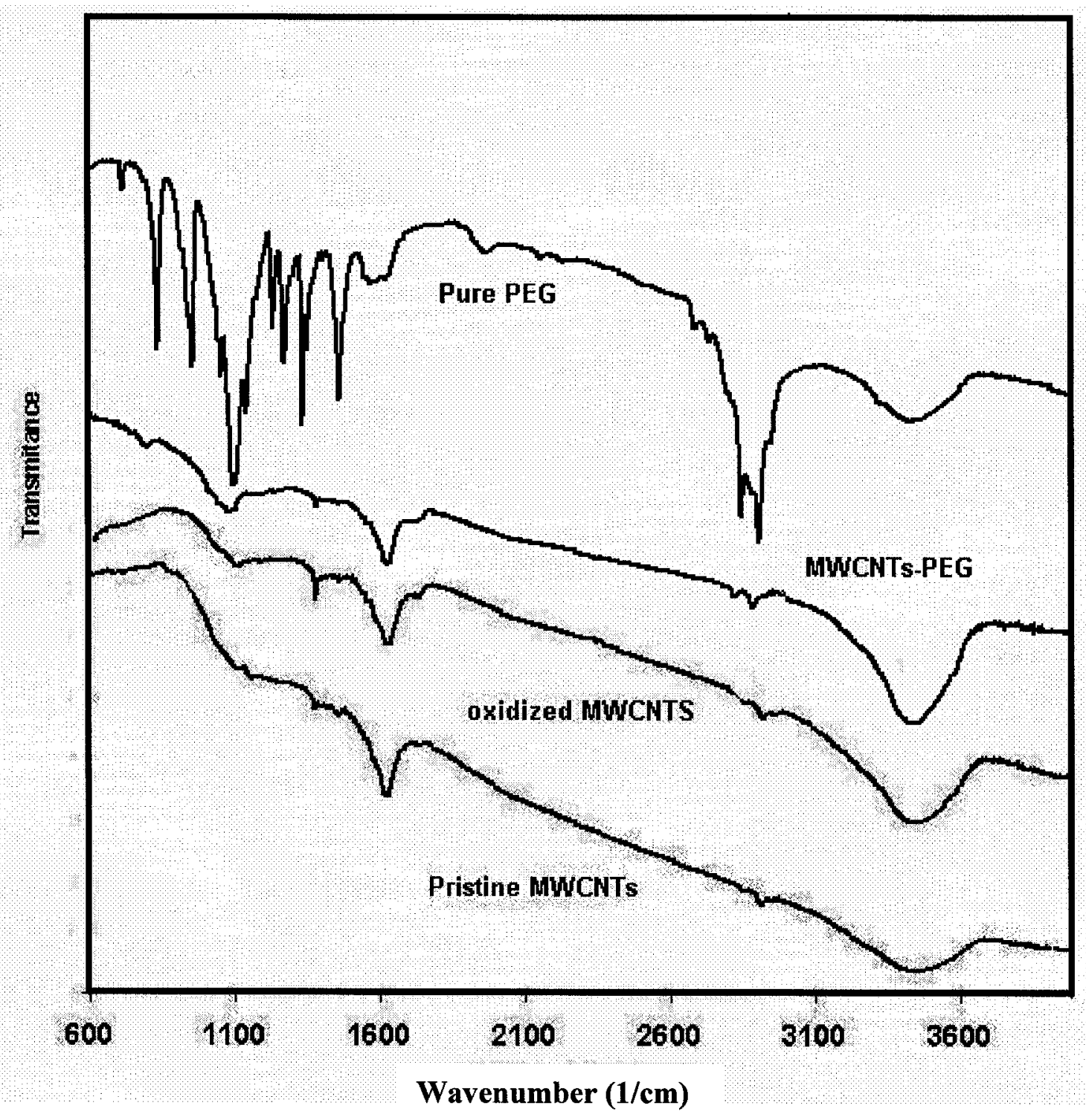

Figure 5.3. IR spectra of pristine MWCNTs, oxidized MWCNTs, MWCNTs-PEG and Pure PEG. 
not strong compared with the pure PEG compounds due to the fact that nearly $16 \%$ of the MWCNTs surface was functionalized with the PEG groups, as was concluded from the TGA study. This finding was confirmed by another study done to study the attachment of PEG to single-walled carbon nanotubes [11].

Figure 5.4 shows the IR spectra of the pristine MWCNTs, oxidized MWCNTs, and MWCNTs-ODA, as well as pure ODA. Sidewall functionalizaton of MWCNTs changed its spectrum significantly. The peak at approximately $3500 \mathrm{~cm}^{-1}$; characteristic of an $\mathrm{O}-\mathrm{H}$ stretch, became broader with MWCNTs-ODA compared with the oxidized MWCNTs, likely due to decreasing the number of the $\mathrm{OH}$ groups by reaction with ODA. Further evidence of the functionalization of the MWCNTs with ODA is the appearance of two strong peaks between 2850 and $3000 \mathrm{~cm}^{-1}$ assigned to the $\mathrm{C}-\mathrm{H}$ stretching of the ODA chains, similar to pure ODA.

\subsubsection{Modified MWCNTs solubility}

Solubilities of the modified MWCNTs were studied using different solvents; deionized water, dichloromethane, methanol, and hexane. Figure 5.5 shows the photos of pristine MWCNTs, oxidized MWCNTs, MWCNTs-ODA, and MWCNTs-PEG, suspensions in different solvents. It is clear from the Figure that pristine MWCNTs were completely insoluble (unsuspendable) in both water and methanol, but significantly soluble, forming a dark black solution, in dichloromethane, a relatively non polar solvent. This is due to the hydrophobicity of the MWCNTs, which allows them to be suspended in non-polar solvents. Although hexane is a non-polar solvent, the pristine MWCNTs was not 


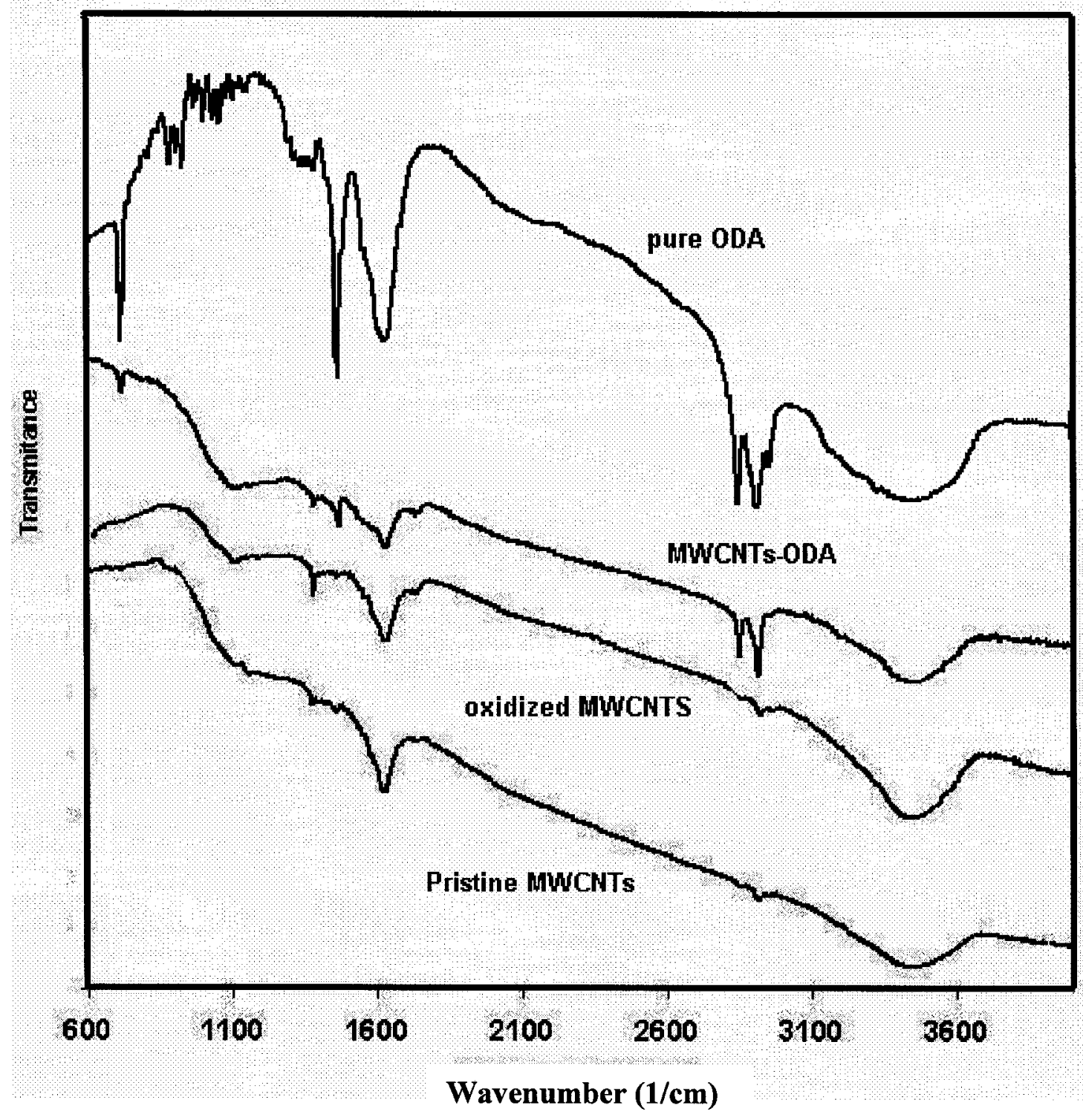

Figure 5.4. IR spectra of pristine MWCNTs, oxidized MWCNTs, MWCNTs-ODA and Pure ODA. 

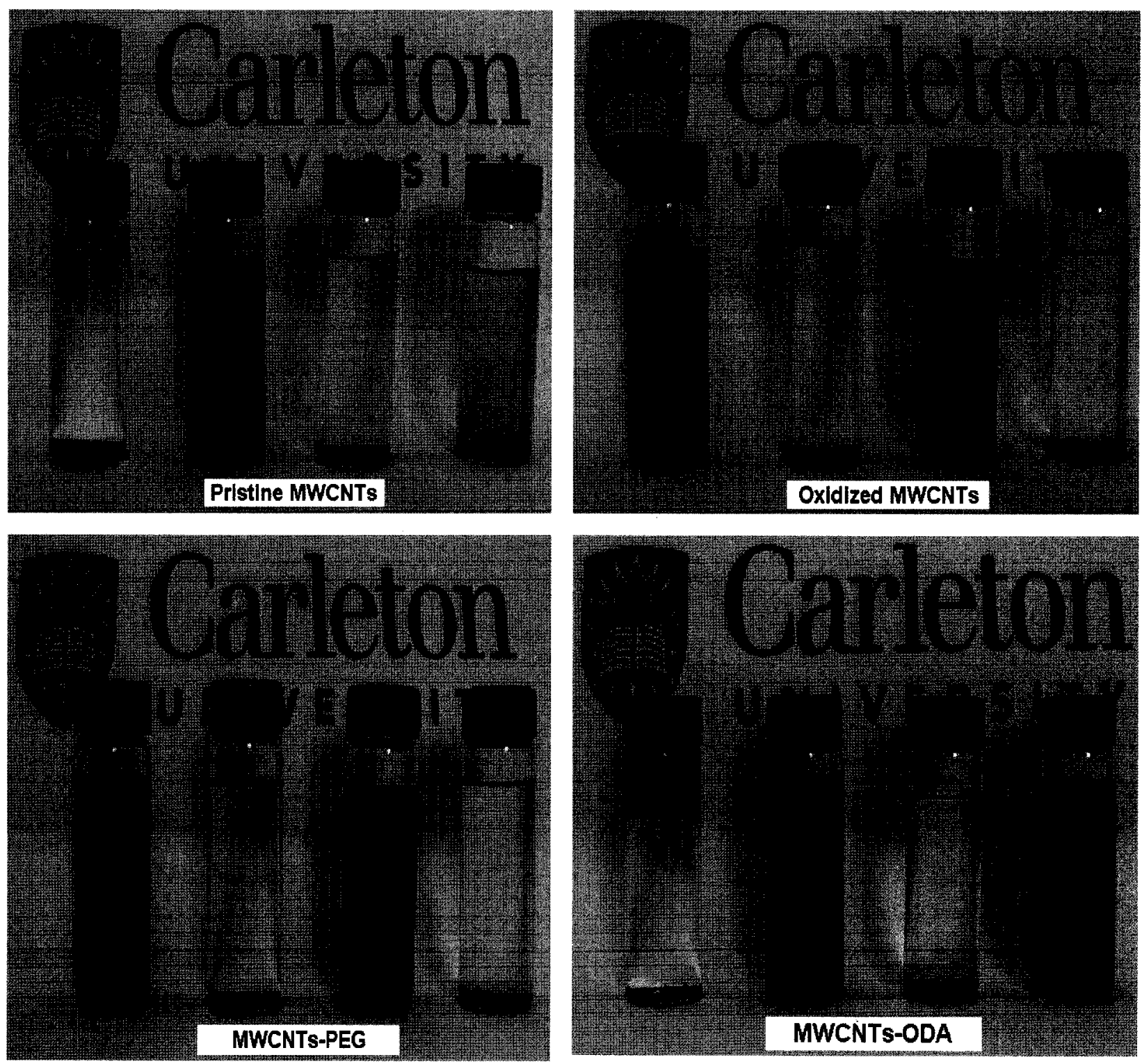

Figure 5.5. Solubilities of the modified MWCNTs in different solvents (from left to right, deionized water, dichloromethane, methanol, and hexane). 
significantly soluble, this is may be due to the different polarity between MWCNTs and hexane. Substance will dissolve in a solvent of similar polarity. If the solvent is too polar such as water or methanol, the relatively non-polar pristine MWCNTs can not "separate" the solvent molecules from one another, and hence the solubility is low. On the other hand, if the solvent is too non-polar, such as hexane, then it can not "separate" the MWCNTs from one another, and again solubility is low. If the polarity of both the solute (MWCNTs) and the solvent is just matching, such as dichloromethane, then the solute and solvent can separate on another, resulting in solubility. So, the solubility is due to both solvent and solute polarity. On the other hand, oxidation of the MWCNTs and the introduction of carboxylic groups increased the hydrophilic character of the MWCNTs. That was clear from the Figure as oxidized MWCNTs were significantly soluble in water and methanol and poorly soluble in dichloromethane and hexane. Further modification of the oxidized MWCNTs with PEG groups did not affect the solubility, as the MWCNTsPEG was significantly soluble in water and methanol and poorly soluble in dichloromethane and hexane. On the other hand, further reaction of the oxidized MWCNTs with ODA, decreased the hydrophilic character of the CNTs, due to the formation of the MWCNTs-ODA tubes. The solubility in polar solvents; water and methanol, was greatly inhibited whereas the solubility in dichloromethane and hexane relatively non-polar solvents was greatly enhanced. It is noteworthy to mention that introduction of the ODA groups along the surface of the MWCNTs only decreased the hydrophilicity of the tubes, but also it decreased their density; compared with water (MWCNTs-ODA floated on water). 


\subsubsection{X-ray diffraction measurements}

X-ray diffraction was applied in order to investigate the change in the crystalline structure of the pristine MWCNTs upon the side wall functionalization with PEG and ODA. Figure 5.6 compares the XRD patterns for the pristine MWCNTs, MWCNTs-PEG, and MWCNTs-ODA. Generally, it is clear from the Figure that the pristine MWCNTs, MWCNTs-PEG, and MWCNTs-ODA, exhibit two peaks; one at $26.14^{\circ}$ (002 plane) and the other $44.22^{\circ}$ (100 plane), corresponding to an interplanar space of $3.41 \mathrm{~A}^{\circ}$ and 2.05 $\mathrm{A}^{\circ}$, respectively. The Figure shows that functionalization of the MWCNTs with PEG groups did not alter the crystallographic character of the MWCNTs as it posessed only two prominent peaks, whereas the MWCNTs-ODA was characterized by a slightly different pattern which could be due to the high degree of functionalization of ODA compared with PEG on the surface of the MWCNTs; nearly $39 \%$ (by weight) of MWCNTs were functionalized with ODA, and 16\% (by weight) was functionalized with PEG (TGA data). MWCNTs-ODA sample contains three different peaks at $31.72^{\circ}, 45.4^{\circ}$, and $56.56^{\circ}$, with interplanar d-spacing $2.8185 \mathrm{~A}^{\circ}, 1.9960 \mathrm{~A}^{\circ}$, and $1.6258 \mathrm{~A}^{\circ}$, respectively. The XRD of the pure ODA was performed and its pattern was compared with that of the MWCNTs-ODA. There were no matches with previously mentioned peaks presents on MWCNTs-ODA with that of the pure ODA. The pure ODA XRD pattern shows many uniform peaks which are considered to result from the crystalline structure of the pure ODA. The new peaks presents on the XRD pattern of the MWCNTs-ODA may be due to the breakdown of the ODA crystalline structure and the formation of a new crystalline structure with the MWCNTs upon the formation of MWCNTs-ODA. 


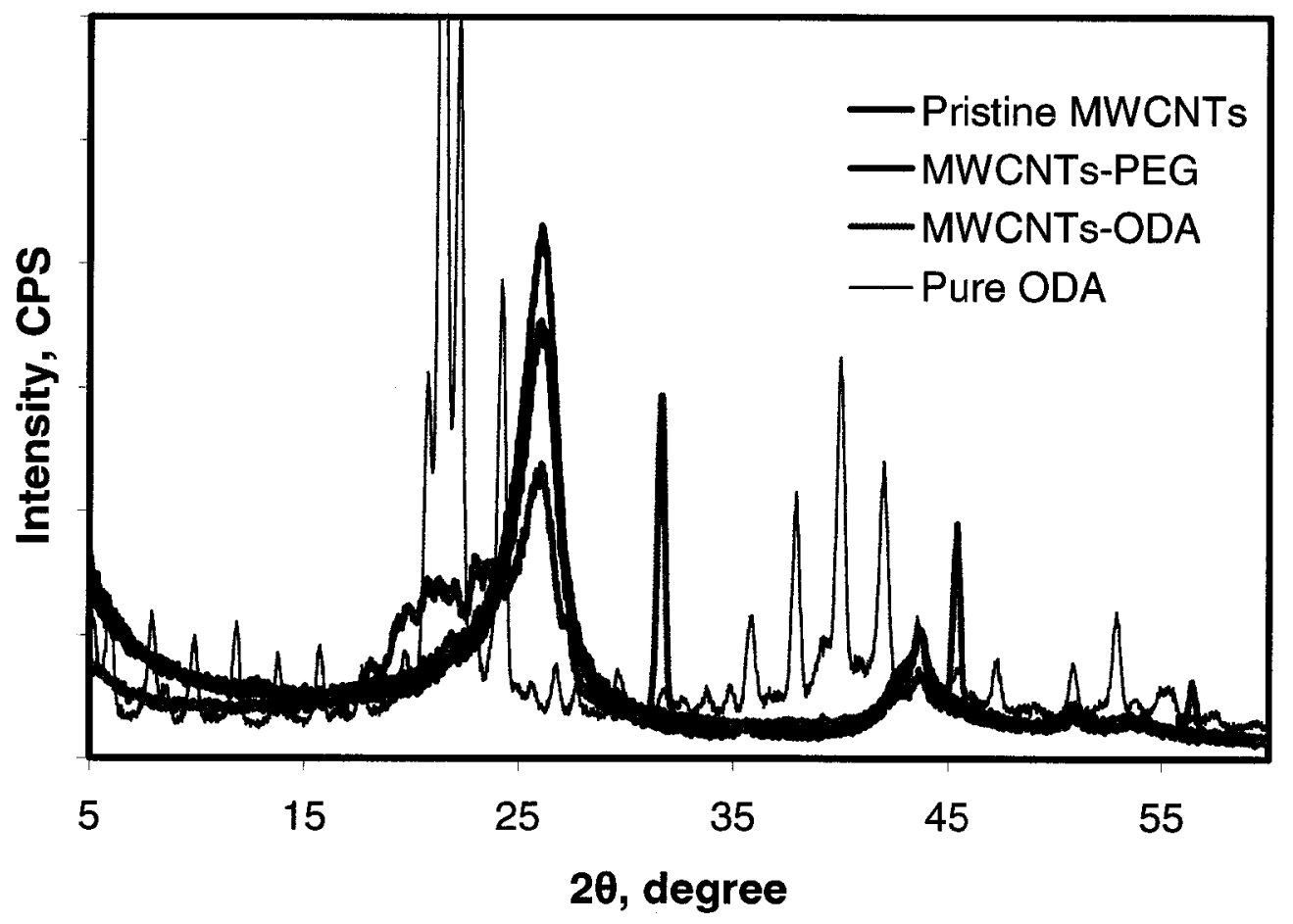

Figure 5.6. XRD patterns of pristine MWCNTs, MWCNTs-PEG, MWCNTs-ODA, and pure ODA. 


\subsubsection{Scanning electron microscopy (SEM)}

The surface morphological structure of the modified MWCNTs was studied using SEM imaging. Figure 5.7 shows representative images for the pristine MWCNTs, MWCNTsPEG, and MWCNTs-ODA. It is clear from the Figure that the pristine MWCNTs are highly tangled tubes with diameters of 100-200 nm. Side-walled functionalization with PEG and ODA did not alter the morphological structure of MWCNTs surfaces significantly, as observed from their SEM images.

\subsection{Conclusions}

Side-walled functionalization of MWCNTs was achieved using polyethylene glycol and octadecylamine. Different characterization techniques were used to investigate the formation of MWCNTs-PEG and MWCNTs-ODA. TGA showed that almost 16\% (by weight) of the MWCNTs were functionalized with PEG and 39\% (by weight) was functionalized with ODA. The percent surface coverage was estimated for both MWCNTs-ODA and MWCNTs-PEG, and calculations showed that total surface area covered were $46.3 \%$ and $0.38 \%$, respectively. The IR spectra for MWCNTs-PEG and MWCNTs-ODA identified the characteristic stretching peaks for the successful linkage between MWCNTs and PEG and ODA. MWCNTs-PEG contains many of the hydrophilic groups and were suspendable in aqueous solution, whereas MWCNTs-ODA contain more hydrophobic groups were not suspendable in aqueous solution, but were suspendable in relatively non-polar organic solvents, such as dichloromethane. XRD and SEM measurements showed that there was not any significant change of either the 

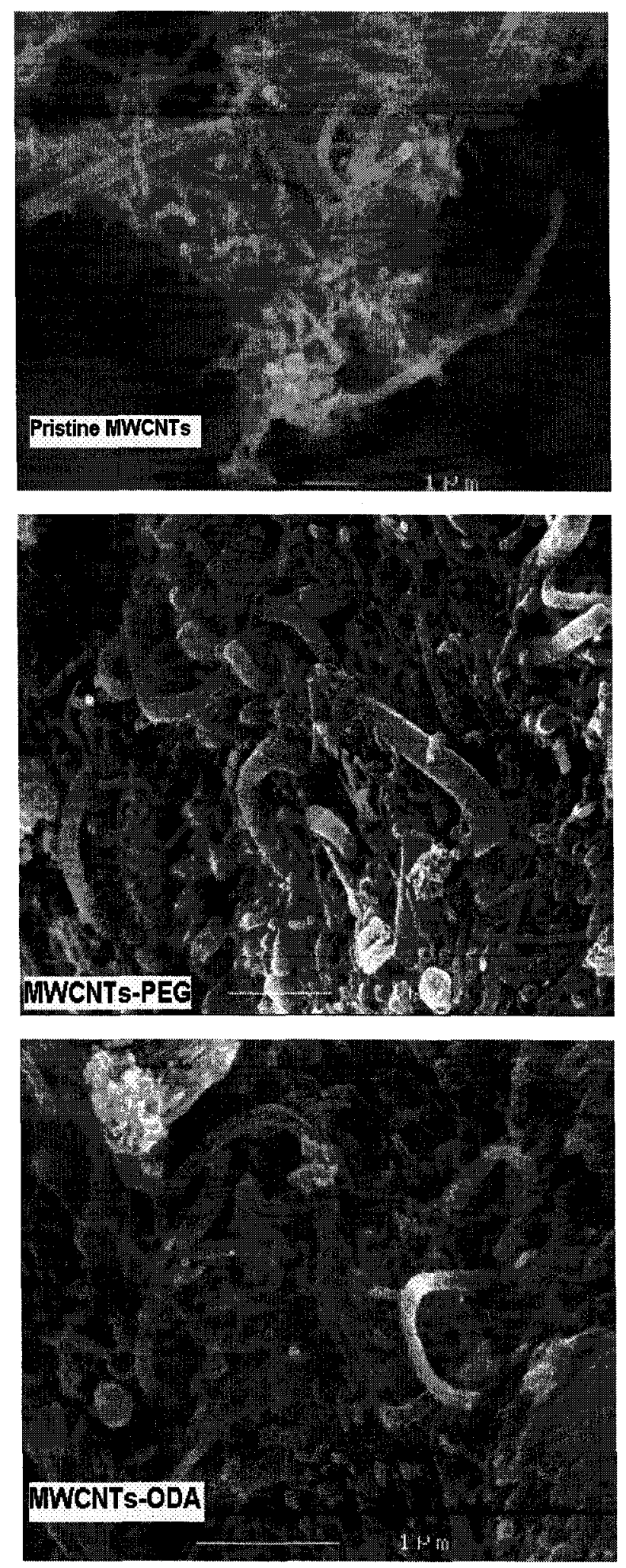

Figure 5.7. SEM images of pristine MWCNTs, MWCNTs-PEG, and MWCNTs-ODA. 
crystalline structure or the surface morphology of the MWCNTs after the functionalization with PEG and ODA. 


\subsection{References}

[1] Baskaran D, Mays J W, Bratcher M S, Angewandte Chemie International Edition. 2004, 43,2138

[2] O'Connell M J, Tour P, Ausman K D, Smalley R E, Chemical Physics Letters 2001, 342, 265.

[3] Michelson E T, Chiang I W, Zimmerman J L, Boul P J, Lozano J, Liu J, Smalley R E, Hauge R H, Margrave J L, Journal of Physical Chemistry, B 1999, 103, 4318.

[4] Chen J, Rao A M, Lyuksyutov S, Itkis M E, Hamon M A, Hu H, Cohn R W, Eklund P C, Colbert D T, Smalley R E, Haddon R C, Journal of Physical Chemistry, B 2001, 105, 2525.

[5] Pompeo F, Resasco D E, Nano Letters 2002, 2, 369.

[6] Peng H, Alemany L B, Margrave J L, Khabashesku V N, Journal of the American Chemical Society 2003, 125, 15174.

[7] Bianco A, Prato M, Advanced Materials 2003, 15, 1765.

[8] Bangerjee S, Kahn M G C, Wong S S, Chemistry - A European Journal 2003, 9, 1898.

[9] Dyke C A, Tour J M, Chemistry - A European Journal.2005, 10, 812.

[10] Bangerjee S, Benny T H, Wong S S, Advanced.Materials 2005, 1, 17.

[11] Jung D H, Ko Y K, Jung H T, Materials Science and Engineering C 2004, 24, 117. 


\section{CHAPTER 6}

\section{THERMODYNAMICS STUDY AND COMPUTER}

\section{MODELING OF THE ADSORPTION OF ANALYTES \\ ON CHEMICALLY MODIFIED MULTI-WALLED}

CARBON NANOTUBES 


\subsection{Introduction}

Recently, releases of different pollutants to the environment have drawn the attention of scientists due to their toxic effects. Most of these pollutants have limited solubility in water and as a result, they exist only at very low concentrations. Many research studies have showed the ability of carbon nanotubes (CNTs) to adsorb different pollutants from various aqueous samples [1-15]. This ability of CNTs is due to strong interaction between the CNTs surface and the pollutants due to the unique structure of CNTs as a result of the delocalized $\pi$-electrons on the hexagonal arrays of carbon atoms in grapheme sheets of CNTs surface. There is no study was done to investigate the adsorption of different type of analytes at equilibrium on chemically modified MWCNT and evaluate the thermodynamic parameters of the adsorption. The thermodynamic evaluation of the adsorption is very important in order to achieve a better understanding of the adsorption process.

In this chapter the effect of temperature on the adsorption of pentachlorophenol (PCP), 2,4,5-trichlorophenol (TCP), 3,3',4,4'-tetrachlorobiphenyl (PCB77) and 2,2',5,5'-tetrabromobiphenyl (PBB52), were studied using different modified multiwalled carbon nanotubes; namely, pristine MWCNTs, oxidized MWCNTs, and MWCNTs fuctionalized with polyethylene glycol (MWCNTs-PEG) and octadecyl amine (MWCNTs-ODA). The thermodynamic parameters of adsorption, i.e. the free energy, enthalpy and entropy of were calculated. A computer modeling program was used as a comparative study. 


\subsection{Experimental}

\subsubsection{Adsorbents}

The modified MWCNTs were prepared as detailed in Chapter 2 and Chapter 5. Endcapped C18 (a hydrophobic sorbent used for the extraction of non-polar analytes in aqueous samples) was obtained from Chromatographic Specialties Inc.

\subsubsection{Chemicals}

PCP and TCP were obtained from Sigma-Aldrich Company, whereas PCB77 and PBB52 (AccuStandard, 100\% pure) were purchased from Chromatographic Specialties Inc.

\subsubsection{Thermodynamics studies}

$20.0 \mathrm{mg}$ of adsorbent were introduced into $14 \mathrm{~mL}$ glass vials. $10.0 \mathrm{~mL}$ aqueous solution containing the four analytes was added to the MWCNTs. The vials were then shaken for 24 hours at different temperatures. Each suspension was then centrifuged at $3000 \mathrm{rpm}$ and the supernatant solution was analyzed for the target analytes using GC-ECD. The amount of the analyte adsorbed at equilibrium was calculated as follows:

$$
q=\frac{\left(C_{0}-C_{t}\right) V}{m}
$$

Where $\mathrm{q}$ is the amount of analyte adsorbed $(\mathrm{mg} / \mathrm{g}), \mathrm{C}_{0}$ is the initial aqueous concentration of the analyte $(\mathrm{mg} / \mathrm{L}), \mathrm{C}_{\mathrm{t}}$ is the concentration of the analyte after shaking for a certain period of time $(\mathrm{mg} / \mathrm{L}), \mathrm{V}$ is the solution volume $(\mathrm{L})$ and $\mathrm{m}$ is the mass of adsorbent $(\mathrm{g})$. 


\subsubsection{Adsorption computer modeling}

Computer modeling was performed for the adsorption of different analytes to the pristine and modified MWCNTs to determine the lowest energy configuration and to estimate the free energy of adsorption. The modeling was completed using the following steps:

\subsubsection{Generation of initial poses}

A simplified version of U-Dock v1.00 [16] was used to generate initial poses of analyte molecules (guest or ligand) in the vicinity of the CNTs structure.

Hosts: A structure of a $400 \AA^{2}$ fragment of pristine CNTs was made using 17 benzene rings $\left(\mathrm{C}_{102} \mathrm{H}_{42}\right)$ and the geometry was optimized in AM1 (Austin Model 1, which is a semi-empirical method for the quantum calculation of molecular electronic structure) level in Spartan [17]. The required functional groups (carboxylic acid, polyethylene chain, and amide) were added to build functionalized CNT structures.

Guests: structures of analytes (PCP, TCP, PCB77, PBB52) were drawn using CCG-MOE (Chemical Computing Group, Molecular Operating Environment)and different conformers of PCB77 and PBB52 only were produced, to find the most likely conformer of each molecule, using a systematic conformer search method. A database including conformers of all ligands was made and used for docking.

\subsubsection{Docking}

Docking was done using U-Dock to generate initial poses of complex, random orientations of each conformer in input database by placing each inside a theoretical box of $20 \times 20 \times 20$ angstroms (docking box) in the vicinity of the host structure. The resultant 
geometries of the complex were then relaxed using an MMFF94s force field and born solvation model. All atoms on the host structure (except for the functional group atoms) were fixed during minimization. At least 50 poses were built for each complex system.

\subsubsection{Calculation of free and solvation energies}

Top 10 poses with the lowest energy configuration of each complex were sent to AM1 calculations in Spartan where geometries were optimized and free energies were calculated. Also, solvation energies were calculated using SM5.4/A method (a quantum mechanical solvation model used to calculate free energies of aqueous solvation). The structure of the complex with lowest free energy of adsorption was chosen to represent the predicted optimum geometry of complex.

\subsubsection{Calculation of predicted $\Delta G_{A d s o r p t i o n}$}

The resulting global minimum energy structure for each complex was used to calculate the predicted $\Delta G_{A d s o r p t i o n}$ for each system. The predicted $\Delta G_{A d s o r p t i o n}$ of an analyte with a surface is

$$
\Delta G_{\text {Adsorption }}=G_{\text {products }}-G_{\text {reactants }}
$$

In this case, the reactants are the analyte and the surface is the CNTs, and the product is the adsorbed analyte (the complex), Thus,

$$
\Delta G_{\text {Adsorption }}=G_{\text {Complex }}-G_{C N T}-G_{\text {analyte }}
$$

Recognizing that the experimental values are generated from aqueous solution data, solvation terms need to be added to the predicted free energy of adsorption. Thus,

$$
\Delta G_{\text {solvation }}=\Delta G_{\text {solv }_{\text {complex }}}-\Delta G_{\text {solv }_{C N T}}-\Delta G_{\text {solv }_{\text {ganalye }}}
$$


and so the predicted free energy of adsorption is:

$$
\text { predicted } \Delta G_{\text {Adsorption }_{\text {aq }}}=\Delta G_{\text {Adsorption }}+\Delta G_{\text {solv }}
$$

or,

predicted $\Delta G_{\text {Adsorption }_{a q}}=\left(G_{\text {Complex }}-G_{C N T}-G_{\text {analyte }}\right)+\left(\Delta G_{\text {solv }_{\text {complex }}}-\Delta G_{\text {solv }_{C N T}}-\Delta G_{\text {solv }_{\text {analye }}}\right)(6$

or

predicted $\Delta G_{\text {Adsorption }_{\text {aq }}}=\left(G_{\text {Complex }}+\Delta G_{\text {solv }_{\text {omplex }}}\right)-\left[\left(G_{C N T}+\Delta G_{\text {solv }_{C N T}}\right)+\left(G_{\text {analyte }}+\Delta G_{\text {solv }_{\text {analyc }}}\right)\right](6$

where the $\Delta G_{s o l v, X}$ values are the free energies of solvation for each of the anlayte, the CNTs and the complex formed when an analyte adsorbed onto the CNTs surface.

These predicted free energies of adsorption were then compared to the ones measured in equilibrium adsorption experiments.

\subsection{Results and Discussion}

\subsubsection{Temperature studies and evaluation of the thermodynamic data}

The effect of temperature on the adsorption of TCP, PCP, PCB77, and PBB52, on modified MWCNTs and $\mathrm{C} 18$ was studied at $5^{\circ} \mathrm{C}, 15^{\circ} \mathrm{C}, 25^{\circ} \mathrm{C}$, and $35^{\circ} \mathrm{C}$ using a temperature controlled water bath. All samples were equilibrated for 24 hours and the standard free energy change $\left(\Delta G^{\circ}\right)$, average standard enthalpy change $\left(\Delta H^{\circ}\right)$, and standard entropy change $\left(\Delta S^{\circ}\right)$, were calculated using the thermodynamic equations in Chapter 3. The initial aqueous concentrations were $131 \mathrm{ng} / \mathrm{ml} \mathrm{TCP}, 100 \mathrm{ng} / \mathrm{ml} \mathrm{PCP}, 61$ $\mathrm{ng} / \mathrm{ml} \mathrm{PCB77,} \mathrm{and} 62 \mathrm{ng} / \mathrm{ml}$ PBB52.

Table 6.1 shows the different thermodynamic parameters for the adsorption of TCP, PCP, PCB77, and PBB52, onto pristine MWCNTs, oxidized MWCNTs, MWCNTs-PEG, MWCNTs-ODA, and C18. It is clear from the table that the adsorption of each analyte on 
Table 6.1. Different thermodynamic parameters for the adsorption of TCP, PCP, PCB77, and PBB52, onto pristine MWCNTs, oxidized MWCNTs, MWCNTs-PEG, MWCNTs-ODA, and C18.

\begin{tabular}{|c|c|c|c|c|c|c|c|c|c|c|c|c|}
\hline & TCP & PCP & PCB77 & PBB52 & TCP & PCP & PCB77 & PBB52 & TCP & PCP & PCB77 & PBB52 \\
\hline & \multicolumn{4}{|c|}{$\Delta \mathbf{G}^{\circ}(\mathbf{k J} / \mathrm{mole})$} & \multicolumn{7}{|c|}{$\Delta \mathrm{H}^{\circ} \mathrm{kJ} / \mathrm{mole}$ (average between $5^{\circ} \mathrm{C}$ and $35^{\circ} \mathrm{C}$ ) } & \\
\hline Temp. & \multicolumn{12}{|c|}{ Pristine MWCNTs } \\
\hline $5^{\circ} \mathrm{C}$ & $-32 \pm 3$ & $-27 \pm 1$ & $-22 \pm 2$ & $-24 \pm 2$ & & & & & $29 \pm 10$ & $25 \pm 11$ & $212 \pm 20$ & $302 \pm 21$ \\
\hline $15^{\circ} \mathrm{C}$ & $-31 \pm 1$ & $-25 \pm 2$ & $-24 \pm 2$ & $-25 \pm 2$ & & & & & $25 \pm 15$ & $17 \pm 13$ & $211 \pm 21$ & $306 \pm 31$ \\
\hline $25^{\circ} \mathrm{C}$ & $-30 \pm 3$ & $-24 \pm 1$ & $-26 \pm 1$ & $-27 \pm 1$ & & & & & $21 \pm 8$ & $13 \pm 12$ & $211 \pm 16$ & $313 \pm 11$ \\
\hline \multirow[t]{2}{*}{$35^{\circ} \mathrm{C}$} & $-29 \pm 2$ & $-22 \pm 1$ & $-29 \pm 3$ & $-34 \pm 3$ & & & & & $17 \pm 11$ & $6 \pm 10$ & $214 \pm 13$ & $315 \pm 19$ \\
\hline & & & & & $-24 \pm 3$ & $-20 \pm 4$ & $37 \pm 3$ & $63 \pm 2$ & & & & \\
\hline & \multicolumn{12}{|c|}{ Oxidixed MWCNTs } \\
\hline $5^{\circ} \mathrm{C}$ & $-20 \pm 1$ & $-21 \pm 2$ & $-26 \pm 1$ & $-26 \pm 1$ & & & & & $127 \pm 12$ & $183 \pm 12$ & $246 \pm 12$ & $308 \pm 12$ \\
\hline $15^{\circ} \mathrm{C}$ & $-22 \pm 1$ & $-22 \pm 2$ & $-28 \pm 2$ & $-29 \pm 2$ & & & & & $126 \pm 13$ & $181 \pm 10$ & $254 \pm 26$ & $306 \pm 16$ \\
\hline $25^{\circ} \mathrm{C}$ & $-23 \pm 2$ & $-24 \pm 1$ & $-31 \pm 2$ & $-32 \pm 2$ & & & & & $126 \pm 20$ & $180 \pm 11$ & $264 \pm 14$ & $307 \pm 14$ \\
\hline \multirow[t]{3}{*}{$35^{\circ} \mathrm{C}$} & $-25 \pm 2$ & $-27 \pm 2$ & $-33 \pm 1$ & $-35 \pm 1$ & & & & & $128 \pm 14$ & $184 \pm 15$ & $273 \pm 20$ & $308 \pm 31$ \\
\hline & & & & & $15 \pm 4$ & $30 \pm 3$ & $45 \pm 2$ & $59 \pm 5$ & & & & \\
\hline & \multicolumn{12}{|c|}{ MWCNTs-PEG } \\
\hline $5^{\circ} \mathbf{C}$ & $-20 \pm 2$ & $-19 \pm 1$ & $-25 \pm 1$ & $-22 \pm 2$ & & & & & $111 \pm 19$ & $188 \pm 12$ & $203 \pm 20$ & $259 \pm 21$ \\
\hline $15^{\circ} \mathrm{C}$ & $-22 \pm 1$ & $-22 \pm 2$ & $-27 \pm 2$ & $-24 \pm 3$ & & & & & $111 \pm 20$ & $189 \pm 15$ & $202 \pm 21$ & $257 \pm 18$ \\
\hline $25^{\circ} \mathrm{C}$ & $-23 \pm 1$ & $-23 \pm 1$ & $-28 \pm 3$ & $-29 \pm 3$ & & & & & $110 \pm 16$ & $187 \pm 11$ & $200 \pm 31$ & $267 \pm 17$ \\
\hline \multirow[t]{2}{*}{$35^{\circ} \mathrm{C}$} & $-24 \pm 2$ & $-25 \pm 3$ & $-32 \pm 1$ & $-30 \pm 1$ & & & & & $111 \pm 13$ & $189 \pm 17$ & $204 \pm 11$ & $255 \pm 13$ \\
\hline & & & & & $10 \pm 3$ & $33 \pm 5$ & $32 \pm 3$ & $50 \pm 4$ & & & & \\
\hline
\end{tabular}


Table 6.1. (continued) Different thermodynamic parameters for the adsorption of TCP, PCP, PCB77, and PBB52, onto pristine MWCNTs, oxidized MWCNTs, MWCNTs-PEG, MWCNTs-ODA, and C18.

\begin{tabular}{|c|c|c|c|c|c|c|c|c|c|c|c|c|}
\hline & TCP & PCP & PCB77 & PBB52 & TCP & PCP & PCB77 & PBB52 & TCP & PCP & PCB77 & PBB52 \\
\hline & \multicolumn{4}{|c|}{$\Delta \mathbf{G}^{\circ}(\mathbf{k J} / \mathbf{m o l e})$} & \multicolumn{7}{|c|}{$\Delta \mathbf{H}^{\circ} \mathrm{kJ} / \mathrm{mole}$ (average between $5^{\circ} \mathrm{C}$ and $35^{\circ} \mathrm{C}$ ) } & \\
\hline Temp. & \multicolumn{12}{|c|}{ MWCNTs-ODA } \\
\hline $5^{\circ} \mathrm{C}$ & $-33 \pm 2$ & $-34 \pm 1$ & $-29 \pm 1$ & $-22 \pm 2$ & & & & & $32 \pm 21$ & $54 \pm 13$ & $331 \pm 31$ & $260 \pm 26$ \\
\hline $15^{\circ} \mathrm{C}$ & $-32 \pm 1$ & $-33 \pm 2$ & $-31 \pm 3$ & $-25 \pm 1$ & & & & & $28 \pm 11$ & $49 \pm 12$ & $326 \pm 29$ & $271 \pm 19$ \\
\hline $25^{\circ} \mathrm{C}$ & $-31 \pm 1$ & $-33 \pm 1$ & $-34 \pm 1$ & $-31 \pm 3$ & & & & & $23 \pm 16$ & $47 \pm 16$ & $326 \pm 18$ & $292 \pm 18$ \\
\hline \multirow[t]{3}{*}{$35^{\circ} \mathrm{C}$} & $-30 \pm 3$ & $-31 \pm 1$ & $-46 \pm 4$ & $-33 \pm 2$ & & & & & $19 \pm 12$ & $39 \pm 13$ & $354 \pm 39$ & $279 \pm 27$ \\
\hline & & & & & $-24 \pm 3$ & $-19 \pm 5$ & $63 \pm 3$ & $53 \pm 5$ & & & & \\
\hline & \multicolumn{12}{|l|}{$\mathrm{C18}$} \\
\hline $5^{\circ} \mathrm{C}$ & $-21 \pm 1$ & $-21 \pm 1$ & $-20 \pm 1$ & $-23 \pm 1$ & & & & & $212 \pm 21$ & $151 \pm 21$ & $237 \pm 24$ & $260 \pm 23$ \\
\hline $15^{\circ} \mathrm{C}$ & $-23 \pm 2$ & $-22 \pm 2$ & $-23 \pm 2$ & $-25 \pm 2$ & & & & & $212 \pm 19$ & $149 \pm 17$ & $240 \pm 19$ & $267 \pm 21$ \\
\hline $25^{\circ} \mathrm{C}$ & $-25 \pm 1$ & $-24 \pm 1$ & $-26 \pm 2$ & $-28 \pm 2$ & & & & & $211 \pm 18$ & $151 \pm 13$ & $242 \pm 31$ & $278 \pm 19$ \\
\hline \multirow[t]{2}{*}{$35^{\circ} \mathrm{C}$} & $-28 \pm 3$ & $-26 \pm 3$ & $-27 \pm 3$ & $-31 \pm 3$ & & & & & $214 \pm 31$ & $153 \pm 17$ & $237 \pm 26$ & $269 \pm 35$ \\
\hline & & & & & $38 \pm 3$ & $21 \pm 6$ & $46 \pm 4$ & $52 \pm 7$ & & & & \\
\hline
\end{tabular}


each adsorbent is spontaneous in this temperature range as all values $\Delta \mathrm{G}^{\circ}$ were negative. The value of $\Delta \mathrm{G}^{\circ}$ depends on both the analyte type and the type of adsorbent. In the case of TCP and PCP adsorption on pristine MWCNTs, $\Delta \mathrm{G}^{\circ}$ becomes less negative as the temperature increased, whereas in the case of PCB77 and PBB52, $\Delta \mathrm{G}^{\circ}$ becomes more negative as the temperature increased.

The following equation summarizes the adsorption process:

Analyte $_{\text {(aq.) }}+$ Adsorbent $_{(\text {aq.) }} \underset{\text { desorption }}{\stackrel{\text { adsortion }}{\rightleftarrows}}$ Analyte-adsorbent complex (aq.)

The values of the thermodynamic parameters mainly depends on the interaction between the reactants (analyte and adsorbent), and the products (analyte-adsorbent complex) and the solvents molecules (water) surrounding them. For example, the formation of a stable analyte-adsorbent complex is favored when the $\Delta \mathrm{G}^{\circ}$ of adsorption is negative. $\Delta H^{\circ}$ could be negative (exothermic) when the energy needed to breakdown the bonds between the analyte and the water molecules, and adsorbent and the water molecules, is less than the energy needed to form new bonds between the analyte and the adsorbent molecules, and vice versa. The calculated values of $\Delta H^{\circ}$ were found to be negative (exothermic) for the adsorption of TCP and PCP, and it was found to be positive (endothermic) for the adsorption of PCB77 and PBB52, on pristine MWCNTs and MWCNTs ODA. Decreasing the temperature, in the case of exothermic reaction, leads to increasing the adsorption as the adsorption become more spontaneous $\left(\Delta \mathrm{G}^{\circ}\right.$ becomes more negative by decreasing the temperature), whereas in the case where the reaction is endothermic, increasing the temperature, leads to increasing the adsorption as the adsorption become more spontaneous $\left(\Delta \mathrm{G}^{\circ}\right.$ becomes more negative by increasing the temperature). In case of using oxidized MWCNTs and MWCNTs-PEG, $\Delta \mathrm{H}^{\circ}$ was positive (endothermic) for all 
the analytes. This may be indicated that the energy needed to form the bonds between the analyte and MWCNTs-PEG or oxidized MWCNTs were very high. This may be to overcome the repulsion forces between the analytes and the oxygen functional groups presents on the surface of these two adsobents. Also the solvation energy of the molecules; either analyte or adsorbent, contribute to the heat of adsorption. Solvation energy could be negative which indicates that the molecules are most likely to be dissolved in water (hydrophilic), or positive which indicates that the molecules are most likely will not dissolved in water (hydrophobic). The solvation energy of TCP and PCP is most likely negative values as both molecules are polar and hydrophilic, which may contribute to the negative heat of adsorption on both pristine MWCNTs and MWCNTsODA. On the other hand, PCB77 and PBB52 are less polar and more hydrophobic than chlorophenol molecules, which make their solvation energy more positive and hence make their $\Delta \mathrm{H}^{\circ}$ positive for all adsorbent.

In the case of $\Delta \mathrm{S}^{\circ}$ and according to equation 6.8 , it could be positive, which may be due the formation of the analyte-adsorbent complex is more disordered. For all the adsorption processes on different adsorbents, the $\Delta \mathrm{S}^{\circ}$ values were positive for the four analytes at all temperatures. The positive values suggest increasing randomness at the solid/solution interface and this may be due to the loss of some of the structural water molecules around the adsorbate and the resultant increase in the degree of freedom of the TCP, PCP, PCB77 and PBB52 on the pristine MWCNTs.

As was explained previously, due to the presence of the surface oxygen functional groups on oxidized MWCNTs and MWCNTs-PEG, $\Delta \mathrm{G}^{\circ}$ becomes more negative by increasing the temperature, as a result of endothermic reaction; $\Delta \mathrm{H}^{\circ}$ is positive for all the analytes 
and accompanied with positive $\Delta \mathrm{S}^{\circ}$. This indicated that the adsorption of the four analytes on the oxidized MWCNTs and MWCNTs-PEG is an entropy driven process. C18 adsorption behavior was nearly similar to the oxidized MWCNTs and MWCNTsPEG adsorbents; i.e. $\Delta \mathrm{H}^{\circ}$ and $\Delta \mathrm{S}^{\circ}$ are positive, entropy driven process.

This points out another advantage of the MWCNTs-ODA over the other MWCNTs and C18, since adsorption increased by decreasing the temperature, similar to the pristine MWCNTs, but with higher adsorption capability. This enables MWCNTs-ODA to be applied as a promising adsorbent for the removal of different pollutants from aqueous solution at normal and sub-normal temperatures.

\subsubsection{Computer modeling of adsorption}

The predicted free energies of adsorption $\Delta G_{A d s o r p t i o n}$ for the four analytes on pristine and modified MWCNTs were calculated using the computer modeling based on the lowest energy configuration of each complex. The poses that simulate the adsorption of each analyte on different MWCNTs with minimal energies are presented in Figures 6.1, 6.2, 6.3 and 6.4. The Figures showed that the more polar parts of each analyte were directed mostly away from the adsorbent as a result of the attraction force towards the solvent molecules (water molecules).

The predicted $\Delta G_{\text {Adsorption }}$ was mainly dependent on complex formation energy and solvation energy as was explained in equations 6.6 and 6.7

The calculations for predicted $\Delta G_{\text {Adsorption }_{\text {aqneous }}}$ of different analytes on pristine and modified MWCNTs are presented in Table 6.2. The computer models used the following approximation to calculate the free energy of adsorption: 

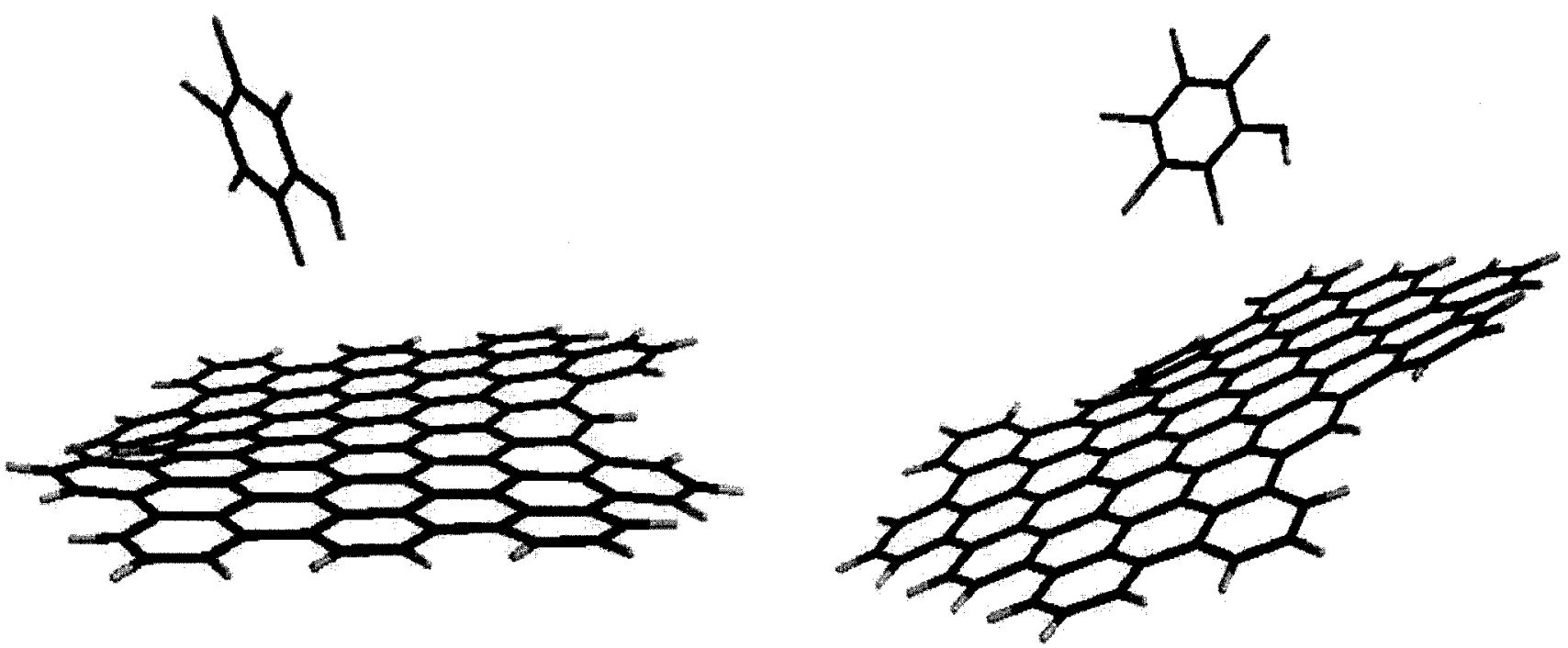

Pristine MWCNTs and TCP
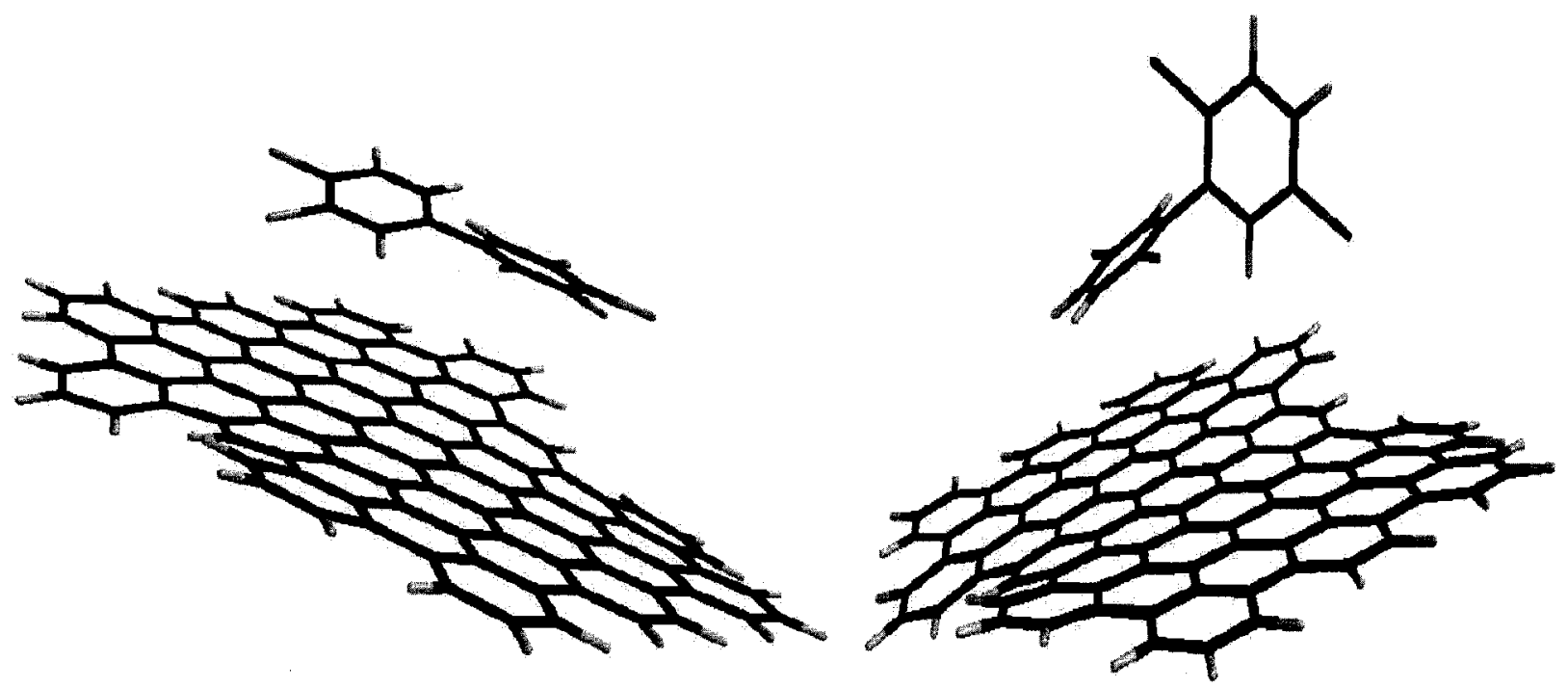

Pristine MWCNTs and PCB77

Pristine MWCNTs and PBB52

Figure 6.1. Adsorption modeling of the four analytes on pristine MWCNTs.

The black, blue, white, yellow, green, and red colors represent carbon, oxygen, hydrogen, chlorine, nitrogen, and bromine atoms, respectively. 


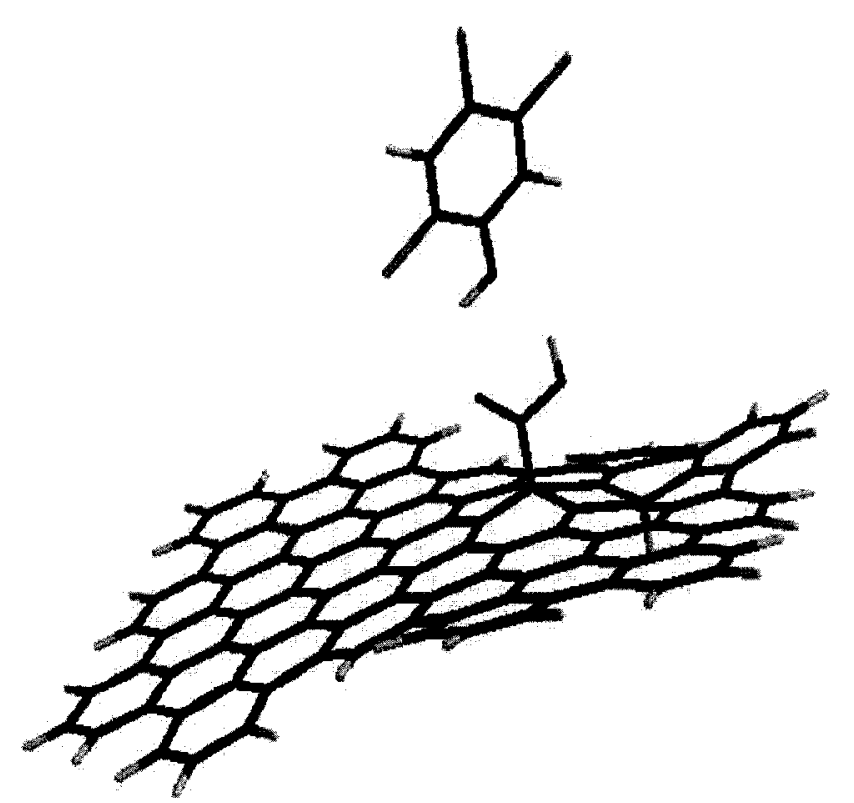

Oxidized MWCNTs and TCP

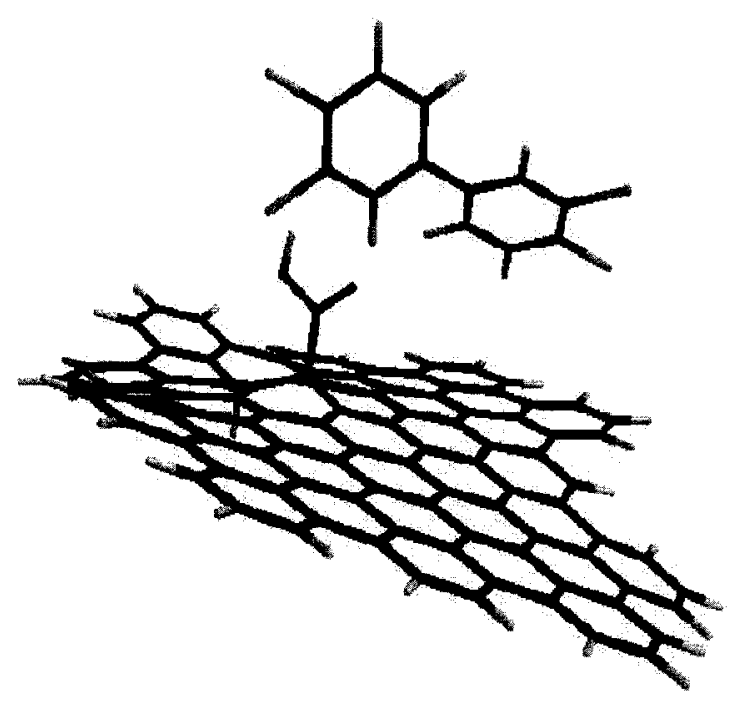

Oxidized MWCNTs and PCB77

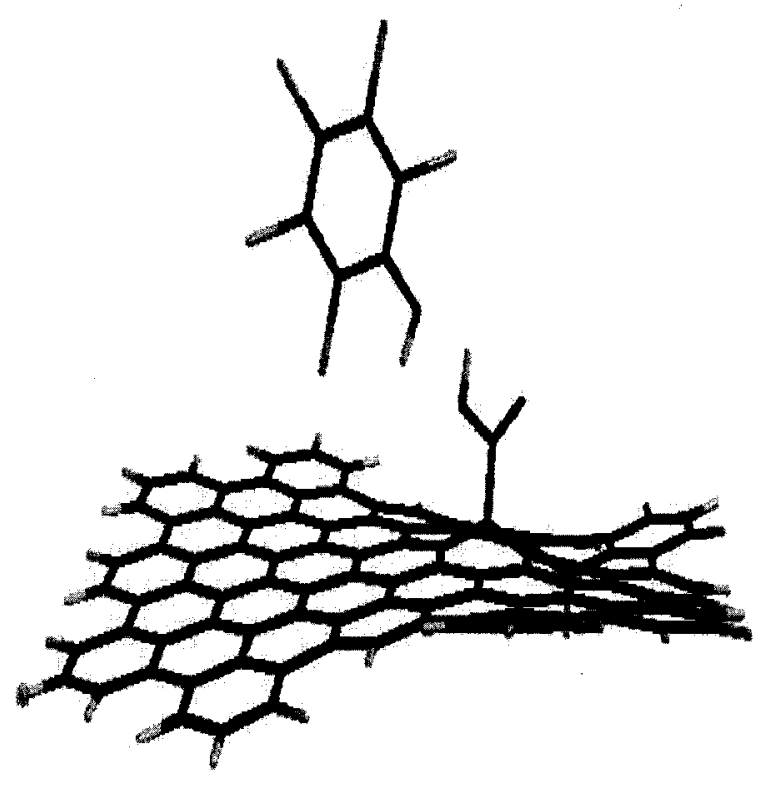

Oxidized MWCNTs and PCP

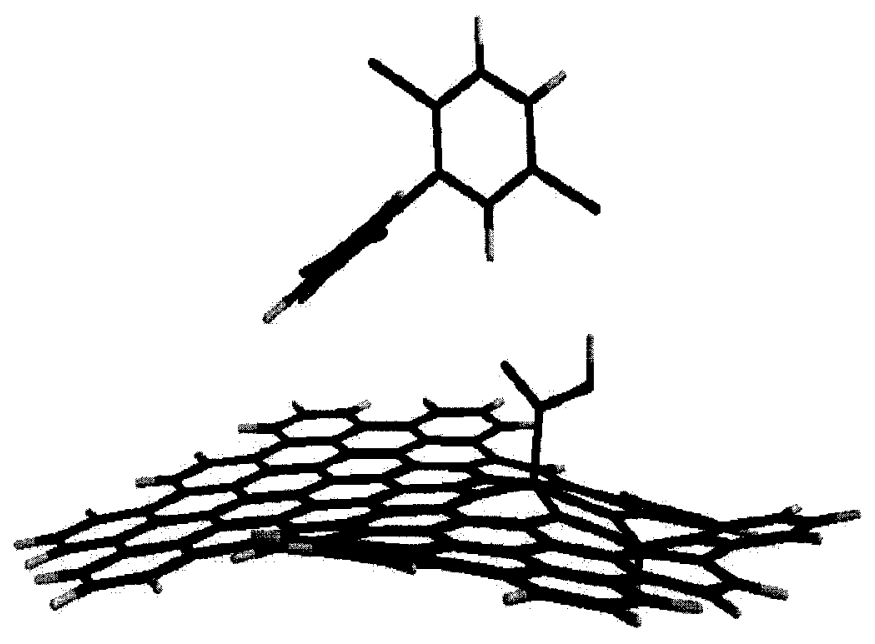

Oxidized MWCNTs and PBB52

Figure 6.2. Adsorption modeling of the four analytes on oxidized MWCNTs.

The black, blue, white, yellow, green, and red colors represent carbon, oxygen, hydrogen, chlorine, nitrogen, and bromine atoms, respectively. 


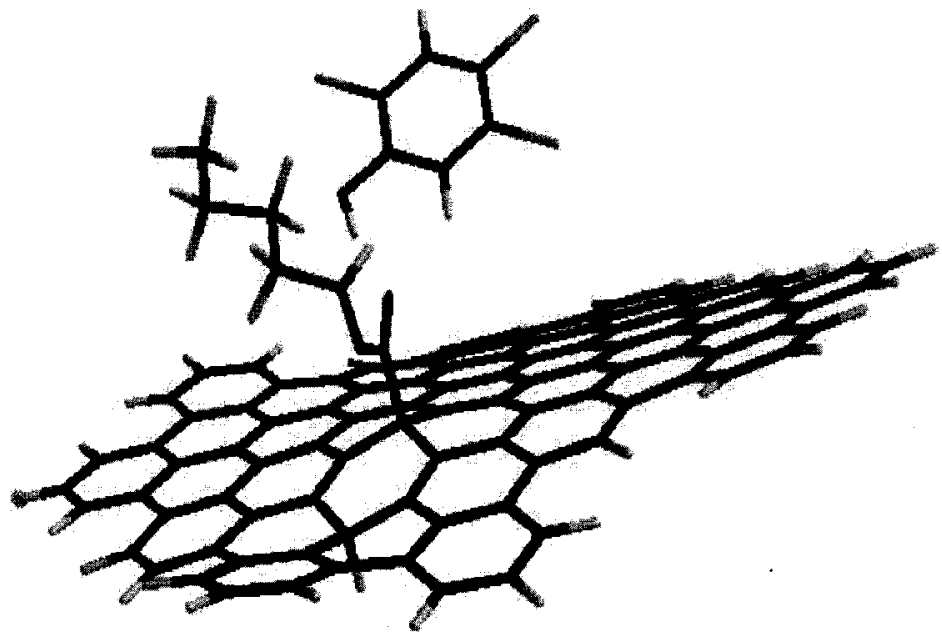

MWCNTs-ODA and TCP

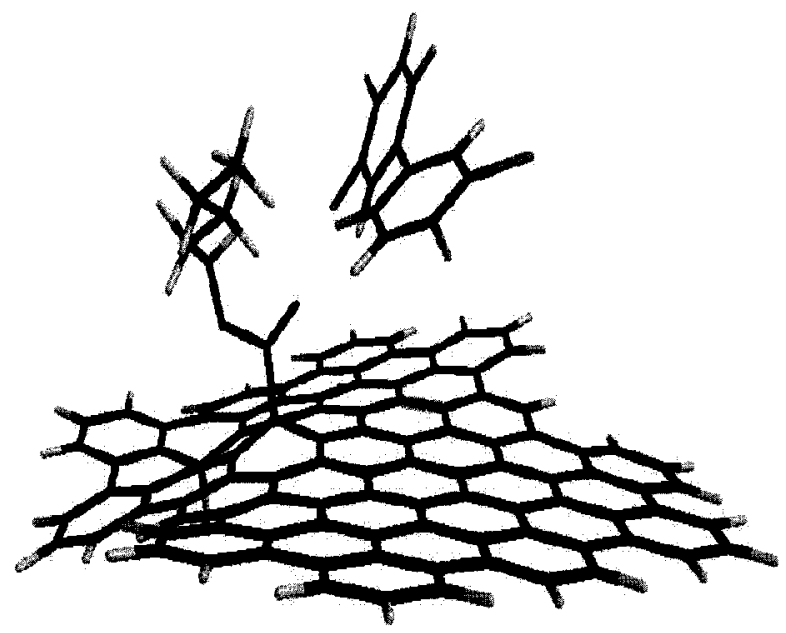

MWCNTs-ODA and PCB77

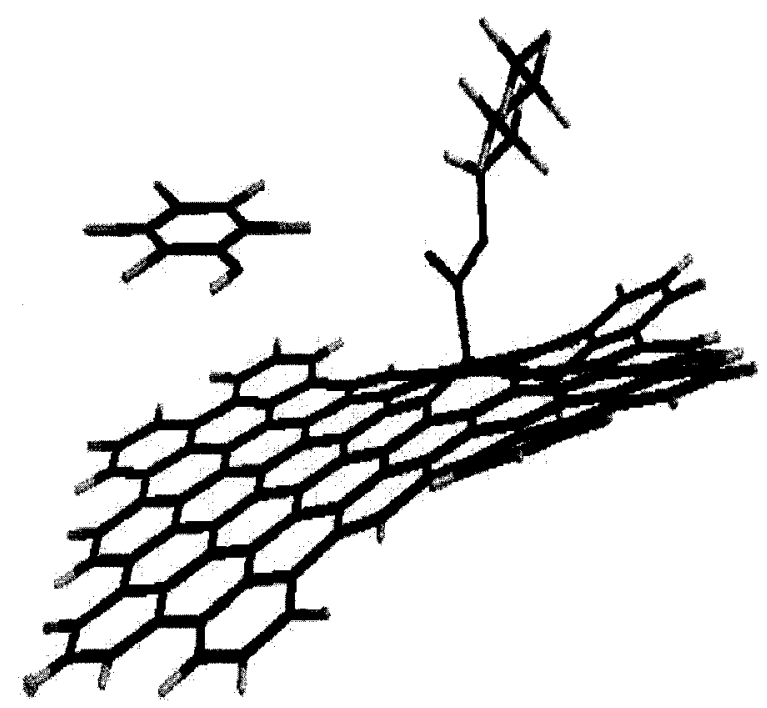

MWCNTs-ODA and PCP

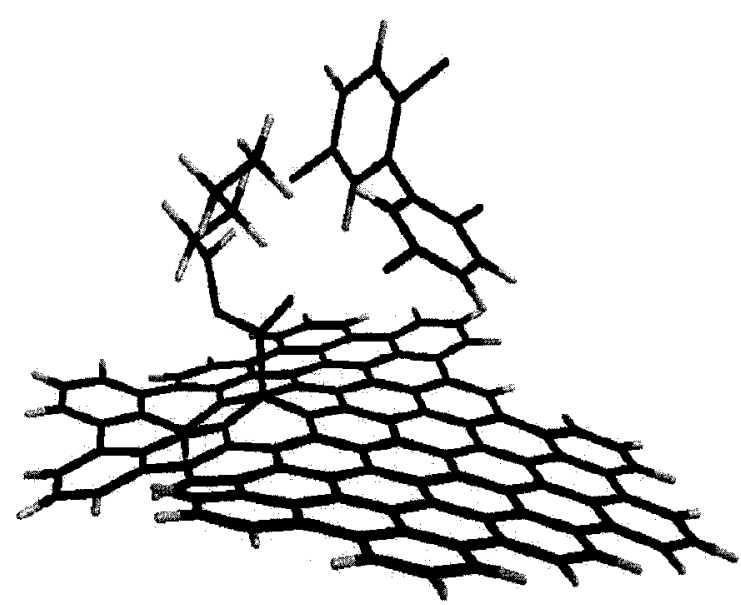

MWCNTs-ODA and PBB52

Figure 6.3. Adsorption modeling of the four analytes on MWCNTs-ODA.

The black, blue, white, yellow, green, and red colors represent carbon, oxygen, hydrogen, chlorine, nitrogen, and bromine atoms, respectively. 


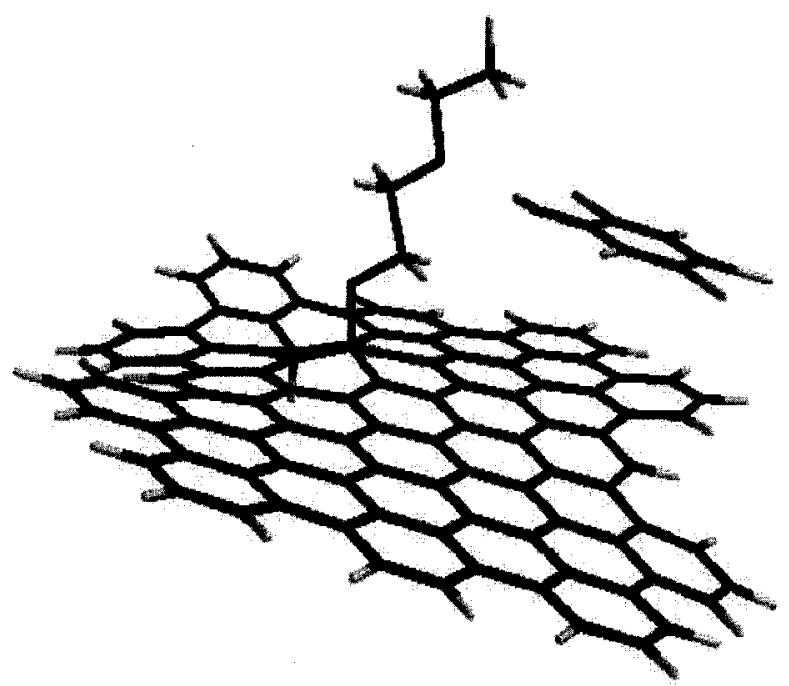

MWCNTs-PEG and TCP

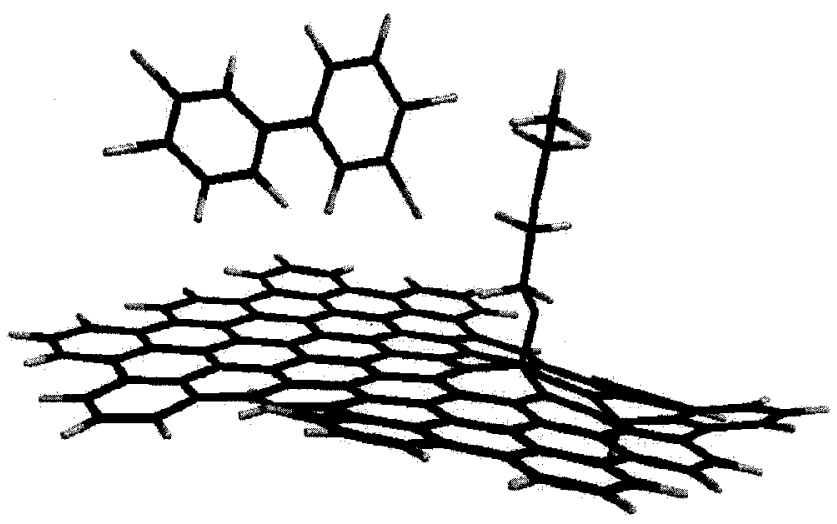

MWCNTs-PEG and PCB77

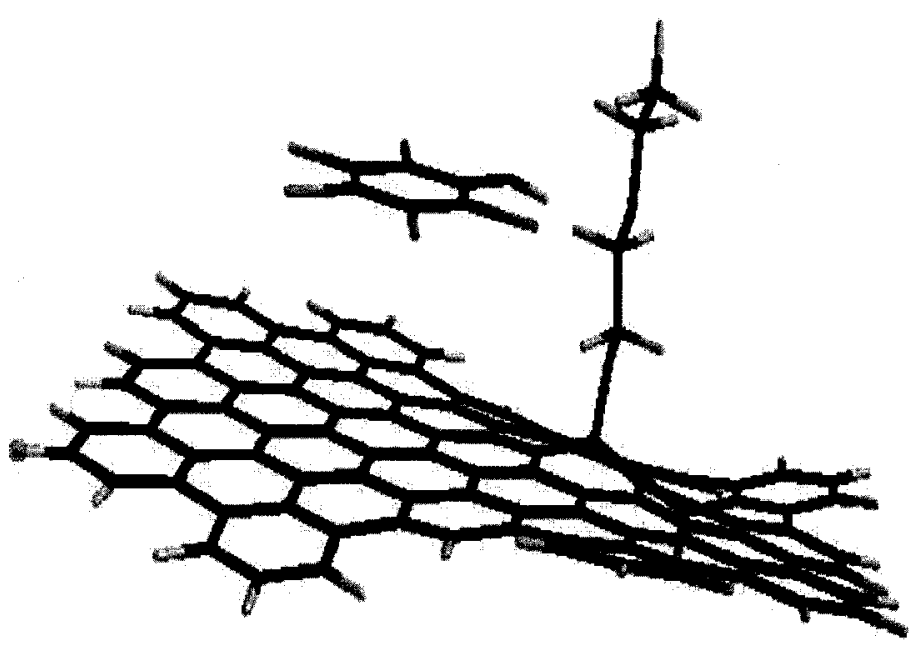

MWCNTs-PEG and PCP

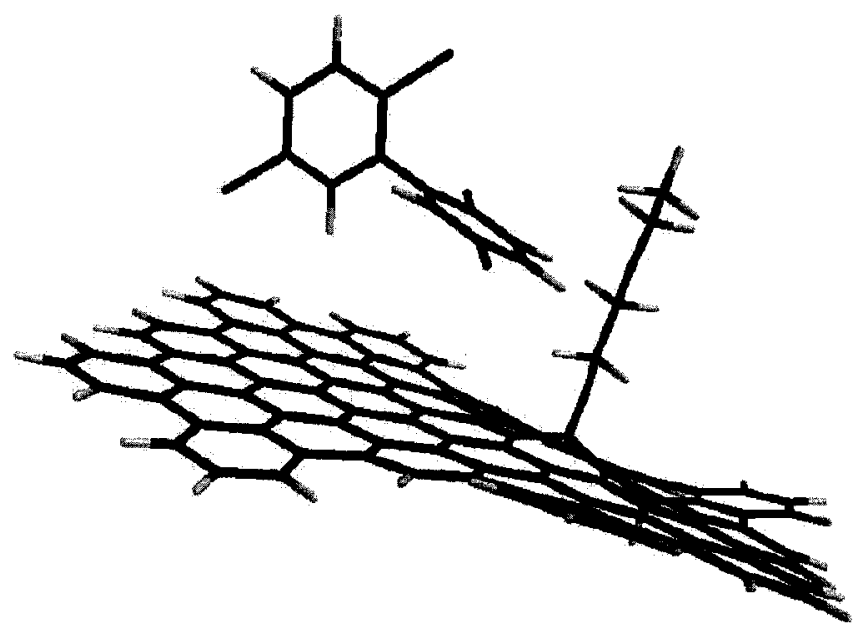

MWCNTs-PEG and PBB52

Figure 6.4. Adsorption modeling of the four analytes on MWCNTs-PEG.

The black, blue, white, yellow, green, and red colors represent carbon, oxygen, hydrogen, chlorine, nitrogen, and bromine atoms, respectively. 
Table 6.2. Calculation of predicted $\Delta G_{\text {Adsorption }_{a q}}$ for the adsorption of different analytes on pristine and modified MWCNTs.

\begin{tabular}{cccccc}
\hline & $\Delta G_{\text {solv }}$ & $G$ & $\Delta G_{\text {solv, complex }}$ & $G_{\text {complex }}$ & predicted $\Delta G_{\text {Adsorption }_{\text {aq }}}$ \\
\hline Pristine MWCNTs & -132.1 & 2499.5 & & & \\
TCP & -18.3 & 113.3 & -139.5 & 2659.2 & 57.3 \\
PCP & -17.5 & 54.5 & -137.2 & 2601.5 & 59.9 \\
PCB77 & -7.1 & 275.5 & -128.2 & 2805.6 & 67.5 \\
PBB52 & -13.8 & 256.3 & -122.6 & 2822.9 & 64.6 \\
\hline Oxidized MWCNTs & -147.4 & 2587.8 & & & \\
TCP & -18.3 & 113.3 & -137.8 & 2750.3 & 76.9 \\
PCP & -17.5 & 54.5 & -134.4 & 2689.4 & 77.5 \\
PCB77 & -7.1 & 275.5 & -137.9 & 2907.9 & 61.2 \\
PBB52 & -13.8 & 256.3 & -143.8 & 2890.2 & 63.4 \\
\hline MWCNTs-PEG & -132.6 & 2852.8 & & & \\
TCP & -18.3 & 113.3 & -125.8 & 3016.2 & 75.2 \\
PCP & -17.5 & 54.5 & -121.6 & 2958.6 & 79.8 \\
PCB77 & -7.1 & 275.5 & -123.6 & 3177.4 & 65.2 \\
PBB52 & -13.8 & 256.3 & -127.9 & 3158.4 & 67.8 \\
\hline MWCNTs-ODA & -33.9 & 695.3 & & & 56.0 \\
TCP & -18.3 & 113.3 & -143.8 & 3068.5 & 3005.3 \\
PCP & -17.5 & 54.5 & -143.7 & 3226.5 & 3208.3 \\
\hline PCB77 & -13.8 & 256.3 & -142.2 & \\
\hline
\end{tabular}


1) for simplicity, the computer modeling accounts for the MWCNTs (host or target) as a 17 fused benzene rings with 102 carbon atoms, whereas the actual MWCNTs consists of enormous number of carbon atoms fused together in 6 and 5 membered rings (like benzene) with high aromatic characters.

2) as was estimated earlier in Chapter 2 and Chapter 5, the MWCNTs surface was covered with different functional groups; carboxylic, phenolic and lactonic for the oxidized MWCNTs, octadecyl chains for MWCNTs-ODA, and polyethyelene chains for MWCNTs-PEG. The computer modeling used only one surface group for each modified MWCNTs, carboxylic group for the oxidized MWCNTs, and a short chain for MWCNTs-ODA and MWCNTs-PEG.

3) the summation of solvation energies of the MWCNTs $\left(\Delta G_{s o l v}\right)$; either pristine or modified, and the analytes $\left(\Delta G_{\text {sol }_{\text {andjut }}}\right)$ before the adsorption are higher than the solvation energy for the complex formed $\left(\Delta G_{\text {salv }_{\text {complex }}}\right)$. This may be explained in the light of strong adsorption (physical adsorption) between the analytes and MWCNTs. As was explained earlier, the presence of the delocalized $\pi$ electrons on any of the analytes and MWCNTs increases their adsorption efficiency and as a result the new complex is more hydrophobic and less accessible for solvation compared with the original reactants.

The relation between the predicted and experimental free energy of adsorption for different analytes on pristine and modified MWCNTs were presented in Table 6.3. The table shows that both of the free energies, predicted and experimental, become more and more negative due to increasing the \% adsorption regardless the type of adsorbent or the 
Table 6.3. Relation between the $\%$ adsorption and the predicted and experimental free energy of adsorption for different analytes on pristine and modified MWCNTs.

\begin{tabular}{|c|c|c|c|c|}
\hline Adsorbent & Analyte & $\begin{array}{c}\% \\
\text { Adsorption }\end{array}$ & $\begin{array}{l}\Delta G_{\text {Adsorption }}(\mathrm{kJ} / \\
\text { Experimental }\end{array}$ & Predicted \\
\hline \multirow[t]{4}{*}{ Pristine MWCNTs } & TCP & 97.2 & -30.5 & 57.3 \\
\hline & PCP & 94.2 & -28.2 & 59.9 \\
\hline & PCB77 & 81.1 & -25.8 & 67.5 \\
\hline & PBB52 & 88.3 & -27.3 & 64.6 \\
\hline \multirow[t]{4}{*}{ Oxidized MWCNTs } & TCP & 65.3 & -22.7 & 76.9 \\
\hline & PCP & 70.0 & -23.2 & 77.5 \\
\hline & PCB77 & 97.7 & -30.9 & 61.2 \\
\hline & PBB52 & 98.2 & -32.2 & 63.4 \\
\hline \multirow[t]{4}{*}{ MWCNTs-PEG } & TCP & 64.9 & -22.7 & 75.2 \\
\hline & PCP & 62.5 & -22.4 & 79.8 \\
\hline & PCB77 & 92.1 & -28.3 & 65.2 \\
\hline & PBB52 & 94.5 & -29.3 & 67.8 \\
\hline \multirow[t]{4}{*}{ MWCNTs-ODA } & TCP & 98.2 & -31.1 & 61.1 \\
\hline & РCP & 99.1 & -32.7 & 56.0 \\
\hline & PCB77 & 99.2 & -34.1 & 53.4 \\
\hline & PBB52 & 97.1 & -31.0 & 55.1 \\
\hline
\end{tabular}


analyte adsorbed. This may indicate that the adsorption process is a product favored reaction. The relation between the predicted and experimental free energy of adsorption were plotted and presented in Figure 6.5. It is clear from the Figure that both of the experimental and predicted free energies of adsorption are in good correlation with one another with a correlation coefficient $\left(\mathrm{R}^{2}\right)$ of 0.836 .

The fact that all the predicted free energies of adsorption are positive, whereas the experimental values are negative may be due to the following previously mentioned approximations and the fact that, the methods used for calculation of free energies and solvation energies are adequate for such simple systems; the major difference between the model (computer results) versus experiment is the fact that only a small fragment of the adsorbents (capable of binding to one ligand only) is used to build each model, while the experiment includes gigantic macromolecular adsorbent, capable of binding to multiple analyte molecules. Entropy changes correspond to changes in the number of particles and degrees of freedom of each particle when the (adsorption) reaction occurs. Figure 6.6 demonstrates a symbolic schematic diagram for the comparison of the model versus experiment adsorption, assuming that the realistic adsorbent binds to three analyte molecules $(\mathrm{N}=3)$. In both model and experiment, the number of particles reduces by $\mathrm{N}$ upon binding. Since in the model there are $\mathrm{N}$ adsorbent molecules rather than one, in both reactants and products, the number of particles (and the entropy terms) are overestimated. Arrows could be used to show overestimation; so for the model we will use: $\mathrm{S}_{\text {products }} \uparrow \uparrow$ and $S_{\text {reactants }} \uparrow \uparrow$ Since the product in experiment is a multiple body complex, it has extra (shared) vibrations resulting extra degrees of freedom, incomparable to (and more than) 


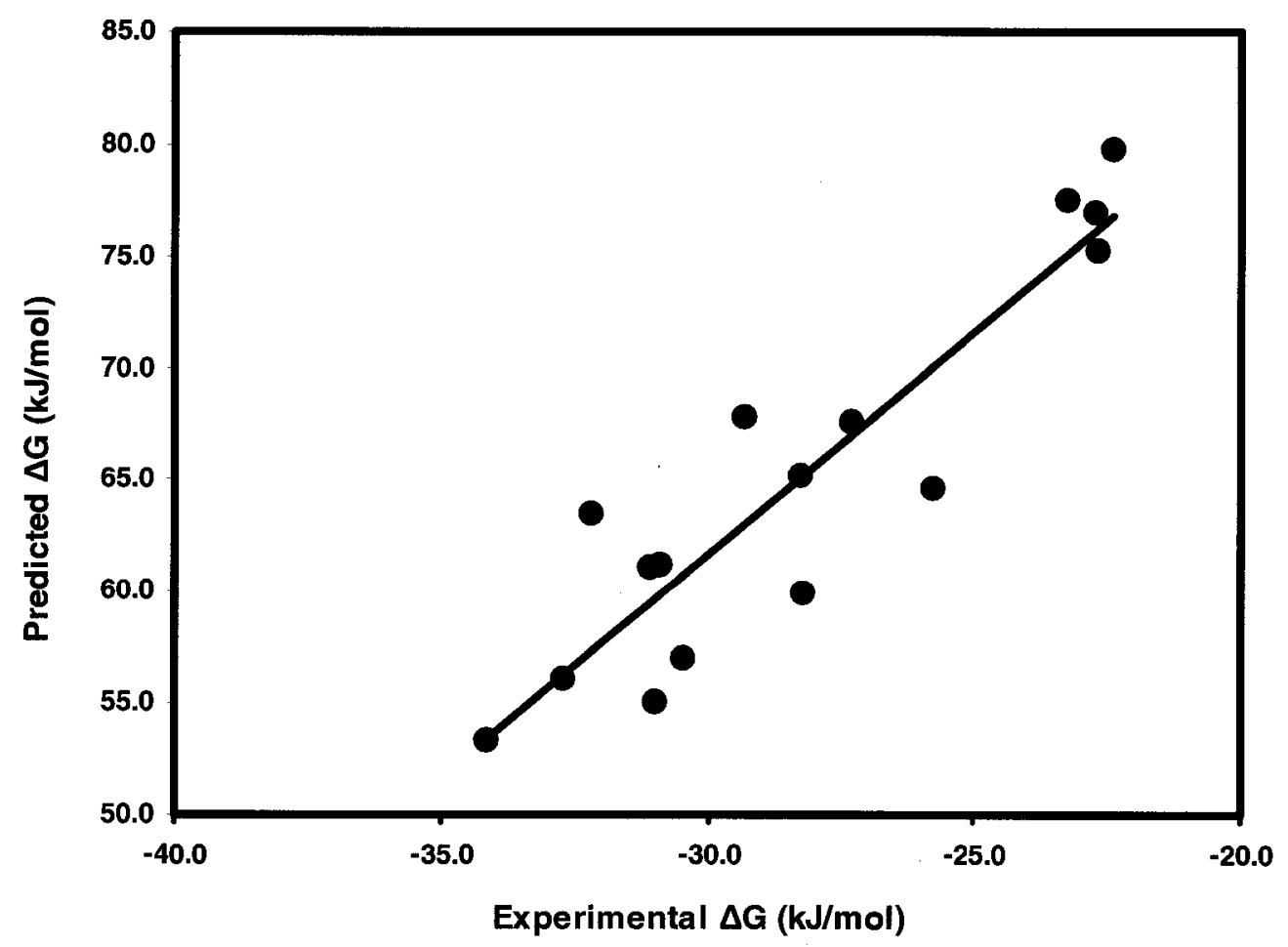

Figure 6.5. Comparison between the experimental and predicted free energies of adsorption. 


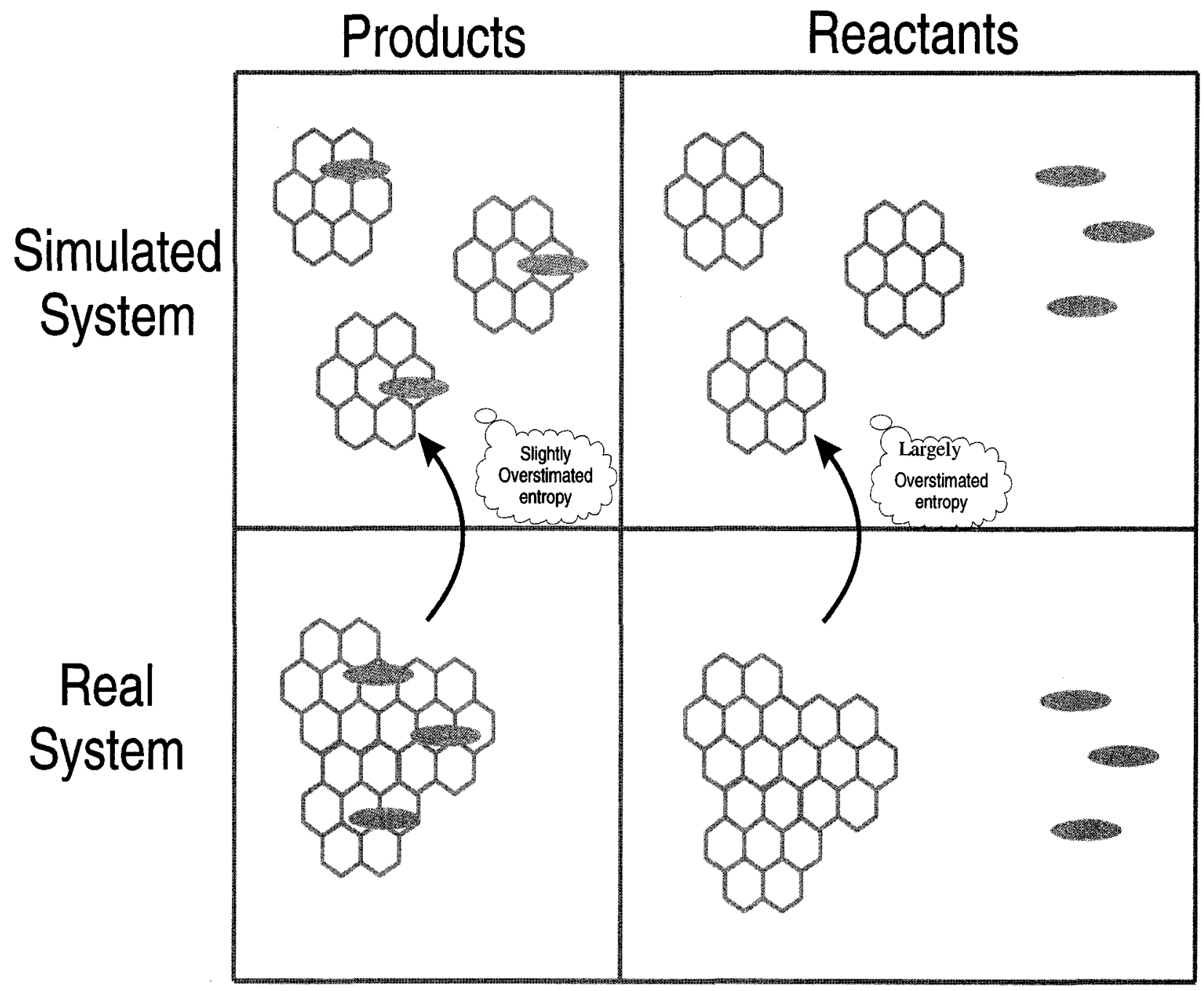

Figure 6.6. Schematic diagram of model vs. experiment for the adsorption on MWCNTs. 
any other molecule in Figure 6.6, so the entropy of the complex in the model is less overestimated. So for the model, instead of $S_{\text {products }} \uparrow \uparrow, S_{\text {products }} \uparrow$ was used. Thus for adsorption reaction, the entropy change is calculated as:

$\Delta \mathrm{S}=\mathrm{S}_{\text {products }} \uparrow-\mathrm{S}_{\text {reactants }} \uparrow \uparrow$

So the overall $\Delta S$ in model is underestimated $(\Delta S \downarrow)$, and so overall $\Delta \mathrm{G}(=\Delta H-T \Delta S)$ is overestimated $(\Delta \mathrm{G} \uparrow)$. That is why the adsorption free energies of the experiments are negative, while the adsorption free energies of the models are positive. As long as in the experiments, the adsorbents (pristine or functionalized) bind to a large number of analytes, the errors (overestimations) remain relatively constant. This is confirmed by successful correlation of models vs experiments build for four different adsorbents.

\subsection{Conclusions}

The effect of the temperature on the adsorption was studied experimentally and the thermodynamic parameters; free energy, enthalpy, and entropy, were calculated. All the adsorption processes were spontaneous at all temperatures (negative free energy) and the enthalpy values were mainly dependent on the type of adsorbent and type of analyte used. The entropy values were positive which indicate entropy driven adsorption. A computer modeling was performed to simulate the adsorption processes of different analytes on pristine and modified MWCNTs and the energy of adsorption was calculated. The predicted free energy values were in good correlation with the experimental free energy values. 


\subsection{References}

[1] Fang G Z, He J X, Wang S, Journal of Chromatography, $A$ 2006, 1127, 12.

[2] Zhou Q, Xiao J, Wang W, Journal of Chromatography, A 2006, 1125, 152.

[3] Basheer C, Alnedhary A A, Rao B S M, Valliyaveettil S, Lee H K, Analytical Chemistry 2006, 78, 2853.

[4] Zhou Q, Wang W, Xiao J, Analytica Chimica Acta 2006, 559, 200.

[5] Zhou Q, Xiao J, Wang W, Liu G, Shi Q, Wang J, Talanta 2006, 68, 1309.

[6] Zhou Q, Wang W, Xiao J, Wang J, Liu G, Shi Q, Guo G, Microchimica Acta 2006, 152, 215-224.

[7] Liang P, Ding Q, Song F, Journal of Separation Science 2005, 28, 2339.

[8] Cai Y, Cai Y, Mou S, Lu Y, Journal of Chromatographia A 2005, 1081, 245.

[9] Lu W F, Ding M Y, Zheng R, Journal of Chromatographic Science 2005, 43, 383.

[10] Ambrosi A, Antiochia R, Campanella L, Dragone R, Lavagnini I, Journal of Hazardous Materials 2005, 122, 219.

[11] Pan C, Xu S, Zou H, Guo Z, Zhang Y, Guo B, Journal of the American Society for Mass Spectrometry 2005, 16, 263.

[12] Liu G, Wang J, Zhu Y, Zhang X, Analytical Letters 2004, 37, 3085.

[13] Liang, Pei; Liu, Yan; Guo, Li; Zeng, Jing; Lu, Hanbing, Journal of Analytical Atomic Spectrometry 2004, 19, 1489.

[14] Cai Y, Jiang G, Liu J, Zhou Q, Analytical Chemistry 2003, 75, 2517.

[15] Lu C, Chung Y L, Chang K F, Water Research 2005, 39, 1183. 
[16] Shadnia H, Wright J, U-Dock docking algorithm, unpublished results, running on MOE® platform (Chemical Computing Group, Monteral).

[17] Spartan 2002 Wavfunction Inc., Irvine, CA. 


\title{
CHAPTER 7
}

\author{
ADSORPTION STUDY AND METHOD \\ DEVELOPMENT OF CHEMICALLY MODIFIED \\ MULTI-WALLED CARBON NANOTUBES AS \\ ADSORBENTS FOR SOLID PHASE EXTRACTION
}




\subsection{Introduction}

A wide variety of pollutants are currently being released into the environmental and consequently contaminating global resources with potentially deleterious effects. Organic pollutants such as chlorophenols and polyhalogenated biphenyls are present in environmental waters at very low concentrations; $\mu \mathrm{g} / \mathrm{L}$, and often below. As a result, very low detection limits methods are required for direct determination and monitoring of such pollutants in the environment. Solid phase extraction (SPE) [1-5] is one of the most popular enrichment techniques which have replaced the traditional, laborious and timeconsuming liquid-liquid extraction (LLE) method. One important problem associated with SPE is the choice of sorbent, as each sorbent has different affinities depending on the physico-chemical properties of the pollutants, such as polarity and solubility. MWCNTs were used previously as the packing materials for SPE of different pollutants. Many research studies showed the ability of CNTs for adsorption of different pollutants such as sulfonamides in eggs and pork [6], dichlorodiphenyltrichloroethane and its metabolites at trace level in water samples [7], organophosphorous pesticides in wastewater sludge [8], nicosulfuron, thifensulfuron-methyl and metsulfuron-methyl in water samples [9], atrazine and simazine in environmental water samples [10,11], trace copper in water samples [12], chlorophenols in environmental water samples [13], amygdaline [14], pharmaceuticals in spiked water samples [15], drugs in urine [16], chlorobenzenes [17], trace metal ions [18], and bisphenol A, 4-n-nonylphenol, and 4-tertoctylphenol [19].

In general, MWCNTs showed good efficiency in the extraction of the above mentioned 
analytes and the determination of their concentrations in different complex matrices. One of the studies [11] made a comparison between different adsorbent materials (MWCNTs, C18 silica and activated carbon) for the extraction of atrazine and simazine. It was found that for the extraction of simazine, MWCNTs were much better than $\mathrm{C}_{18}$ silica, whereas for atrazine, $\mathrm{C} 18$ silica achieved greater extraction than MWCNTs. Activated carbon did not give the expected extraction efficiency because of its large size and less active sites for adsorption compared with MWCNTs and C18 silica. The study demonstrated that MWCNTs could be used as a valuable alternative adsorbent for SPE of atrazine and simazine in many real water samples.

The above mentioned research work used pristine or purified carbon nanotubes to study the SPE of a certain class of analyte, and ignoring the other classes which co-exist with the target analyte. These methods lack the selectivity for the other analytes, whereas CNTs were proved to have a strong adsorption capacity for all type of pollutants. There is no research focus on the method development and application of chemically modified CNTs as an adsorbent for SPE of different analytes from natural samples.

In this chapter the adsorption/desorption behavior of pentachlorophenol (PCP), 2,4,5trichlorophenol (TCP), 3,3',4,4'-tetrachlorobiphenyl (PCB77) and 2,2',5,5'tetrabromobiphenyl (PBB52), were studied using different modified multi-walled carbon nanotubes; namely, pristine MWCNTs, oxidized MWCNTs, and MWCNTs fuctionalized with polyethylene glycol (MWCNTs-PEG) and octadecyl amine (MWCNTs-ODA). A commercially available C18 SPE cartridge was used to compare its adsorption properties with the modified MWCNTs. Method development and evaluation of different 
adsorbents for the extraction of the target analytes from Rideau River fresh water samples is detailed.

\subsection{Experimental}

\subsubsection{Sample Collection and Preparation}

In August 2006, a sample of Rideau River Surface Water (RRSW) sample was collected from a sample collection location close to the Steacie Building at Carleton University in Ottawa, Ontario, using an acid-pre-cleaned Teflon $2.0 \mathrm{~L}$ bottle. The sample was filtered through a $0.45 \mu \mathrm{m}$ polycarbonate membrane (Millipore) immediately after the collection and stored in the dark at $4{ }^{\circ} \mathrm{C}$. The $\mathrm{pH}$ and conductivity of the sample were measured using S47K SevenMulti Modular Meter System and were found to be 8.1 and $300 \mu \mathrm{S}$, respectively. Total organic carbon (TOC) and inorganic carbon (IC) concentrations were measured by a SHIMADZU Total Organic Carbon Analyzer after filtration and were found to be $10.7 \mathrm{mg} / \mathrm{L}$ and $29.5 \mathrm{mg} / \mathrm{L}$, respectively.

\subsubsection{Adsorbents}

The modified MWCNTs were prepared as detailed in Chapter 2 and Chapter 5. Endcapped C18 on silica; $20 \%$ loading with specific surface area of $490 \mathrm{~m}^{2} / \mathrm{g}$, (a hydrophobic sorbent used for the extraction of non-polar analytes in aqueous samples) was obtained from Chromatographic Specialties Inc.

\subsubsection{Chemicals}


PCP and TCP were obtained from Sigma-Aldrich Company, whereas PCB77 and PBB52 (AccuStandard, 100\% pure) were purchased from Chromatographic Specialties Inc.

\subsubsection{Reagents}

Stock solutions were prepared by dissolving appropriate amounts of PCP, TCP, PCB77 and PBB52 in acetone, separately. An aqueous solution containing TCP (58 ng/ml), PCP (61 ng/ml), PCB77 (52 ng/ml), and PBB52 (56 ng/ml), was prepared by addition of aliquots of the stock solutions to deionized water.

\subsubsection{Instrumentation}

Varian 3600 gas chromatograph with an electron capture detector (GC-ECD) was used for the determination of PCP, TCP, PCB77, and PBB52. GC-ECD properties were as follows: $30 \mathrm{~m} \times 0.25 \mathrm{~mm}$ id $\times 0.25 \mu \mathrm{m}$ film thickness DB-5 silica capillary column (J \& W Scientific), helium as the carrier gas at a flow rate of $1.0 \mathrm{~mL} / \mathrm{min}$; nitrogen as the make-up gas at a flow rate of $27 \mathrm{~mL} / \mathrm{min}$; injector temperature, $300^{\circ} \mathrm{C}$; column initial temperature, $70^{\circ} \mathrm{C}$; and final temperature, $280^{\circ} \mathrm{C}$; with heating rate, $15^{\circ} \mathrm{C} / \mathrm{min}$; detector temperature, $300^{\circ} \mathrm{C}$. The sample size injected was $1 \mu \mathrm{L}$.

\subsubsection{Analytical procedure}

Due to the polarity of PCP and TCP, an acetylation step was required prior to the injection of this sample into the GC-ECD. For acetylation, $3.0 \mathrm{~mL}$ of $5 \% \mathrm{~K}_{2} \mathrm{CO}_{3}$ solution was added to the aqueous solution of PCP and TCP and the solution was shaken for 1 minute, followed by the addition of $2.0 \mathrm{~mL}$ of acetic anhydride, and vigorous shaking for 
2 minutes to ensure complete acetylation of the PCP and TCP. The acetylated PCP and TCP were extracted into n-hexane with 2 minutes of shaking. Acetic anhydride (reagent grade $\geq 98$ ) and $\mathrm{K}_{2} \mathrm{CO}_{3}$ (analytical grade) were obtained from Aldrich and Optima grade hexane was obtained from Fisher Scientific.

\subsubsection{Solid phase extraction (SPE) procedure}

Inert glass tubes (Supelco), $3 \mathrm{~mL}$ capacity, were used as the packing cartridges for SPE. The adsorbent was packed into the cartridge and Teflon upper and lower frits at each end of the cartridge were used to hold the adsorbent packing in place. Conditioning of the SPE cartridge with $5 \mathrm{ml}$ deionized water, followed by $5 \mathrm{ml}$ methanol, and finally with 5 $\mathrm{ml}$ of deionized water, was performed prior to the extraction of the target analytes. 20.0 $\mathrm{ml}$ of the aqueous solution containing TCP (58 ng/ml), PCP (61 ng/ml), PCB77 (52 $\mathrm{ng} / \mathrm{ml})$, and PBB52 $(56 \mathrm{ng} / \mathrm{ml})$ was passed through the cartridge at a measured flow rate using a vacuum. The aqueous solution was then analyzed for the remaining PCP, TCP, PCB, and PBB by liquid-liquid extraction. The set up of the SPE system is shown in Figure 7.1 .

After the extraction, a measured amount of the elution solvent was passed through the SPE cartridge with a flow rate of $1.0 \mathrm{ml} / \mathrm{min}$ and the amount of solvent was collected again in $15 \mathrm{ml}$ glass vial. Then, the amount of solvent was reduced to an approximate volume of $0.2 \mathrm{ml}$ using a gentle stream of nitrogen gas. $10 \mathrm{ml}$ of deionized water was added to the extract followed by derivatization of the chlorophenols and further analysis using GC-ECD. 


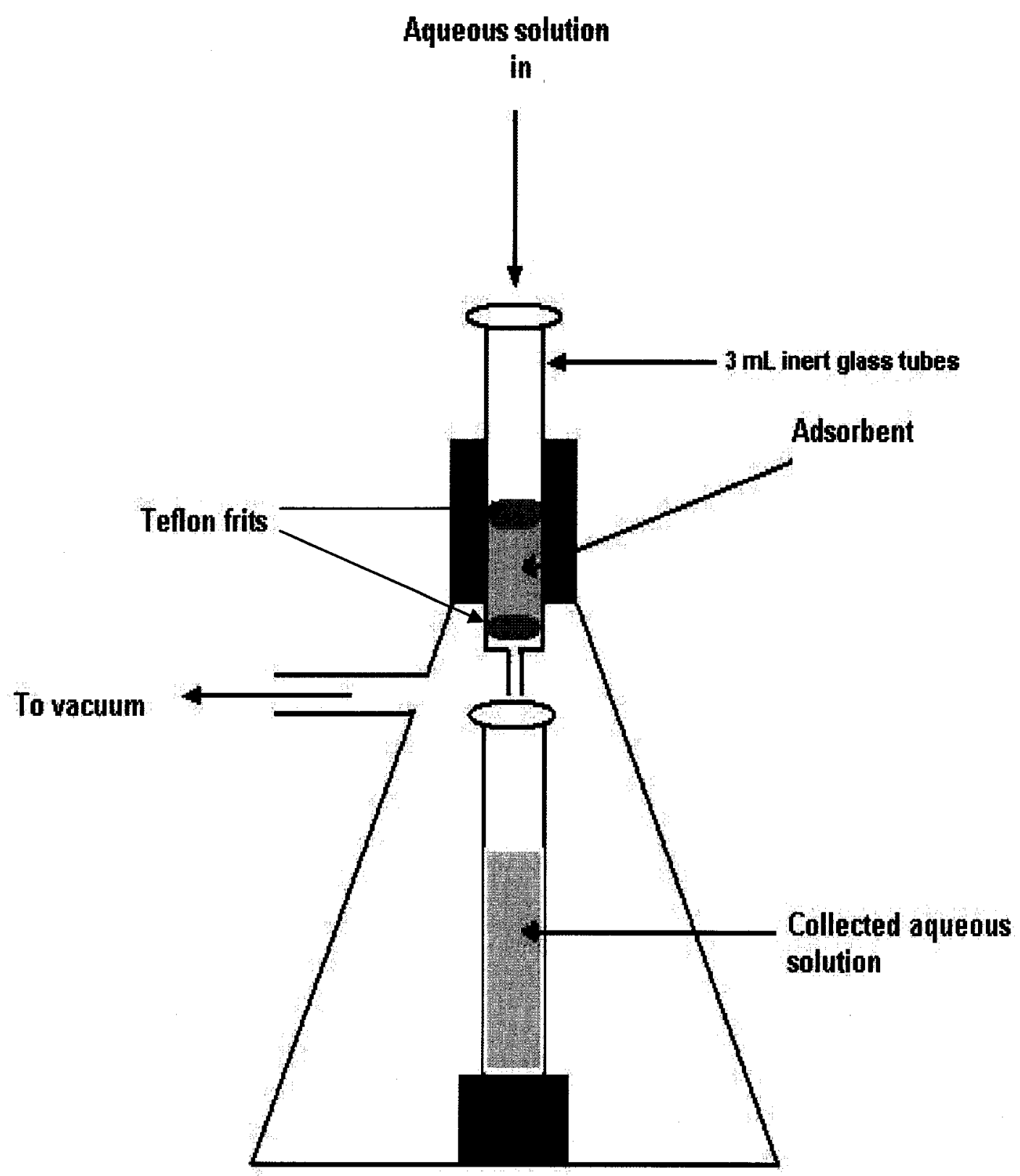

Figure 7.1. Schematic diagram of the solid phase extraction system set up. 


\subsection{Results and Discussion}

This chapter discusses different factors affecting the adsorption and desorption processes of the target analytes and the SPE method development for the extraction of different analytes from aqueous solution including surface water sample.

\subsubsection{Adsorption study}

The adsorption process was greatly affected by various factors such as the type of adsorbent, type of adsorbate, flow rate, mass of adsorbent, and $\mathrm{pH}$ of the aqueous solution.

\subsubsection{Effect of flow rate}

Flow rate of the aqueous sample always makes a significant impact on the analysis time, and is one of the most important parameters to be considered in the SPE process. Moreover, it may affect the interaction between the adsorbent and the analytes, as high flow rate may decrease the interaction and hence decrease the time of adsorption of the analytes into the adsorbent. The effect of the flow rate on the adsorption of different analytes of interest; PCP, TCP, PCB77, and PBB52 on different adsorbents; pristine MWCNTs, MWCNTs-PEG, MWCNTs-ODA, and C18 was studied at constant adsorbent mass; $(20 \mathrm{mg})$, and in an unbuffered aqueous solution $(\mathrm{pH}=6.0)$. Five settings of the flow rate were used for all adsorbents; $2,5,10,15$, and $20 \mathrm{~mL} /$ minute. Figures 7.2, 7.3, 7.4, and 7.5 show the flow rate effect on the adsorption of TCP, PCP, PCB77, and PBB52, on the different adsorbents. Generally, adsorption of the four analytes was decreased by increasing the flow rate from $2 \mathrm{~mL} / \mathrm{min}$ to $20 \mathrm{~mL} / \mathrm{min}$, regardless the type of adsorbent used. This may be attributed to decreasing the contact time between the adsorbate and the 


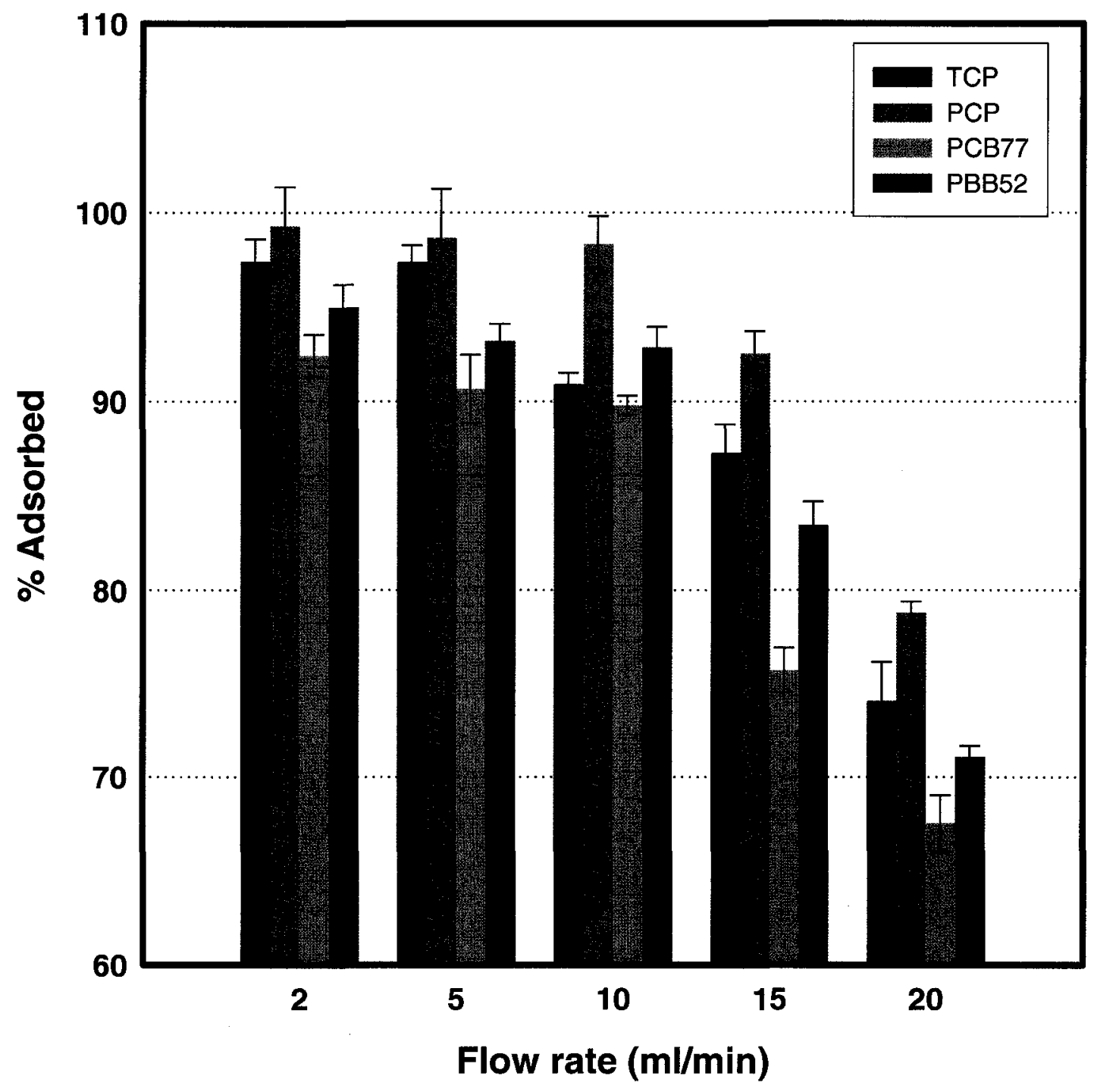

Figure 7.2. Effect of flow rate on the adsorption of TCP, PCP, PCB77, and PBB52 on pristine MWCNTs. 


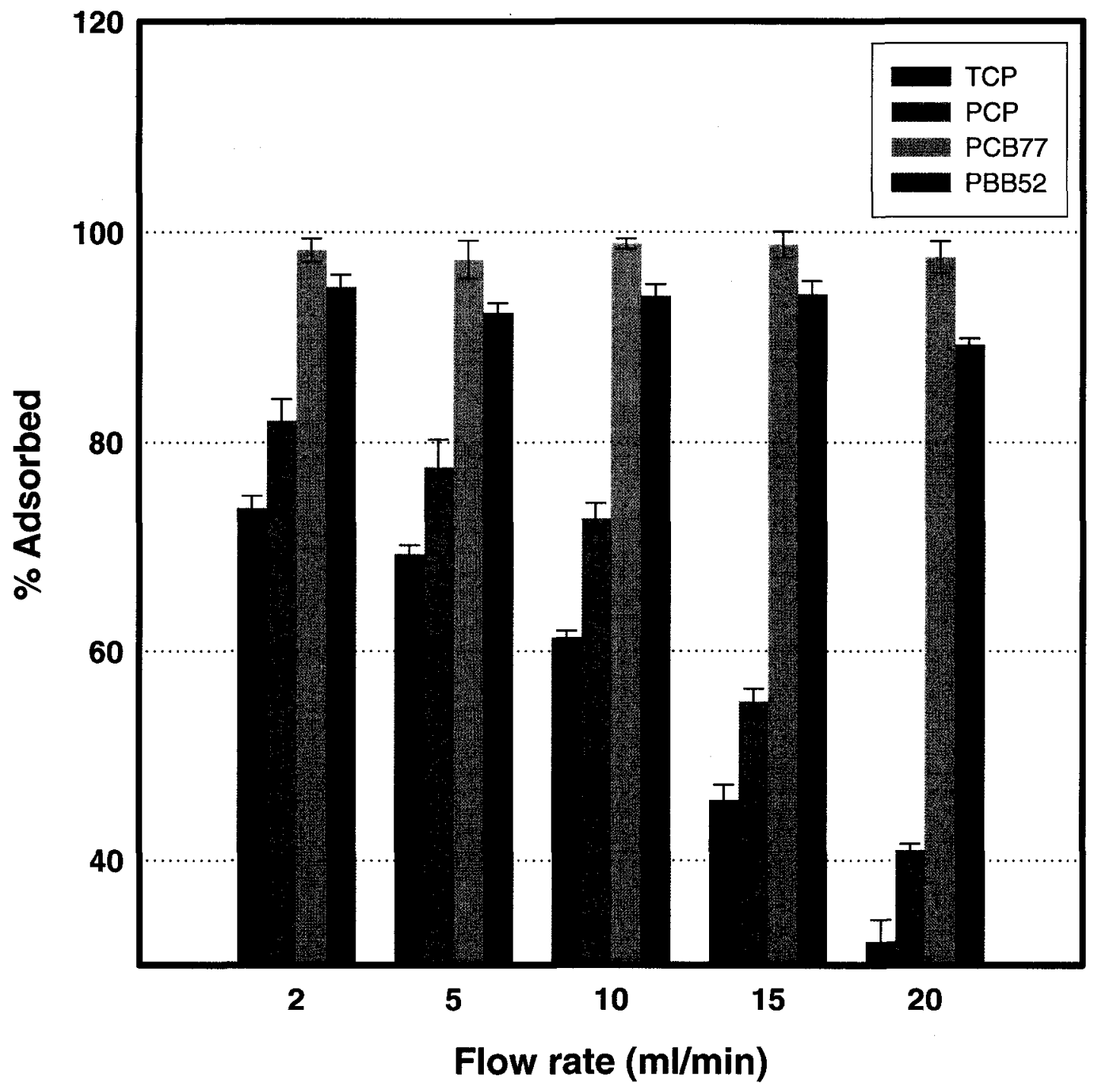

Figure 7.3. Effect of flow rate on the adsorption of TCP, PCP, PCB77, and PBB52 on MWCNTs-PEG. 


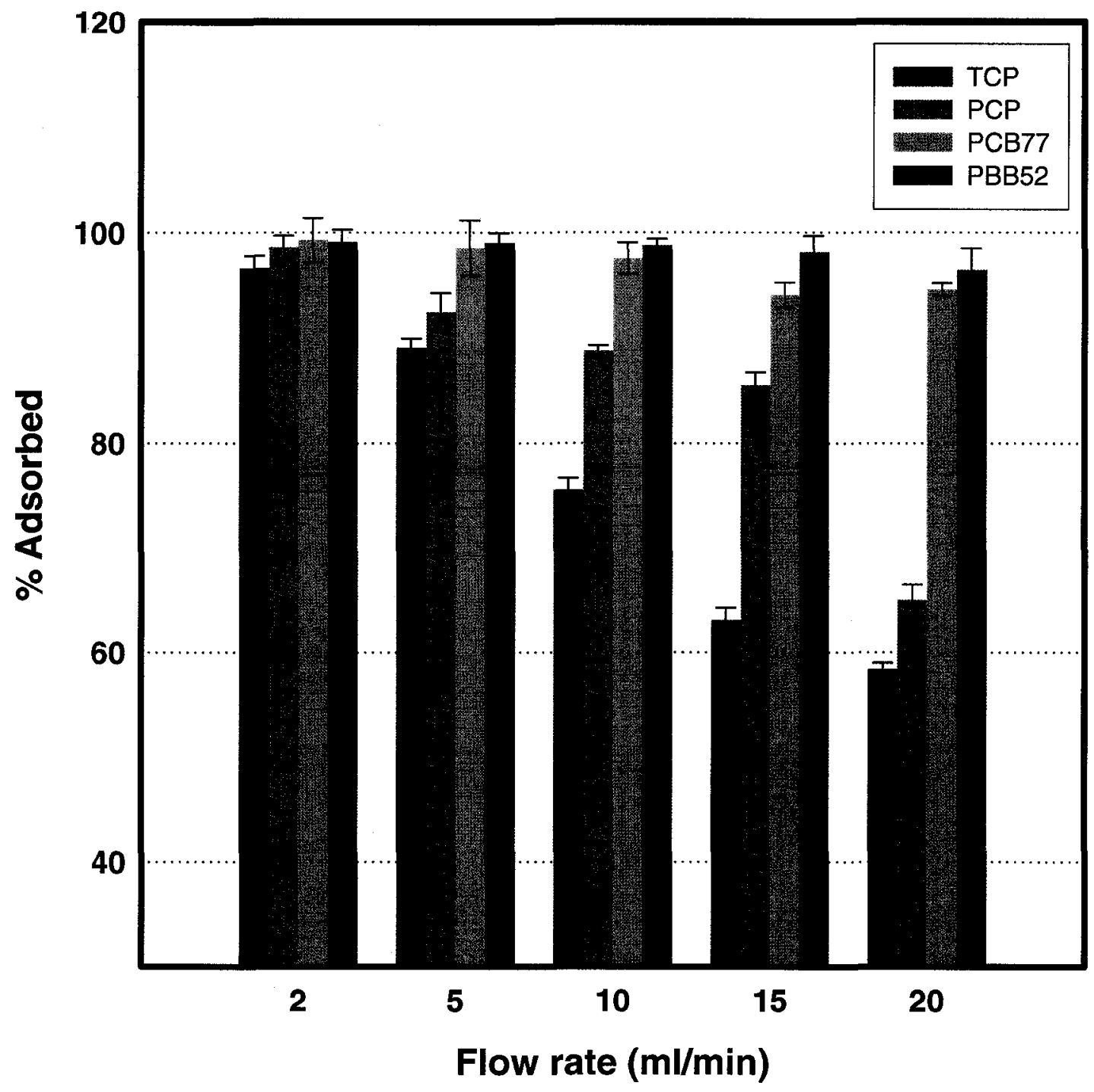

Figure 7.4. Effect of flow rate on the adsorption of TCP, PCP, PCB77, and PBB52 on MWCNTs-ODA. 


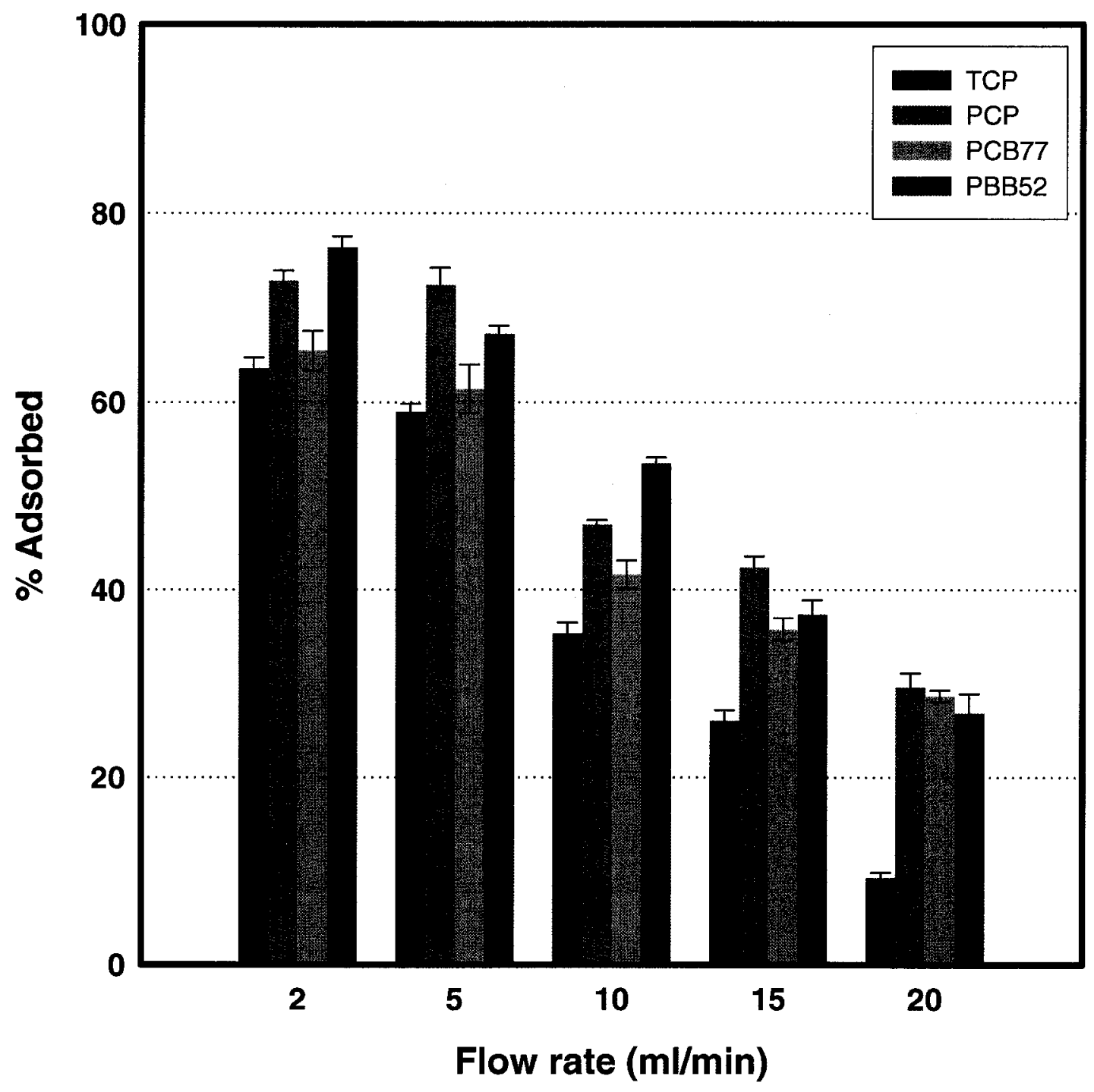

Figure 7.5. Effect of flow rate on the adsorption of TCP, PCP, PCB77, and PBB52 on C18. 
adsorbent. Also, Figure 7.2 shows that pristine MWCNTs have higher affinity towards the adsorption of TCP and PCP compared with PCB77 and PBB52. This may attributed to the number of benzene rings in the adsorbed analytes. The presence of one benzene ring on both TCP and PCP molecules allow them to be adsorbed easily on the MWCNTs. On the other hand, PCB77 and PBB52 contains two benzene rings, one of them is perpendicular on the other, which makes the adsorption more difficult. Figure 7.3 shows that MWCNTs-PEG has higher affinity towards the adsorption of non-polar analytes such as PCB77 and PBB52. This may be due to the fact that MWCNTs-PEG contain more oxygen-function groups; either from the oxidation of the carbon nanotubes or from the polyethylene glycol itself, compared with the other adsorbents. As was explained earlier in Chapter 4, these oxygen-containing functional groups present on the surface of the MWCNTs inhibit the adsorption of chlorophenols to the surface of the adsorbent due to the localization of the $\pi$-electron of the MWCNTs as well as the solvent effect. The inhibition of the oxygen functional groups to the adsorption of chlorophenols was confirmed by studying their adsorption on oxidized MWCNTs. Oxidized MWCNTs were packed inside the SPE cartridge and the aqueous solution was passed through it. It was not possible to control the flow rate as a result of the great hydrophilicity of the oxidized MWCNTs, which tended to block the Teflon frits and reduce the flow rate of the solution. Oxidized MWCNTs were able to adsorb $87.6 \%, 55.46 \%, 99.64 \%$, and $100 \%$ of TCP, PCP, PCB77, and PBB52, respectively, from the aqueous solution, whereas MWCNTsPEG were able to adsorb $73.7 \%, 82.0 \%, 98.3 \%$, and $98.8 \%$ of TCP, PCP, PCB77, and PBB52, respectively, from the aqueous solution. 
Figure 7.4 presents the applicability of MWCNTs-ODA as the packing material for SPE of TCP, PCP, PCB77, and PBB52 from aqueous solution. The Figure shows that MWCNTs-ODA was able to adsorb most of the analytes; more than $98 \%$ with a 2.0 $\mathrm{ml} / \mathrm{min}$ flow rate, much better than the pristine MWCNTs and MWCNTs-PEG. This may be due to the presence of both the long chains of ODA as well as the delocalized $\pi$ electrons on the MWCNTs surface. It is clear from Figure 7.5 that C18 showed a lower adsorption for the four analytes compared with the other adsorbents. This may be due the lack of the delocalized $\pi$ electrons on the silica compared with MWCNTs. The $\pi-\pi$ interaction between the MWCNTs and benzene ring(s) of the TCP, PCP, PCB77, and PBB52 is likely the main reason for the great adsorption properties of carbon nanotubes.

The comparison between the adsoption affinities of each analyte with different adsorbents was performed to explore the suitability of each adsorbent towards a certain analyte and the results are shown in Figure 7.6. For TCP, the adsorption affinity was pristine MWCNTs $\approx$ MWCNTs-ODA $>$ MWCNTs-PEG $>$ C18. This may be attributed to the high concentration of oxygen containing functional groups on the surface of MWCNTs-PEG and the unsuitability of $\mathrm{C} 18$ for the extraction of polar analytes such as TCP and PCP. MWCNTs-PEG shows higher adsorption affinity towards TCP compared with $\mathrm{C} 18$, and lower adsorption compared with MWCNTs-ODA. This may be explained as follows: adsorption of TCP on MWCNTs-PEG is the net results between enhancement of adsorption with the presence of the $\pi-\pi$ interaction between the non-functionalized sites of the carbon tubes and $\mathrm{TCP}$, and reduction of adsorption by the $\pi-\pi$ dispersion 


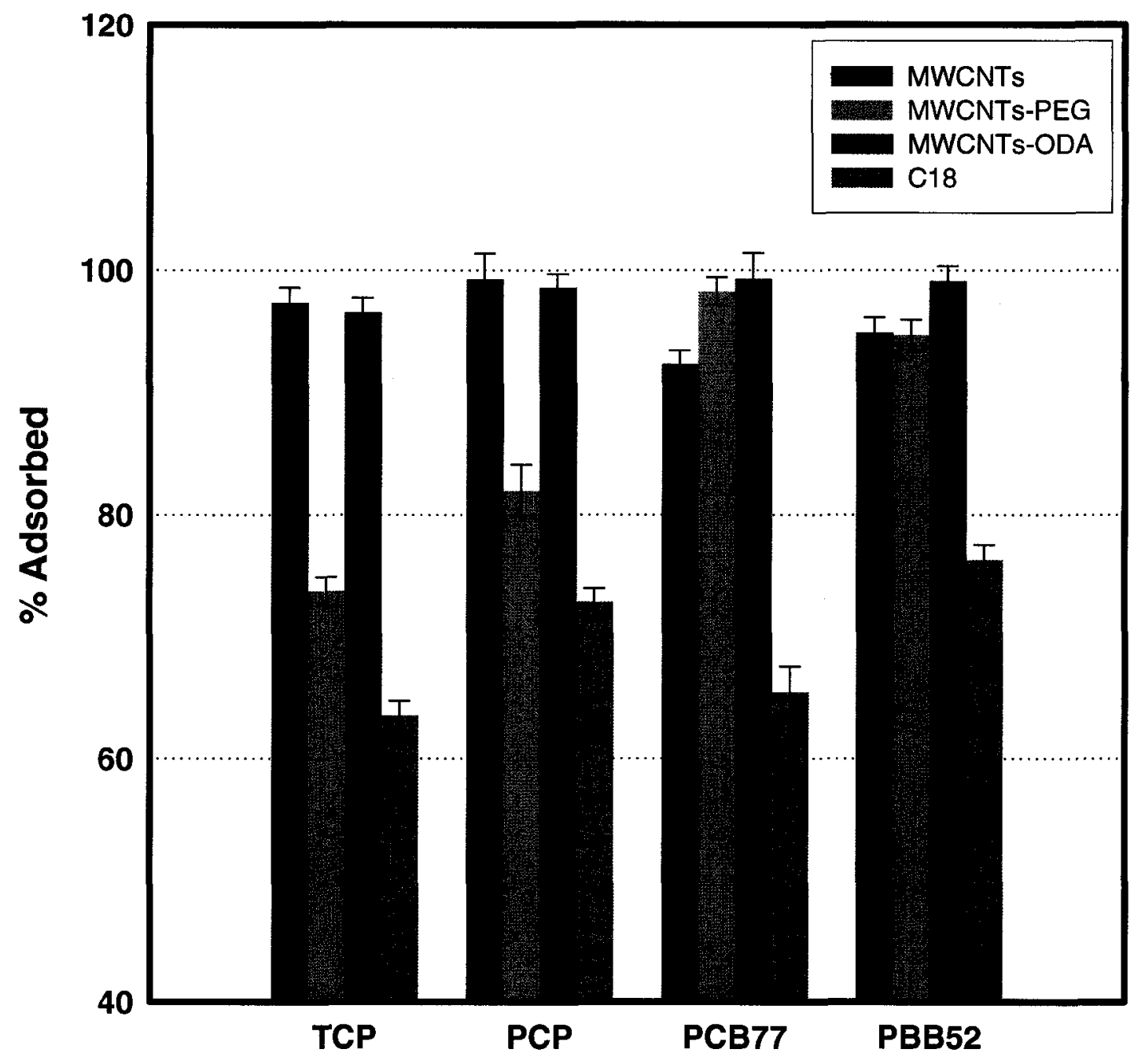

Figure 7.6. Comparison between the adsorption of each analytes with different adsorbents (flow rate is $2 \mathrm{ml} / \mathrm{min}$, mass of adsorbent is $20 \mathrm{mg}$ ). 
between the oxygen containing function groups and TCP. The same effect was observed for the adsorption of PCP on the different types of adsorbents.

In the case of PCB77, the adsorption affinity follows the following order pristine MWCNTs-ODA $>$ MWCNTs-PEG $>$ MWCNTs $>$ C18. This may be due to the absorption between the chains of the ODA or the PEG that was created on the surface of MWCNTs, as well as the adsorption on the nonfunctionalized MWCNTs surface. According to the TGA (Chapter 5), the degree of functionalization of MWCNTs with ODA was higher than PEG; $39 \%$ and $16 \%$, respectively. This could be the reason for the higher affinity of MWCNTs-ODA compared with MWCNTs-PEG.

\subsubsection{Effect of adsorbent mass}

The effect of adsorbent mass on the adsorption of PCP, TCP, PCB77, and PBB52 was studied for different adsorbents; pristine MWCNTs, MWCNTs-PEG, MWCNTs-ODA, C18 and oxidized MWCNTs, at a fixed flow rate $(5.0 \mathrm{ml} / \mathrm{min})$, and using an unbuffered aqueous solution $(\mathrm{pH}=6.0)$. It is important to mention again that due to the great solubility of oxidized MWCNTs, it was not possible to adjust the flow rate, and as a result the data obtained did not reflect the actual adsorption behavior. Five different masses were used; $5,10,15,20$, or $30 \mathrm{mg}$ of the adsorbent were packed inside the SPE cartridge. Effects of changing the adsorbent mass on the \% of analyte adsorbed are presented in Table 7.1 and Figures 7.7, 7.8, 7.9, and 7.10. Generally, it is clear that increasing the amount of adsorbent led to increasing the \% of the analyte adsorbed. Increasing the adsorbent mass may affect the adsorption in different ways. It may 
Table 7.1. Effect of mass on the adsorption of the target analytes on different adsorbent

$$
(n=3)
$$

\begin{tabular}{|c|c|c|c|c|}
\hline$\%$ Adsorbed & TCP & PCP & PCB77 & PBB52 \\
\hline Adsorbent mass (mg) & \multicolumn{4}{|c|}{ Pristine MWCNTs } \\
\hline 5 & $63.9 \pm 1.4$ & $69.7 \pm 1.5$ & $68.2 \pm 2.1$ & $65.4 \pm 1.1$ \\
\hline 10 & $72.6 \pm 1.5$ & $77.0 \pm 2.8$ & $70.9 \pm 1.1$ & $67.8 \pm 0.9$ \\
\hline 15 & $81.0 \pm 1.9$ & $87.9 \pm 1.1$ & $73.6 \pm 1.2$ & $76.3 \pm 1.5$ \\
\hline 20 & $97.3 \pm 1.1$ & $98.7 \pm 1.5$ & $80.7 \pm 1.0$ & $83.2 \pm 1.8$ \\
\hline 30 & $98.0 \pm 1.8$ & $98.5 \pm 1.1$ & $86.2 \pm 1.0$ & $84.1 \pm 1.6$ \\
\hline Adsorbent mass (mg) & \multicolumn{4}{|c|}{ MWCNTs-PEG } \\
\hline 5 & $25.2 \pm 1.4$ & $41.5 \pm 1.2$ & $88.4 \pm 1.1$ & $69.6 \pm 1.5$ \\
\hline 10 & $29.9 \pm 1.5$ & $43.3 \pm 1.9$ & $91.8 \pm 1.9$ & $75.1 \pm 1.4$ \\
\hline 15 & $34.8 \pm 1.6$ & $46.7 \pm 1.3$ & $99.1 \pm 1.4$ & $80.6 \pm 1.5$ \\
\hline 20 & $69.2 \pm 1.9$ & $77.6 \pm 1.5$ & $97.4 \pm 1.8$ & $94.1 \pm 1.9$ \\
\hline 30 & $69.5 \pm 1.8$ & $79.7 \pm 1.6$ & $98.4 \pm 1.5$ & $94.2 \pm 2.1$ \\
\hline Adsorbent mass (mg) & \multicolumn{4}{|c|}{ MWCNTs-ODA } \\
\hline 5 & $76.1 \pm 1.9$ & $71.9 \pm 1.1$ & $79.0 \pm 1.9$ & $81.9 \pm 1.2$ \\
\hline 10 & $86.0 \pm 1.6$ & $92.4 \pm 1.9$ & $85.6 \pm 1.8$ & $89.0 \pm 1.3$ \\
\hline 15 & $91.7 \pm 1.9$ & $95.2 \pm 1.8$ & $96.2 \pm 1.4$ & $98.2 \pm 1.0$ \\
\hline 20 & $98.0 \pm 1.4$ & $96.4 \pm 2.1$ & $98.6 \pm 1.5$ & $99.0 \pm 1.1$ \\
\hline 30 & $99.2 \pm 1.5$ & $98.7 \pm 1.5$ & $99.1 \pm 1.1$ & $99.7 \pm 1.9$ \\
\hline Adsorbent mass (mg) & \multicolumn{4}{|c|}{ C18 } \\
\hline 5 & $19.8 \pm 1.8$ & $30.2 \pm 1.1$ & $25.3 \pm 1.4$ & $27.6 \pm 1.0$ \\
\hline 10 & $28.1 \pm 1.0$ & $42.0 \pm 1.6$ & $41.1 \pm 1.9$ & $47.2 \pm 1.9$ \\
\hline 15 & $43.0 \pm 1.9$ & $59.0 \pm 1.8$ & $53.2 \pm 1.3$ & $55.0 \pm 2.1$ \\
\hline 20 & $58.9 \pm 1.4$ & $72.4 \pm 1.3$ & $61.4 \pm 1.2$ & $67.2 \pm 1.8$ \\
\hline 30 & $64.9 \pm 1.3$ & $75.1 \pm 1.4$ & $76.1 \pm 1.3$ & $80.0 \pm 1.7$ \\
\hline Adsorbent mass (mg) & \multicolumn{4}{|c|}{ Oxidized MWCNTs } \\
\hline 5 & $63.5 \pm 1.5$ & $38.9 \pm 1.9$ & $96.1 \pm 2.1$ & $97.8 \pm 1.6$ \\
\hline 10 & $73.5 \pm 1.8$ & $44.9 \pm 2.3$ & $97.9 \pm 1.2$ & $98.1 \pm 1.4$ \\
\hline 15 & $87.5 \pm 1.4$ & $45.6 \pm 1.6$ & $99.2 \pm 1.9$ & $98.4 \pm 1.3$ \\
\hline 20 & $87.6 \pm 1.5$ & $55.5 \pm 1.3$ & $99.6 \pm 1.1$ & $100.1 \pm 2.1$ \\
\hline 30 & $91.1 \pm 1.7$ & $75.2 \pm 1.9$ & $100 \pm 1.5$ & $100.1 \pm 1.5$ \\
\hline
\end{tabular}




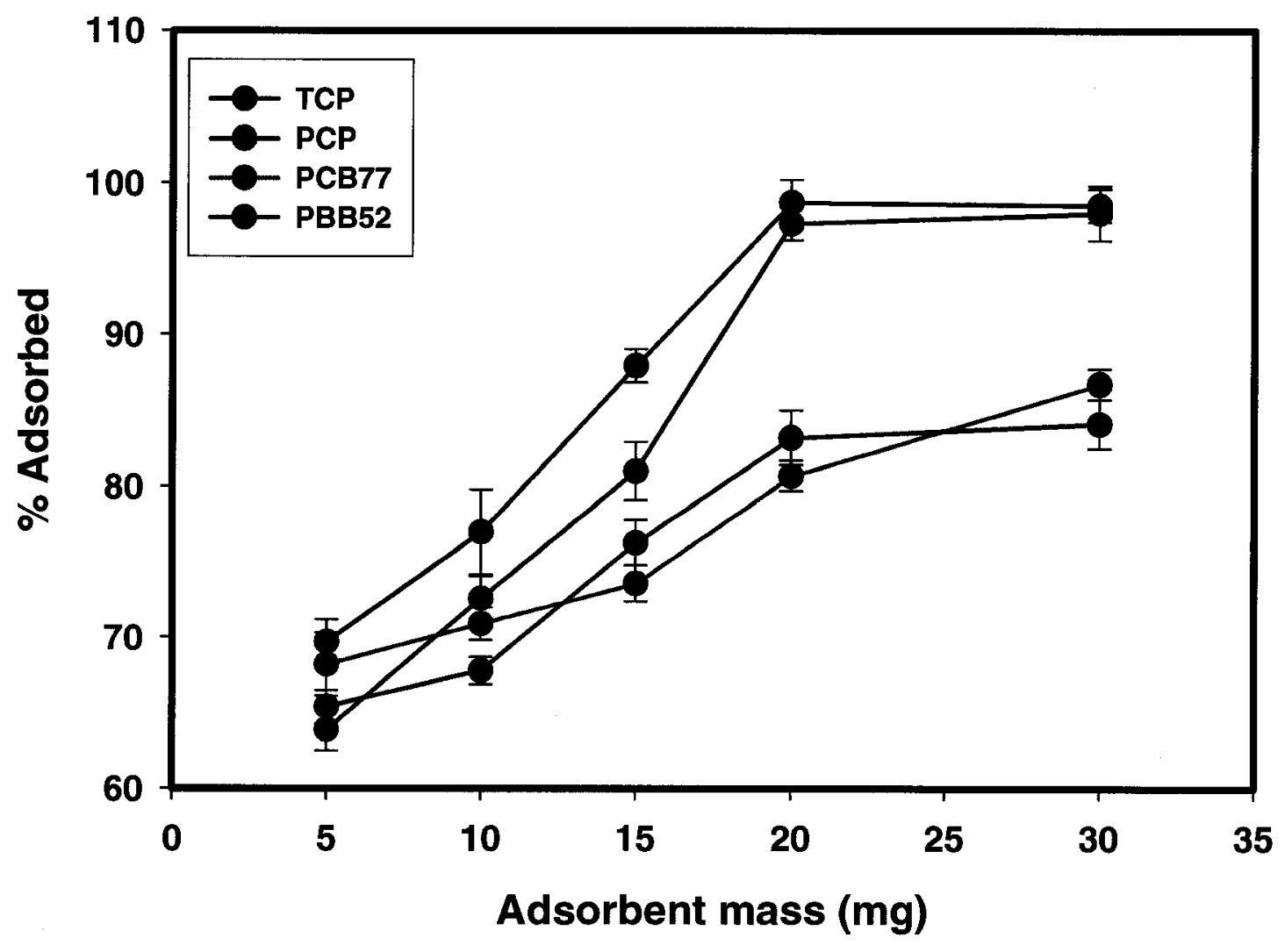

Figure 7.7. Effect of pristine MWCNTs mass on adsorption of TCP, PCP, PCB77, and PBB52. 


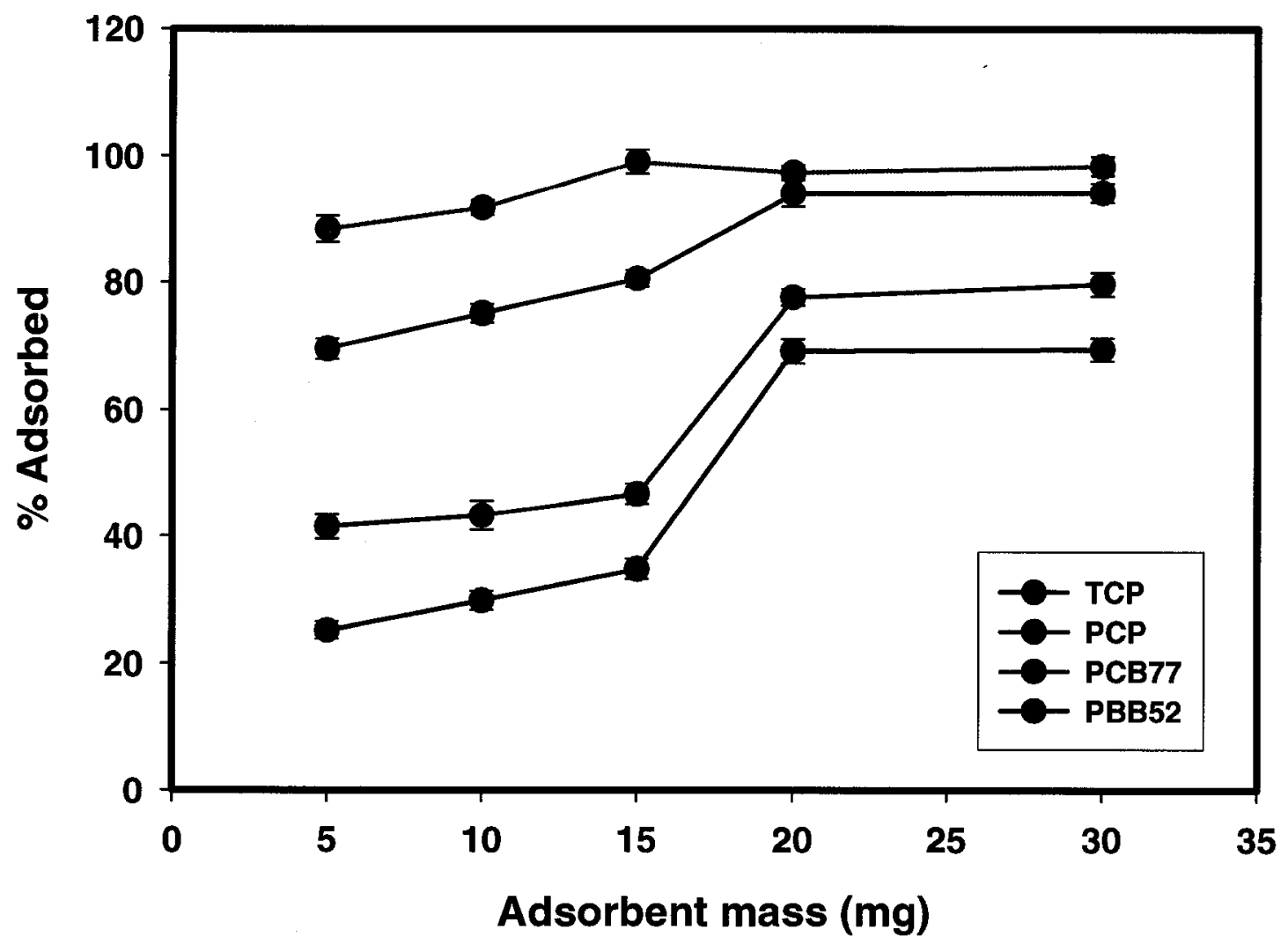

Figure 7.8. Effect of MWCNTs-PEG mass on the adsorption of TCP, PCP, PCB77, and PBB52. 


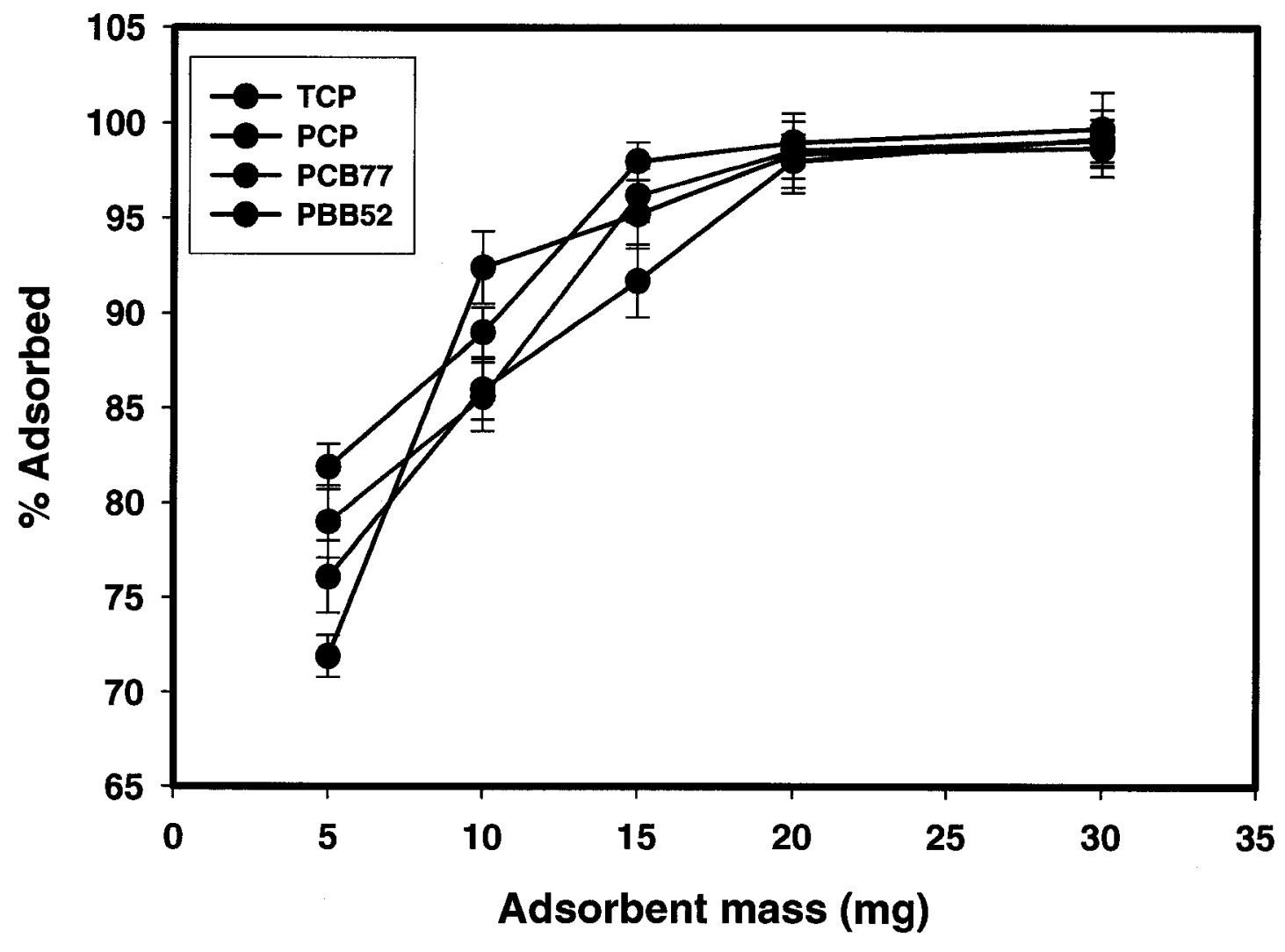

Figure 7.9. Effect of MWCNTs-ODA mass on the adsorption of TCP, PCP, PCB77, and PBB52. 


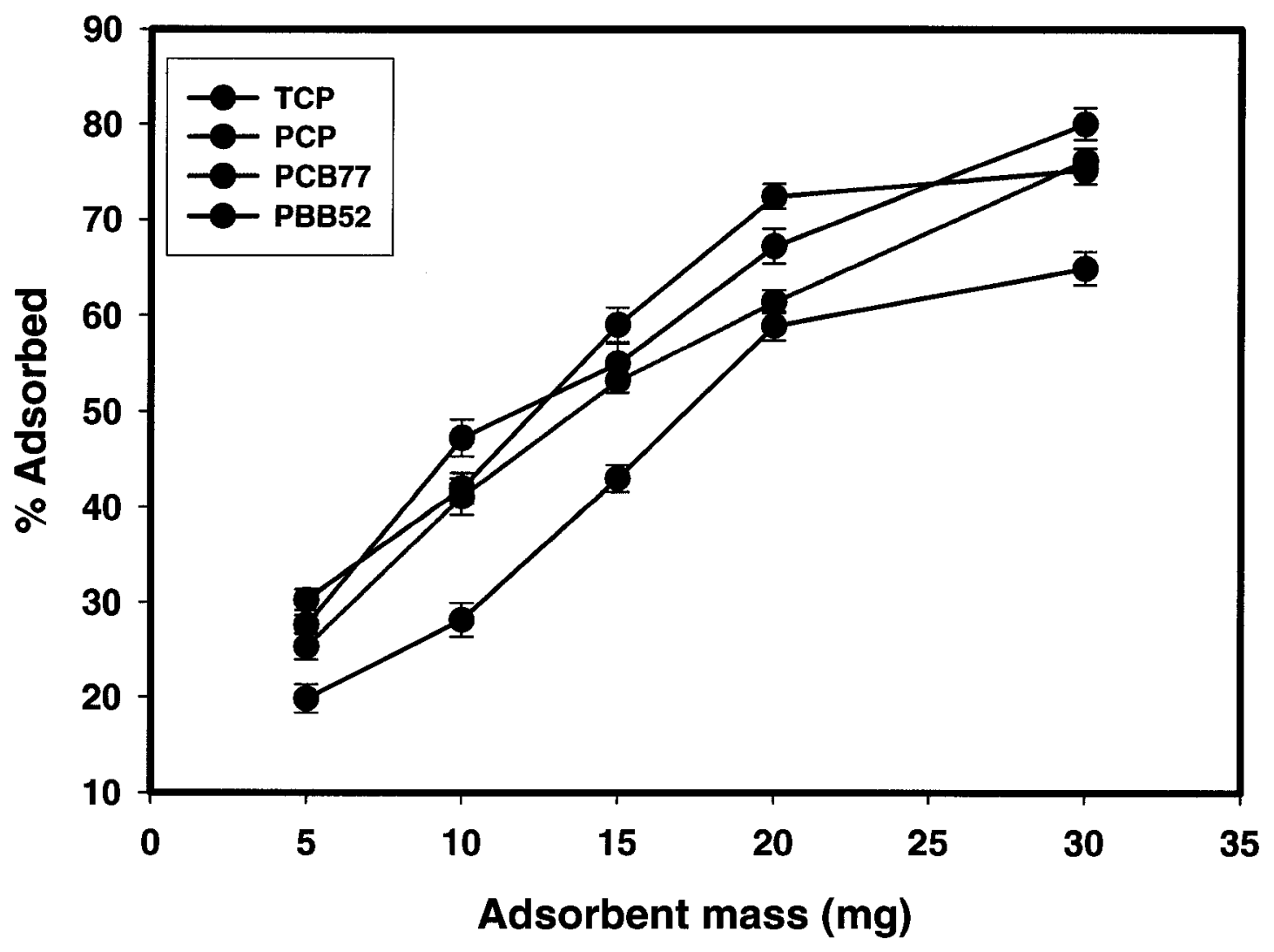

Figure 7.10. Effect of $\mathrm{C} 18$ mass on the adsorption of TCP, PCP, PCB77, and PBB52. 
increase the exposed surface area and the binding sites which is available for adsorption, and it may decrease the flow rate due to increasing the bed size. This may allows more efficient adsorption and longer interaction time between the analytes and the adsorbent, and hence increase the $\%$ adsorption. Figure 7.7 shows that the $\%$ adsorption increased with increasing mass of pristine MWCNTs, to a maximum at $20 \mathrm{mg}$ of adsorbent. The adsorption of TCP and PCP were higher than PCB77 and PBB52. The conformational structure maight plays an important role as TCP and PCP are much easier in adsorption than PCB77 and PBB52. In the case of MWCNTs-PEG, the \% adsorption of PCB77 and PBB52 were higher than TCP and PCP. This was explained earlier as a result of the $\pi-\pi$ interactions between the chlorophenols and the oxygen containing functional groups on the MWCNTs-PEG surface. As was predicted, MWCNTs-ODA had the highest \% adsorption of the four analytes and this is due to the dual properties of MWCNTs-ODA as it contains the octadecyl chains as well as the effect of the delocalized $\pi$ electrons which enhance the adsorption of both analytes, polar and non polar. For C18, it follows the same trend as the increasing \% adsorption with increasing $\mathrm{C} 18$ mass. But it was clear that $\mathrm{C} 18$ had the lowest $\%$ adsorption for the four analytes compared with the other MWCNTs. This give the MWCNTs advantages over the common types of adsorbent such as $\mathrm{C} 18$. The same effect was studied using the oxidized MWCNTs and the results are shown in Figure 7.11. Surprisingly, oxidized MWCNTs had better \% adsorption for the four analytes, compared with the other adsorbents But, it was clear that non-polar analytes such as PCB77 and PBB52, are adsorbed more on the oxidized tubes, compared with the chlorophenols (polar). This finding confirms that the modification of MWCNTs with oxygen containing functional groups decrease the adsorption of phenolic 


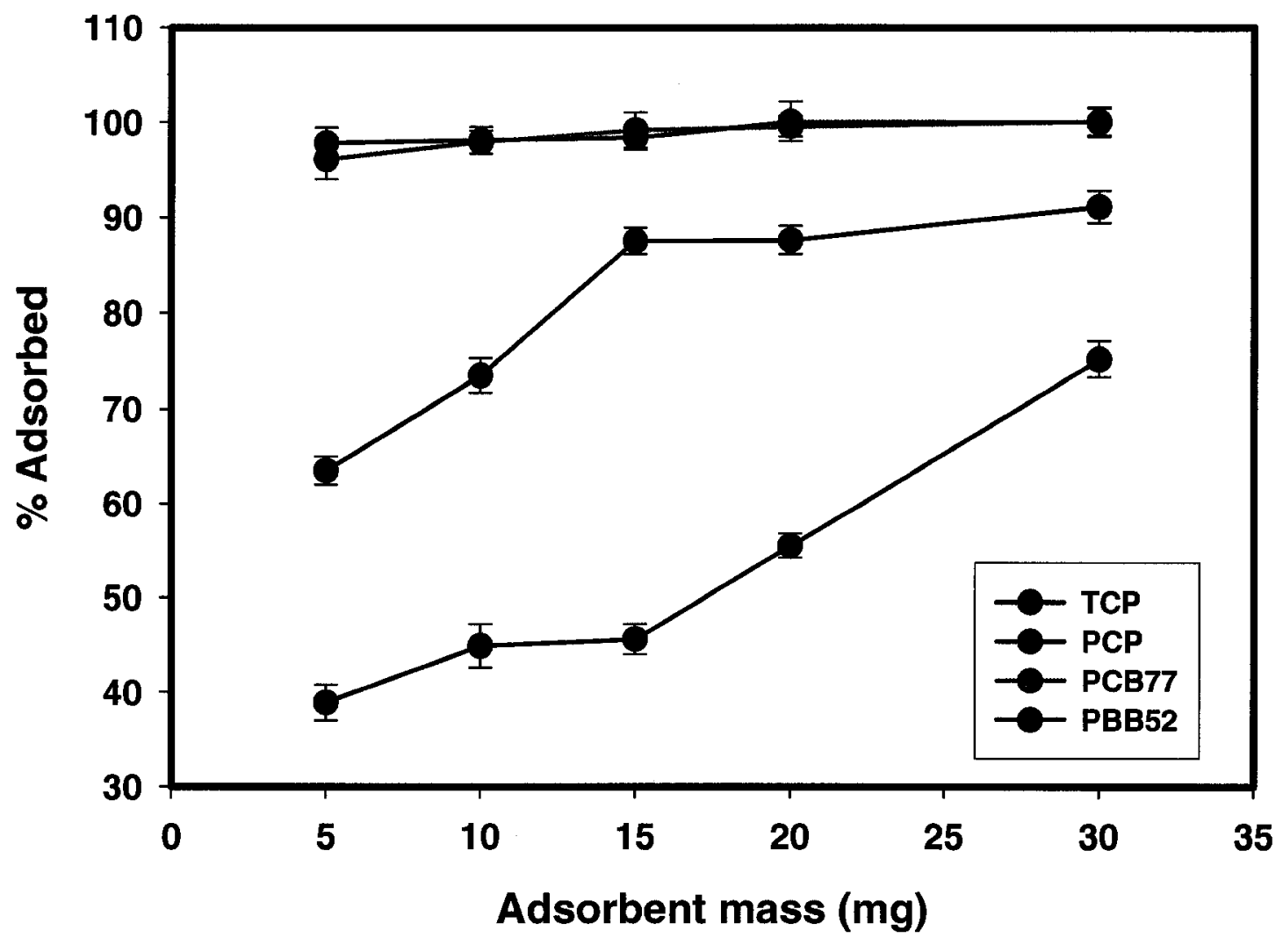

Figure 7.11. Effect of oxidized MWCNTs mass on the adsorption of TCP, PCP, PCB77, and PBB52. 
compounds due to the $\pi-\pi$ interaction and/or solvent effects on the MWCNTs-PEG surface [20-23].

\subsubsection{Effect of $\mathrm{pH}$}

The effect of solution $\mathrm{pH}$ on the adsorption of the analytes of interest on different MWCNTs was studied at constant adsorbent mass $(20 \mathrm{mg})$ and flow rate $(5 \mathrm{ml} / \mathrm{min})$. The $\mathrm{pH}$ range was varied from $3.0-11.0$ to more than cover the $\mathrm{p} K_{\mathrm{a}}$ values of TCP $\left(\mathrm{p} K_{\mathrm{a}}=\right.$ 6.94) and PCP $\left(\mathrm{p} K_{\mathrm{a}}=4.80\right)$. Figure 7.12 shows the effect of changing the solution $\mathrm{pH}$ on the adsorption on pristine MWCNTs. Changing the $\mathrm{pH}$ from 3.0 to 8.0 did not affect the adsorption of both PCB77 and PBB52, as expected, since neither are themselves acidic or basic. Increasing the $\mathrm{pH}$ to 11.0 , decreased the adsorption of both analytes slightly and this is may be due to the presence of many deprotonated surface functional groups at this high $\mathrm{pH}$, possibly leading to the adsorption of water molecules, which may block the way for the other analytes to be adsorbed on surface [22,24]. Chlorophenols in general are greatly affected by the $\mathrm{pH}$ of the solution. At $\mathrm{pH} 3.0$, the adsorption of PCP and TCP were very low due to the competition between the chlorophenols and $\mathrm{H}^{+}$on the adsorption on the same active sites $[23,25]$. At this low $\mathrm{pH}, \mathrm{PCP}$ had higher adsorption than TCP on the surface of the MWCNTs, but increasing the $\mathrm{pH}$ from 3 to 5 reversed the trend, i.e. TCP had higher adsorption than PCP. This is due to the ionization of PCP molecules and formation of the negative ions, but not in the case of TCP due to its higher $\mathrm{p} K_{\mathrm{a}}$ value. Further increase of the solution $\mathrm{pH}$ from 5.0 to 8.0 led to the decrease in the adsorption of both PCP and TCP due to further ionization of PCP and TCP and the repulsion between the MWCNTs surface and the anionic chlorophenolide ions $[21,25]$. 


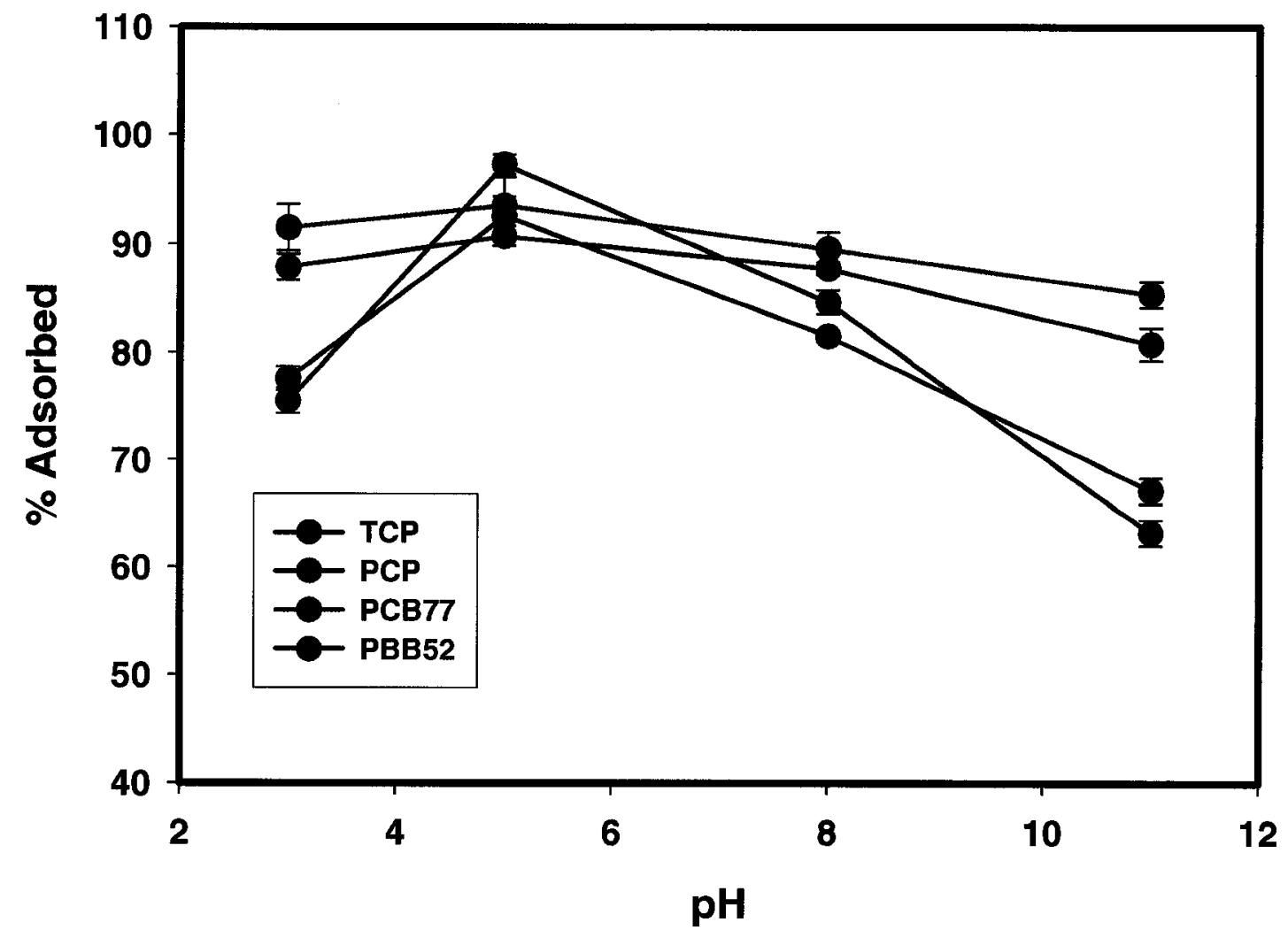

Figure 7.12. Effect of $\mathrm{pH}$ on the adsorption of TCP, PCP, PCB77, and PBB52 on pristine MWCNTs. 
Increasing the $\mathrm{pH}$ from 8.0 to 11.0 had a dramatic effect on the adsorption of TCP and PCP, as all the chlorophenols then existed in the anionic forms and further repulsion as well as the competition between the analytes and the hydroxyl group's presents, on the solution at such high $\mathrm{pH}$, for the adsorption on the MWCNTs active sites.

In the case of MWCNTs-PEG adsorbent, the $\mathrm{pH}$ affects the adsorption of the four analytes greatly as presented in Figure 7.13 . At $\mathrm{pH} 3.0$, for all the analytes, the adsorption was low due to the protonation of the oxygen functional groups on the surface of MWCNTs-PEG. The effect here was greater than the pristine MWCNTs, as the MWCNTs-PEG contains much more oxygen function groups which bind protons at this low $\mathrm{pH}$. At $\mathrm{pH}$ higher than 8.0, most of the surface oxygen functional groups, such as carboxylic acid (-COOH; $\mathrm{pKa}$ around 8.0) and phenolic (-OH, $\mathrm{pKa}$ around 11.0) are ionized and a repulsion forces occurs between the analytes and the surface of the MWCNTs-PEG. For the non-polar analytes, PCB77 and PBB52, their adsorption was not affected greatly within $\mathrm{pH}$ range 5.0 to 8.0 , as most of the MWCNTs-PEG active sites were accessible. The $\mathrm{pH}$ effect on the adsorption of TCP and PCP onto MWCNTs-PEG was more severe than on pristine MWCNTs, as a result of the presence of the ionizable oxygen functional groups in the PEG chains. PCP adsorption was higher than TCP adsorption except at $\mathrm{pH} 5.0$, where most of the PCP molecules ( $\mathrm{pKa} 4.75$ ) were ionized and TCP molecules (pKa 6.95) were not.

Figure 7.14 presents the effect of the $\mathrm{pH}$ on the adsorption properties of MWCNTs-ODA with different analytes. It is clear from the Figure that MWCNTs-ODA was affected with 


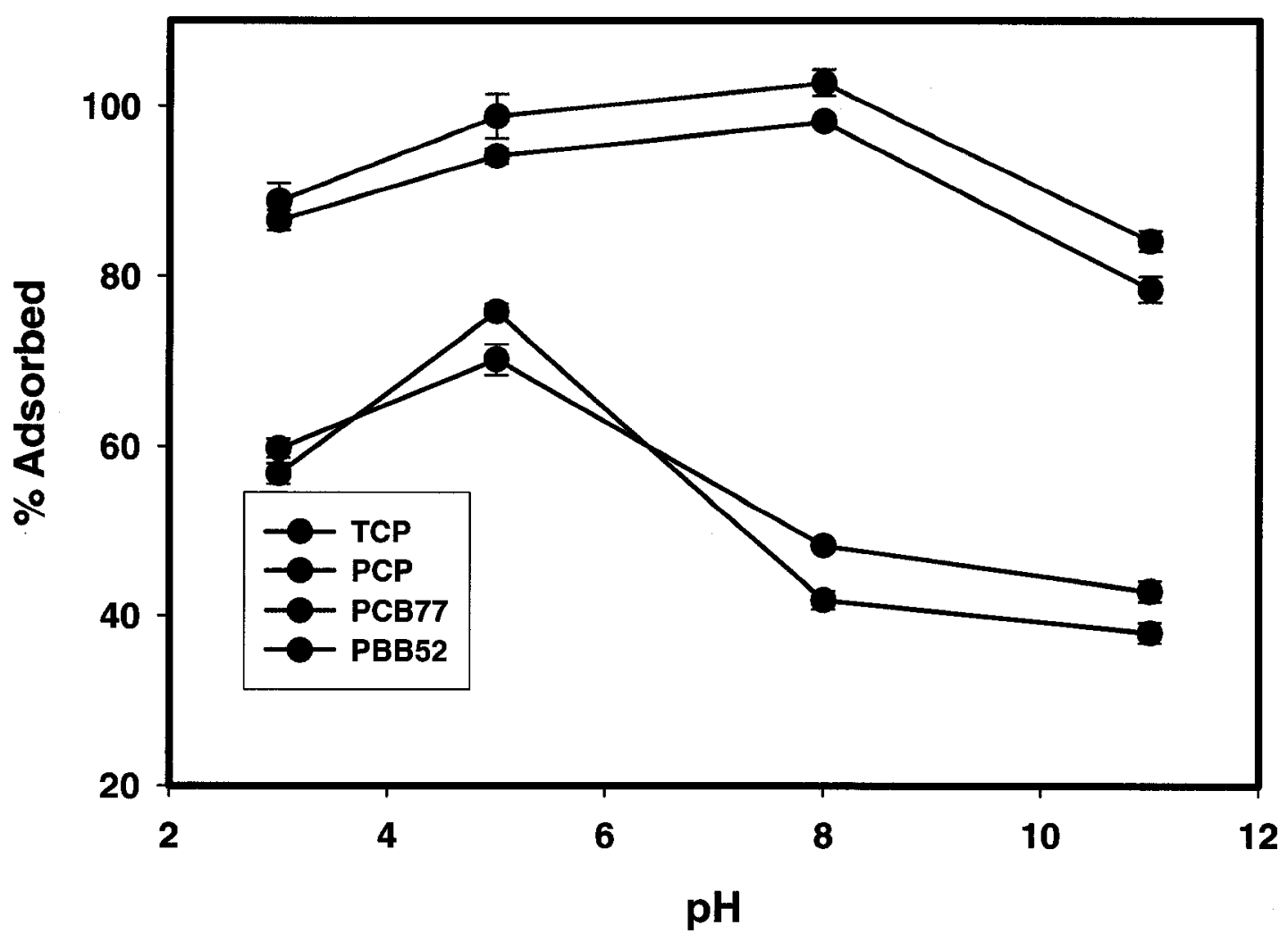

Figure 7.13. Effect of $\mathrm{pH}$ on the adsorption of TCP, PCP, PCB77, and PBB52 on MWCNTs-PEG. 


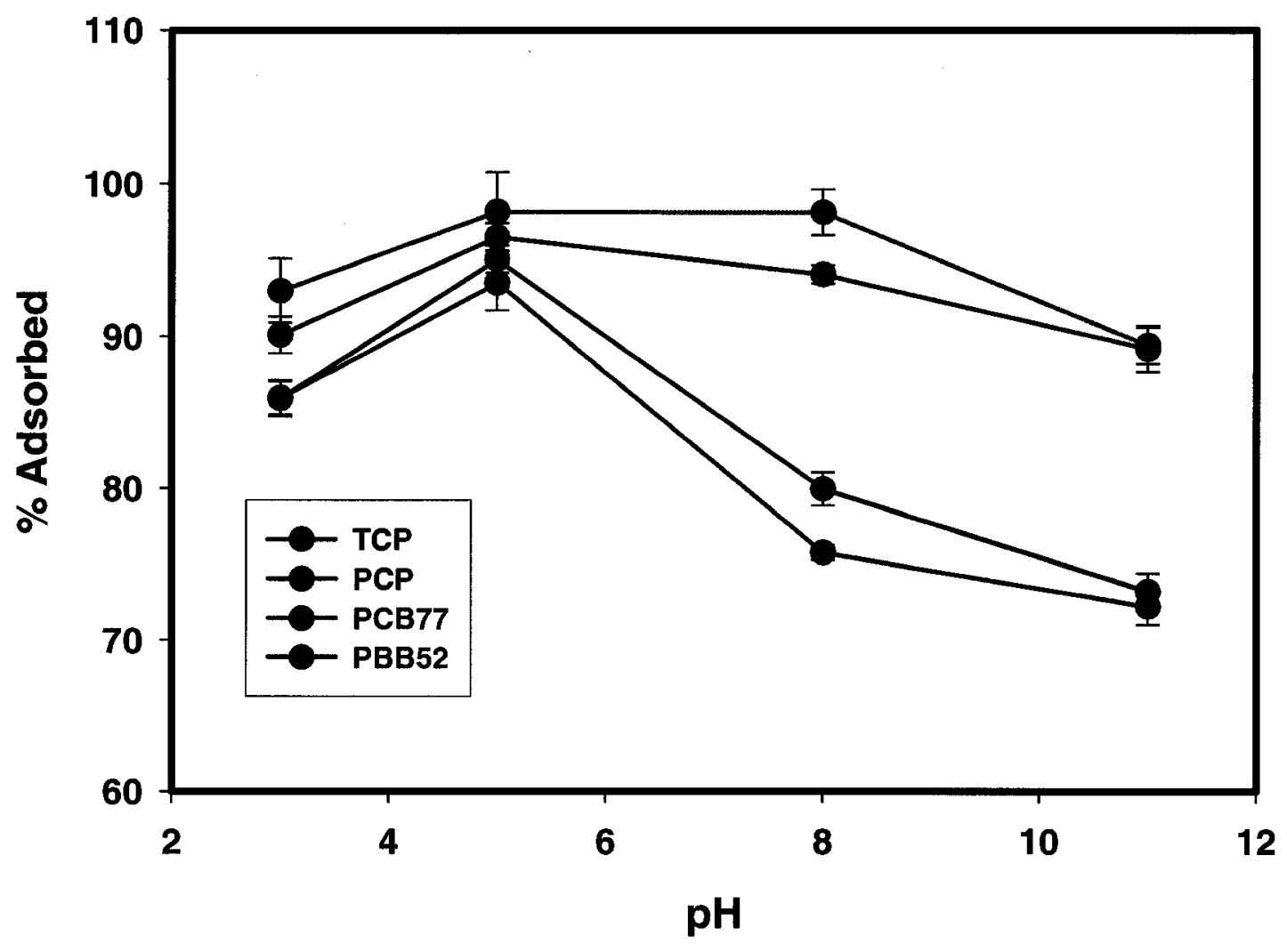

Figure 7.14. Effect of $\mathrm{pH}$ on the adsorption of TCP, PCP, PCB77, and PBB52 on MWCNTs-ODA. 
changing the $\mathrm{pH}$ and this effect depended on both the type of analytes and the $\mathrm{pH}$ value, as well. Between $\mathrm{pH} 3.0$ and 11.0, the decrease in the adsorption of the four analytes was in between the pristine MWCNTs and MWCNTs-PEG, as MWCNTS-ODA contains fewer oxygen functional groups than MWCNTs-PEG and more than pristine MWCNTs. But this decrease in the adsorption due to the oxygen function groups in the MWCNTsODA, was compensated with the presence of the ODA chains on the MWCNTs surface which increased the absorption part. The effect of $\mathrm{pH}$ was less in the case of MWCNTsODA compared with pristine MWCNTs and MWCNTs-PEG.

The adsorption at different $\mathrm{pH}$ on $\mathrm{C} 18$ was studied and the results are presented in Figure 7.15. It is clear from the Figure that the adsorption in general was low at $\mathrm{pH} 3.0$, especially for TCP and PCP due to the competition between the analytes and protons for the adsorption on C18. This effect became less pronounce by increasing the $\mathrm{pH}$ to 5.0. The adsorption became steady between $\mathrm{pH} 5.0$ and 11.0 for PCB77 and PBB52, as neither they nor the $\mathrm{C} 18$ surface contain exchangeable protons. In the case of TCP and PCP, the adsorption decreased between $\mathrm{pH} 5.0$ and 11.0 due to the ionization of the chlorophenols.

To confirm the effect of the surface oxygen functional groups on the adsorption of the four analytes of interest, the effect of $\mathrm{pH}$ was studied for the oxidized MWCNTs and the results are shown in Figure 7.16. It is clear from the Figure that the adsorptions of PCB77 and PBB52 were higher than TCP and PCP, due to the inhibition of the adsorption of the chlorophenols as was discussed previously. The adsorption of the four analytes was affected by changing the $\mathrm{pH}$ in the same manner like the other modified MWCNTs. 


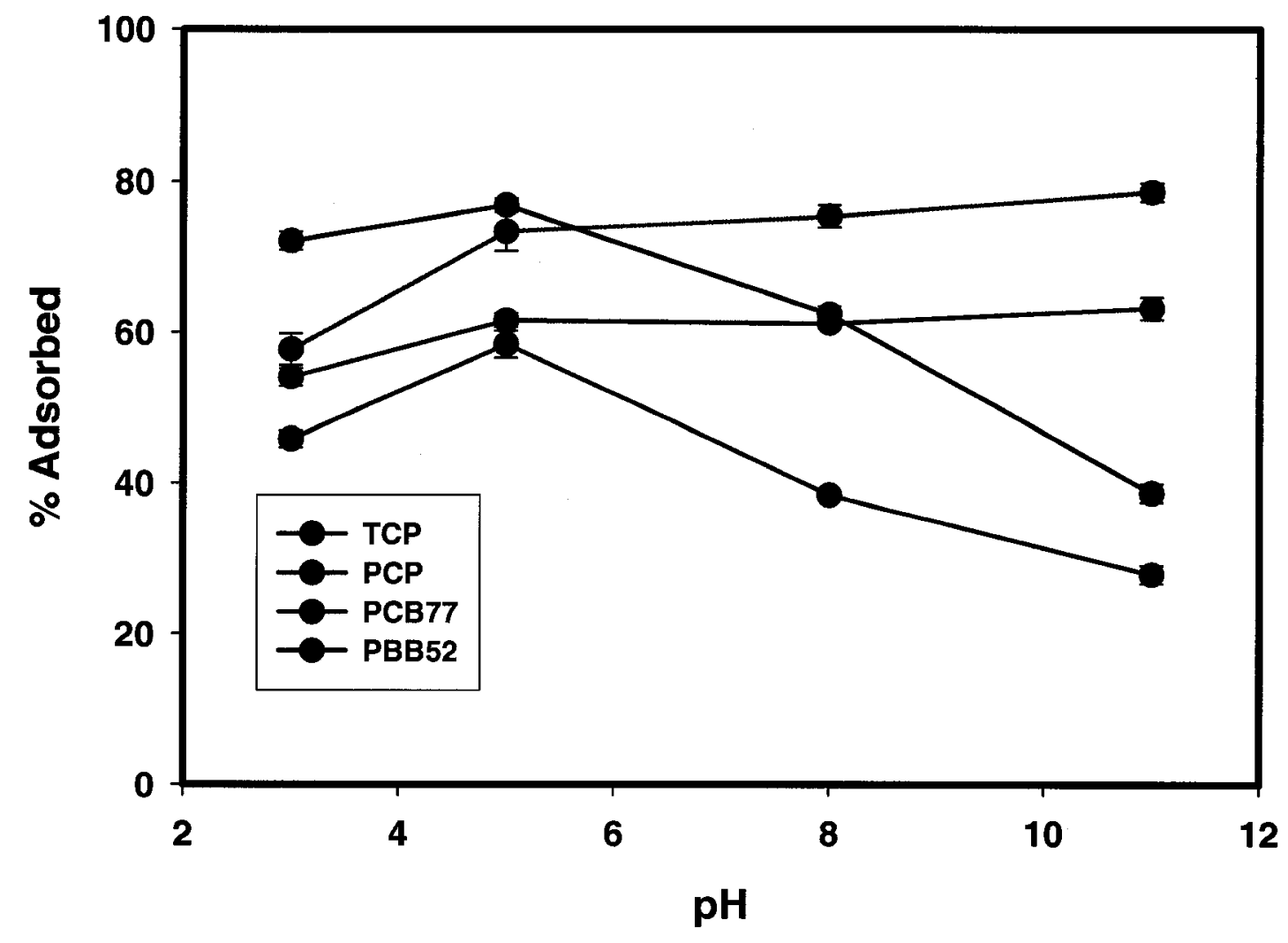

Figure 7.15. Effect of $\mathrm{pH}$ on the adsorption of TCP, PCP, PCB77, and PBB52 on C18. 


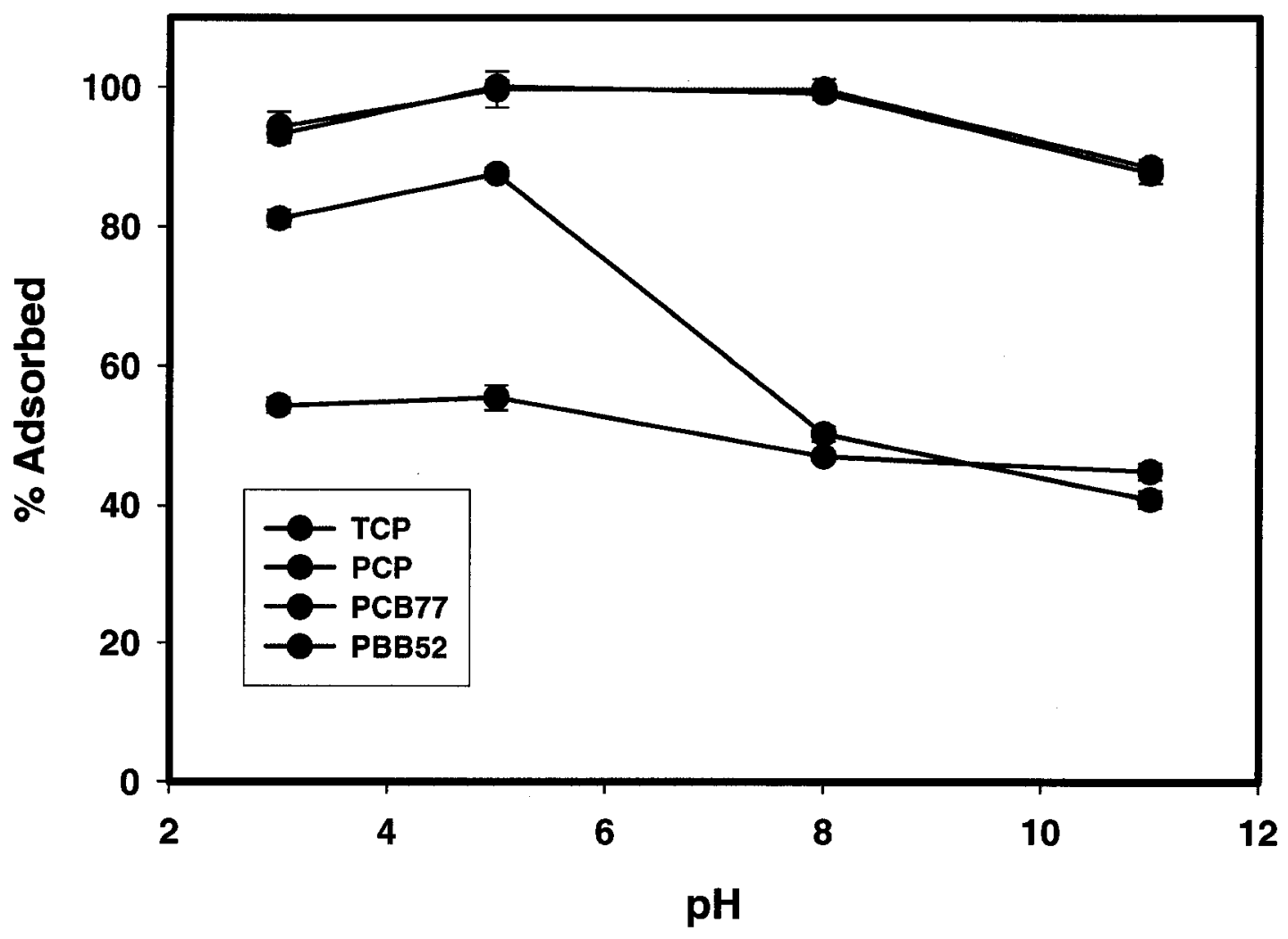

Figure 7.16. Effect of $\mathrm{pH}$ on the adsorption of PCP, TCP, PCB77, and PBB52 on oxidized MWCNTs. 
The adsorption of both PCB77 and PBB52 were almost 100\%, and this may be due to the very low flow rate that had been used for the oxidized MWCNTs due to their solubility in aqueous solution. The very low flow rate increased the interaction time between the analytes and the adsorbent and hence enhanced the adsorption.

\subsection{Desorption study}

In SPE procedures, different elution efficiencies can be obtained when different solvents are used because of the chemical and physical properties of the organic solvents, the nature of the extracted analytes, and the characteristics of the adsorbents used as the SPE material.

The SPE process could be summarized as follows:

For the adsorption step:

Analyte $_{(\text {aq. })}+$ Adsorbent $_{(\text {aq. })} \rightleftarrows$ Adsorbent-Analyte complex $_{(\text {solid) }}+\mathrm{H}_{2} \mathrm{O}$

and for the desorption step:

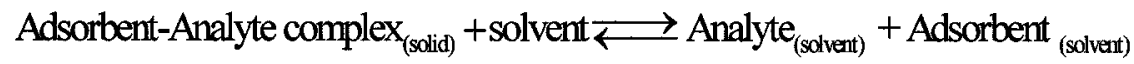

where, the analyte is any of the four target analytes, the adsorbent is any of the pristine or modified MWCNTs, and the solvent is any of the organic solvent used for elution of the adsorbed analytes from the adsorbent. In order to get successful desorption process, the solvent molecules should overcome the attraction forces between the analyte and adsorbent, i.e. the solvent molecules should form a stronger bonds with both of the adsorbent and the analyte, than the analyte and adsorbent form with one another. The 
nature of the analyte, adsorbent, and the solvent used play very important roles. According to the rule "Like dissolves like", if the analyte is polar, it will be desorbed into a polar solvent. Or in another words, the analyte and the solvent should have matching polarity and also the adsorbent and the solvent should have matching polarity.

\subsubsection{Effect of solvent type}

In these experiments different organic solvents were compared in order to study the desorption of TCP, PCP, PCB77, and PBB52, from the modified MWCNTs, and C18. Aqueous solutions containing the four analytes were passed through the SPE cartridges containing each type of the adsorbent under investigation; pristine MWCNTs, MWCNTsPEG, MWCNTs-ODA, and C18. The analysis for the concentration of the target analytes were measured in the each solvent to determine the $\%$ desorbed from each adsorbent. Figure 7.17 shows the effect of acetone, methanol, and hexane as elution solvent, on the elution of TCP, PCP, PCB77, and PBB52, from pristine MWCNTs. The graph shows that the order for the overall elution performance was for acetone $>$ hexane $>$ methanol. This is due to the hydrophobicity of the pristine MWCNTs, as the relatively non polar solvents, acetone and hexane, will out compete with the target analytes for the adsorption on the pristine MWCNTs surface and as a result lead to the desorption of the adsorbed target analytes. The desorption of the four analytes using acetone was more efficient than hexane due to the partial polarity of the acetone compared with hexane. This enable the acetone to be associated with the pristine MWCNTs much more than hexane and as a result, replacing (desorb) the adsorbed analytes. 


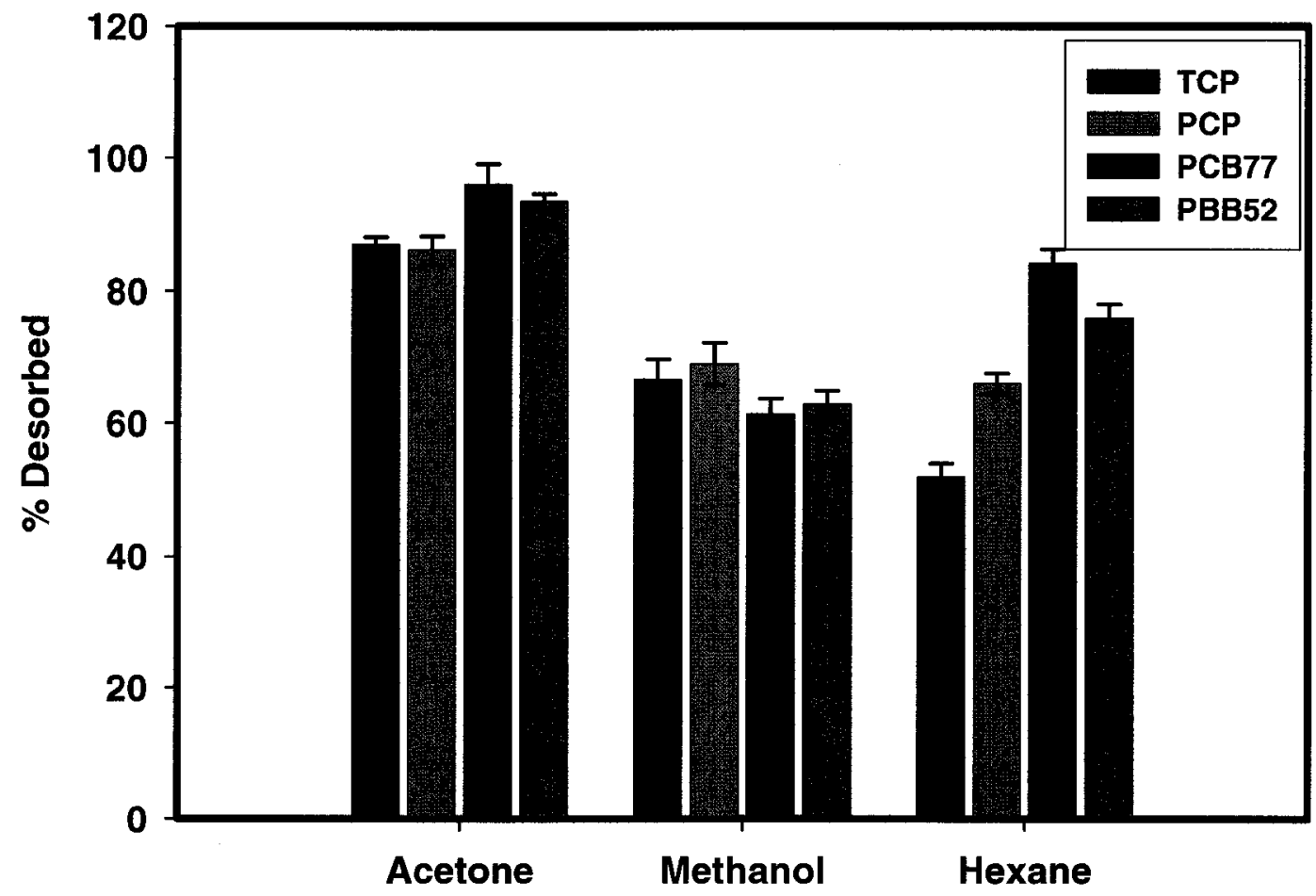

Figure 7.17. Effect of solvent on the elution of different analytes adsorbed on pristine MWCNTs. 
Figure 7.18 shows the effect of different solvents on the elution of adsorbed analytes on MWCNTs-ODA. The elution performance was similar to pristine MWCNTs, but with slightly higher recovery. The similarity may again be attributed to the hydrophobicity of the MWCNTs-ODA and the high recovery of the adsorbed analytes may be due to the fact that most of the adsorbed analytes were absorbed between the ODA chains on the surface of the MWCNTs. This may indicate that the elution of absorbed analytes is much easier than the physically adsorbed analytes on the surface of the MWCNTs due to the $\pi-\pi$ interaction between the aromatic ring(s) of the target analytes and the MWCNTs. It was clear as well that methanol, as a polar solvent, eluted more polar analyes; TCP and PCP, than the non-polar analytes; PCB77 and PBB52. The opposite trend was observed for the other non-polar solvents acetone and hexane, as they eluted the non-polar anlaytes with higher efficiency than the polar analytes. This may be again explained by that fact "like dissolves like" as the polar solvent tends to dissolve polar analytes, whereas nonpolar solvent tends more to dissolve non-polar analytes.

In the case of MWCNTs-PEG, methanol had the highest efficiency followed by acetone and then hexane as is presented in Figure 7.19. This is due to fact the MWCNTs-PEG contains polar functional groups which interact strongly with a small polar molecule such as methanol, rather than acetone or hexane, as was described by equation 7.2. This adsorbent contains hydroxyl groups $(-\mathrm{OH})$ either from the PEG chains or from the unfunctionalized carboxylic or phenolic groups on the MWCNTs surface. This may lead to the formation of hydrogen bonding between the solvent molecules and the adsorbent. Methanol followed by acetone may thus desorb more analytes than hexane, via the formation of hydrogen bonds with the surface oxygen functional groups on the 


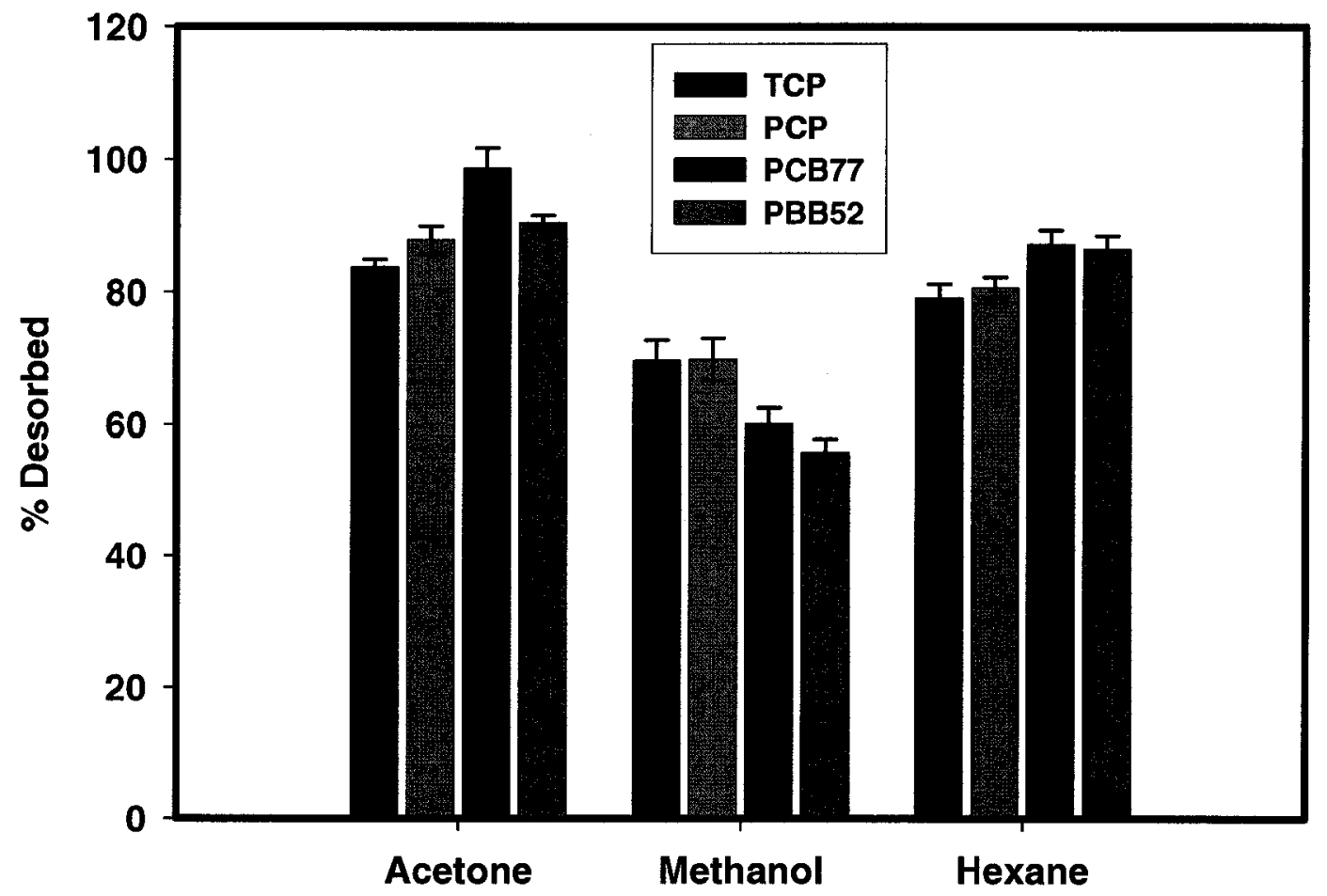

Figure 7.18. Effect of solvent on the elution of different analytes adsorbed on MWCNTsODA. 


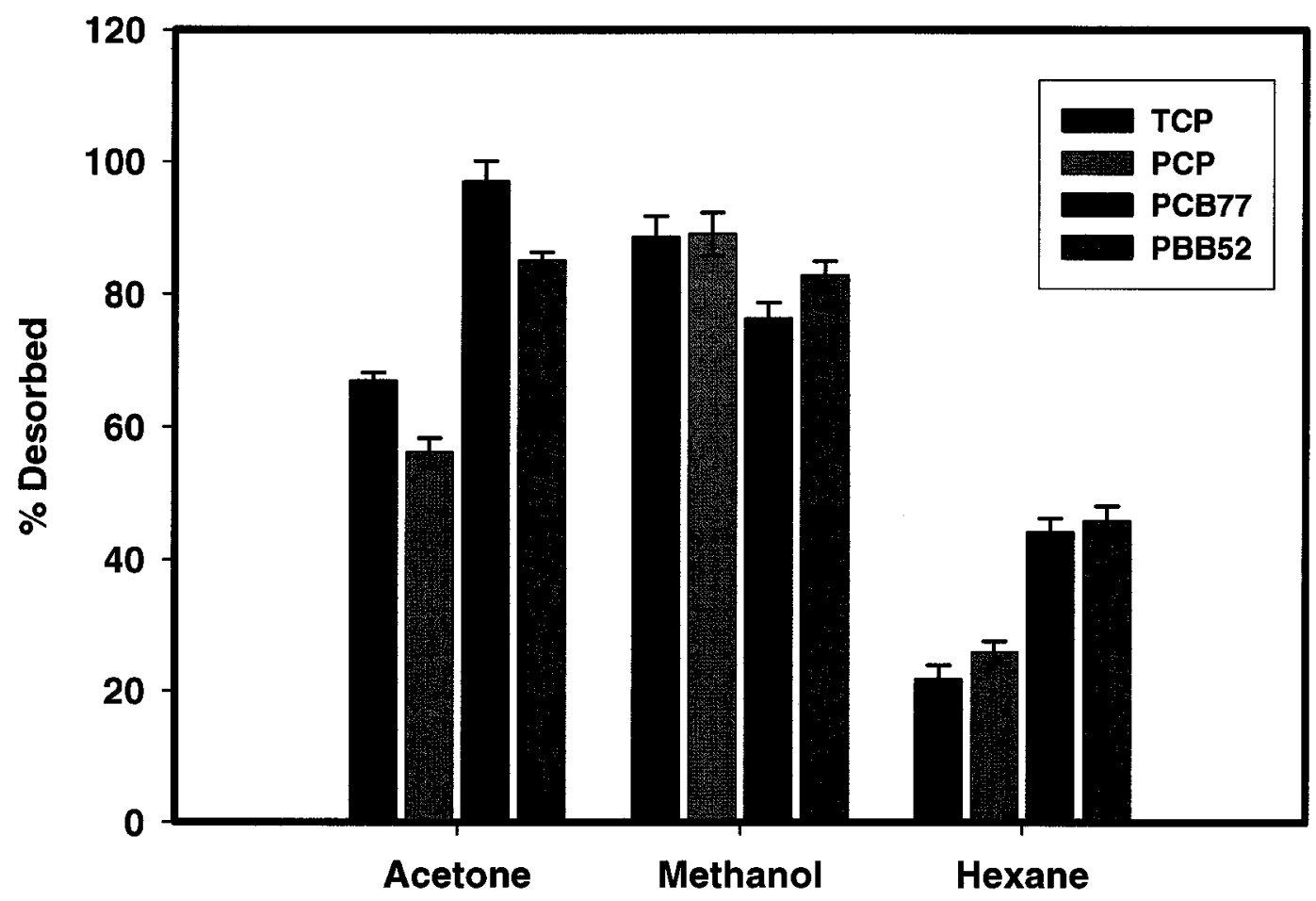

Figure 7.19. Effect of solvent on the elution of different analytes adsorbed on MWCNTsPEG. 
MWCNTs-PEG adsorbent. Figure 7.20 presents the effect of elution organic solvents on the elution of TCP, PCP, PCB77, and PBB52, adsorbed on C18. The Figure that hexane showed the poorest efficiency, whereas methanol and acetone showed comparable efficiencies. Acetone and methanol showed good recoveries for the non-polar analytes; PCB77 and PBB 52, more than the polar analytes; TCP and PCP. This indicates strong retention of TCP and PCP, likely absorbed in the $\mathrm{C} 18$ chains.

In general acetone shows a greater overall efficiency for the elution of most of the studied analytes from modified carbon nanotubes, followed by methanol and then hexane.

\subsubsection{Effect of solvent volume}

The effect of solvent volume on the elution was studied and the results are presented in Table 7.2. The table shows that the elution of different analytes was greatly affected by the amount of solvent used for elution. Generally, the elution efficiency increased with increasing the solvent volume, regardless the type of the solvent applied, and mostly it was reaches the maximum elution by using 4.0 and $5.0 \mathrm{~mL}$ of the solvent. This may be explained in the basis of equation 7.2:

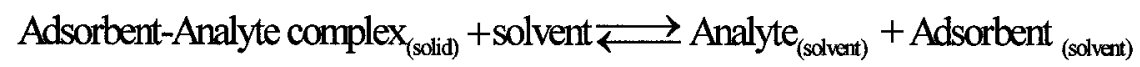

Addition of more fresh solvent to the system shift the desorption process to the right where the adsorbent and analyte are surrounded by more solvent molecules. The more solvent volume was added the more the desorption and elution of the analytes.

\subsubsection{Method development study}

\subsubsection{Limits of detection and calibration curves of the GC-ECD}

The four analytes, TCP, PCP, PCB77, and PBB52, were measured using ECD-GC and 


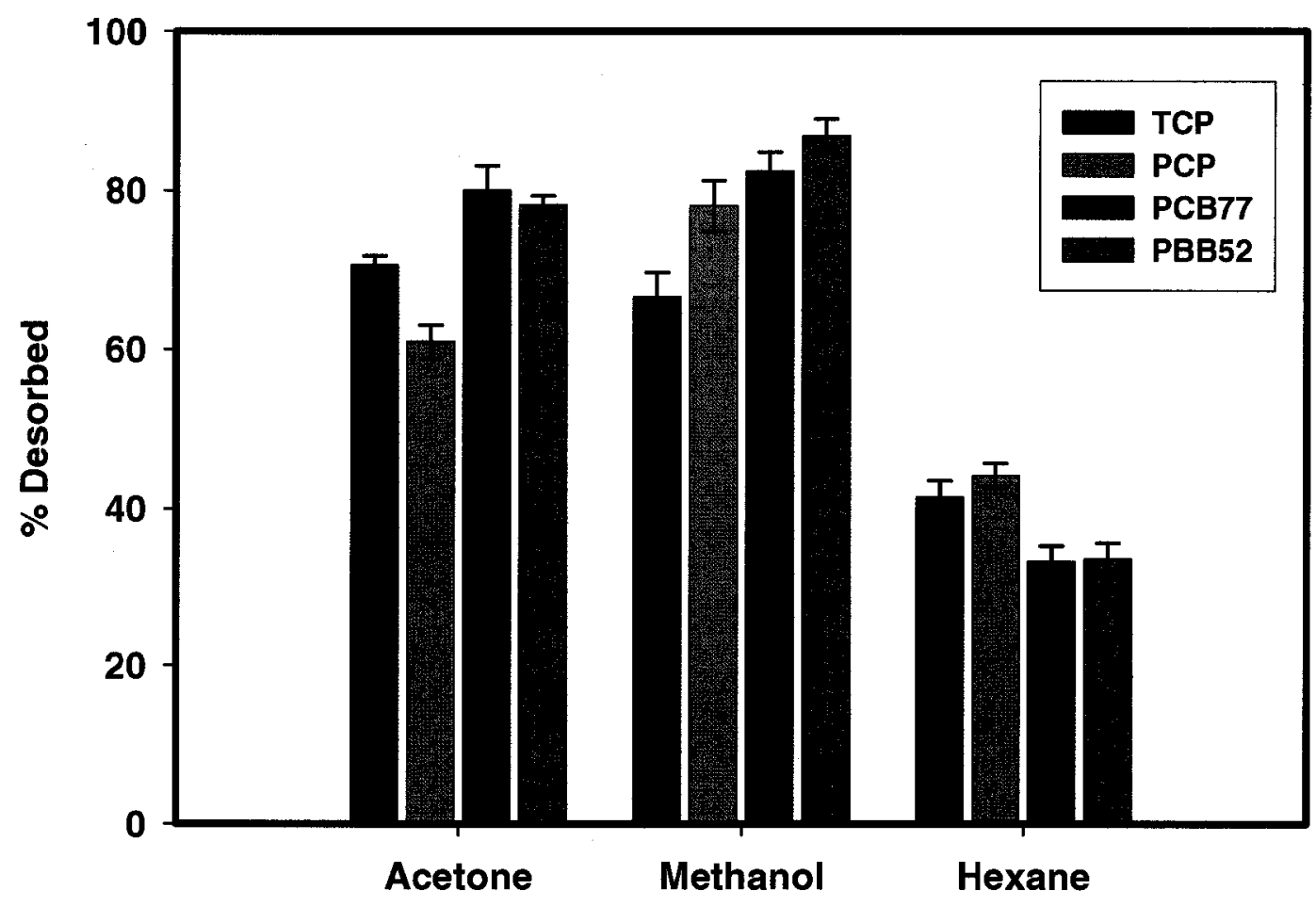

Figure 7.20. Effect of solvent on the elution of different analytes adsorbed on C18. 
Table 7.2. Effect of elution solvent volume on the elution of TCP PCP, PCB77, and PBB52, that had been adsorbed on pristine MWCNTs, MWCNTs-ODA, MWCNTs-PEG, and C18. $(\mathrm{n}=3)$

\begin{tabular}{|c|c|c|c|c|c|c|c|c|}
\hline \multicolumn{5}{|c|}{ Pristine MWCNTs } & \multicolumn{4}{|c|}{ MWCNTs-ODA } \\
\hline$\%$ desorbed & TCP & PCP & PCB77 & PBB52 & TCP & PCP & PCB77 & BB52 \\
\hline \multicolumn{5}{|c|}{ Solvent volume $(\mathrm{ml})$} & \multicolumn{4}{|c|}{ Acetone } \\
\hline 1.0 & $49.6 \pm 3.0$ & $58.1 \pm 4.0$ & $67.9 \pm 2.0$ & $74.0 \pm 2.0$ & $47.2 \pm 3.0$ & $42.0 \pm 2.0$ & $76.4 \pm 4.0$ & $80.8 \pm 3.0$ \\
\hline 3.0 & $64.7 \pm 5.0$ & $75.4 \pm 4.0$ & $85.0 \pm 3.0$ & $89.7 \pm 3.0$ & $63.5 \pm 4.0$ & $75.4 \pm 3.0$ & $80.7 \pm 5.0$ & $88.1 \pm 4.0$ \\
\hline 4.0 & $87.0 \pm 3.0$ & $86.2 \pm 5.0$ & $96.0 \pm 1.0$ & $93.5 \pm 4.0$ & $83.8 \pm 2.0$ & $87.8 \pm 4.0$ & $98.7 \pm 2.0$ & $90.5 \pm 2.0$ \\
\hline 5.0 & $89.5 \pm 1.0$ & $87.7 \pm 3.0$ & $99.9 \pm 6.0$ & $97.3 \pm 2.0$ & $93.6 \pm 6.0$ & $92.3 \pm 2.0$ & $100.0 \pm 4.0$ & $97.0 \pm 5.0$ \\
\hline \multicolumn{5}{|c|}{ Solvent volume $(\mathrm{ml})$} & \multicolumn{4}{|c|}{ Methanol } \\
\hline 1.0 & $31.1 \pm 4.0$ & $36.5 \pm 4.0$ & $24.5 \pm 3.0$ & $30.7 \pm 5.0$ & $33.9 \pm 3.0$ & $40.4 \pm 1.0$ & $26.5 \pm 5.0$ & $21.7 \pm 6.0$ \\
\hline 3.0 & $44.3 \pm 5.0$ & $49.2 \pm 2.0$ & $50.0 \pm 4.0$ & $45.8 \pm 2.0$ & $43.4 \pm 5.0$ & $58.0 \pm 3.0$ & $39.1 \pm 6.0$ & $43.3 \pm 4.0$ \\
\hline 4.0 & $66.6 \pm 4.0$ & $69.0 \pm 3.0$ & $61.4 \pm 2.0$ & $62.9 \pm 4.0$ & $69.7 \pm 6.0$ & $69.9 \pm 6.0$ & $60.2 \pm 3.0$ & $55.7 \pm 3.0$ \\
\hline 5.0 & $70.0 \pm 4.0$ & $72.6 \pm 5.0$ & $63.7 \pm 4.0$ & $65.4 \pm 6.0$ & $77.4 \pm 6.0$ & $74.7 \pm 3.0$ & $65.4 \pm 2.0$ & $68.9 \pm 2.0$ \\
\hline \multicolumn{5}{|c|}{ Solvent volume (ml) } & \multicolumn{4}{|c|}{ Hexane } \\
\hline 1.0 & $25.4 \pm 3.0$ & $18.5 \pm 3.0$ & $43.5 \pm 5.0$ & $32.4 \pm 2.0$ & $53.8 \pm 5.0$ & $63.8 \pm 2.0$ & $61.1 \pm 1.0$ & $52.9 \pm 3.0$ \\
\hline 3.0 & $39.6 \pm 2.0$ & $42.0 \pm 2.0$ & $57.4 \pm 6.0$ & $50.8 \pm 1.0$ & $62.6 \pm 3.0$ & $77.3 \pm 3.0$ & $78.9 \pm 2.0$ & $66.6 \pm 4.0$ \\
\hline 4.0 & $51.8 \pm 5.0$ & $66.0 \pm 4.0$ & $84.2 \pm 5.0$ & $75.9 \pm 4.0$ & $79.1 \pm 4.0$ & $80.7 \pm 5.0$ & $87.3 \pm 1.0$ & $86.5 \pm 1.0$ \\
\hline $\mathbf{5 . 0}$ & $57.8 \pm 3.0$ & $67.9 \pm 1.0$ & $85.6 \pm 4.0$ & $82.9 \pm 3.0$ & $82.6 \pm 3.0$ & $90.4 \pm 2.0$ & $90.6 \pm 7.0$ & $87.2 \pm 6.0$ \\
\hline \multicolumn{5}{|c|}{ MWCNTs-PEG } & \multicolumn{4}{|c|}{$\mathbf{C 1 8}$} \\
\hline$\%$ desorbed & TCP & PCP & PCB77 & PBB52 & TCP & PCP & PCB77 & BB52 \\
\hline \multicolumn{5}{|c|}{ Solvent volume (ml) } & \multicolumn{4}{|c|}{ Acetone } \\
\hline 1.0 & $25.9 \pm 4.0$ & $17.0 \pm 3.0$ & $52.9 \pm 3.0$ & $64.2 \pm 2.0$ & $45.3 \pm 2.0$ & $37.1 \pm 2.0$ & $53.3 \pm 2.0$ & $40.0 \pm 3.0$ \\
\hline 3.0 & 3.0 & $41.4 \pm 5.0$ & $75.0 \pm 2.0$ & $70.8 \pm 4.0$ & $2 \pm 4.0$ & $45.3 \pm 4.0$ & $66.3 \pm 1.0$ & $58.6 \pm 2.0$ \\
\hline 4.0 & $67.0 \pm 5.0$ & $56.2 \pm 3.0$ & $97.0 \pm 6.0$ & $85.1 \pm 3.0$ & $70.6 \pm 5.0$ & $61.0 \pm 6.0$ & $80.0 \pm 4.0$ & $78.1 \pm 4.0$ \\
\hline 5.0 & $69.5 \pm 2.0$ & $61.7 \pm 4.0$ & $91.9 \pm 7.0$ & $90.1 \pm 6.0$ & $76.5 \pm 3.0$ & $77.6 \pm 2.0$ & $81.7 \pm 5.0$ & $86.7 \pm 6.0$ \\
\hline \multicolumn{5}{|c|}{ Solvent volume (ml) } & \multicolumn{4}{|c|}{ Methanol } \\
\hline 1.0 & $58.3 \pm 3.0$ & $60.8 \pm 4.0$ & $39.7 \pm 2.0$ & $52.7 \pm 3.0$ & $36.2 \pm 2.0$ & $31.0 \pm 4.0$ & $61.6 \pm 2.0$ & $62.2 \pm 6.0$ \\
\hline 3.0 & $74.3 \pm 2.0$ & $79.2 \pm 1.0$ & $52.0 \pm 3.0$ & $70.8 \pm 2.0$ & $41.8 \pm 1.0$ & $55.0 \pm 5.0$ & $74.9 \pm 1.0$ & $77.2 \pm 5.0$ \\
\hline 4.0 & $88.6 \pm 6.0$ & $89.0 \pm 2.0$ & $76.4 \pm 3.0$ & $82.9 \pm 5.0$ & $66.6 \pm 3.0$ & $78.0 \pm 3.0$ & $82.5 \pm 3.0$ & $86.9 \pm 5.0$ \\
\hline $\mathbf{5 . 0}$ & $92.0 \pm 3.0$ & $92.6 \pm 3.0$ & $83.7 \pm 6.0$ & $85.4 \pm 3.0$ & $76.1 \pm 4.0$ & $83.7 \pm 1.0$ & $88.4 \pm 2.0$ & $85.1 \pm 4.0$ \\
\hline \multicolumn{5}{|c|}{ Solvent volume (ml) } & \multicolumn{4}{|c|}{ Hexane } \\
\hline 1.0 & $7.1 \pm 3.0$ & $8.9 \pm 4.0$ & $23.5 \pm 2.0$ & $28.4 \pm 3.0$ & $17.2 \pm 5.0$ & $13.9 \pm 1.0$ & $20.5 \pm 3.0$ & $23.5 \pm 4.0$ \\
\hline 3.0 & $19.6 \pm 4.0$ & $22.0 \pm 5.0$ & $37.4 \pm 3.0$ & $40.8 \pm 2.0$ & $26.8 \pm 6.0$ & $32.9 \pm 2.0$ & $25.1 \pm 4.0$ & $28.3 \pm 3.0$ \\
\hline 4.0 & $21.8 \pm 3.0$ & $26.0 \pm 4.0$ & $44.2 \pm 6.0$ & $45.9 \pm 6.0$ & $41.4 \pm 4.0$ & $44.2 \pm 6.0$ & $33.3 \pm 5.0$ & $33.6 \pm 6.0$ \\
\hline 5.0 & $27.8 \pm 5.0$ & $27.9 \pm 2.0$ & $45.6 \pm 1.0$ & $52.9 \pm 3.0$ & $45.6 \pm 2.0$ & $42.9 \pm 3.0$ & $35.6 \pm 2.0$ & $32.9 \pm 6.0$ \\
\hline
\end{tabular}


their chromatograph is presented in Figure 7.21. The analytical Figures of merit for the determination of the four analytes, TCP, PCP, PCB77, and PBB52, using GC-ECD were calculated from their calibration curves. The calibration curves were constructed by plotting peak area (counts) versus analyte concentration $(\mathrm{ng} / \mathrm{ml})$ as shown in Figure 7.22. The linear ranges of the calibration curves of the target analytes using GC-ECD were examined using a series of concentrations and the results are presented in Table 7.3. Note that the calibration curves were linear for TCP and PCB77 within the concentration ranges from $2.0 \mathrm{ng} / \mathrm{ml}$ to $2000 \mathrm{ng} / \mathrm{ml}$, whereas it was linear within the range from 2.0 $\mathrm{ng} / \mathrm{ml}$ to $1000 \mathrm{ng} / \mathrm{ml}$ for PCP and PBB52. The correlation coefficients for the four calibration curves were found to be greater than 0.995 . The sensitivity; slope of the calibration curve, of the GC-ECD determination of the four analytes in aqueous solution was as the following order, $\mathrm{PCP}>\mathrm{PBB} 52>\mathrm{PCB} 77>\mathrm{TCP}$, presumably the result of the number and type of halogenated atom present (PCP contains five chlorine atoms, PBB52 contains four bromine atoms, PCB77 contains four chlorine atoms, and TCP contains three chlorine atoms). The limit of detection (LOD), defined as the concentration giving a signal three times the standard deviation of blanks (signal/noise ratio of 3), was measured by integrating blank peak areas for each analyte in ten (10) independent performances in hexane as the blank. The limit of quantification (LOQ) was the lowest analyte concentration that could be quantified in a sample with acceptable relative standard deviation (RSD) under the stated operational conditions of the method. LOQ was determined as the analyte concentration corresponding to a signal/noise ration of 10 . It is clear from Table 7.3, the chlorinated phenols, TCP, and PCP, had the highest LOD and LOQ whereas the polyhalogenated biphenyls; PCB77 and PBB52, had the lowest LOD 


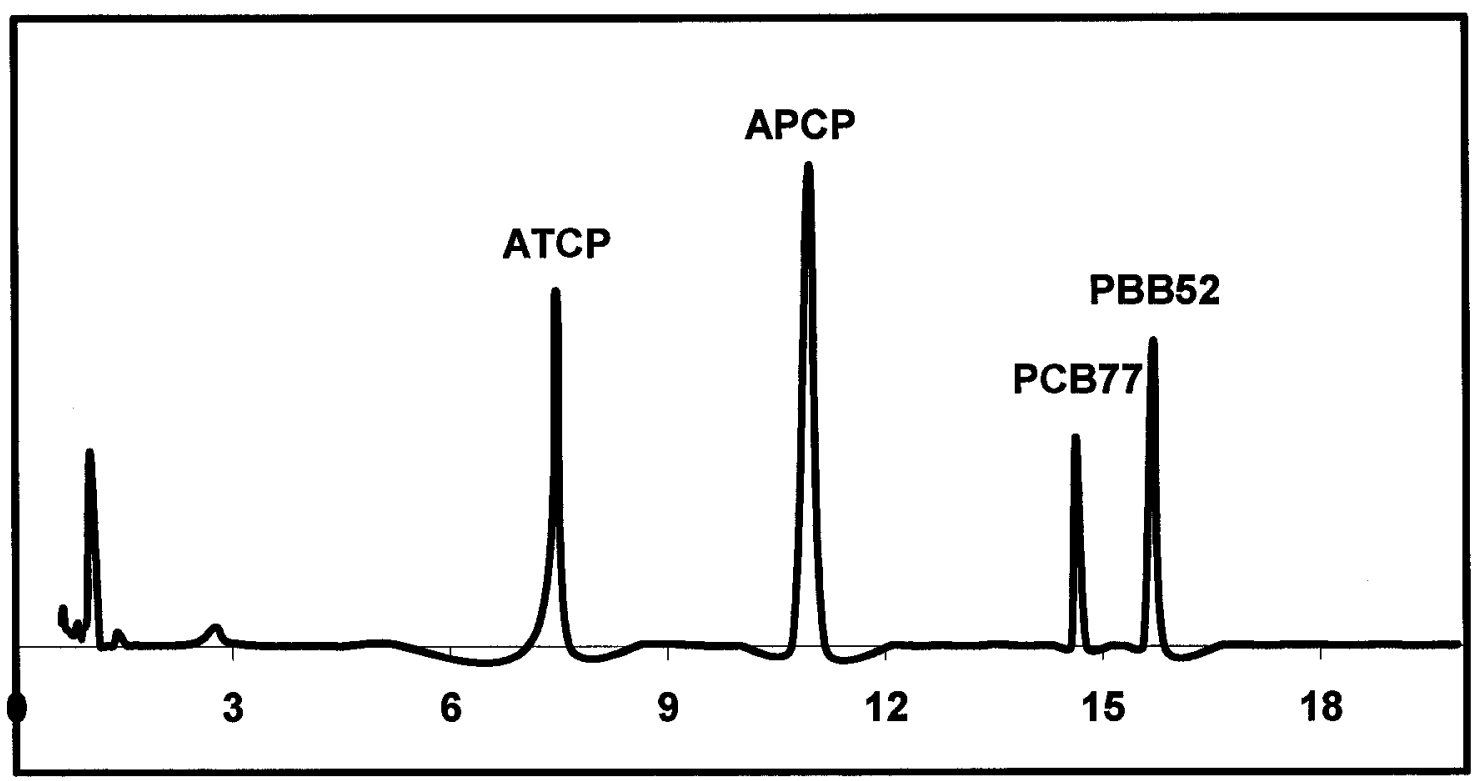

Retention time (minutes)

Figure 7.21. Chromatogram of $50 \mathrm{ng} / \mathrm{ml}$ of TCP, PCP, PCB77 and PBB52, by GC-ECD, in hexane. ATCP and APCP are the peaks of acetylated TCP and PCP, respectively. 


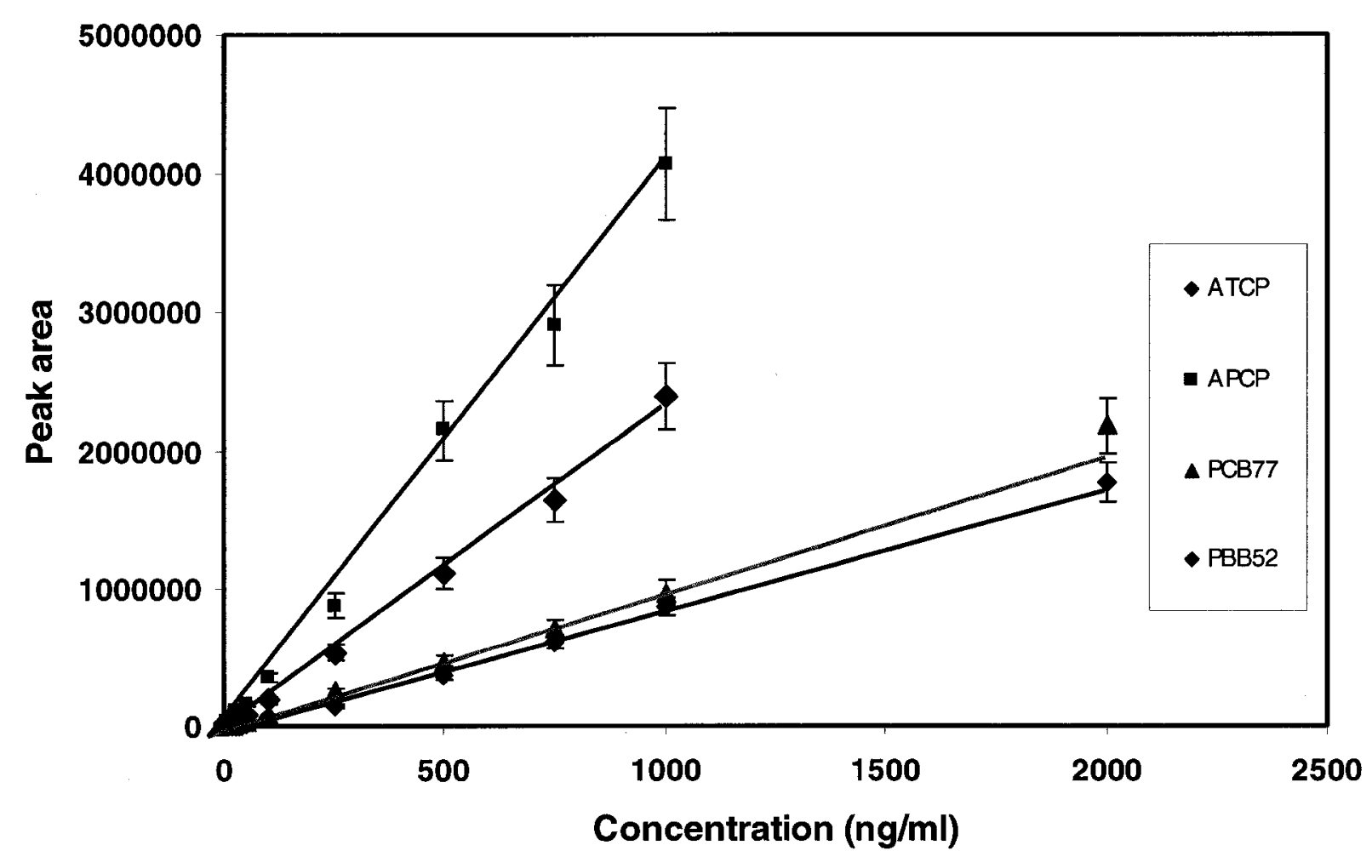

Figure 7.22. Calibration curves of TCP, PCP, PCB77, and PBB52 using gas chromatography-electron capture detector. 
Table 7.3. Figures of merit for TCP, PCP, PCB77, and PBB52 using gas chromatography-electron capture detection.

\begin{tabular}{|c|c|c|c|c|c|c|}
\hline Compound & LDR (ng/ml) & Sensitivity (slope) & $\mathbf{R}^{2}$ & LOD (ng/ml) & LOQ (ng/ml) & Precision (\%RSD) \\
\hline TCP & $2-2000$ & 866.96 & 0.996 & 0.99 & 3.3 & 7.0 \\
\hline PCP & $2-1000$ & 4019.70 & 0.997 & 0.77 & 2.6 & 10 \\
\hline PCB77 & $2-2000$ & 1047.9 & 0.995 & 3.7 & 12.0 & 10 \\
\hline PBB52 & $2-1000$ & 2298.5 & 0.996 & 6.8 & 22.0 & 9.0 \\
\hline
\end{tabular}

LDR: Linear dynamic range (ng/ml).

Sensitivity: Slope of the calibration curve.

Correlation coefficient $\left(\mathbf{R}^{2}\right)$

LOD: limit of detection (ng/ml).

LOQ: limit of quantification (ng/ml). 
and LOQ. The average relative standard deviation was $9.0 \%$, showing the good reproducibility of the GC-ECD for the determination of the target analyst.

\subsubsection{SPE method detection limits (MDL)}

The applicability of the modified MWCNTs to be used as solid phase extraction packing material for the preconcentration and determination of the four analytes of interests was studied. Deionized water, $100.0 \mathrm{~mL}$, was spiked with TCP, PCP, PCB77, and PBB52, in order to have concentrations range between 2.0 and $200.0 \mathrm{ng} / \mathrm{mL}$, in different flasks. 20.0 mg of the adsorbent was packed inside the SPE cartridge as detailed in Chapter 6 , and conditioned with $5 \mathrm{~mL}$ of deionized water followed by $5 \mathrm{~mL}$ methanol and finally with 5 $\mathrm{ml}$ deionized water. The solution was passed through the cartridge at a constant flow rate of $10 \mathrm{~mL} / \mathrm{min}$. The concentrations of the four analytes were then measured in the filtrate to determine the amount of analytes had been adsorbed. The retained analytes were desorbed using $10.0 \mathrm{~mL}$ of acetone with a flow rate of $1.0 \mathrm{~mL} / \mathrm{min}$. The extract was concentrated to an approximate volume of $0.2 \mathrm{~mL}$ using a gentle stream of nitrogen gas. Deionized water, $10 \mathrm{~mL}$, was added to the extract followed by derivatization of the chlorophenols. $1.0 \mu \mathrm{L}$ of the sample was injected into the GC-ECD for the determination of the four analytes. Table 7.4 shows the \% adsorbed (average) of each analyte after the preconcentration using SPE with different packing material; pristine MWCNTs, MWCNTs-PEG, MWCNTs-ODA, and C18. It was observed that MWCNTs-ODA had the highest adsorption capacities for the four analytes under investigation, polar and nonpolar, followed by the pristine MWCNTs, and then MWCNTs-PEG, whereas C18 had the poorest adsorption capacities. The effect of the analytes concentration on the $\%$ 
Table 7.4. \% TCP, PCP, PCB77, and PBB52 adsorbed on different SPE

\section{$\% \quad$ Adsorbed}

\begin{tabular}{lllll} 
Adsorbent type & TCP & PCP & PCB77 & PBB52 \\
\hline Pristine MWCNTs & $97.2 \pm 1.5$ & $94.2 \pm 2.1$ & $81.1 \pm 1.4$ & $88.3 \pm 1.9$ \\
MWCNTs-PEG & $64.9 \pm 1.6$ & $62.5 \pm 1.9$ & $92.1 \pm 1.2$ & $94.5 \pm 1.5$ \\
MWCNTs-ODA & $98.2 \pm 1.4$ & $99.1 \pm 2.1$ & $99.2 \pm 3.0$ & $97.1 \pm 1.8$ \\
& & & & \\
C18 & $45.5 \pm 1.2$ & $48.4 \pm 2.3$ & $64.5 \pm 1.1$ & $72.5 \pm 1.2$ \\
\hline
\end{tabular}

- volume of the sample is $100 \mathrm{~mL}$ of $200 \mathrm{ng} / \mathrm{mL}$, amount of adsorbent is $20 \mathrm{mg}$, and flow rate of $10 \mathrm{~mL} /$ minute.

- $\quad n=3$ 
recovery of the four analytes from the different adsorbents was studied using $100.0 \mathrm{~mL}$ spiked deionized water samples and the results are presented in Table 7.5 and Figure 7.23. It is clear from the Figure that \% recovery was generally constant within the selected range of concentrations; $97.2 \pm 1.5 \%$ and $98.2 \pm 1.4 \%$ for pristine MWCNTs, $98.2 \pm 1.4$ $\%$ and $99.1 \pm 2.1 \%$ for MWCNTs-ODA, $57.5 \pm 1.6 \%$ and $62.5 \pm 1.9 \%$ for MWCNTsPEG, $45.5 \pm 1.2 \%$ and $48.4 \pm 2.3 \%$ for $\mathrm{C} 18$, for TCP and PCP, respectively. These results suggest that the total method detection limits (MDL); including adsorption, desorption, derivatization, and GC-ECD measurements, for both TCP and PCP were $1.0 \mathrm{ng} / \mathrm{mL}$ and $6.0 \mathrm{ng} / \mathrm{mL}$ for both PCB77 and PBB52. The relative standard deviation values were between 5.2 and $16.1 \%(n=3)$, which indicates the good reproducibility of the SPE preconcentration method using any of the above mentioned adsorbents. It was reported that the method detection limit (MDL) for the preconcentration and further determination of PCP by HPLC using MWCNTs as SPE packing material was $80 \mathrm{ng} / \mathrm{mL}$ [13]. This is much higher compared with the proposed method when pristine MWCNTs or MWCNTsODA were used for the preconcentration/determination of PCP in spiked RRSW.

The volume of the sample is one factor that greatly affects the reliability and reproducibility of the SPE preconcentration method and may change the analytical results. It is very important to get satisfactory recoveries for the four analytes under investigation in as large a volume of sample solutions as possible, especially at very low concentrations. The effect of sample volume was studied using by spiking $20 \mathrm{~mL}$ of 200 $\mathrm{ng} / \mathrm{mL}$ solution, into different volume of deionized water, and the results are presented in Figure 7.24. Generally, good recoveries were obtained for the four analytes when the sample volume was between $20 \mathrm{~mL}$ and $2000 \mathrm{~mL}$ using the pristine and modified 
Table 7.5. \% Recovered (average) and method detection limits of TCP, PCP, PCB77, and PBB52, adsorbed on different SPE adsorbent.

\begin{tabular}{|c|c|c|c|c|c|c|c|c|c|c|c|c|}
\hline & Prist & tine $\mathrm{MWCl}$ & VTs & $\mathbf{M}$ & NCNTs-PE & & MV & NCNTs-OD & & & C18 & \\
\hline & $\begin{array}{c}\text { MDL } \\
\text { (ng/mL) }\end{array}$ & $\begin{array}{c}\text { Recovery } \\
(\%)\end{array}$ & $\begin{array}{c}\text { R.S.D. } \\
(\%)\end{array}$ & $\begin{array}{c}\text { MDL } \\
(\mathbf{n g} / \mathbf{m L})\end{array}$ & $\begin{array}{c}\text { Recovery } \\
(\%)\end{array}$ & $\begin{array}{l}\text { R.S.D. } \\
(\%)\end{array}$ & $\begin{array}{c}\text { MDL } \\
\text { (ng/mL) }\end{array}$ & $\begin{array}{c}\text { Recovery } \\
(\%)\end{array}$ & $\begin{array}{c}\text { R.S.D. } \\
(\%)\end{array}$ & $\begin{array}{c}\text { MDL } \\
\text { (ng/mL) }\end{array}$ & $\begin{array}{c}\text { Recovery } \\
(\%)\end{array}$ & $\begin{array}{c}\text { R.S.D. } \\
(\%)\end{array}$ \\
\hline TCP & 1.0 & 92.8 & 7.6 & 1.0 & 55.2 & 5.2 & 1.0 & 100.0 & 7.7 & 1.0 & 47.3 & 6.6 \\
\hline PCP & 1.0 & 97.5 & 8.1 & 1.0 & 61.8 & 6.5 & 1.0 & 97.9 & 6.4 & 1.0 & 52.4 & 5.9 \\
\hline PCB77 & 6.0 & 79.9 & 14.1 & 6.0 & 90.2 & 16.1 & 6.0 & 95.8 & 12.1 & 6.0 & 58.8 & 13.4 \\
\hline PBB52 & 6.0 & 80.7 & 15.0 & 6.0 & 92.9 & 15.1 & 6.0 & 93.1 & 9.77 & 6.0 & 68.5 & 12.5 \\
\hline
\end{tabular}

- volume of the sample is $100 \mathrm{~mL}$, amount of adsorbent is $20 \mathrm{mg}$, and flow rate of $10 \mathrm{~mL} / \mathrm{minute}$.

$-10.0 \mathrm{~mL}$ of acetone with flow rate of $1.0 \mathrm{ml} / \mathrm{minute}$ was used for desorption.

$-\mathrm{n}=3$ 
Pristine MWCNTs

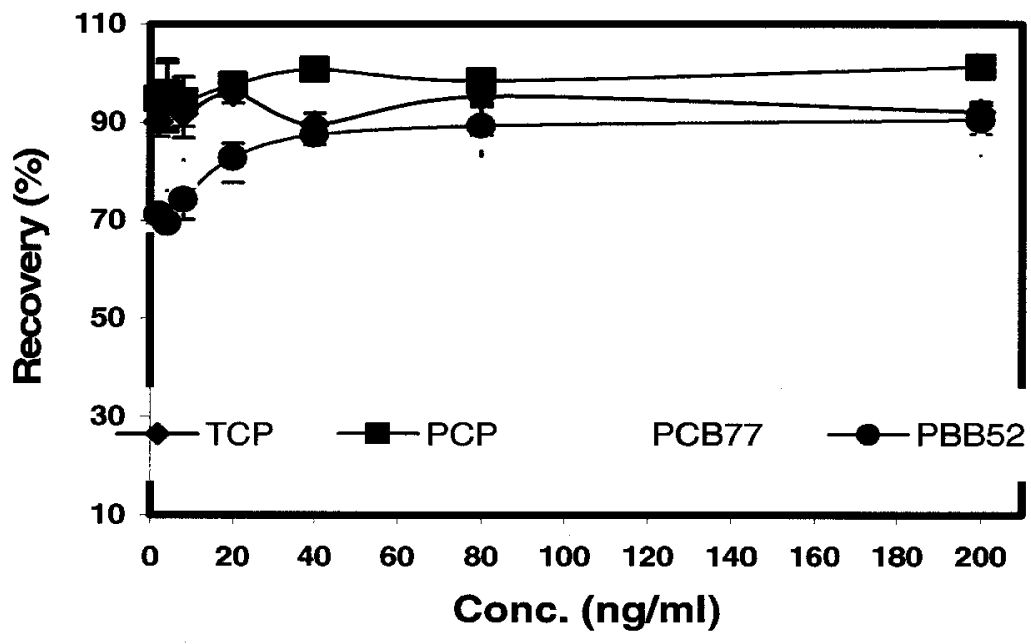

MWCNTS-PEG

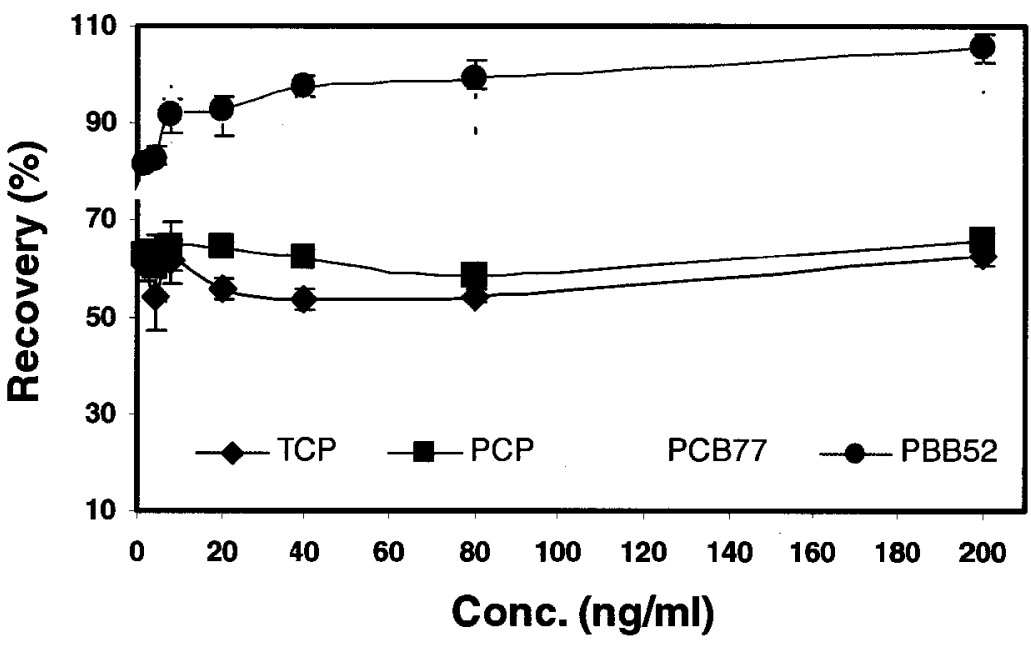

MWCNTs-ODA

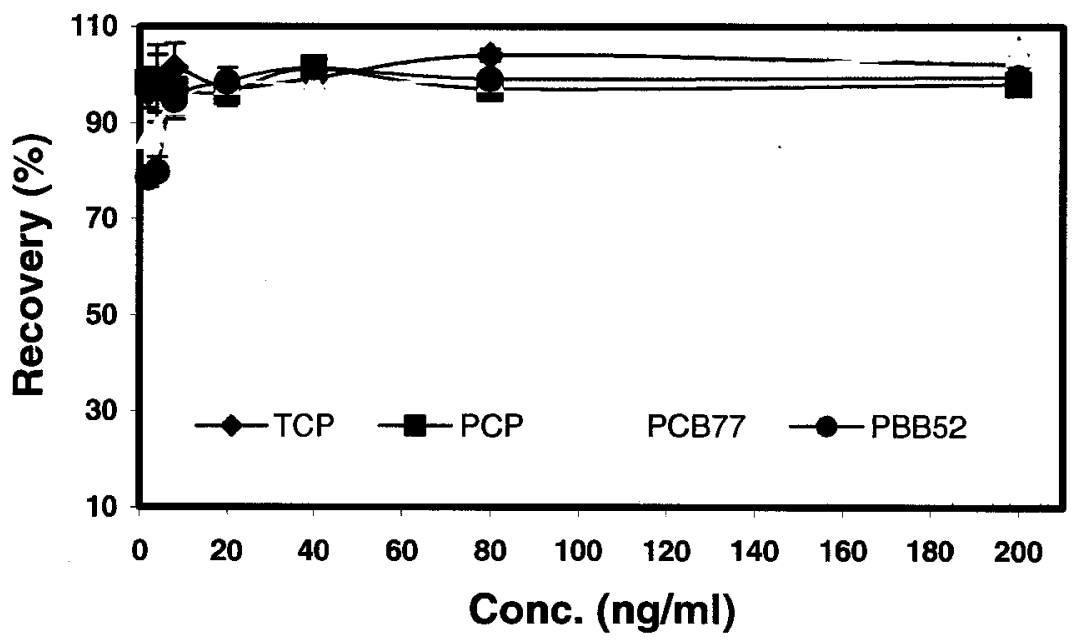

C18

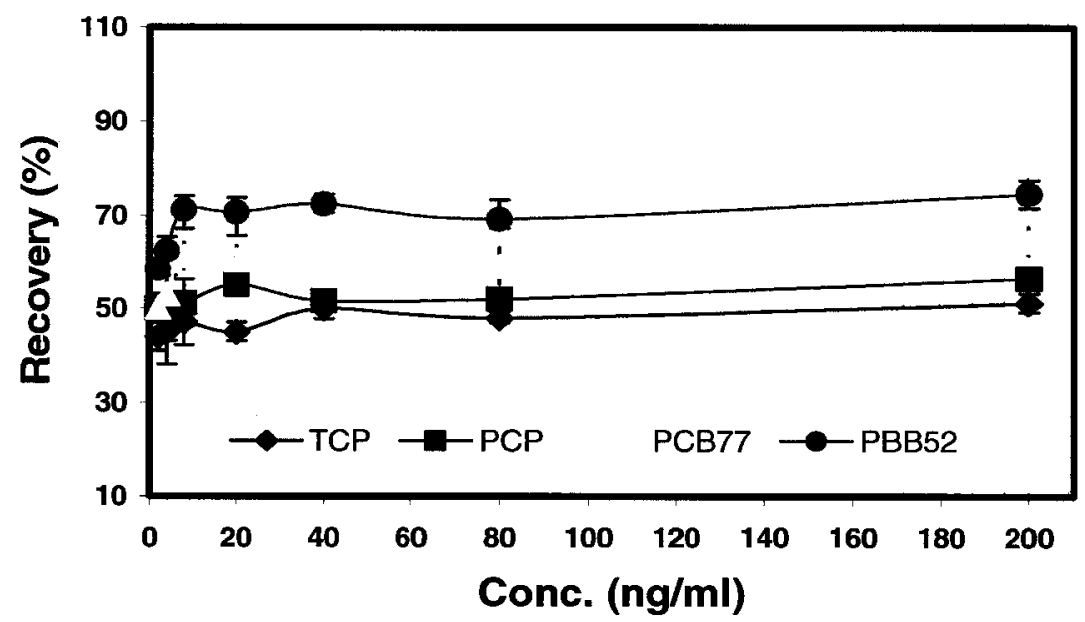

Figure 7.23. The dependence of the \% Recovery of four analytes, TCP, PCP, PCB52, and PBB77, on the concentrations, after solid phase extraction (SPE) using pristine MWCNTs, MWCNTs-ODA, MWCNTs-PEG, and C18. 
Pristine MWCNTs

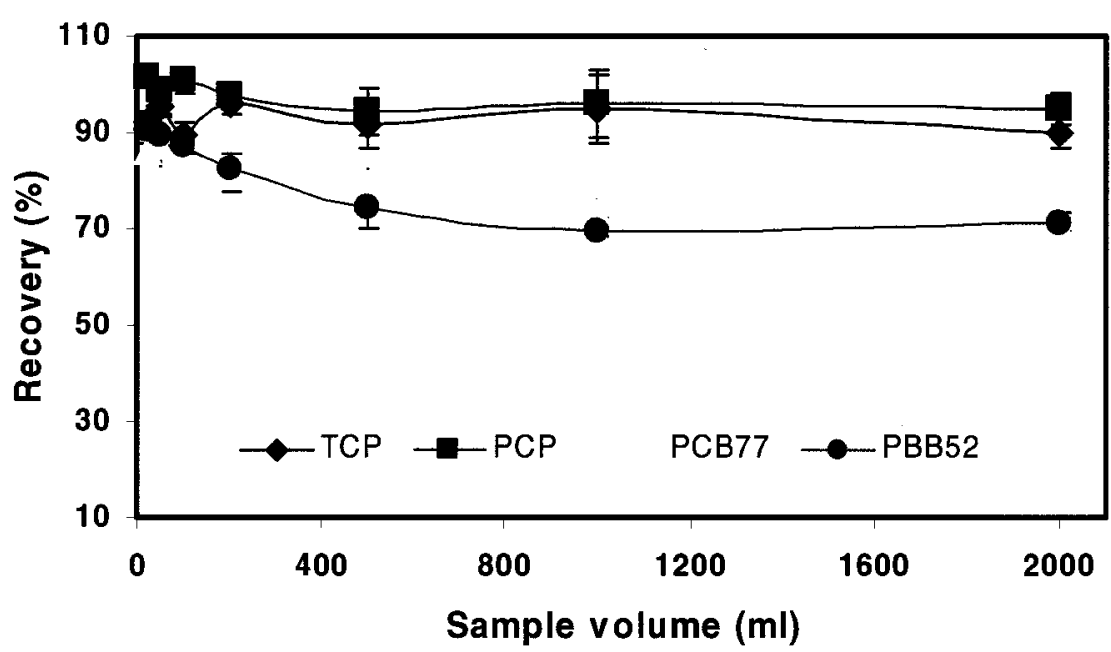

MWCNTS-PEG

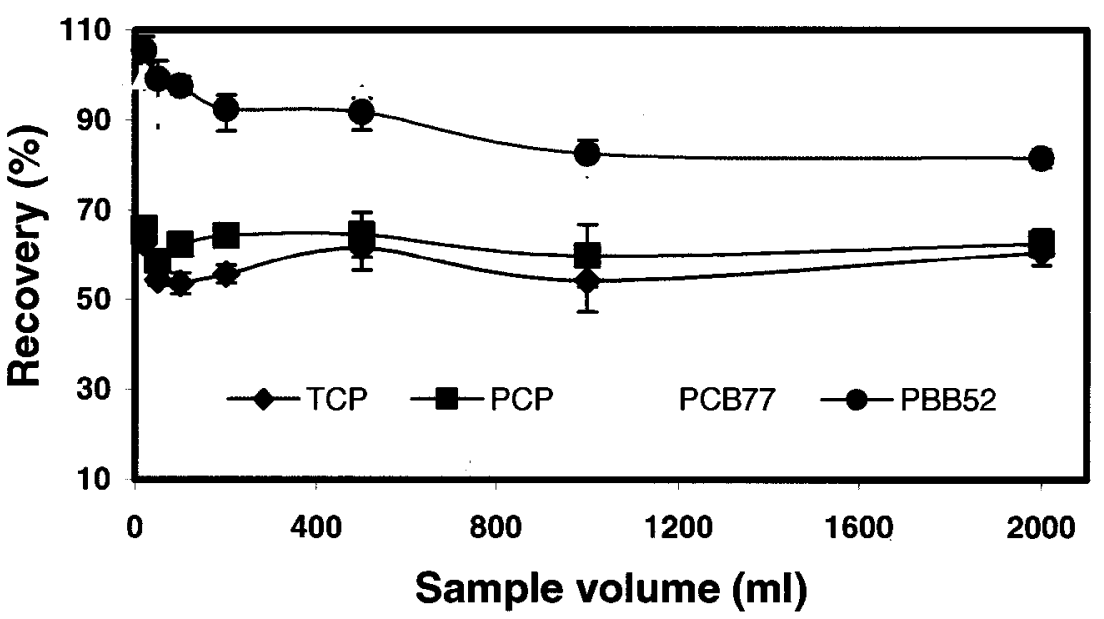

MWCNTS-ODA

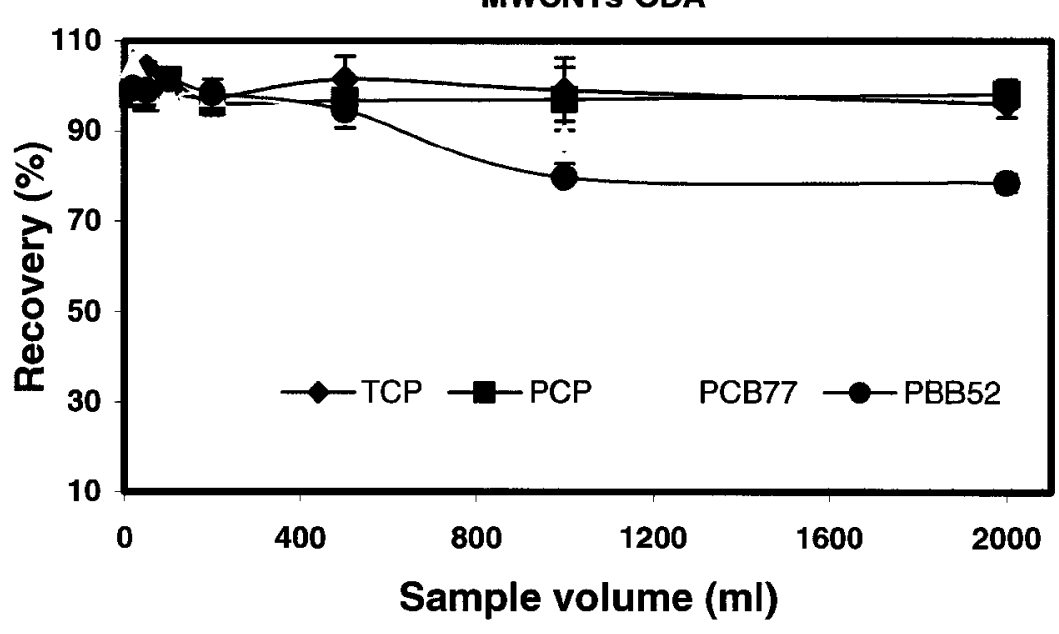

C18

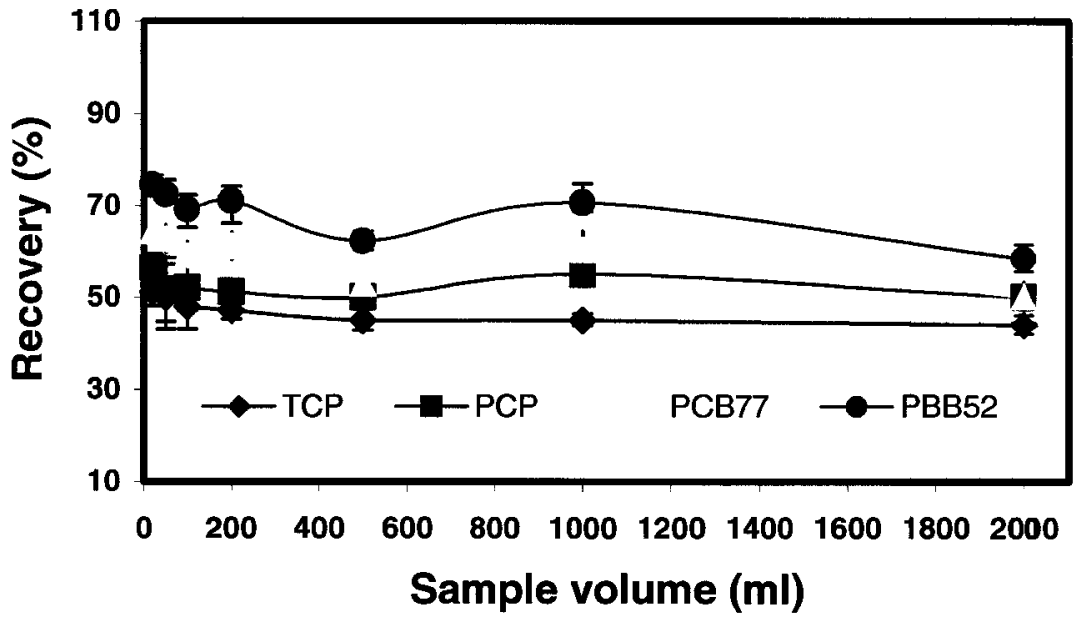

Figure 7.24. The dependence of the \% Recovery of four analytes, TCP, PCP, PCB52, and PBB77, on the sample volume, after solid phase extraction (SPE) using pristine MWCNTs, MWCNTs-ODA, MWCNTs-PEG, and C18. 
MWCNTs, and C18. It was not practical to use greater volumes than $2000 \mathrm{ml}$, as the flow rate was only $10 \mathrm{ml} / \mathrm{min}$. These results show good agreement with another study where 83-87\% recoveries of the chlorophenols were obtained when MWCNTs used as the packing materials for SPE [13].

\subsubsection{Analytical performance and real sample analysis}

Rideau River Surface Water (RRSW) samples were spiked with TCP, PCP, PCB77, and PBB52 to obtain $200 \mathrm{ng} / \mathrm{mL}$ as the final concentrations. The spiked water was kept in dark, stirred and left to quilibrate. A small aliquot of the spiked RRSW was removed and the concentrations of the four analytes were measured at different intervals of time. Figure 7.25 shows the variation of the PCP, TCP, PCB77 and PBB52 concentrations with time. It is clear from the Figure that the four analytes generally reached equilibrium after 6 hours after the spiking. It was observed that the equilibrium concentrations of the chlorophenols; TCP and PCP, were $197.0 \pm 5.0 \mathrm{ng} / \mathrm{ml}$ and $194.0 \pm 6.0 \mathrm{ng} / \mathrm{ml}$, respectively, whereas for the PCB77 and PBB52, their equilibrium concentrations were $143.0 \pm 4.0$ $\mathrm{ng} / \mathrm{ml}$ and $142.0 \pm 5.0 \mathrm{ng} / \mathrm{ml}$, respectively. The extended time for equilibration may be due to the presence of the naturally occurring organic matter such as humic acids, which interacts with the analytes in the water. The observed decreased in the equilibrium concentrations of PCB77 and PBB52 may be due to the nature of the two analytes as both of them are non-polar and have a tendency to adsorb on the glass flasks. Both of TCP and PCP are polar analytes and their chance to be adsorbed to the glass wares is very low.

\subsubsection{SPE cartridge regeneration/reusability}

Experiments were performed to determine if the four analytes under investigationwere 


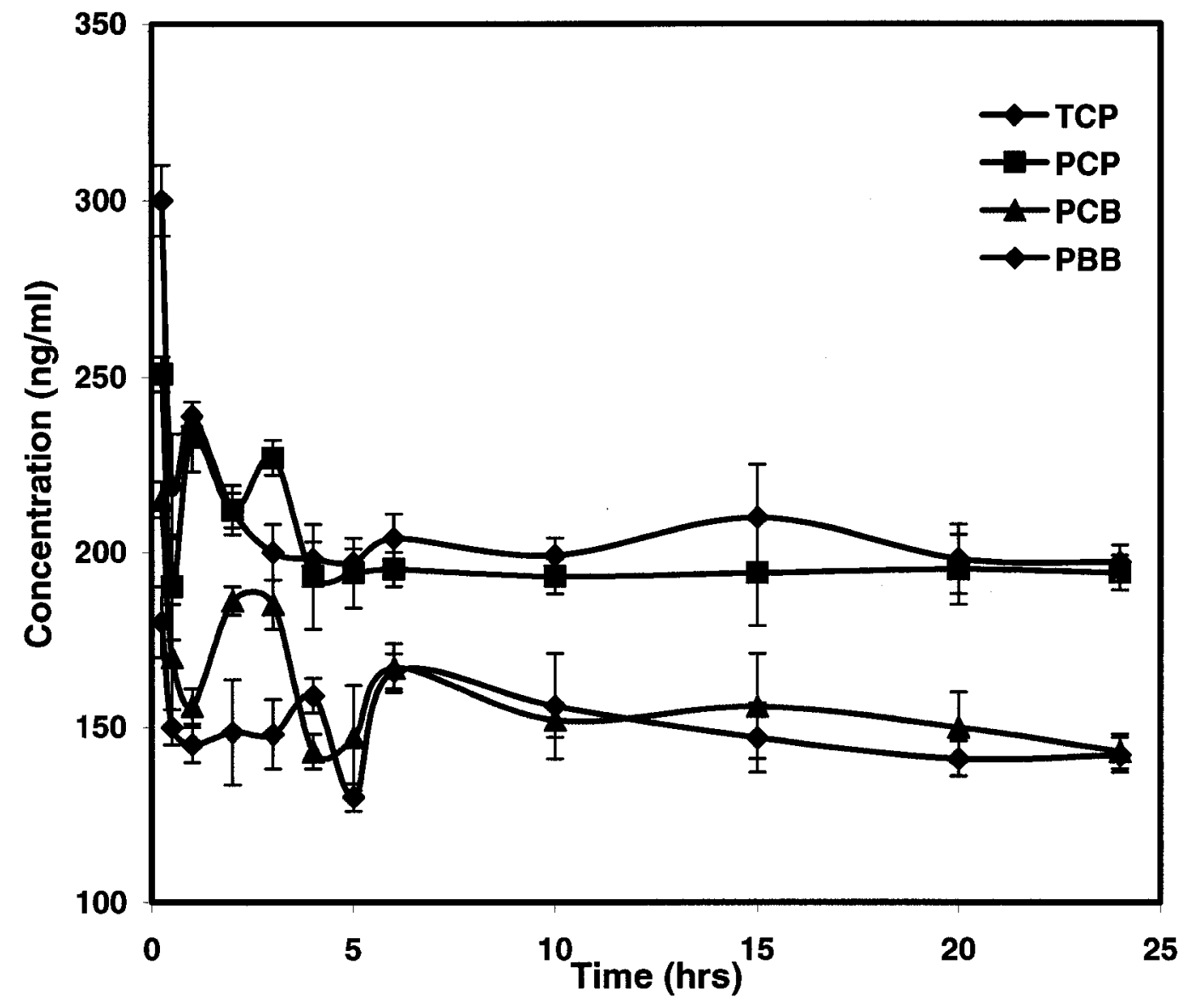

Figure 7.25. Equilibration of the Rideau River Surface Water (RRSW) sample spiked with TCP, PCP, PCB77, and PBB52. 
efficiently desorbed from different packing materials, and hence whether SPE cartridge made from these materials could be reused. The experiments were performed using Rideau River Surface Water (RRSW) samples spiked with TCP, PCP, PCB77, and PBB52, and the results are shown in Figure 7.26. Generally, MWCNTs; both pristine and modified, can be regenerated after having the adsorbed analytes desorbed and retained their adsorption efficiency for at least three (3) adsorption/desorption (regeneration) cycles upon elution with acetone. In the case of $\mathrm{C} 18$, the recoveries of analytes decreased significantly used more than once. Although, there was not a clear explanation for this phenomena, but it was thought it may be due to the conditioning of the C18 SPE cartridge with water/methanol/water which allows the water and methanol molecules to be adsorbed on the $\mathrm{C} 18$, but this is a common procedure to increase the wet-ability of the C18 material; due to its hydrophobicity, and hence increase its adsorption efficiency. On the other hand, it was proposed that the amount of $\mathrm{C} 18$ chains on the silica may be decreased with the reuse of the cartridge, but measuring the amount of $\mathrm{C} 18$ on the silica before and after adsorption/desorption process; by heating the $\mathrm{C} 18$ on a muffle furnace at $600{ }^{\circ} \mathrm{C}$ for 6 hours, shows that it was changed insignificantly. The weight $\%$ of oxidizable material were found to be $22.4 \pm 3.6 \%$ and $21.3 \pm 0.9 \%$, before and after use in the SPE process, respectively.

\subsubsection{Effect of $\mathrm{pH}$ on SPE extraction}

The effect of changing the $\mathrm{pH}$ of the RRSW sample was investigated by decreasing the $\mathrm{pH}$ from 8.2 to 3.0 using $1 \mathrm{M} \mathrm{HNO}_{3}$. Figure 7.27 shows that extraction of the chlorophenols were greatly affected by changing the $\mathrm{pH}$. At pH 3.0, TCP and PCP exist 

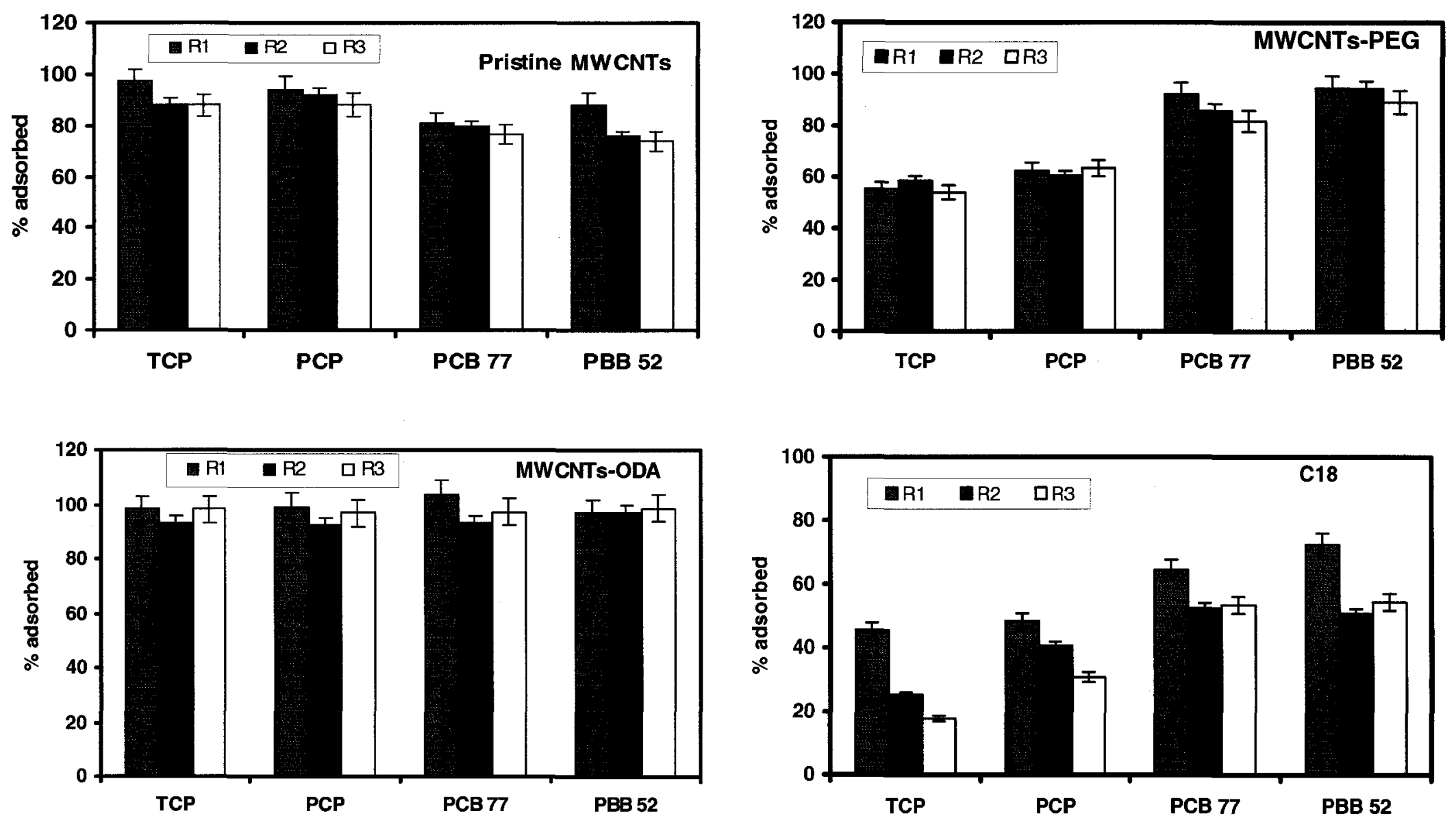

Figure 7.26. Regeneration/reusability of the SPE cartridge for the extraction of the four analytes, TCP, PCP, PCB52, and PBB77, using pristine MWCNTs, MWCNTs-ODA, MWCNTs-PEG, and C18. 

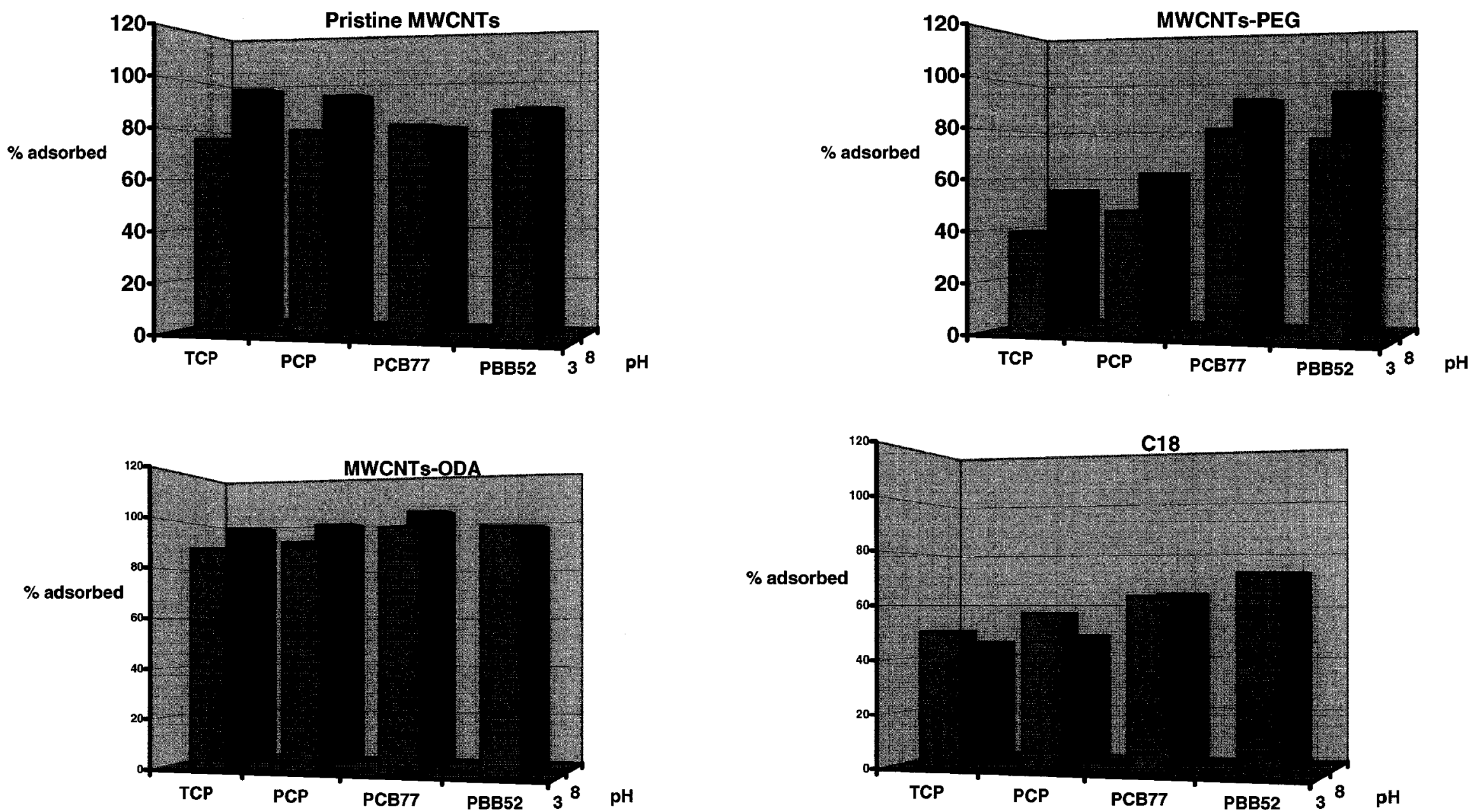

Figure 7.27. The effect of decreasing the RRSW pH from 8.2 to 3.0 on $\%$ adsorbed of the target analytes; on different SPE adsorbents; pristine MWCNTs, MWCNTs-PEG, MWCNTs-ODA, and C18. 
in their protonated form, which increases their adsorption. This was true when C18 was used as the SPE adsorbent, due to the hydrophobicity of the C18 silica surface. In the case of using MWCNTs, either pristine or modified, the opposite trend was observed, likely due the presence of polar oxygen containing functional groups, such as $-\mathrm{COOH}$ and $-\mathrm{OH}$, on the MWCNTs surface [26]. The decrease in the adsorption of the chlorophenols was obvious when MWCNTs-PEG was used as SPE adsorbent, due to the presence of higher concentration of oxygen functional groups, either on the surface of the MWCNTs which were previously oxidized, or due to the hydroxyl groups on the polyethylene glycol groups [27,28]. The same trend was found when MWCNTs was used for solid phase extraction of chlorophenols in environmental water samples [13]. At very low or high $\mathrm{pH}$; less than 5.0 or more than 9.0 , respectively, the extraction was adversely affected, whereas there was not a significant effect between $\mathrm{pH}$ 5-9. Except for MWCNTs-PEG, there was not significant change in adsorption of the non-polar analytes; PCB77 and PBB52, by changing the pH. This is might be due to the neutral nature of the adsorbed analytes, and the lack of the surface oxygen function groups on the adsorbent surface, compared with MWCNTs-PEG.

The amount of total organic carbon (TOC) was measured for the spiked RRSW before and after the SPE preconcentration process using pristine MWCNTs. It was found that TOC value decreased after the SPE process from $7.5 \pm 2.8 \mathrm{mg} / \mathrm{L}$ to $1.73 \pm 1.5 \mathrm{mg} / \mathrm{L}$. This could be due to the adsorption not only of the organic pollutants, but also the natural organic compounds that exist in the RRSW to the MWCNTs. C18-SPE was used previously for the extraction and characterization of dissolved organic matter [29-32]. This may be another advantage of MWCNTs as an effective adsorbent for the natural 
organic matter. The adsorption of the natural organic matter (NOM) to SPE adsorbents, may enhance the extraction of the analytes, if they are adsorbed on the NOM.

\subsection{Conclusions}

The application of pristine and chemically modified MWCNTs for SPE of different analytes; TCP, PCP, PCB77 and PBB52, was studied. Several factors that affect the adsorption efficiency were studied. The flow rate of the aqueous sample was studied and it showed that increasing the flow rate decreased the adsorption efficiency for most of the analytes on various adsorbents. This may be due to decreasing the interaction time between the analyte and adsorbent. The effect of adsorbent mass was studied as well. The study showed that increasing the mass of adsorbent increased the adsorption efficiency as more binding sites were available for binding the target analytes. The effect of solution $\mathrm{pH}$ was studied and results showed a very sensitive trends depended on analyte type (polar or non-polar), type of adsorbent, and $\mathrm{pH}$ values. Generally, at very low $\mathrm{pH}$ such as 3.0, the adsorption decreased due to the competition between the adsorbed analytes and the protons for the active binding sites; i.e. the protonation of the active binding sites. Ionization of the chlorophenols lead to the decreased in the adsorption efficiency due to the repulsion forces occurs between the phenolate and the active binding sites. At higher $\mathrm{pH}$; higher that 8.0, the adsorption decreased due to the ionization of the oxygen containing functional groups; $-\mathrm{COOH}$ and $-\mathrm{OH}$. Desorption of different analytes from pristine and modified MWCNTs were studied using different solvents. The results showed that acetone was the best solvent for all the analytes compared with methanol and hexane, due to the matching polarity of the solvent and either the analyte or the adsorbent. In general, The adsorption/desorption study 
showed that MWCNTs-ODA had the higher adsorption capacity for the four analytes of interest as well as the ease of desorption.

Solid phase extraction method development was investigated. The calibration curves and Figures of merits of the four analytes were constructed and they showed great reproducibility and sensitivity. The calibration curves were linear over three orders of magnitude of concentrations; $2.0 \mathrm{ng} / \mathrm{ml}$ to $1000.0 \mathrm{ng} / \mathrm{ml}$, with very low limits of detection and quantification using GC-ECD for determination. The detection limit of the SPE method with different adsorbents were measured and found to $1.0 \mathrm{ng} / \mathrm{ml}$ for the chlorophenols, and $6.0 \mathrm{ng} / \mathrm{ml}$ for the PCB77 and PBB52, with very good recoveries, especially when MWCNTs-ODA was used as the adsorbent. The regeneration and reusability of the different MWCNTs SPE cartridge were studied and the results showed that the SPE cartridges could be used for three cycles of adsorption/desorption with no loss of efficiency. The effect of decreasing the RRSW pH was studied and it showed no significant effect on the adsorption of the non polar analytes; PCB77 and PBB52, whereas it decreased the adsorption of the polar analytes; TCP and PCP, likely due to competition between the analytes and the existing protons for the oxygen containing surface binding sites present on the MWCNTs.

Finally, it was found that MWCNTs-ODA can be used successfully as an SPE adsorbent for the extraction of different analytes; polar and non polar, with great efficiency, recovery, reproducibility, sensitivity and precision, within a wide range of analyte concentrations. 


\subsection{References}

[1] Lin C K, Trends Analytical Chemistry 1988, 7, 340.

[2] Moors M, Massart D L, McDowall R D, Pure Applied Chemistry 1994, 66, 27.

[3] Thurmn E M, Mills M S, Solid-Phase extraction, Principles and Practice. Wiley, New York, 1988.

[4] Terada K, Analytical Sciences 1991, 7, 187

[5] Barceló D, Hennion M C, Analytica Chimica Acta 1995, 318, 1.

[6] Fang G Z, He J X, Wang S, Journal of Chromatography, A 2006, 1127, 12.

[7] Zhou Q, Xiao J, Wang W, Journal of Chromatography, A 2006, 1125, 152.

[8] Basheer C, Alnedhary A A, Rao B S M, Valliyaveettil S, Lee H K, Analytical Chemistry 2006, 78, 2853.

[9] Zhou Q, Wang W, Xiao J, Analytica Chimica Acta 2006, 559, 200.

[10] Zhou Q, Xiao J, Wang W, Liu G, Shi Q, Wang J, Talanta 2006, 68, 1309.

[11] Zhou Q, Wang W, Xiao J, Wang J, Liu G, Shi Q, Guo G, Microchimica Acta 2006, 152, 215-224.

[12] Liang P, Ding Q, Song F, Journal of Separation Science 2005, 28, 2339.

[13] Cai Y, Cai Y, Mou S, Lu Y, Journal of Chromatographia A 2005, 1081, 245.

[14] Lu W F, Ding M Y, Zheng R, Journal of Chromatographic Science 2005, 43, 383.

[15] Ambrosi A, Antiochia R, Campanella L, Dragone R, Lavagnini I, Journal of Hazardous Materials 2005, 122, 219.

[16] Pan C, Xu S, Zou H, Guo Z, Zhang Y, Guo B, Journal of the American Society for Mass Spectrometry 2005, 16, 263. 
[17] Liu G, Wang J, Zhu Y, Zhang X, Analytical Letters 2004, 37, 3085.

[18] Liang, Pei; Liu, Yan; Guo, Li; Zeng, Jing; Lu, Hanbing, Journal of Analytical Atomic Spectrometry 2004, 19, 1489.

[19] Cai Y, Jiang G, Liu J, Zhou Q, Analytical Chemistry 2003, 75, 2517.

[20] Couglin R W, Ezra F S, Environmental Science \& Technology.1968, 2, 291.

[21] Dąbrowski A, Podkościenly P, Hubicki Z, Barczak M, Chemosphere 2005, 58, 1049.

[22] Peng X, Li Y, Luan Z, Di Z, Wang H, Tian B, Jia Z, Chemical Physics Letters 2003, 376, 154 .

[23] László K, Colloids and Surfaces A, Physicochemical and Engineering Aspects.2005, 265, 32.

[24] Lu C, Chung Y L, Chang K F, Water Research 2005, 39, 1183.

[25] Liu X, Pinto N G, Carbon 1997, 35, 1387.

[26] Lu C, Chung Y L, Chang K F, Water Research 2005, 39, 1183.

[27] Dąbrowski A, Podkościenly P, Hubicki Z, Barczak M, Chemosphere 2005, 58, 1049.

[28] László K, Colloids and Surfaces A, Physicochemical and Engineering Aspects.2005, 265, 32.

[29] Schwede T S B, Chin Y P, Dria K J, Hatcher P, Kaiser E, Sulzberger B, Aquatic Sciences 2005, 67, 61 .

[30] Roubeuf V, Mounier S, Benaim J Y, Organic Geochemistry 2000, 31, 127

[31] Kim S, Simpson A. J, Kujawinski E B, Freitas M A, Hatcher P G, Organic Geochemistry 2003, 34, 1325. 
[32] Magnuson M L, Kelty C A, Sharpless C M, Linden K G, Metz W D, Kashinkunti R, Environmental Science \& Technology 2002, 36, 5252. 


\section{CHAPTER 8}

\section{SUMMARY AND CONCLUSIONS}


For the first time, the potential applications of pristine and chemically modified multi-walled carbon nanotubes (MWCNTs) for solid phase extraction (SPE) of polar analytes; 2,4,5-trichlorophenol (TCP) and pentachlorophenol (PCP), and non polar analytes; 3,3',4,4'-tetrachlorobiphenyl (PCB77) and 2,2',5,5'-tetrabromobiphenyl (PBB52), from aqueous solution, was studied and investigated.

\section{Oxidation and characterization of MWCNTs:}

In the thesis, chemical oxidation of pristine MWCNTs using different oxidizing agents; $\mathrm{HNO}_{3}, \mathrm{KMnO}_{4}$, and $\mathrm{H}_{2} \mathrm{O}_{2}$, was studied. The oxidation of MWCNTs leads to the formation of acidic oxygen functional groups such as carboxylic, phenolic, and carbonyl, on the MWCNTs surface. This modification improved the suspension stability and solubility of MWCNTs in aqueous solution. The oxidized MWCNTs were able to be suspended in water; with high stability, for more than six months. The oxidized MWCNTs were titrated to determine the concentrations of the acidic function groups and the results revealed the presence of considerable amounts of the acidic functional groups that likely enhanced the suspension of the MWCNTs. IR measurements showed the presence of carboxylic acid function groups especially for the MWCNTs oxidized with nitric acid and hydrogen peroxide. SEM revealed that the pristine MWCNTs and oxidized MWCNTs are highly tangled tubes, but have smaller diameters than the pristine. However, large pieces of amorphous carbon were present when MWCNTs were oxidized with $\mathrm{KMnO}_{4}$. There was not a significant change in specific surface area before and after oxidation, except for the MWCNTs oxidized with $\mathrm{KMnO}_{4}$, which had lower specific surface area. The degree of alignment of the MWCNTs was increased upon oxidation as was revealed by XRD measurements. 
Adsorption of pentachlorophenol by MWCNTs:

The adsorption behavior of pentachlorophenol (PCP) on pristine and oxidized MWCNTs was studied. The results showed that pristine MWCNTs are good adsorbents for the removal of PCP from aqueous solutions in a very short time. Although the adsorption of PCP onto the oxidized MWCNTs was less than onto the pristine MWCNTs, both are good adsorbents for the removal of PCP from aqueous solutions. The kinetics and equilibrium of the adsorption were studied. The kinetics of the adsorption were controlled by diffusion of PCP from the aqueous phase to the solid phase of the pristine and oxidized MWCNTs. PCP then underwent slower intra-particle diffusion. A comparison was made between pristine MWCNTs and activated charcoal (AC) and the results showed that intra-particle diffusion was more significant in AC. The equilibrium adsorption of PCP on pristine and oxidized MWCNTs, and AC at different temperatures was studied and the adsorption equilibrium was well described using different adsorption models. The thermodynamic parameters showed that the adsorption process is product favored, and becomes more so at lower temperature for the pristine MWCNTs, since the adsorption is exothermic. However, the adsorption process becomes more product favored at higher temperature for the oxidized MWCNTs since the adsorption is endothermic. The magnitude of the adsorption enthalpies suggests a weak type of bonding between the PCP and pristine and oxidized MWCNTs. The entropy values were positive for the pristine and oxidized MWCNTs implying that the PCP is more ordered in the aqueous phase than on the MWCNTs surface due to loss of structured water surrounding the PCP molecules. 


\section{Chemical modification of MWCNTs:}

Further chemical modification of MWCNTs by side walled functionalization using polyethylene glycol (PEG) and octadecylamine (ODA) was studied. IR and solubility measurements proved the presence of the functional groups on the MWCNTs-ODA and MWCNTs-PEG surfaces. TGA analysis showed MWCNTs-ODA and MWCNTs-PEG contained $39 \%$ and $16 \%$ by weight ODA and PEG, respectively. The calculations showed that $46.3 \%$ and $0.38 \%$ of the total surface area was covered by ODA and PEG chains, respectively, suggesting the ODA chains were normal to the surface, but PEG chains lay flat on the surface. XRD and SEM measurements showed that there was not any significant change of either the crystalline structure or the surface morphology of the MWCNTs after functionalization with PEG and ODA.

\section{Thermodynamic study and computer modeling:}

The effect of temperature on adsorption was studied and the thermodynamic parameters; free energy, enthalpy, and entropy of adsorption, were calculated. All the adsorption processes were spontaneous at all temperatures (negative free energy) and the enthalpy and entropy values were dependent on the type of adsorbent and type of analyte used. A comparison was made between the experimental free energy of adsorption and predicted free energy of adsorption. The predicted free energy was calculated using a independent computer model (docking) which simulated the adsorption processes of different analytes on pristine and modified MWCNTs. A good correlation was obtained between the experimental and the predicted free energy, which may indicated the validity of the study. 
Solid phase extraction using MWCNTs:

The application of pristine and chemically modified MWCNTs for SPE of different analytes; TCP, PCP, PCB77 and PBB52, was studied. The effects of aqueous solution flow rate, $\mathrm{pH}$ and adsorbent mass were investigated. The results showed that increasing the flow rate decreased the adsorption efficiency for most of the analytes on different adsorbents due to decreasing the interaction time between the analyte and adsorbent. The effect of solution $\mathrm{pH}$ showed a significant change on the adsorption efficiencies depending on the type of analyte, type of adsorbent and the $\mathrm{pH}$. The effect of adsorbent mass showed that increasing the mass of adsorbent was accompanied by increasing adsorption efficiency as more binding sites are available for binding the target analytes, till a certain mass, where monolayer coverage of the surface is obtained. Monolayer coverage does not mean that the whole adsorbent surface is covered with the analyte molecules only, but may be due to the adsorption of the solvent (water) molecules as well. Desorption of different analytes from pristine and modified MWCNTs were studied using different solvents. Acetone was the best solvent for all the analytes compared with methanol and hexane, due to the matching polarity of the solvent and either the analyte or the adsorbent. Generally, SPE process was greatly affected by different factors such as the type of adsorbent, type of adsorbate, flow rate, mass of adsorbent, $\mathrm{pH}$ of the aqueous solution, elution solvent, and its quantity.

Method development was performed to investigate the applicability of pristine and chemically modified MWCNTs as packing materials for SPE using model solutions and freshwater samples. The method calibration curves were constructed and they were linear for TCP and PCB77 within the concentration range from $2.0 \mathrm{ng} / \mathrm{ml}$ to $2000 \mathrm{ng} / \mathrm{ml}$, and from $2.0 \mathrm{ng} / \mathrm{ml}$ to $1000 \mathrm{ng} / \mathrm{ml}$ for PCP and PBB52, with correlation coefficients higher 
than 0.995 , and average relative standard deviation of $9.0 \%$. The method detection limits of SPE with different adsorbents were studied and were found to be $1.0 \mathrm{ng} / \mathrm{ml}$ for the chlorophenols, and $6.0 \mathrm{ng} / \mathrm{ml}$ for the PCB77 and PBB52, all with very good recoveries, especially when MWCNTs-ODA was used as the adsorbent. The regeneration and reusability of the different MWCNTs SPE cartridge were studied and the results showed that the SPE cartridge could be used for at least three cycles of adsorption/desorption with excellent efficiency.

Overall, it was concluded that chemical modification of MWCNTs is very successful tool for increasing the adsorption efficiency of MWCNTs in SPE or for remediation purposes. MWCNTs functionalized with long chains of ODA showed great advantages over pristine and other modified MWCNTs, and conventional adsorbents such as C18. MWCNTs-ODA was the best adsorbent and could be used successfully as an SPE adsorbent for the extraction of different organic pollutants; polar and non polar, with great efficiency, recovery, reproducibility, sensitivity and precision, and high dynamic range. 